Fausto de Assis Moraes

\title{
CALIBRAÇÃO DE MODELO DE DECAIMENTO DE CLORO APLICADO A SETOR DE REDE DE DISTRIBUIÇÃO DE ÁGUA
}

Dissertação Apresentada à Escola de Engenharia de São Carlos da Universidade de São Paulo, como Parte dos requisitos para obtenção do título de Mestre em Hidráulica e Saneamento.

ORIENTADORA: Profa Tit. Luisa Fernanda Ribeiro Reis

São Carlos

2008 

A meus pais, Francisco de Assis Moraes e Yara Maria de Jesus, por me incentivarem durante toda a vida, e a meus irmãos Fábio e Flávia. 



\section{AGRADECIMENTOS}

A Deus.

A Professora Luisa Fernanda Ribeiro Reis, pela orientação, pelas idéias, competência, ensinamentos e por ajudar a superar obstáculos.

Ao Conselho Nacional de Desenvolvimento Cientifico e Tecnológico (CNPq) pela bolsa de mestrado.

Ao Professor Luis Antonio Daniel, pelas sugestões e contribuição feita na primeira qualificação.

Aos Professores Márcia Damianovich e Rodrigo de Melo Porto, pelas sugestões e contribuições feitas na segunda qualificação.

Ao Departamento de Hidráulica e Saneamento por toda e estrutura concedida e colaboração para realizar este trabalho.

Aos amigos do Laboratório de Simulação Numérica (Labsin), Alice Araújo, Milena Collodel, Tiago Galvão, Sérgio Salgado, Sergio Moreira, Marco Morato, Kátia Ventura, Frederico Odan, Marcel Pierezan, Alexandre Soares que contribuíram com a técnica, a paciência, compreensão e bom humor em todos os dias do trabalho.

A Caroline por toda experiência e carinho que ajudaram na realização deste trabalho.

Agradeço em especial ao Frederico Keizo Odan por contribuir diretamente a este trabalho na realização de diversas pesquisas de campo e a reproduzir alguns resultados usados neste trabalho.

A Marcel Pierezan e a Narume Abe por participarem da campanha de campo e pela dedicação para viabilizar o trabalho.

Ao $\mathrm{CNPq}$, na qualidade de agência financiadora do projeto intitulado como, "Instrumentação de redes hidráulicas reais para avaliação continua de parâmetros de qualidade da água", do qual este trabalho faz parte. 
A empresa de saneamento do município de São Carlos, SAAE (Serviço Autônomo de Água e Esgoto), por todo apoio para a realização da campanha de campo e informações concedidas para a realização do trabalho.

Ao Departamento de Transportes da Escola de Engenharia de São Carlos por viabilizar o levantamento topográfico emprestando os equipamentos.

Ao Professor Ricardo Ernesto Schaal que ajudou na realização deste trabalho.

Ao técnico Paulo Sergio Batista por ajudar tecnicamente e pessoalmente na realização de uma das etapas deste trabalho.

A todos os professores, colegas e funcionários do Departamento de Hidráulica e Saneamento da EESC/USP, pela excelente receptividade, conhecimento fornecido e colaboração.

A todos os amigos da turma do mestrado que fiz e espero nunca perder contado, que não citarei os nomes para ser breve e não cometer injustiças devido à memória.

Aos amigos que convivi diariamente, Bruno (Salgado), Lucas (Cortella), Artur (Alface), Yuri (Biba), Pablo (Lemão), Cauê, Tomaz e Felipe (Coletta).

Enfim, a todos que de alguma maneira contribuíram para a realização deste trabalho. 


\section{SUMÁRIO}

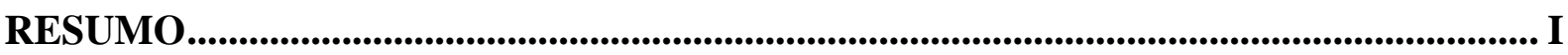

ABSTRACT ................................................................................................................................. III

LISTA DE FIGURAS......................................................................................................... V

LISTA DE TABELAS …...................................................................................... IX

LISTA DE ABREVIATURAS E SIGLAS ......................................................................... XIII

LISTA DE SÍMBOLOS ............................................................................................... XV

1. INTRODUÇÃO ……...................................................................................................................

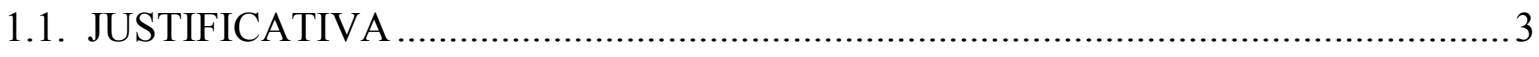

1.2. OBJETIVO

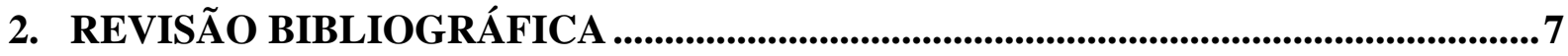

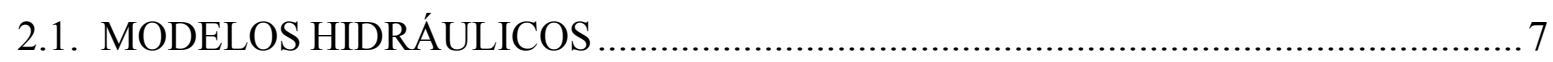

2.1.1. Calibração dos modelos hidráulicos......................................................................

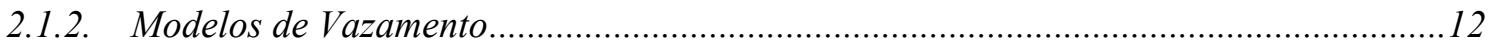

2.2. QUALIDADE DA ÁGUA EM REDES DE ABASTECIMENTO DE ÁGUA .............20

2.3. DECAIMENTO DO CLORO EM REDES DE ABASTECIMENTO ............................23

2.3.1. Modelo de decaimento de cloro ...........................................................................23

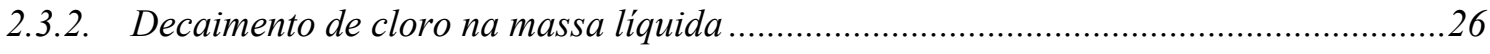

2.3.3. Decaimento de cloro devido à interação com a parede ................................................28

2.3.4. Combinações dos modelos de reações na massa líquida e com a parede da tubulação.30

2.4. MODELO DE QUALIDADE USADO PELO EPANET 2 .......................................... 32

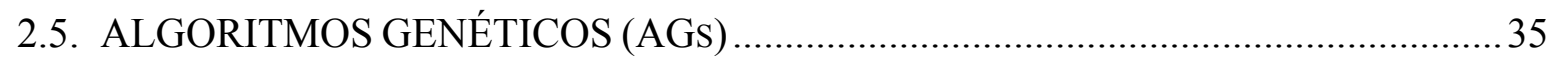

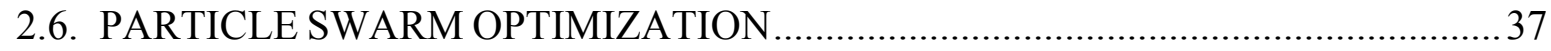

2.7. TRABALHOS RELACIONADOS À CALIBRAÇÃO DE QUALIDADE ...................39

3. MATERIAIS E MÉTODOS....................................................................................45

3.1. SISTEMA DE DISTRIBUIÇÃO ALVO DO ESTUDO …………………………........45

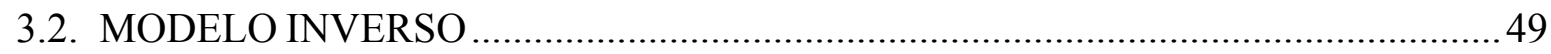

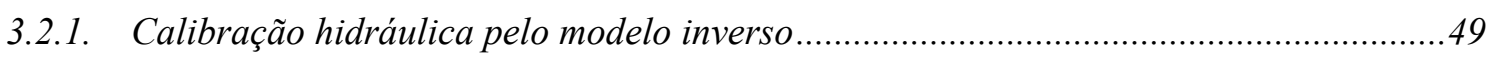

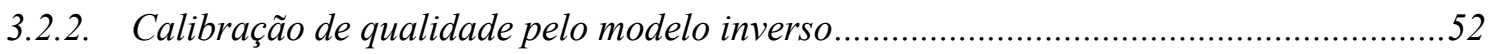

3.3. MODELO DE SIMULAÇÃO HIDRÁULICA......................................................... 54 
3.5.1. Calibração Hidráulica..

3.5.2. Consideração do tempo de residência da água para cada nó observado... 66

3.5.3. Calibração de qualidade da água 68

3.6. EQUIPAMENTOS E PROCEDIMENTOS PARA CAMPANHA DE CAMPO 70

3.6.1. Monitoramento do cloro residual. 70

3.6.2. Determinação do decaimento de cloro na massa líquida. 71

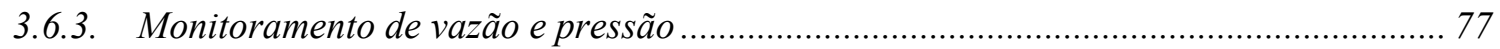

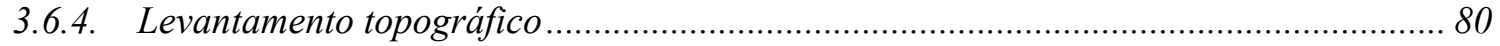

4. RESULTADOS E DISCUSSÕES 81

4.1. CAMPANHA DE CAMPO. 81

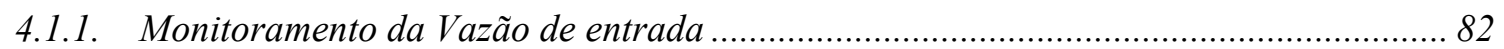

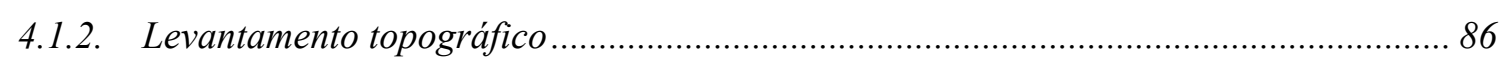

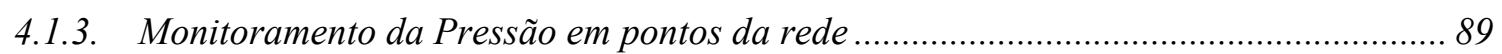

4.1.4. Monitoramento contínuo do cloro residual ................................................................... 98

4.2. CALIBRAÇÃO DOS PARÂMETROS DOS AGS ................................................... 105

4.3. CALIBRAÇÕES HIDRÁULICAS PRELIMINARES ............................................ 108

4.4. CALIBRAÇÃO HIDRÁULICA VARIANDO OS MODELOS DE VAZAMENTO 113

4.4.1. Resultados do Teste 1 do modelo Araújo et al. (T.1.A) ................................................ 115

4.4.2. Resultados do Teste 2 do modelo Araújo et al. (T.2.A) .............................................. 117

4.4.3. Resultados do Teste 1 do modelo Germanopoulos e Jowitt (T.1.GJ) ............................ 120

4.4.4. Resultados do Teste 2 do modelo Germanopoulos e Jowitt (T.2.GJ) ........................... 122

4.4.5. Resultados do Teste 3 do modelo Germanopoulos e Jowitt (T.3.GJ)........................... 125

4.4.6. Resultados do Teste 4 do modelo Germanopoulos e Jowitt (T.4.GJ)........................... 127

4.4.7. Resultados do Teste 1 do modelo Tucciarelli et al. (T.1.T) .......................................... 129

4.4.8. Resultados do Teste 2 do modelo Tucciarelli et al. (T.2.T) ....................................... 131

4.4.9. Resultados do Teste 3 do modelo Tucciarelli et al. (T.3.T) ........................................ 133

4.4.10. Resultados do Teste 4 do modelo Tucciarelli et al. (T.4.T) .......................................... 135

4.5. ANÁLISE DO TEMPO DE RESIDÊNCIA DE CADA TESTE ................................ 137

4.5.1. Resultados para o tempo de residência do teste T.1.A …............................................ 139

4.5.2. Resultados para o tempo de residência do teste T.2.A .............................................. 139

4.5.3. Resultados para o tempo de residência do teste T.1.GJ.............................................. 140

4.5.4. Resultados para o tempo de residência do teste T.2.GJ ............................................... 141

4.5.5. Resultados para o tempo de residência do teste T.3.GJ ............................................ 142 
4.5.6. Resultados para o tempo de residência do teste T.4.GJ..............................................143

4.5.7. Resultados para o tempo de residência do teste T.1.T ................................................. 144

4.5.8. Resultados para o tempo de residência do teste T.2.T ................................................ 145

4.5.9. Resultados para o tempo de residência do teste T.3.T ................................................ 147

4.5.10. Resultados para o tempo de residência do teste T.4.T ................................................. 148

4.6. DETERMINAÇÃO DO K BULK PELO “TESTE DA GARRAFA” ............................. 148

4.7. ARQUIVOS PARA CALIBRAR O DECAIMENTO DE CLORO........................... 152

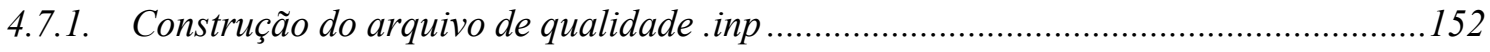

4.7.2. Construção do arquivo com as observações de cloro .in .............................................. 155

4.7.3. Construção do arquivo in dos AGs para a calibração de qualidade............................155

4.8. RESULTADOS OBTIDOS DA CALIBRAÇÃO QUALIDADE ............................. 156

4.9. CALIBRAÇÃO DA REDE SEM CONSIDERAR O VAZAMENTO E

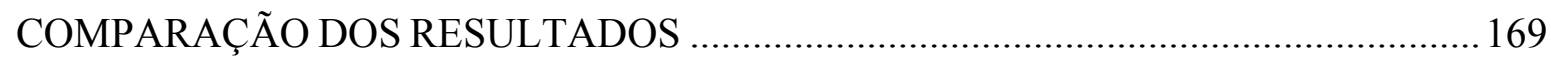

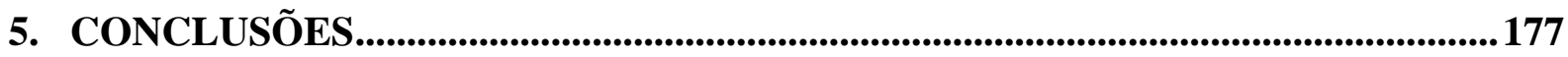

6. RECOMENDAÇÕES PARA TRABALHOS FUTUROS ......................................181

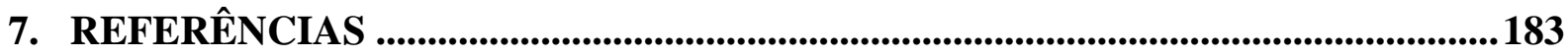

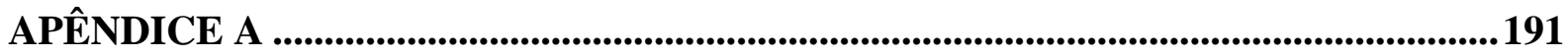

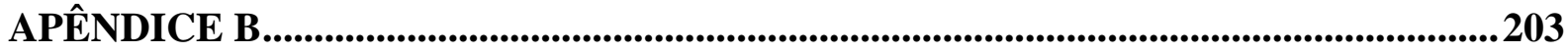

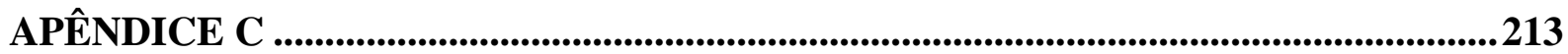





\section{RESUMO}

MORAES, F.A. (2008). Calibração de Modelo de Decaimento de Cloro Aplicado a Setor de Rede de Distribuição de Água Real. São Carlos, 2008. 225p. Dissertação (Mestrado) Escola de Engenharia de São Carlos, Universidade de São Paulo, São Carlos.

$\mathrm{O}$ crescente adensamento populacional em grandes centros urbanos vem propiciando crescentes demandas hídricas. Esse fato aliado às limitações das fontes para abastecimento, tanto do ponto de vista quantitativo como qualitativo, impõe que políticas de gerenciamento da água sofram transformações no futuro próximo. Nesse sentido, devem merecer atenção especial as técnicas de reuso, bem como o uso racional e otimizado da água em meio urbano. O presente trabalho enfoca um dos principais aspectos do gerenciamento da qualidade da água para abastecimento, que é a manutenção do residual de cloro no interior da rede conforme a Portaria 518/2004. Trata-se de um problema complexo, uma vez que o cloro decai, ao longo do tempo, e se mistura nos nós da rede, sofrendo mudanças de concentração. Visando à modelagem e simulação do comportamento do cloro residual como uma ferramenta eficiente de gerenciamento dos sistemas de distribuição de água, muitos estudos têm sido realizados e reportados pela literatura assumindo-se que os efeitos do decaimento são representados pelos coeficientes $\mathrm{K}_{\text {bulk }}$ e $\mathrm{K}_{\text {wall. }}$. $\mathrm{O}$ presente trabalho realiza a calibração hidráulica e de qualidade para um setor de rede de distribuição de água real do município de São Carlos -SP -Brasil, considerando o vazamento. Para tanto, calibradores hidráulicos já testados por outros autores foram usados, e um calibrador de qualidade para resolução do problema inverso, que utiliza em conjunto o simulador EPANET 2.0 e os algoritmos genéticos (AGs) como ferramenta de otimização, foram desenvolvido. Foi evidenciada a importância de se considerar o vazamento na calibração hidráulica e conseqüentemente na calibração de qualidade. Foi desenvolvida também uma metodologia para a calibração dos parâmetros dos AGs através do uso do "Particle Swarm Optimization" (PSO). Foram testados ainda diversos modelos de vazamento para determinação de qual modelo seria capaz de representar de maneira mais fidedigna o comportamento hidráulico da rede e os resultados obtidos apontaram os modelos que admitem vazamento por comprimento linear da tubulação como sendo mais adequados.

Palavras chave: redes de distribuição de água, qualidade da água, cloro residual, algoritmos genéticos, vazamento. 


\begin{abstract}
MORAES, F.A.(2008). Calibration of the chorine decay model applied to a prototype water supply distribution network sector. São Carlos, 2008. 225p. Master Degree Dissertation - São Carlos School of Engineering, University of São Paulo, São Carlos, Brazil.

The rising population density of large urban centers is gradually increasing water supply demands. This together with the paucity of water sources requires that the future water administration policies go through a transformation from both quantitative and qualitative points of view. Thus rational use of available water and water reuse deserve special attention in the urban environment. This study focuses on one these main aspects of water quality management, namely, the maintenance of residual chlorine in the hydraulic network according the respective Directive No. 518/2004. This is a complex problem in view of the fact that chlorine decays in time and undergoes mixing at the network nodes, consequently producing changes in its concentration. Numerous studies on modeling and simulation of behavior of residual chlorine, as an efficient water distribution system management tool, have been made and reported in literature. These studies assume that chlorine decay in the network can be represented through the $\mathrm{K}_{\text {bulk }}$ and $\mathrm{K}_{\text {wall }}$ coefficients. This research work conducts hydraulic and water quality calibration of a prototype water distribution sector in the city of São Carlos - SP - Brazil, while taking into account leakages in the network. Hydraulic calibration programs previously tested by others and a water quality calibration program were employed for the solution of the inverse problem for determination of unknown parameters. This problem was solved using hydraulic simulator EPANET 2.0 in conjunction with the genetic algorithms (AGs). These procedures showed the importance of considering network leakages in hydraulic calibration and consequently in the calibration of water quality. A method for the calibration of AG parameters was also developed through the use of "Particle Swarm Optimization" (PSO). Various representations for leakage were tested in order to identify the model that best described the hydraulic performance of the network. Thus it was possible to show that the models, which consider leakage per unit length, were the most adequate.
\end{abstract}

Key words: water distribution networks, water quality, residual chlorine, genetic algorithms, leakages. 


\section{LISTA DE FIGURAS}

FIGURA 2.1 - Análise de sensibilidade do modelo a parâmetros hidráulicos e de qualidade41

FIGURA 3.1 - Mapa de São Carlos (SP) 45

FIGURA 3.2 - Parque Fher (foto de satélite retirada do GoogleEarth) ................................ 46

FIGURA 3.3 - Bomba de adução subterrânea e reservatório do Parque Fehr ........................ 46

FIGURA 3.4 - PV da tubulação que abastece o Reservatório Ipanema. ................................ 47

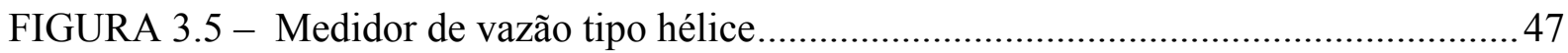

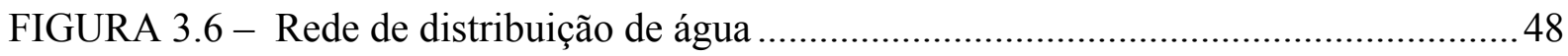

FIGURA 3.7 - Esquema de distribuição dos consumos para os nós. .................................... 49

FIGURA 3.8 - Fluxograma do processo iterativo para avaliação hidráulica, determinação dos fatores de consumo e dos parâmetros do vazamento. 58

FIGURA 3.9 - Fluxograma do processo de calibração dos Parâmetros dos AGs mais a calibração Hidráulica.

FIGURA 3.10 - Fluxograma do processo de interação da rotina no $\mathrm{C}++$ mais o simulador e os AGs 65

FIGURA 3.11 - Fluxograma da análise do tempo de residência d água nos nós observado ...67

FIGURA 3.12 - Fluxograma do calibrador de qualidade e a interação com a GAlib $C++\ldots . .69$

FIGURA 3.13a - Equipamentos usados no "teste da garrafa"..... 72

FIGURA 3.13b - Gráfico de linearização 77

FIGURA 3.14 - Curva de Calibração do manômetro x Data Logger. .78

FIGURA 3.15 - Curva de Calibração do manômetro x Aferidor de pressão. .79

FIGURA 3.16 - Curva de Calibração do aferidor x Data Logger. .79

FIGURA 4.1 - Rede de distribuição de água e instalações 81

FIGURA 4.2 - Pontos de Medição de Vazão e Pressão. 83

FIGURA 4.3 - Gráfico de Vazão e Pressão medidos no tubo que abastece o reservatório do Jardim Ipanema 
FIGURA 4.4 - Pontos nos quais realizou-se o levantamento topográfico .............................. 86

FIGURA 4.5 - Pontos onde foram instalados os medidores de pressão.................................. 91

FIGURA 4.6 - Pontos considerados com pressões medidas ................................................ 92

FIGURA 4.7 - Comportamento das pressões nos nós considerados ...................................... 92

FIGURA 4.8 - Enumeração de todos os nós da rede do parque Fehr ................................... 94

FIGURA 4.9 - Comportamento do nível do reservatório.................................................. 96

FIGURA 4.10 - Pontos com cotas nos quais realizou-se o levantamento topográfico ........... 98

FIGURA 4.11 - Pontos de monitoramento do cloro residual .............................................. 99

FIGURA 4.12 - Ativação/Calibração das Sondas ............................................................... 100

FIGURA 4.13 - Ponto de instalação da sonda (saída do reservatório).................................. 100

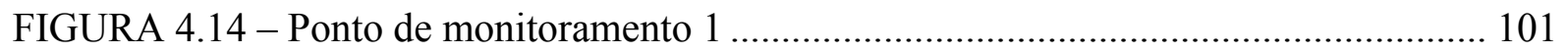

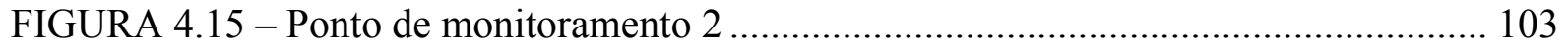

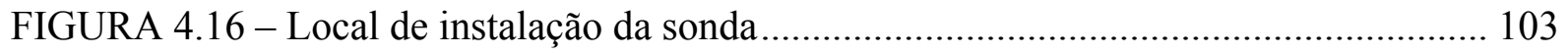

FIGURA 4.17 - Ponto de Monitoramento 2 (Estação Elevatória de Esgoto) ........................ 104

FIGURA 4.18 - Fluxograma das diversas calibrações hidráulicas ..................................... 113

FIGURA 4.19 - Tempo de residência do nó 43 no teste T.1.A........................................... 139

FIGURA 4.20 - Tempo de residência do nó 43 no teste T.2.A.......................................... 140

FIGURA 4.21 - Tempo de residência do nó 43 no teste T.1.GJ ......................................... 141

FIGURA 4.22 - Tempo de residência do nó 43 no teste T.2.GJ ........................................ 142

FIGURA 4.23 - Tempo de residência do nó 43 no teste T.3.GJ .......................................... 143

FIGURA 4.24 - Tempo de residência do nó 43 no teste T.4.GJ .......................................... 144

FIGURA 4.25 - Tempo de residência do nó 43 no teste T.1.T .......................................... 144

FIGURA 4.26 - Tempo de residência do nó 43 no teste T.1.T em destaque ....................... 145

FIGURA 4.27 - Tempo de residência do nó 43 no teste T.2.T …........................................ 146

FIGURA 4.28 - Tempo de residência do nó 43 no teste T.2.T em destaque ....................... 147

FIGURA 4.29 - Tempo de residência do nó 43 no teste T.3.T .......................................... 147 
FIGURA 4.30 - Tempo de residência do nó 43 no teste T.4.T.

FIGURA 4.31 - Gráfico dos dados observados e calibrados

FIGURA 4.32 - Discriminação das parcelas de consumo de cloro ..... 165

FIGURA 4.33 - Comparativo das Concentrações de cloro observadas nos nós 166

FIGURA 4.34 - Comportamento da concentração de cloro do nó 43 com os dados observados em campo.

FIGURA 4.35 - Comportamento da concentração de cloro com os dados observados em campo (Fonte: Vieira, 2002)...

FIGURA 4.36 - Comportamento da concentração de cloro do nó 43 com dados observados em campo e demostrando o erro relativo do sensor da sonda de medição de cloro de $\pm 0,05 \mathrm{mg} / \mathrm{L}$ 168

FIGURA 4.37 - Tempo de residência do nó 43 sem considerar o vazamento.

FIGURA 4.38 - Discriminação das parcelas de consumo de cloro desconsiderando-se os vazamentos 172

FIGURA 4.39 - Comportamento da concentração de cloro com os dados observados em campo desconsiderando-se os vazamentos

FIGURA 4.40 - Comportamento da concentração de cloro do nó 43 com dados observados em campo e demostrando o erro relativo do sensor da sonda de medição de cloro de $\pm 0,05 \mathrm{mg} / \mathrm{L}$ desconsiderando-se os vazamentos.

FIGURA 4.41 - Comportamento dos multiplicadores do consumo de referência de todos os teste ao longo do dia

FIGURA 4.42 - Comportamento dos $K f$ s de todos os teste ao longo do dia 175 


\section{LISTA DE TABELAS}

TABELA 2.1 - Modelos cinéticos de decaimento do cloro. 27

TABELA 3.1 - Parâmetros dos AGs fixados e intervalos de procura 63

TABELA 3.2 - Relação de equipamentos das sondas e suas respectivas funções 71

TABELA 3.3 - Relação de equipamentos do "teste da garrafa". 72

TABELA 4.1 - Vazão monitorada na saída do reservatório. 84

TABELA 4.2 - Vazões de cada sistema de distribuição abastecido pelo reservatório 85

TABELA 4.3 - Resultados do levantamento topográfico

TABELA 4.4 - Pressão dos nós para cada hora do dia. 95

TABELA 4.5 - Valores das pressões e vazões para os dois padrões

TABELA 4.6 - Comparação entre as pressões dinâmicas e estáticas dos pontos. 97

TABELA 4.7 - Resultado das concentrações de cloro livre para cada hora do dia. 102

TABELA 4.8 - Resultado das concentrações de cloro livre para cada hora do dia-Ponto 2.105

TABELA 4.9 - Opções pré-fixadas para ambos os métodos de otimização. 106

TABELA 4.10 - Intervalos de procura para a otimização dos AGs . 106

TABELA 4.11 - Parâmetros Fixados para os dois métodos de otimização. 107

TABELA 4.12 - Resultados obtidos da calibração dos parâmetros dos AGs. 107

TABELA 4.13 - Resultados obtidos com a calibração hidráulica depois da calibração dos parâmetros dos AGs. 108

TABELA 4.14 - Valores da função objetivo e resultados para cada semente. 108

TABELA 4.15 - Resultados obtidos com a exclusão do ponto observado 4 . 109

TABELA 4.16 - Valores da função objetivo e resultados para cada semente sem o nó 4 .... 109

TABELA 4.17 - Resultados obtidos com a exclusão dos pontos observados 4 e 22 110

TABELA 4.18 - Valores da função objetivo e resultados sem os nós 4 e 22 110

TABELA 4.19 - Resultados obtidos com a exclusão dos pontos observados 4 e 44 111 
TABELA 4.20 - Valores da função objetivo e resultados sem os nós 4 e 44 ....................... 111

TABELA 4.21 - Todos os resultados obtidos e seus comparativos ..................................... 112

TABELA 4.22 - Testes realizados e seus respectivos intervalos de procura ........................ 114

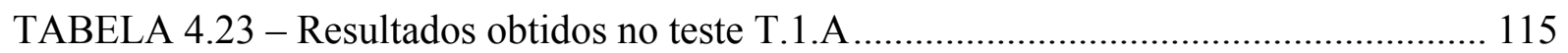

TABELA 4.24 - Valores da função objetivo e resultados do teste T.1.A............................. 116

TABELA 4.25 - Multiplicadores do consumo de referência do teste T.1.A........................ 116

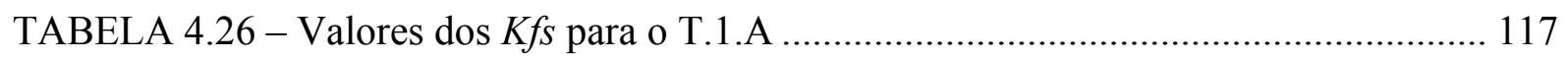

TABELA 4.27 - Resultados obtidos no teste T.2.A ...................................................... 118

TABELA 4.28 - Valores da função objetivo e resultados do teste T.2.A............................. 118

TABELA 4.29 - Multiplicadores do consumo de referência do teste T.2.A........................ 119

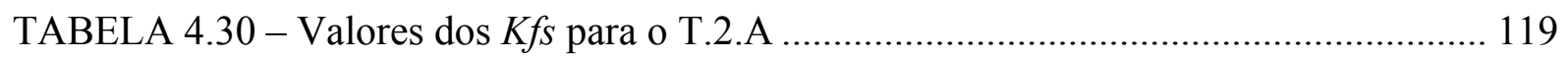

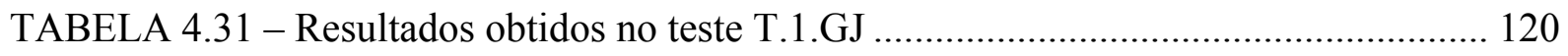

TABELA 4.32 - Valores da função objetivo e resultados do teste T.1.GJ .......................... 120

TABELA 4.33 - Multiplicadores do consumo de referência do teste T.1.GJ ....................... 121

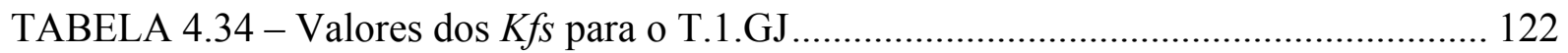

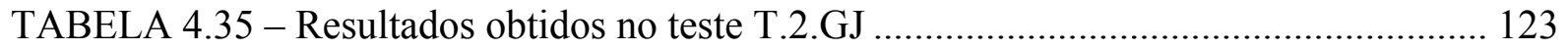

TABELA 4.36 - Valores da função objetivo e resultados do teste T.2.GJ ........................... 123

TABELA 4.37 - Multiplicadores do consumo de referência do teste T.2.GJ ....................... 124

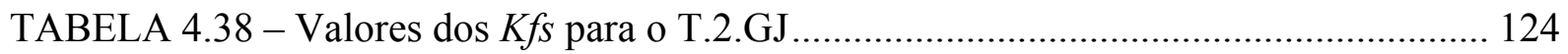

TABELA 4.39 - Resultados obtidos no teste T.3.GJ ........................................................... 125

TABELA 4.40 - Valores da função objetivo e resultados do teste T.3.GJ .......................... 125

TABELA 4.41 - Multiplicadores do consumo de referência do teste T.3.GJ ....................... 126

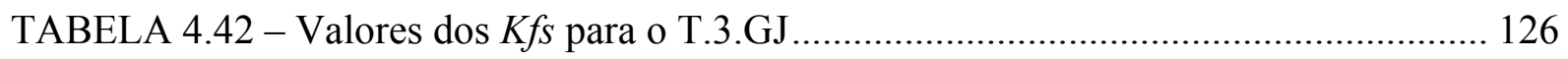

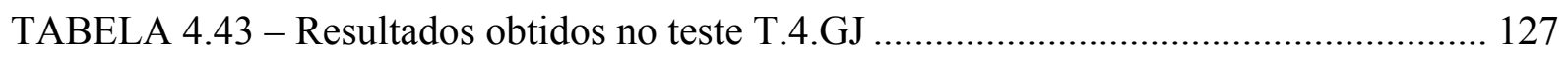

TABELA 4.44 - Valores da função objetivo e resultados do teste T.4.GJ .......................... 127

TABELA 4.45 - Multiplicadores do consumo de referência do teste T.4.GJ ....................... 128 
TABELA 4.46 - Valores dos $K f s$ para o T.4.GJ ............................................................. 128

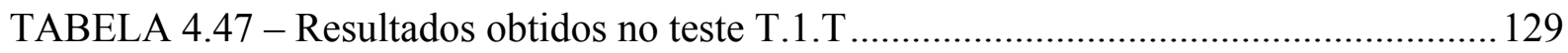

TABELA 4.48 - Valores da função objetivo e resultados do teste T.1.T ............................. 129

TABELA 4.49 - Multiplicadores do consumo de referência do teste T.1.T......................... 130

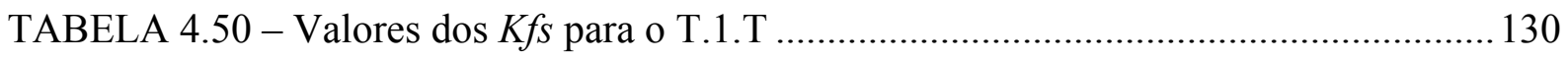

TABELA 4.51 - Resultados obtidos no teste T.2.T ......................................................... 131

TABELA 4.52 - Valores da função objetivo e resultados do teste T.2.T ............................. 131

TABELA 4.53 - Multiplicadores do consumo de referência do teste T.2.T......................... 132

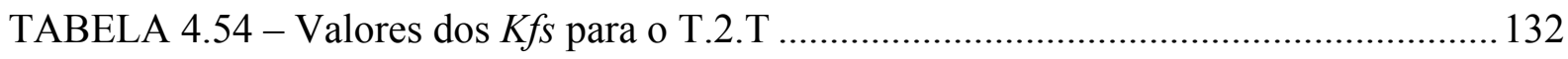

TABELA 4.55 - Resultados obtidos no teste T.3.T ......................................................... 133

TABELA 4.56 - Valores da função objetivo e resultados do teste T.3.T ............................. 133

TABELA 4.57 - Multiplicadores do consumo de base do teste T.3.T................................. 134

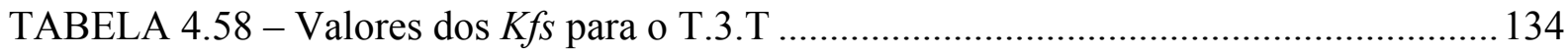

TABELA 4.59 - Resultados obtidos no teste T.4.T ........................................................ 135

TABELA 4.60 - Valores da função objetivo e resultados do teste T.4.T ............................. 135

TABELA 4.61 - Multiplicadores do consumo de referência do teste T.4.T.......................... 136

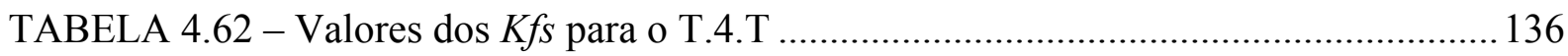

TABELA 4.63 - Padrão do comportamento do nível do reservatório ................................... 138

TABELA 4.64 - Tabela com os resultados do "teste de garrafa" .......................................... 150

TABELA 4.65 - Cálculo dos multiplicadores da concentração de cloro................................ 154

TABELA 4.66 - Resultados da $1^{\mathrm{a}}$ calibração para $\mathrm{K}_{\text {bulk }}$ e $\mathrm{K}_{\text {wall }}$ considerando todos os testes 157

TABELA 4.67 - Intervalos usados para $1^{\mathrm{a}}$ calibração .................................................... 157

TABELA 4.68 - Parâmetros, valores e tipo de AGs usados na $1^{\mathrm{a}}$ calibração ........................ 158

TABELA 4.69 - Intervalos usados para 2 ${ }^{\mathrm{a}}$ calibração ...................................................... 159

TABELA 4.70 - Parâmetros, valores e tipo de AGs usados na $2^{\text {a }}$ calibração ........................ 159 
TABELA 4.71 - Resultados da $2^{\mathrm{a}}$ calibração para $\mathrm{K}_{\text {bulk }}$ e $\mathrm{K}_{\text {wall }}$ considerando todos os testes 160

TABELA 4.72 - Intervalos usados para $3^{\mathrm{a}}$ calibração 163

TABELA 4.73 - Parâmetros, valores e tipo de AGs usados na $3^{\text {a }}$ calibração 163

TABELA 4.74 - Resultados da $3^{\mathrm{a}}$ calibração para $\mathrm{K}_{\text {bulk }}$ e $\mathrm{K}_{\text {wall }}$ considerando todos os testes 164

TABELA 4.75 - Tratamento estatístico dos dados de calibração para o decaimento de cloro 166

TABELA 4.76 - Resultados obtidos com a calibração hidráulica sem vazamentos 169

TABELA 4.77 - Resultados obtidos com a calibração hidráulica sem vazamentos 170

TABELA 4.78 - Multiplicadores do consumo de referência desconsiderando os vazamentos 170

TABELA 4.79 - Resultados da calibração para $K_{\text {bulk }}$ e $K_{\text {wall }}$ sem vazamentos 171

TABELA 4.80 - Tratamento estatístico dos dados de calibração para o decaimento de cloro 


\section{LISTA DE ABREVIATURAS E SIGLAS}

AG algoritmo genético

AGs algoritmos genéticos

BLX- $\alpha$ recombinação mistura (Blend Crossover)

DIP doenças infecciosas e parasitárias

DVM método do volume discreto

EPA Environmental Protection Agency

EDM método dirigido pelo evento

ES Estado do Espírito Santo

EESC Escola de Engenharia de São Carlos

FDM método das diferenças finitas

FOSM Método de primeira-ordem do segundo momento

IWA International Water Association

LABSIN Laboratório de Simulação Numérica

LNEC Laboratório Nacional de Engenharia Civil

MIT Massachusetts Institute of Technology

MSEQ Minimização do Somatório dos Erros ao Quadrado

MS Estado de Mato Grosso do Sul

MG Método Gráfico

PEAD polietileno de alta densidade

PVC cloreto de polivinila

PV posto de visita

PSO Particle Swarm Optimization

PE Estado de Pernambuco

RS Estado do Rio Grande do Sul

SP Estado de São Paulo

SAAE Serviço Autônomo de Água e Esgoto

SRS Stochastic Remainder Sampling

THMs trihalometanos

TTHMs trihalometanos totais

TDM método dirigido pelo tempo

USP Universidade de São Paulo

WSP Water Simulation Packages 


\section{LISTA DE SÍMBOLOS}

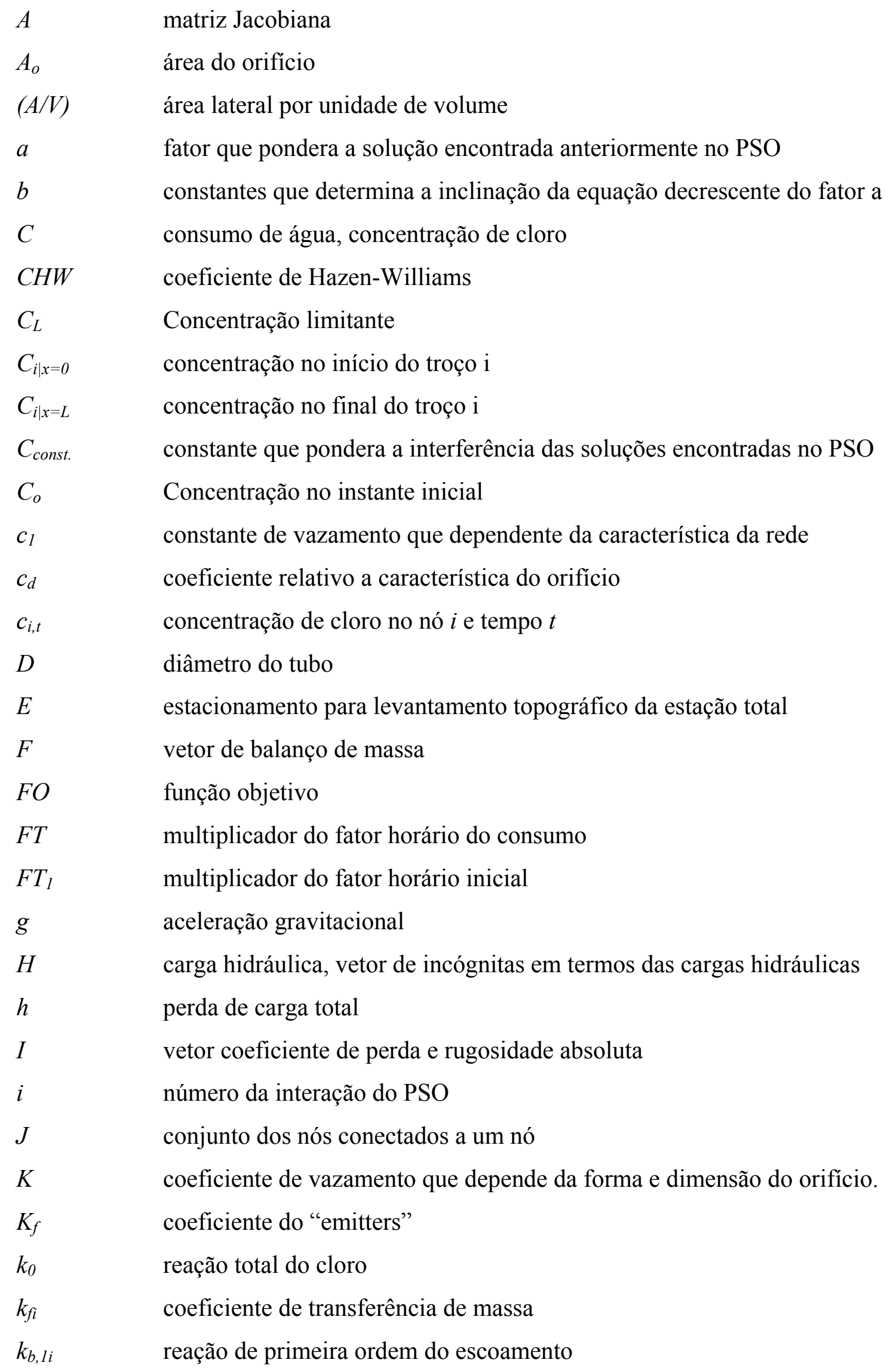


$k_{w, 1 i} \quad$ reação de primeira ordem da parede

$k_{w, O i}$

reação de ordem zero da parede

$k_{b, 2 i}$

reação de segunda ordem do escoamento

$K_{\text {bulk }}$

$K_{\text {wall }}$

coeficiente de reação no escoamento

$K_{f}$

coeficiente de reação devido a interação com a parede

$L$

coeficiente de transferência de massa

comprimento da tubulação

$m$

coeficiente de perda de carga localizada

$\min$

minimizar

$n$

o expoente da formulação de perda de carga x vazão

$n^{P}$

número de padrões operacionais com observações de pressão

$n^{Q}$

número de padrões operacionais com observações de vazão

$n^{P D}$

número de padrões operacionais observados

$P$

presssão, partícula (solução) no PSO

$P_{f}$

pressão do "emitter"

$P_{s d}^{*}$

melhor solução encontrada por uma partícula no PSO

$P_{g d}^{*}$

melhor solução encontrada por uma população de partículas no PSO

$Q$

vazão

$q_{f}$

vazamento considerado pelo "emitter"

$q$

vazamento

$R\left(C_{i, t}\right) \quad$ taxa total de reação do cloro

$R_{\text {eynolds }} \quad$ número de Reynolds

$R^{0}(V) \quad$ perda local correspondente a interferência de uma válvula

$R$

coeficiente de resistência da tubulação

$r$

perda de carga que depende da formulação utilizada

$r_{h i}$

raio hidráulico

$r_{\text {bulk }}$

taxa de reação devido ao escomento

$r_{\text {wall }}$

taxa de reação devido a interação com a parede

Sh

número de Sherwood

Sc

número de Schmidt

sgn

sinal da equação

$T S$

vazão total abastecida

$T S^{*}$

consumo de base

$T D$

consumo total 


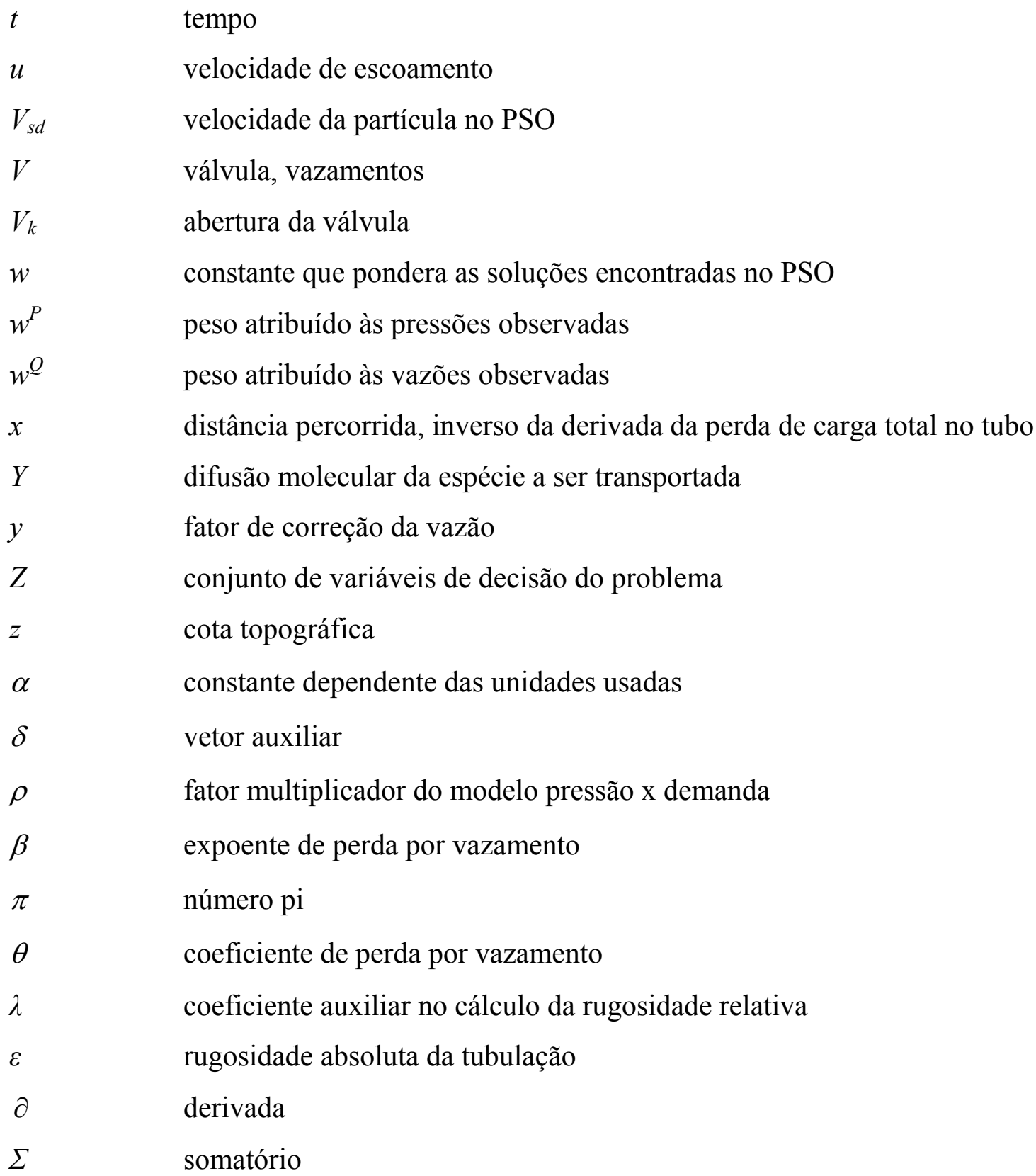





\section{INTRODUÇÃO}

Dentre as possíveis melhorias no saneamento ambiental, os sistemas de abastecimento de água são os que provocam maior impacto na redução das doenças infecciosas.

O beneficio que os sistemas de abastecimento de água podem trazer à saúde da população, em todos os estratos sociais, ao proporcionar oportunidades de higiene, conforto e bem-estar, mesmo às camadas sociais mais desfavorecidas, tem um reflexo imediato na redução da demanda por serviços de saúde.

Entretanto, os sistemas de distribuição de água quando operados e construídos inadequadamente podem representar grande perigo à saúde da população. Assim, tanto no Brasil, como em países desenvolvidos, já houve registros de ocorrências de doenças graves vinculadas à água devidas a falhas ou negligências na operação de sistemas de abastecimento (TSUTIYA, 2005).

AZEVEDO (1996) cita que, no início de 1996, 123 pacientes renais crônicos, após terem sido submetidos a sessões de hemodiálise em uma clínica da cidade de Caruaru (PE), passaram a apresentar quadro clínico compatível com uma grave hepatoxicose não correlacionada com nenhum dos fatores usualmente tidos como causadores deste tipo de intoxicação. Destes, 54 vieram a falecer até cinco meses após o início dos sintomas. De acordo com informações fornecidas pela Secretaria de Saúde do Estado de Pernambuco, a referida clínica recebia água sem tratamento completo e a cloração usualmente era feita no próprio caminhão tanque utilizado para transportá-la, em períodos de falha do abastecimento pela rede pública.

MARTINS et al. (2001) avaliaram a economia que poderia ser obtida na redução dos gastos com consultas, procedimentos médicos, tratamentos medicamentosos e outros gastos 
ligados a saúde, com o investimento na qualidade da água, chegando à relação de US\$1,16, para cada dólar investido com os serviços de água e esgoto. E se considerados fatores subjetivos como conforto e bem estar, essa marca pode chegar a US\$3,50 para cada dólar investido com serviços de água e esgoto.

TSUTIYA (2005) demonstra forte correlação entre a proporção de pessoas abastecidas por sistemas públicos de água e a proporção de óbitos de crianças menores de um ano de idade por doenças infecciosas e parasitárias (DIP) no Brasil.

Devido à importância de um sistema adequado de abastecimento de água, maiores investimentos estão sendo feitos, principalmente nas últimas décadas, com o objetivo de melhorar a tecnologia e conseqüentemente a qualidade da água para maior número de consumidores, especialmente dos países em desenvolvimento, onde a situação de abastecimento de água é menos favorável. TSUTIYA (2005) ainda afirma que, no Brasil, o imenso progresso em relação à implantação de sistemas de abastecimento de água se deu nas décadas de 1970 e 1980 com a implementação do PLANASA - Plano Nacional do Saneamento - que permitiu ao país atingir níveis de atendimento próximos a $90 \%$ da população urbana.

Além da garantia de água para abastecimento da população, existe também a preocupação para que essa água seja de qualidade, e desta forma, evitar as doenças de veiculação hídrica, reduzir gastos com a Saúde, possibilitar o crescimento econômico da região e todos os demais benefícios diretos e indiretos que o abastecimento pode trazer (COPASA, 2005).

A International Water Association (IWA), uma respeitável associação internacional que vem promovendo o desenvolvimento dos serviços de abastecimento de água e incentivando o contato entre especialistas de todo o mundo, publicou, em 2005, a Carta de Bona para o Abastecimento Seguro de Água para Consumo Humano. O documento apresenta 
o enquadramento global, descrevendo as condições institucionais e operacionais que são requisitos básicos para gerir o abastecimento de água, desde a origem até o consumidor. Demonstra a clara iniciativa para o estabelecimento de diretrizes que garantam a qualidade da água servida desde o produtor até o consumidor, com planos de segurança da qualidade da água servida e da constante verificação da qualidade da água com os objetivos de qualidade e segurança (IWA, 2005)

\subsection{JUSTIFICATIVA}

Apesar do controle exercido sobre a qualidade da água na saída das estações de tratamento de água, diversos são os fatores que promovem a sua degradação ao longo dos sistemas de distribuição. Assim, é comum o uso de cloro no processo de desinfecção da água, uma vez que ele age como desinfetante e oxidante, e a manutenção do residual de cloro livre na rede, visando o combate de organismos patogênicos não eliminados no processo de tratamento ou provenientes de eventuais contaminações na rede.

Contudo, o excesso de cloro pode produzir odor na água e a reação com substâncias húmicas resultando em substâncias com potencial carcinogênico (ZIEROLF et al., 1998; BOCELLI et al., 2003).

Assim sendo, é usual limitar-se a concentração do residual de cloro nos sistemas de abastecimento. No Brasil, de acordo com Portaria 518/2004 do Ministério da Saúde (BRASIL, 2004), após a etapa da desinfecção, a água deve conter um teor mínimo de cloro residual livre de $0,5 \mathrm{mg} / \mathrm{L}$, sendo obrigatória a manutenção de, no mínimo, 0,2 mg/L em qualquer ponto da rede de distribuição. Além disso, estabelece o teor máximo de cloro residual livre de 2,0 mg/L (Art. 16 ${ }^{\circ}$ ). 
Apesar de a referida portaria estabelecer a freqüência e o número de amostras que devem ser realizadas com vistas à verificação do cloro residual presente nas redes e recomendar que tais amostras sejam representativas, ela não fornece o indicativo claro da localização dos pontos de coleta. Apenas estabelece que pontos estratégicos, como de grande circulação de pessoas (hospitais, trechos vulneráveis do sistema como as pontas de rede e locais com intermitência de abastecimento ou com sistemáticas de agravo à saúde devido a doenças de veiculação hídrica) devem ser amostrados.

O ideal seria se todos os nós da rede fossem monitorados, entretanto restrições econômicas devem nortear a identificação de um número reduzido de pontos representativos. Assim, torna-se difícil determinar os pontos de monitoramento do cloro residual sem o suporte de um modelo de simulação computacional que reproduza, próximo da realidade, o comportamento dinâmico do residual de cloro no interior do sistema.

Um modelo de qualidade da água só é uma ferramenta eficaz e confiável quando os principais mecanismos (níveis de reservatório, concentrações de entrada do cloro residual, tubulações, distribuição geométrica da rede) são adequadamente representados e seus parâmetros (rugosidade, coeficientes de vazamento, coeficientes de decaimento de cloro) são condizentes com a realidade de campo.

A literatura tem convergido quanto a alguns aspectos, no que se refere aos modelos de decaimento do cloro em redes:

- A necessidade de um simulador hidráulico eficiente: todos os trabalhos evidenciam a necessidade do conhecimento do comportamento hidráulico da rede, reconhecendo que se deve contar com um simulador hidráulico confiável na representação do verdadeiro comportamento da rede, antes de se proceder à simulação da qualidade da água em termos do cloro residual presente, tendo em vista a interferência do modelo hidráulico nos resultados da simulação da qualidade; 
- Utilização modelos de simulação de qualidade de água baseados nas equações de transporte simplificadas (equação reação-advecção), utilizando a lei da conservação de massa para determinar a distribuição das substâncias espacialmente e temporalmente; e

- É admitido que o decréscimo do desinfetante residual se dê por combinação de reações que ocorrem no escoamento e junto às paredes das tubulações, sendo suas influências representadas pelas respectivas constantes cinéticas $\mathrm{K}_{\text {bulk }}$ e $\mathrm{K}_{\text {wall }}$ (VIEIRA et al., 2004; MUNAVALLI \& KUMAR, 2005; CHEUNG, 2005), embora considerem diferentes modelos para simular o comportamento do fenômeno.

Já os parâmetros condizentes com a realidade de campo só são obtidos através da calibração do modelo de qualidade da água em termos das suas constantes cinéticas $\left(\mathrm{K}_{\text {bulk }} \mathrm{e}\right.$ $\mathrm{K}_{\text {wall }}$ ), com base em observações de campo. A investigação de valores para tais constantes constitui alvo dos estudos desenvolvido neste trabalho de pesquisa, visando um sistema real no Brasil onde esse tipo de investigação ainda é escasso.

\subsection{OBJETIVO}

O objetivo deste trabalho é construir uma rotina computacional com vistas ao desenvolvimento de um modelo de calibração de redes de abastecimento em termos das constantes de decaimento de cloro, $\mathrm{K}_{\text {bulk }}$ e $\mathrm{K}_{\text {wall }}$ e realizar uma calibração desses parâmetros aplicados no setor de rede de distribuição de água. 


\section{REVISÃO BIBLIOGRÁFICA}

\subsection{MODELOS HIDRÁULICOS}

\subsubsection{Calibração dos modelos hidráulicos}

Segundo SOARES (2003), do ponto de vista hidráulico, o emprego de modelos de simulação de redes requer que os parâmetros relevantes sejam identificados para a reprodução realística do comportamento do sistema, sob diferentes condições operacionais, através da calibração.

As primeiras calibrações de redes baseavam-se no procedimento de tentativa e erro, adotando critérios para melhorar a calibração. (WALSKI, 1983; BHAVE, 1988).

ORMSBEE \& WOOD (1986) propuseram o método explícito para a calibração de redes de distribuição de água. O processo é formulado em termos dos fatores de atrito e de uma reformulação das equações governantes do escoamento, que são resolvidas explicitamente para determinadas condições operacionais.

BOULOS \& ORMSBEE (1991), por sua vez, apresentaram um aperfeiçoamento do método explícito proposto por ORMSBEE \& WOOD (1986), sendo que o método original é aplicado na determinação de um grupo de coeficientes de rugosidade com base em dados simultâneos de vazão e pressão observados durante testes de incêndio ocorridos simultaneamente para determinadas situações de contorno. A melhoria obtida por BOULOS \& ORMSBEE (1991) é atribuída ao fato do método ganhar flexibilidade, uma vez que se pode considerar diversos testes de incêndio, sob diferentes condições de contorno (observações em tempos diferentes).

Com o desenvolvimento das técnicas de otimização, os métodos anteriores foram substituídos por métodos “automáticos” de otimização e calibração. 
LANSEY \& BASNET (1991) apresentaram um algoritmo capaz de minimizar a diferença entre os valores observados e os simulados de vazões em tubos e pressões em nós em conjunto um modelo de simulação para diminuir as dificuldades de cálculo. Os autores concluíram que o método poderia ser aplicado a qualquer sistema e apresentaria grande habilidade de procura da solução ótima. Entretanto, o método apresenta a deficiência de não conseguir realizar a calibração sem um grande número de dados confiáveis do sistema.

DATTA \& SRIDHARAN (1994) propuseram um método de calibração dos coeficientes de Hazen-Williams dos tubos de uma rede, através da resolução do problema inverso, ou seja, da minimização da função objetivo expressa pela soma ponderada dos quadrados das diferenças entre os valores computados e os respectivos valores observados. Esse método apresenta vantagens, pois diferentes condições operacionais com variado número de medidas de pressão e vazão para cada condição podem ser utilizados. Neste trabalho, é apresentada a discussão dos efeitos da escolha dos pesos e das considerações de estimativas iniciais, e também a análise da sensibilidade das incertezas nos valores estimados.

GRECO \& GIUDICE (1999) também realizaram a calibração através da resolução do problema inverso pela minimização das diferenças entre os valores observados e simulados ao quadrado. Neste trabalho, a rugosidade foi o parâmetro a ser calibrado para uma rede hipotética, porém primeiramente foi feita uma estimativa da rugosidade através de restrições determinadas pela matriz de sensibilidade.

O trabalho desenvolvido por SAVIC \& WALTERS (1997) usam Algoritmos Genéticos como ferramenta de otimização na calibração de rugosidades de uma rede, com vantagens sobre os métodos anteriores baseados em tentativa e erro.

LINGIREDDY \& ORMSBEE (2002) utilizaram os Algoritmos Genéticos para calibrar a rugosidade absoluta da rede e demandas. No trabalhado desenvolvido, foram calibradas duas redes de distribuição de água, e para ambas as redes utilizadas, os autores 
observaram a superioridade da performance dos Algoritmos Genéticos em relação aos outros métodos de otimização. Para tanto, resolveram o problema expresso em termos da minimização dos quadrados das diferenças entre os valores observados e simulados das variáveis de estado do problema (pressões em alguns nós, vazões em alguns trechos e níveis de tanque).

MALLICK et al. (2002) implementaram uma metodologia para quantificar o impacto provocado no modelo devido à consideração de setores com coeficientes de rugosidades homogêneos e identificaram a melhor divisão das tubulações em grupos homogêneos. Os autores concluíram que como o método exigiu menor esforço na coleta de dados para a calibração e a melhor simplificação do modelo para que este ainda consiga representar as condições físicas do sistema, reforçando a idéia de que existe um número ótimo de setores com coeficientes de rugosidades homogêneos a serem considerados nas simulações.

BASCIÀ \& TUCCIARELLI (2003) produziram um procedimento capaz de simultaneamente criar zonas de mesma rugosidade e calibrar a rugosidade dos tubos dessas zonas. O objetivo da metodologia é agrupar todos os tubos da rede em pequenos grupos de mesmos parâmetros, mantendo uma tolerância entre os valores computados e os valores observados. O procedimento foi aplicado para uma rede hipotética de laboratório que apresentava dois tipos diferentes de tubos e foram calibrados usando dois pontos de medida de pressão e um conjunto de três diferentes situações operacionais, manipuladas através de uma válvula. Os resultados obtidos com a comparação entre os valores computados e os valores obtidos em campo foram considerados bons pelos autores.

KAPELAN et al. (2007) desenvolveram um método de calibração que é capaz de determinar os valores dos parâmetros a serem calibrados e suas incertezas em uma única simulação de calibração, pois julga necessário determinar a incerteza desses valores calibrados. O cálculo das incertezas dos valores calibrados usualmente é feito usando o 
método de primeira-ordem do segundo momento (FOSM), no qual é necessário o cálculo de derivadas e uma série de restrições. Para superar esses problemas, os autores propuseram um método que não exige cálculos de derivadas, contudo apresenta a deficiência de exigir um esforço computacional maior que o método FOSM.

KIM (2008), através do método da matriz de independência do endereço-orientado, apresenta o desenvolvimento do método para a calibração de redes reais com tubos com diversas características. Sua justificativa é a de que os métodos convencionais no regime transiente e a calibração dos parâmetros para diversos tipos de tubos sofrem de questões como custos e tempos de armazenamento de dados, bem como outras diversas dificuldades associadas à representação numérica de sistemas reais. No entanto, seu método é apenas testado para rede hipotética de tubos de diferentes características. Para isso, o Algoritmo Genético é incorporado ao método da matriz de independência do endereço-orientado para calibrar diversos parâmetros como: localização e quantificação dos vazamentos, rugosidade e velocidade da onda de propagação.

TUCCIARELLI \& TERMINI (1998), TUCCIARELLI et al. (1999) realizaram trabalhos pioneiros ao considerarem perdas por vazamento de redes de distribuição de água. Ambos os trabalhos consideram os consumos dependentes das pressões.

TUCCIARELLI \& TERMINI (1998) criaram um procedimento em dois passos para a calibração. O primeiro passo é a estimativa dos parâmetros no modelo de simulação da rede para um dado conjunto de medidas de pressão, logo após modifica-se as aberturas das válvulas e adquiri-se um novo conjunto de medidas. O segundo passo é feito resolvendo-se o problema inverso e o procedimento é realizado até que haja convergência dos parâmetros avaliados. Sendo que, as diferentes correlações entre as medidas na mesma localização e as diferentes aberturas de válvulas são investigadas com a utilização de um esquema simplificado (reservatório, tubo e válvula) e uma rede hipotética. A principal desvantagem do 
método é o grande esforço computacional necessário para a inversão de duas matrizes da função objetivo para cada conjunto de medidas (resistência das válvulas).

TUCCIARELLI et al. (1999) conseguiram eliminar o inconveniente da inversão de duas matrizes, apresentado por TUCCIARELLI \& TERMINI (1998), empregando o método de busca Simulated Annealing, o que constitui um avanço por empregar o processo em uma rede real com medidas de pressões e vazões na função objetivo. $\mathrm{O}$ trabalho anterior não contemplava medidas de vazão na otimização. Outro diferencial do método é a possibilidade de quantificar o total de vazamentos em setores da rede.

SOARES (2003) realizou a calibração da rede hipotética elementar através da implementação de uma rotina computacional, que considerava as perdas por vazamento e os consumos variáveis com a pressão, acoplada ao simulador hidráulico EPANET 2.0 (ROSSMAN, 2000), com vistas à calibração em termos das rugosidades absolutas, consumos, diâmetros e parâmetros do modelo de vazamentos. Para tanto, o autor utilizou modelos inversos resolvidos com o suporte da tecnologia dos Algoritmos Genéticos (AGs) e o procedimento híbrido unindo os AGs com o método Simplex (NELDER \& MEAD, 1965).

REIS et al. (2007), com base no modelo desenvolvido por SOARES (2003) e após algumas modificações, realizaram a calibração dos coeficientes dos "emitters" de cada nó e do expoente global para os "emitters", exigido pelo simulador hidráulico EPANET 2.0, (ROSSMAN, 2000) para a simulação de vazamentos. Esse procedimento foi empregado em um setor de rede real da cidade de Piracicaba, São Paulo. Outra modificação realizada pelos autores foi a implementação de mais um modelo de vazamento na calibração, o modelo proposto por GERMANOPOULOS \& JOWITT (1989), pois SOARES (2003) considerou apenas o modelo de vazamento proposto por TUCCIARELLI et al. (1999). REIS et al. (2007) 
observaram que os dois modelos divergem nos valores do vazamento total da rede encontrando uma diferença entre os valores da ordem de 2,8 vezes.

\subsubsection{Modelos de Vazamento}

Segundo SOARES (2003), existem duas formas de utilizar os modelos de vazamentos propostos pela literatura juntamente com as simulações hidráulicas. A primeira possibilidade é introduzir os vazamentos explicitamente no modelo de simulação hidráulica da rede (GERMANOPOULOS \& JOWITT, 1989; JOWITT \& XU, 1990; TUCCIARELLI \& TERMINI, 1998; TUCCIARELLI et al., 1999). A segunda alternativa é supor que as perdas, função das pressões nos nós da rede, possam ser avaliadas iterativamente, sem que sejam explicitadas relações pressão x vazamento internamente ao modelo. Observa-se que essa última forma facilita o acoplamento do problema de calibração com pacotes computacionais que não incorporam explicitamente os vazamentos no modelo, implicando em um tempo computacional maior, dada a natureza iterativa do procedimento.

GERMANOPOULOS \& JOWITT (1989) foram os pioneiros no emprego explícito das perdas por vazamento nos modelos hidráulicos. Neste trabalho, a função que relaciona a pressão nos nós e a perda por vazamentos é inclusa nas equações de continuidade dos nós.

$$
\sum_{j \in J_{i}} Q_{i j}+0,5 \sum_{j \in J_{i}} q_{i j}+C_{i}=0
$$

sendo, $Q_{i j}$ a vazão no tubo que conecta os nós $i$ e $j, C_{i}$ é o consumo no nó $i, J_{i}$ é o conjunto de todos os nós conectados a $i$ e $q_{i j}$ o vazamento na tubulação entre os nós $i$ e $j$, expresso por:

$$
q_{i j}=c_{1} L_{i j}\left(\overline{P_{i j}}\right)^{\exp }
$$

sendo, $c_{1}$ uma constante que depende das características da rede, $L_{i j}$ é o comprimento da tubulação entre os nós $i$ e $j$ e $\overline{P_{i j}}$ a média das pressões nos nós $i$ e $j$, expressa por: 


$$
\overline{P_{i j}}=0.5\left[\left(H_{i}-z_{i}\right)+\left(H_{j}-z_{j}\right)\right]
$$

As vazões $Q_{i j}$ são assumidas na direção de $i$ para $j$ na equação acima. $C_{i}$ é negativo quando se tratar de uma vazão de entrada para o nó $i$. O nó $j$ pode ser um nó de pressão ou um reservatório. $q_{i j}$ é o vazamento do trecho $i j$, sendo que metade é atribuída a $i$ e a outra metade ao $j$.

$$
Q_{i j}=R_{i j} \sin a l\left(H_{i}-H_{j}\right) \cdot\left|H_{i}-H_{i}\right|^{0,54}
$$

sendo, $R_{i j}$ uma constante para o tubo que conecta os nós $i$ e $j$, que é função do comprimento, diâmetro e rugosidade, expresso em conformidade com a equação de perda de carga utilizada (Hazen-Williams ou Fórmula Universal). No caso da equação de Hazen-Williams:

$$
R_{i j}=\frac{\alpha C H W_{i j} D_{i j}^{2.63}}{L_{i j}^{0.54}}
$$

sendo, $C H W_{i j}$ o coeficiente de Hazen-Williams relativo ao trecho que conecta os nós $i$ e $j ; \alpha$ a constante cujo valor depende das unidades usadas e Sinal $(x)$ denota o sinal de $x$.

O problema da minimização do excesso de pressão é formulado com a função objetivo linear e um conjunto de restrições não-lineares, por causa da não linearidade das equações de continuidade nos nós. O método da teoria linear é utilizado para a solução do problema nãolinear de minimização do excesso de pressão até que sejam determinados, o conjunto de aberturas ótimas das válvulas de controle de pressão e as correspondentes energias de vazões da rede. Assim, benefícios, tais como reduções no desperdício de água e redução de rompimento de tubulações, são também identificados.

A função objetivo para determinar a abertura ótima das válvulas $\left(V_{k}\right)$ consiste na minimização do somatório das diferenças entre as cargas hidráulicas calculadas $H_{i}$ e as cargas hidráulicas requeridas $H_{i}{ }^{*}$ necessárias para atender o consumo, para $I_{d}$ medidas:

$$
\min _{V_{k}} \sum_{i \in I_{d}}\left(H_{i}-H_{i}^{*}\right)
$$


sujeito a:

(a) equação da continuidade nos nós (eq.(2.1));

(b) aberturas máxima e mínima das válvulas:

$V_{k}^{\min } \leq V_{k} \leq V_{k}^{\text {máx }}$

(c) carga hidráulica mínima para os nós:

$H_{i} \geq H_{i}^{*}$

JOWITT \& XU (1990) melhoraram o algoritmo proposto por GERMANOPOULOS \& JOWITT (1989), visto que a função objetivo foi modificada de tal forma que, em vez de minimizar as pressões excessivas dos nós, passou a minimizar as perdas por vazamento diretamente.

$$
\min _{V_{k}} \sum_{i \in I_{d}} q_{i j}
$$

Outra modificação ocorreu no uso de técnicas de linearizações sucessivas, no entanto, com uma sistemática mais adequada para o problema, melhorando os resultados.

VAIRAVAMOORTHY \& LUMBERS (1998) realizaram a otimização da operação das válvulas sem considerar a localização ótima das mesmas. A metodologia usa a técnica de procura da solução através de programação quadrática seqüencial, que gera um vetor direção que é usado para corrigir a direção do vetor solução a cada passo. Para tanto, utilizaram duas funções objetivos.

A primeira minimiza o volume total de vazamento na rede:

$$
\min Z_{1}=\sum_{k=1}^{N P} q_{i j}
$$

sendo, $N P$ o número de tubulações da rede.

A outra função objetivo minimiza a soma dos quadrados dos desvios entre as pressões dos nós e a pressão mínima requerida para esses nós: 


$$
\min Z_{2]}=\sum_{i=1}^{N P Z}\left(H_{i}-H_{i}^{*}\right)^{2}
$$

sendo, NPZ o número de nós com carga hidráulica desconhecida.

REIS et al. (1997), usando Algoritmos Genéticos, apresentaram uma metodologia para determinação do número de válvulas necessárias e a localização ótima de cada uma delas no sistema, minimizando os vazamentos para dados consumos nos nós e níveis de reservatório. O algoritmo genético procura a solução ótima dentre um número máximo de válvulas préestabelecido e consumo nos nós e níveis de reservatórios conhecidos. A procura da localização das válvulas, minimizando o vazamento, ocorre simultaneamente com a procura da abertura ótima das válvulas.

Outros autores investigaram os melhores valores para os parâmetros do modelo de vazamento, através de simulações da rede (TUCCIARELLI \& TERMINI, 1998; TUCCIARELLI et al., 1999; ALONSO et al., 2000; SOARES, 2003; ARAUJO et al., 2006).

TUCCIARELLI et al. (1999) usaram a metodologia de otimização dos vazamentos através do controle da abertura das válvulas, utilizado por TUCCIARELLI \& TERMINI (1998), com algumas alterações.

TUCCIARELLI et al. (1999) desenvolveram uma estimativa de perda de água através de pequenos vazamentos, em diferentes áreas de uma rede de distribuição de água, por meio de um processo iterativo de dois passos. No primeiro passo foi realizada a estimativa dos parâmetros do modelo de simulação da rede. Nesta etapa, foi utilizada a função objetivo que minimiza a diferença entre as cargas hidráulicas e as vazões observadas dos valores calculados, para um dado número de nós e tubulações. O objetivo final desse passo é a determinação dos parâmetros de vazamento como coeficientes e expoente de perda, que constituem o modelo hidráulico. No segundo passo, ocorre a otimização das aberturas das 
válvulas, sendo que, o problema é restrito pelas pressões mínimas exigidas na rede e a pela equação da continuidade dos nós.

O modelo de simulação usado no procedimento de calibração é uma relação entre os parâmetros da rede e as variáveis de estado (vazões e pressões). O modelo assume que o escoamento seja permanente e combinando equações de conservação de massa e conservação da quantidade de movimento em apenas uma equação, em um conjunto de $\mathrm{N}$ equações algébricas:

$$
\sum_{j=1}^{M_{i}} \frac{H_{j}-H_{i}}{\sqrt{R_{i j}\left(I_{i j}, V_{i j}\right)\left|H_{j}-H_{i}\right|}}-\delta_{1} \cdot q_{i}-C . \rho_{i}=0, \quad i=1, \ldots, N
$$

sendo que, $N$ é o número total de nós; $M_{i}$ é o número total de tubulações ligadas ao nó $i ; H$ é a carga hidráulica total no nó $i$ e $j ; q_{i}$ é a perda de água nas tubulações ligadas ao nó $i ; \delta_{1}$ é igual a 1 ou zero, se a pressão total no nó $i$ é maior ou menor, respectivamente, que a cota topográfica deste; $C$ é a consumo total; $\rho_{i}$ é o fator multiplicador do consumo total (restrição do consumo atendido) no nó $i$; $I$ é um vetor, com cada valor correspondendo unicamente ao valor de coeficiente de perda e rugosidade; $V_{i j}$ é uma possível válvula localizada na tubulação entre os nós $i$ e $j$; e $R_{i j}$ é o coeficiente de resistência da tubulação que liga o nó $i$ ao nó $j$.

O termo $q_{i}$ é calculado assumindo-se que nas tubulações, em cada zona, há valores constantes de vazamento por área de superfície de tubo. Assim, no modelo usado por TUCCIARELLI et al. (1999), o vazamento era expresso por:

$$
q_{i}=\left(H_{i}-z_{i}\right)^{\beta} \sum_{j=1}^{M_{i}} \frac{\pi}{2} D_{i j} \theta_{i j} L_{i j}
$$

sendo, $\beta$ o expoente de perda, $\theta_{i j}$ a taxa de vazamento por unidade de superfície da tubulação ligando o nó $i$ ao $j, D_{i j}$ o diâmetro do tubo que liga o nó $i$ ao $j$ e $L_{i j}$ o comprimento do mesmo. 
$R_{i j}$ é o coeficiente de resistência da tubulação que liga o nó $i$ ao nó $j$ e é igual, de acordo com a fórmula de Prandtl-Nikuradse, a:

$$
\begin{aligned}
& R_{i j}=R^{0}\left(V_{i j}\right)+0,0826 \frac{L_{i j}}{\lambda D_{i j}^{5}} \\
& \lambda=4\left(\log \left(\frac{\varepsilon_{i j}}{3,71 D_{i j}}\right)\right)^{2}
\end{aligned}
$$

sendo, $R^{0}\left(V_{i j}\right)$ a perda local correspondente a uma possível válvula de índice $V_{i j}$ localizada na tubulação entre os nós $i$ e $j ; \varepsilon_{\mathrm{ij}}$ a rugosidade absoluta da tubulação entre os nós $i$ e $j$.

TUCCIARELLI, CRIMINI \& TERMINI (1999) também realizaram a análise de perda de água através do problema inverso, sendo o objetivo final, a minimização das perdas de água por meio do controle da apertura das válvulas. Para tanto, usaram a função objetivo que minimiza a diferença das cargas hidráulicas e vazões observadas em campo entre os valores calculados de cargas hidráulicas e vazões. Assim a função objetivo é:

$$
\text { Minimize } O F_{1}=\sum_{j=1}^{n_{h}} w_{h} \frac{\left(H_{j}-H_{j}^{*}\right)^{2}}{\left(\sum_{i=1}^{n_{h}} H_{i}^{*}\right)^{2}}+\sum_{j=1}^{n_{f}} w_{f} \frac{\left(Q_{j}-Q_{j}^{*}\right)^{2}}{\left(\sum_{i=1}^{n_{f}} Q_{i}^{*}\right)^{2}}
$$

sendo, $Q$ o vetor da vazão calculada, $H$ carga hidráulica total calculada, $H^{*}$ e $Q^{*}$ a carga hidráulica total e a vazão medidas em campo, respectivamente, $n_{f}$ e $n_{h}$ o número de tubos e o número de nós observados, respectivamente, $w_{h}$ e $w_{f}$ dois pesos da função objetivo.

Através do cálculo das estimativas dos parâmetros $C, \beta, \theta_{i j}$ e $\varepsilon_{i j}$, são calculadas as perdas $\left(q_{i}\right)$. A estimativa desses parâmetros é realizada através de medições de cargas hidráulicas totais e vazões para determinados nós e tubulações.

ALONSO et al. (2000) consideraram que os vazamentos permanentes são conseqüências das falhas dos tubos e são calculados conforme a lei dos orifícios. Assim: 


$$
q=K\left(P_{1}-P_{2}\right)^{\beta}
$$

$p_{1}$ a pressão a jusante do orifício, $p_{2}$ a pressão depois do orifício, $\beta$ o expoente tendo valor de 0,5 de acordo com a teoria e experimentos em laboratório e $K$ o coeficiente que depende da forma e da dimensão do orifício.

Como os vazamentos através das rupturas podem ser considerados para atmosfera $p_{2}=$ 0. O expoente $\beta$ pode ser determinado em laboratório. Contudo, segundo GOODWIN (1980) ${ }^{1}$ apud ALONSO et al. (2000), os resultados de uma experiência para determinação do expoente $\beta$ mostram que o mesmo varia entre 0,5 e 1,18 . O que poderia ser explicado pela deformação das falhas com a variação da pressão. Assim a equação (2.17) se torna:

$$
q_{f}=K_{f} P_{f}^{\beta}
$$

sendo, $q_{f}$ a vazão que passa pelo orifício, ou seja, o vazamento; $p_{f}$ a pressão no nó do vazamento e $K_{f}$ o coeficiente de cada nó, que é constante durante longos períodos do dia.

A determinação do $K_{f}$ é feita através de um processo iterativo como se segue:

1- as perdas por vazamento são assumidas iguais a zero em cada nó;

2- as pressões em cada nó são calculadas através do modelo de simulação;

3- uma aproximação do vazamento em cada nó $i$ é obtida da seguinte formulação da equação (2.18);

4- soma-se a perda por vazamento ao consumo real em cada nó, e um novo valor global de consumo é obtido;

5- volta-se ao passo 2 , o processo termina quando os valores de vazamentos em cada nó atingem valores estáveis para uma certa tolerância.

VÍTKOVSKÝ et al. (2000) empregaram, juntamente com os Algoritmos Genéticos, a técnica do Transiente Inverso para calibrar uma rede hipotética. Para tanto, incluíram o

\footnotetext{
${ }^{1}$ GOODWIN, S. J. (1980). The results of the experimental program on leakage and leakage control. Tech. Rep.
} TR 145, Water Research Centre. 
vazamento na equação de conservação de massa dos nós e assumiram que os vazamentos só ocorrem nos nós. Como o vazamento é considerado um orifício, ele foi simulado seguindo a lei dos orifícios.

$$
q=c_{d} A_{0} \sqrt{2 g H}
$$

$c_{d}$ coeficiente relativo à sua característica, $A_{0}$ a área do orifício, $g$ a aceleração gravitacional, e $H$ carga hidráulica.

ARAUJO et al. (2003) utilizaram o simulador hidráulico EPANET 2.0, considerando os nós da rede como "emitters" para impor vazamentos como função das pressões nodais na mesma forma da equação (2.18).

No entanto, os autores fizeram uma alteração na formulação de GERMANOPOULOS \& JOWITT (1989) representada pela equação (2.2), para:

$$
q_{i}=c_{1} \times \sum_{j=1}^{m} 0,5 \cdot L_{i j}\left(\bar{P}_{i}\right)^{1.18}
$$

sendo, $P_{i}$ a pressão do nó $i$ em substituição à pressão média do trecho $i j$. Fixaram o mesmo valor de exp $(=1,18)$ empregado por diversos autores e calibraram o modelo em termos de $c$, com base em dados observados de pressão.

SOARES (2003) propõe um modelo de calibração baseado no procedimento iterativo para adicionar vazamentos aos consumos nodais a setores de rede, com o auxílio do EPANET 2.0 (ROSSMAN, 2000). Na sua proposta para determinação dos vazamentos, foi realizado um balanço hídrico que admite que a vazão abastecida total é composta de vazamentos e consumos condicionados pela pressão. Simultaneamente a calibração dos parâmetros do modelo de vazamentos, também ocorre a calibração de outros parâmetros hidráulicos da rede, tais como: rugosidades, diâmetros desconhecidos, consumos especiais, bem como os fatores de consumo (=consumo/consumo referência) para os diversos padrões operacionais 
simulados. SOARES (2003) usa o modelo proposto por TUCCIARELLI et al. (1999) adaptando os índices $\theta$ s como funções das características dos nós e não dos trechos.

REIS et al. (2007), através de algumas alterações no modelo proposto por SOARES (2003), calibraram simultaneamente todos os parâmetros da rede, além dos parâmetros dos modelos de vazamentos propostos por TUCCIARELLI et al. (1999) e GERMANOPOULOS \& JOWITT (1990). Essas alterações foram feitas para adequá-los à avaliação dos coeficientes $K_{f}$ dos "emitters" para cada nó.

Os modelos são ditos modificados porque, no caso GERMANOPOULOS \& JOWITT (1990) foram admitidos vazamentos em função das pressões nodais e não médias dos trechos da rede, enquanto no caso TUCCIARELLI et al. (1999) foram considerados $\theta$ s característicos dos nós e não dos trechos de rede, apesar da possibilidade de usar valores de $\theta$ associados aos trechos. Para efeito de redução do grau de parametrização dos modelos a serem calibrados, é importante que trechos ou nós de rede possam ser agrupados para que valores homogêneos possam ser atribuídos aos parâmetros dos modelos de vazamentos. É importante ressaltar que o EPANET 2.0 só aceita um valor de expoente para toda rede.

\subsection{QUALIDADE DA ÁGUA EM REDES DE ABASTECIMENTO DE}

\section{ÁGUA}

No Brasil não existe um amplo e contínuo controle da qualidade da água ao longo da rede de distribuição. O que se faz é a coleta e análise de amostras d'água em alguns pontos da rede, que na verdade, demonstra a preocupação da manutenção da qualidade da água servida para o consumo.

Existem diversas etapas para a produção de água para o consumo humano, desde a captação da água do manancial superficial (rios, lagos e represas) ou subterrâneo (poço) até o 
cavalete das residências. No entanto, é na estação de tratamento de água que é feito todo o controle de qualidade da água que irá ser servida, sendo raros os casos em que há interferências depois da saída da estação de tratamento com relação a sua qualidade. Desta forma, pode se dizer que existe um controle rigoroso na estação, no sentido de tornar essa água compatível com as necessidades do consumo humano.

Uma das etapas determinantes para a qualidade d'água, na estação de tratamento, é o processo de desinfecção, responsável pelo controle dos organismos patogênicos. Neste processo, o produto químico amplamente utilizado é o cloro, que reage com a matéria orgânica presente na água, eliminando os organismos nocivos a saúde humana.

A desinfecção por meio de agentes químicos tem, portanto, como objetivo controlar doenças de veiculação hídrica e reduzir organismos patogênicos resistentes às etapas anteriores do tratamento ou presentes no sistema de distribuição (DI BERNARDO, 2005).

A manutenção da qualidade d'água na rede é feita através da dosagem de uma concentração de cloro (cloro residual) na rede que terá como função combater possíveis contaminantes que, por ventura, a água tenha contato, pois são comuns falhas na rede de distribuição que as deixam vulnerável.

A dosagem de cloro para constituir o cloro residual é controlada pela legislação brasileira que estabelece, através da Portaria do Ministério da Saúde 518/2004 (BRASIL, 2004), os procedimentos e responsabilidades relativos ao controle e vigilância da qualidade d'água para consumo humano, o seu padrão de potabilidade e outras providências.

O Artigo 13 da Portaria do Ministério da Saúde 518/2004 estabelece que:

“após a desinfecção, a água deve conter um teor mínimo de cloro residual livre de $0,5 \mathrm{mg} / \mathrm{L}$, sendo obrigatória a manutenção de, no mínimo, $0,2 \mathrm{mg} / \mathrm{L}$ em qualquer ponto da rede de distribuição. Recomenda ainda que a cloração seja realizada em $\mathrm{pH}$ inferior a 8,0 e tempo de contato mínimo de 30 minutos e o teor máximo de cloro residual seja de $2,0 \mathrm{mg} / \mathrm{L}$ em qualquer ponto do sistema abastecido." 
Ainda, através do decreto do Ministério da Saúde No 5440, de 4 de maio de 2005 (BRASIL, 2005), que tem um caráter educativo, procura-se promover o consumo sustentável da água e o entendimento da relação entre a sua qualidade e a saúde pública.

FAIR \& GEYER (1954) afirmam que a desinfecção sofre influência de diversos fatores, além do tipo de tratamento empregado no processo, como:

- Espécie e concentração de organismos a serem destruídos;

- Concentração e tipo de desinfetante;

- Características físico-químicas da água;

- Tempo de contato.

Embora o uso do cloro seja indicado para desinfecção da água, por combater organismos patogênicos, quando em contando com outros tipos de substâncias, pode gerar subprodutos que são nocivos a saúde humana.

Em 1977, a EPA (Environmental Protection Agency), com o relatório da "National Organics Monitoring Survey", divulgou o resultado de pesquisas em 113 sistemas de abastecimento de água, concluindo que 27 compostos orgânicos poderiam causar problemas à saúde da população, sendo quatro deles, trihalometanos (THMs), presentes em todas as águas que recebiam cloro como desinfetante. Posteriormente, a EPA propôs o limite de $100 \mu \mathrm{g} / \mathrm{L}$ para a presença de THMs em águas de abastecimento, regulamentando esse limite em 1978.

No Brasil, o limite máximo permitido de trihalometanos totais (TTHMs) é de 0,1mg/L, conforme o Art. 14 da portaria 518/2004 (BRASIL, 2004).

CLARK et al. (1995) afirmam que a presença THMs na água servida à população pode representar um risco a saúde devido ao seu potencial carcinogênico.

BULL et al. (1995) questionam o uso de cloro como desinfetante na água devido ao risco que pode representar à saúde humana, propondo diversas políticas para minimizar essa prática e investigando o uso de outras tecnologias como forma de substituição a cloração. 
BOCCELLI et al. (2003) estudaram o comportamento do cloro residual depois da recloração e a formação dos THMs, encontrando uma estreita relação na formação de THMs causada pela recloração feita sem critérios.

SORLINI \& COLLIVIGNARELLI (2004) comparam diferentes desinfetantes como cloro, dióxido de cloro e ozônio na formação de THMs, concluindo que a formação de TTHMs varia conforme a dose de cloro aplicada, a matéria orgânica presente na água e o brometo inicial da água. Eles também concluem que os desinfetantes alternativos como dióxido de cloro e ozônio diminuem cerca de 97\% a formação de TTHMs.

LYN \& YEH (2005) calibraram o modelo do comportamento dos THMs usando Algoritmo Genético e Simulated de Annealing, através do problema inverso que minimiza a diferença entre a concentração de THMs observada em campo e a modelada.

LEE et al. (2007) pesquisaram os efeitos da recloração da água da rede para manter os níveis aceitáveis de cloro residual e a formação dos THMs. Concluiu-se que a recloração pode ser interessante para manter os níveis aceitáveis de cloro residual em redes de distribuição de água muito longas, permitindo o controle sobre a formação dos THMs.

\subsection{DECAIMENTO DO CLORO EM REDES DE ABASTECIMENTO}

\subsubsection{Modelo de decaimento de cloro}

Quando o cloro adicionado à água percorre o sistema de abastecimento, o seu potencial de desinfecção é reduzido à medida que ocorre a sua interação com os meios físico, químico e biológico do sistema (POWELL et al., 2000).

Fatores como diâmetros, materiais e idade dos tubos, qualidade da água, pH, vazão, tempo de escoamento e temperatura, dentre outros, interferem no decaimento de cloro. 
Embora todos os fatores sejam analisados de forma indireta e conjunta, através de medidas pontuais de cloro livre na rede, eles interferem nas reações do cloro com elementos da parede do tubo e da massa líquida. O cloro residual reage facilmente com diversas espécies orgânicas e inorgânicas presentes, quer seja na água transportada, quer seja na interface com os elementos físicos do sistema (VIEIRA et al., 2004). A perda do desinfetante residual se dá, portanto, por combinação de reações que ocorrem no escoamento e junto às paredes das tubulações, sendo suas influências representadas pelas respectivas constantes cinéticas $\mathrm{K}_{\text {bulk }} \mathrm{e}$ $\mathrm{K}_{\text {wall }}($ CLARK et al., 1993; VIEIRA \& COELHO, 2003).

Comumente, os modelos de transporte de cloro são baseados nas leis de conservação da massa e descritos pela equação de advecção, que assume dimensão única e é descrita na forma:

$$
\frac{\partial C_{i}}{\partial t}=-u_{i} \frac{\partial C_{i}}{\partial x}+R\left(C_{i, t}\right)
$$

sendo, $C_{i}$ a concentração (massa/volume) na tubulação $i$ em função da distância $x$ e do tempo $t ; u_{i}$ a velocidade média do escoamento (comprimento/tempo) na tubulação $i$ e $R$ a taxa de reação (massa/volume/tempo), função da concentração, que representa a combinação dos efeitos das reações no escoamento e na região da parede da tubulação.

Os modelos dinâmicos de qualidade d'água simulam a distribuição da substância química por todas as tubulações do sistema. Além de também simularem o comportamento do sistema de distribuição, no que se refere às mudanças nos níveis dos reservatórios, pressões e vazões resultantes da operação de dispositivos, tais como: registros, bombas, válvulas controladoras de pressão ou vazão e das variações do consumo. Os modelos são baseados no fluxo unidimensional, regime permanente na rede, mistura instantânea e completa das concentrações nos nós, e dispersão longitudinal insignificante. Geralmente admite-se uma única substância química com uma ou mais fontes de contaminação, e cinética de decaimento 
de modelo de primeira ordem que ocorre nas paredes das tubulações (OZDERMIR \& UCAK, 2002).

De acordo com ROSSMAN \& BOULOS (1996), os modelos dinâmicos de qualidade da água podem ser classificados de acordo com as escalas temporal e espacial. Considerandose a escala espacial, os modelos podem ser Eulerianos ou Lagrangeanos. Os modelos Eulerianos dividem as tubulações da rede em uma série de volumes de controle fixos interconectados e registram as mudanças nos contornos ou dentro desses volumes à medida que a água flui através deles. Os modelos Lagrangeanos acompanham as mudanças em uma série de parcelas discretas de água à medida que elas percorrem os tubos da rede.

Os modelos Lagrangeanos podem ser divididos em: métodos dirigidos pelo tempo (TDM) e método dirigido pelo evento (EDM). Já a aproximação Euleriana pode ser dividida em: método das diferenças finitas (FDM) e método do volume discreto (DVM). Essa classificação resulta em quatro modelos, que constituem alvos de análises e comparações realizadas por ROSSMAN \& BOULOS (1996).

Os modelos de simulação dirigidos pelo tempo (TDM) atualizam o estado da rede em intervalos de tempo fixos, ao passo que os modelos dirigidos por eventos (EDM) atualizam o estado do sistema somente quando mudanças ocorrem, como quando uma nova parcela de água chega ao final de um tubo e se mistura com a água de outros condutos conectados a esse nó.

TDM é uma técnica que acompanha a concentração e o tamanho de uma série de segmentos não sobrepostos de água que preenchem cada tubo da rede. Ao longo do tempo, o volume do segmento a montante no tubo aumenta à medida que a água entra no mesmo, enquanto uma perda igual de volume ocorre no segmento a jusante, à medida que a água deixa o tubo. Os volumes dos segmentos intermediários se mantêm constantes. 
EDM é similar a TDM, exceto que ao invés de atualizar a rede toda em passos fixos de tempo, as condições dos trechos e nós são atualizadas somente quando o primeiro segmento de um trecho desaparece através do seu nó a jusante.

As técnicas para resolução da equação (2.21) segundo a aproximação Euleriana podem ser divididas em método das diferenças finitas (FDM) e método do volume discreto (DVM). O FDM usa a técnica de elementos finitos para aproximar as derivadas da equação (2.22) através de uma grade fixa de pontos, no tempo e no espaço. O DVM considera cada tubo como uma série de segmentos igualmente divididos, sob mistura completa, sendo que a cada passo de tempo, a concentração dentro do segmento reage primeiramente no interior de cada segmento, então é transferida para o seguimento adjacente abaixo (jusante). Quando o segmento adjacente é um nó, a massa e o fluxo que entram no nó são adicionados a outras massas e fluxos já recebidas de outros tubos. Depois disso, a reação e transporte desse segmento é completado para todos os tubos, e a concentração resultante da mistura de cada nó é calculada e liberada no primeiro segmento de um tubo com fluxo saindo do nó.

ROSSMAN \& BOULOS (1996), baseados nos resultados obtidos para os testes realizados com o software EPANET 1.0 (1994), concluíram que o método Lagrangeano dirigido pelo tempo (TDM) é o mais versátil e é o que melhor reproduz o comportamento da qualidade da água dentre os quatro modelos testados.

\subsubsection{Decaimento de cloro na massa líquida}

As reações que ocorrem na massa líquida são fundamentalmente regidas pela qualidade da água e suas características físico-químico, tornando-se difícil a padronização do $\mathrm{K}_{\text {bulk }}$ para diversos sistemas de distribuição. Porém, esse não é o maior dos problemas na modelagem, pois esse parâmetro é possível de ser estimado através de análises laboratoriais. 
A literatura apresenta propostas (BOCELLI, 2003; HUA, 1998; VIEIRA et al., 2004;

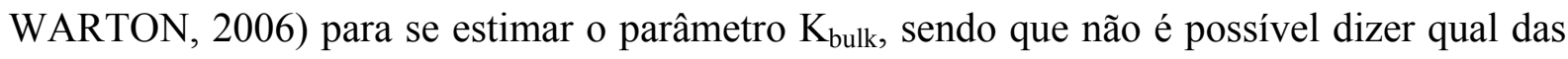
proposições é melhor, pois, como o parâmetro é muito ligado à natureza da água em questão, não se pode dizer qual será o comportamento da curva de decaimento de cloro livre real.

Apesar de os modelos de primeira ordem serem mais utilizados, dada a sua simplicidade, é conveniente testar o ajuste de outros modelos de decaimento. Na TABELA 2.1 resumem-se os modelos de decaimento na massa líquida mais utilizados.

TABELA 2.1 - Modelos cinéticos de decaimento do cloro

\begin{tabular}{|c|c|c|c|}
\hline Modelo & $\begin{array}{c}\text { Forma } \\
\text { diferencial } \\
(\partial \mathrm{C} / \partial \mathrm{t})=\end{array}$ & Forma Integrada $(\mathrm{C})=$ & Referência \\
\hline primeira ordem & $-k C$ & $C_{0} \exp (-k t)$ & $\begin{array}{c}\text { (HASS and } \\
\text { KARRA, 1984) } \\
\text { (ROSSMAN, } \\
\text { 1992) } \\
\text { (VASCONCELOS, } \\
\text { 1997) }\end{array}$ \\
\hline Segunda ordem & $-\mathrm{kCC}_{\mathrm{R}}$ & $\mathrm{C}_{0}(1-\mathrm{R}) /(1-\mathrm{R} \cdot \exp (-\mathrm{ut}))$ & (CLARK, 1998) \\
\hline Ordem n & $-K C^{n}$ & $\left(k t(n-1)+\left(1 / C_{0}\right)^{(n-1)}\right)^{-1 /(n-1)}$ & $\begin{array}{c}\text { (HASS and } \\
\text { KARRA, 1984) }\end{array}$ \\
\hline $\begin{array}{l}\text { Primeira ordem } \\
\text { limitada }\end{array}$ & $-k\left(C-C^{*}\right)$ & $\mathrm{C}^{*}+\left(\mathrm{C}_{0}-\mathrm{C}^{*}\right) \exp (-\mathrm{kt})$ & $\begin{array}{c}\text { (HASS and } \\
\text { KARRA, 1984) }\end{array}$ \\
\hline $\begin{array}{c}\text { Primeira ordem } \\
\text { paralela }\end{array}$ & $\begin{array}{c}-\mathrm{k}_{1} \mathrm{C}_{1},-\mathrm{k}_{2} \mathrm{C}_{2} \mathrm{com} \\
\mathrm{C}_{1,0}=\mathrm{C}_{0} \mathrm{X} \\
\mathrm{C}_{2,0}=\mathrm{C}_{0}(1-\mathrm{x})\end{array}$ & $C_{0} x \exp \left(-k_{1} t\right)+C_{0}(1-x) \exp \left(-k_{2} t\right)$ & $\begin{array}{c}\text { (HASS and } \\
\text { KARRA, 1984) }\end{array}$ \\
\hline
\end{tabular}

C: concentração de cloro; $\mathrm{C}_{0}$ : concentração inicial de cloro; Cr: concentração de todas as espécies que podem reagir com o cloro; $C^{*}$ : concentração limite; $k$ : constantes cinéticas.

$\mathrm{R}, \mathrm{u}$ : parâmetros de ajuste do modelo de segunda ordem; t: tempo

Fonte: Vieira (2004)

O modelo de primeira ordem paralela se ajusta melhor ao verdadeiro comportamento do consumo de cloro livre na massa líquida, pois apresenta as duas fases da degradação do cloro, sendo a inicial uma fase rápida, em que ocorrem rápidas reações do cloro com organismos presentes na água, seguida pela segunda fase, mais lenta, onde existe menos 
matéria para reagir com o desinfetante, diferentemente do modelo de primeira ordem que é frequentemente empregado nas modelações da qualidade da água (VIEIRA et al., 2004). Esse comportamento pode ser observado através de testes laboratoriais denominados "testes de garrafa" (CHEUNG, 2005; ROSSMAN, 2006; VIEIRA et al., 2004, WARTON et al., 2006), que são considerados representativos por serem realizados de maneira a garantir a isenção de reações que nas redes ocorrem junto às paredes dos tubos.

BOCCELLI et al. (2003) estudaram a formação dos THMs em função do consumo de cloro na água e concluíram que o modelo de segunda ordem pode representar melhor o consumo de cloro residual que provoca a formação de THMs.

VIEIRA et al. (2004) observaram que duas situações podem ocorrer no dia-a-dia de um abastecimento de água. A primeira situação que pode ocorrer é a presença de cloro em excesso na água, sendo assim, não há matéria orgânica reagente suficiente para consumir o cloro dosado na água. A segunda situação é a presença de matéria orgânica reagente superior a concentração do cloro, desta forma todo o cloro reage com a matéria orgânica, deixando claro o déficit de cloro na água. Os autores ainda ressaltam que é mais comum deparar-se com a segunda situação em sistemas de abastecimento de água.

\subsubsection{Decaimento de cloro devido à interação com a parede}

O decaimento de cloro também sofre interferência do meio em que a água é transportada como: o tipo e a idade do tubo, e a existência de biofilme, dentre outros fatores que fazem o cloro residual presente na água reagir junto as parede das tubulações, diminuindo sua concentração. A dificuldade na quantificação do consumo de cloro livre devido à sua interação com a parede do tubo é um desafio na modelação, pois a diversidade de diâmetros, de idades de tubo e a falta de cadastramento fazem com que o problema torne-se ainda mais complexo, devido à grande gama de variáveis. 
Essa parcela de reação do cloro com a parede do tubo é representada pelo coeficiente

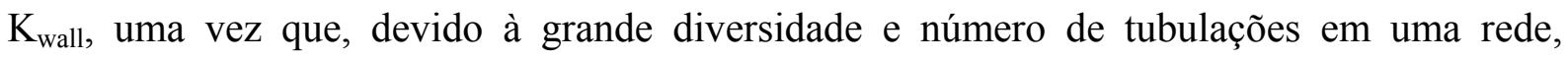
demandar-se-ia muito tempo para se determinar e modelar o $\mathrm{K}_{\text {wall }}$ de cada tubo da rede. Tal fato tornaria necessário o agrupamento de tubos, que potencialmente apresentassem o mesmo comportamento no consumo de cloro livre; e muitas vezes o agrupamento é responsável pela perda de representatividade do modelo em relação ao comportamento observado na rede. Contudo, diversos autores (MUNAVALLI \& KUMAR, 2005; 2006; VIEIRA et al. 2004) têm conseguido modelos bem próximos ao comportamento do $\mathrm{K}_{\text {wall, }}$, vêem propondo metodologias de agrupamento.

VIEIRA et al (2004) determinaram o coeficiente $\mathrm{K}_{\text {wall }}$ em alguns trechos de rede, para tanto, recorreram às suas medições diferenciais de cloro residual, após o conhecimento das características do decaimento no seio da água, sendo necessária a identificação dos trechos onde se verificava um tempo de percurso da massa líquida dentro da rede, de modo que, o efeito do decaimento de cloro seja perceptível através da diferença entre as medições de cloro residual nas seções de montante e jusante. O tempo de percurso depende da magnitude do decaimento do cloro, que por sua vez varia conforme o tipo de material e a idade da tubulação.

HALLAN et al. (2002) subdividiu os materiais dos tubos em dois grandes grupos, de acordo com sua influência sobre $K_{\text {wall }}$ : tubulações de alta reatividade (ex: ferro) e baixa reatividade (ex: cloreto de polivinila - PVC, polietileno de alta densidade - PEAD, e fibrocimento). $\mathrm{O}$ autor concluiu que o material do tubo exerce forte influência no decaimento do cloro e que o ferro é o que apresenta destacadamente maior influência. Verificou-se também que quantidade moderada de biofilme no tubo (51-670 pg ATP $/ \mathrm{cm}^{2}$ ) não tem influência considerável no decaimento do cloro. 
ROSSMAN (2006), estudando o comportamento do cloro em tubos metálicos, concluiu que o decaimento sofre influência principalmente do tipo de material da tubulação.

AL-JASSER (2006) comprovou que a idade do tubo é outro fator determinante do ponto de vista do decaimento do cloro, principalmente em tubos de materiais como ferro e aço e em redes de distribuição de água em que o coeficiente $K_{\text {bulk }}$ não é tão significativo se comparado com o $\mathrm{K}_{\text {wall. }} \mathrm{O}$ autor reafirmou que tubos de ferro promovem taxas de decaimento muito maior que os demais tipos de tubos, e que tubos de PVC, PVC rígido e polietileno têm um decaimento de cloro constante, pouco afetado pela idade dos condutos.

\subsubsection{Combinações dos modelos de reações na massa líquida e com a parede da tubulação}

Como o decaimento de cloro é um fenômeno que corresponde a uma combinação de fatores e é expresso em termos de duas constantes ( $\mathrm{K}_{\text {bulk }}$ e $\left.\mathrm{K}_{\text {wall }}\right)$, é ideal modelar a solução do problema considerando-se as duas constantes que dominam o seu decaimento. Contudo, não é possível afirmar qual combinação melhor se adéqua ao comportamento do sistema, apesar de ser mais comum usar o modelo de primeira ordem para descrever ambos os fenômenos.

MUNAVALLI \& KUMAR (2005), além de utilizarem a equação de primeira ordem em seu estudo, propuseram uma série de combinações relacionadas a seguir:

$\checkmark$ Total reação cinética de primeira ordem

$$
R\left(C_{i},{ }_{t}\right)=-k_{0} c_{i, t}
$$

sendo, $k_{0}$ é a reação total em primeira ordem $\left(\mathrm{d}^{-1}\right)$.

$\checkmark$ Primeira ordem para o escoamento e primeira ordem para o efeito da parede

$$
R\left(C_{i},{ }_{t}\right)=-k_{b, 1 i} c_{i, t}-\frac{k_{w, 1 i} k_{f i}}{r_{h i}\left(k_{w, 1 i}+k_{f i}\right)} c_{i, t},
$$

sendo, $r_{h i}$ o raio hidráulico $(\mathrm{m}) ; k_{w, 1 i}$ a reação de primeira ordem do efeito de parede $(\mathrm{m} / \mathrm{d})$; 
$k_{b, 1 i}$ a reação de primeira ordem do efeito do escoamento $\left(\mathrm{d}^{-1}\right)$ e $k_{f i}$ o coeficiente de transferência da massa (m/d), descrita em detalhes por ROSSMAN (2000).

$\checkmark$ Primeira ordem para o escoamento e ordem zero para o efeito da parede

$$
R\left(C_{i},{ }_{t}\right)=-k_{b, 1 i} c_{i, t}-\operatorname{Min}\left(\frac{k_{f i} c_{i, t}}{r_{h i}}, \frac{k_{w, 0 i}}{r_{h i}}\right) \text {, }
$$

sendo, $k_{w, 0 i}$ é ordem zero do efeito da parede na reação do cloro $\left(\mathrm{mg} / \mathrm{m}^{2} \mathrm{~d}\right)$.

$\checkmark$ Segunda ordem para o escoamento e primeira ordem para o efeito da parede

$$
R\left(C_{i},{ }_{t}\right)=-k_{b, 2 i} c_{i, t}^{2}-\frac{k_{w, 1 i} k_{f i}}{r_{h i}\left(k_{w, 1 i}+k_{f i}\right)} c_{i, t},
$$

sendo, $k_{b, 2 i}$ é a segunda ordem para o escoamento (L/mgd).

$\checkmark$ Segunda ordem para o escoamento e ordem zero para o efeito de parede

$$
R\left(C_{i},{ }_{t}\right)=-k_{b, 2 i} c_{i, t}\left(c_{i, t}-C_{L}\right)-\frac{k_{w, 0 i} k_{f i}}{r_{h i}\left(k_{w, 1 i}+k_{f i}\right)} c_{i, t},
$$

$\checkmark$ Dois componentes de segunda ordem no escoamento e primeira ordem para o efeito de parede

$$
R\left(C_{i},{ }_{t}\right)=-k_{b, 2 i} c_{i, t}\left(c_{i, t}-C_{L}\right)-\frac{k_{w, 1 i} k_{f i}}{r_{h i}\left(k_{w, 1 i}+k_{f i}\right)} c_{i, t},
$$

sendo, $C_{L}$ a concentração limitante de cloro $(\mathrm{mg} / \mathrm{L})$. O valor de $C_{L}$ indica que o cloro decairá a um valor mínimo e não mais que isso. Sendo isso justificado quando não há organismos suficientes para reagir com o cloro depois do $C_{L}$.

$\checkmark$ Dois componentes de segunda ordem no escoamento e ordem zero para o efeito de parede

$$
R\left(C_{i}, t\right)=-k_{b, 2 i} c_{i, t}\left(c_{i, t}-C_{L}\right)-\operatorname{Min}\left(\frac{k_{w, 0 i}}{r_{h i}}, \frac{k_{f i}}{r_{h i}} c_{i, t}\right),
$$




\subsection{MODELO DE QUALIDADE USADO PELO EPANET 2}

O modelo de simulação de qualidade da água utilizado pelo EPANET 2.0 baseia-se no modelo Lagrangeano dirigido pelo tempo (TDM).

O modelo TDM permite acompanhar o decaimento de cloro e seu deslocamento ao longo da rede, quando conhecidos os coeficientes $\mathrm{K}_{\text {bulk }}$ e $\mathrm{K}_{\text {wall. }}$

Segundo o modelo que é utilizado pelo EPANET 2.0, a dispersão longitudinal é um mecanismo de transporte usualmente pouco importante para a maioria das condições operacionais. Significa, portanto, que se admite não existir mistura de massas entre segmentos adjacentes que se deslocam ao longo da tubulação. Assim, desprezando a dispersão longitudinal, obtém-se a seguinte equação de advecção com reação.

$$
\frac{\partial C_{i}}{\partial t}=-u_{i} \frac{\partial C_{i}}{\partial x}+r_{b u l k}\left(C_{i}\right)+r_{\text {wall }}\left(C_{i}\right)
$$

sendo, $C_{i}$ concentração (massa/volume) na tubulação em $i$ em função da distância $x$ e do tempo $t, u_{i}$ velocidade média do escoamento (comprimento/tempo) na tubulação $i, r_{b u l k}$ taxa de reação no escoamento e $r_{\text {wall }}$ taxa de reação na região da parede, ambas em função da concentração.

Para solucionar os encontros dos segmentos nos nós onde ocorrem mistura dos segmentos é considerado que ocorra mistura completa e instantânea, assim a concentração de cloro residual contida no escoamento poder ser obtida através de balanço de massas, pela seguinte equação para um nó específico:

$$
C_{i \mid x=0}=\frac{\sum_{j \varepsilon I_{k}} Q_{j} C_{j \mid x=L_{j}}+Q_{k, e x t} C_{k, \text { ext }}}{\sum_{j \varepsilon I_{k}} Q_{j}+Q_{k, \text { ext }}}
$$

Segundo o modelo de qualidade de água usado pelo EPANET 2.0, uma substância como o cloro, ao ser transportada pela tubulação de uma rede, pode reagir com outros 
componentes presentes na água como substâncias orgânicas e inorgânicas. Podendo descrever a taxa de reação no escoamento, em termos da concentração elevada à potência $n$ :

$$
r_{b u l k}=K_{b u l k} C^{n}
$$

sendo, $K_{\text {bulk }}$ o coeficiente de reação no escoamento, $C$ a concentração e $n$ a ordem da reação. Quando existe uma concentração que limita o decaimento da substância, a taxa de reação pode ser traduzida através da seguinte expressão:

$$
r_{\text {bulk }}=K_{\text {bulk }}\left(C_{L}-C\right) C^{(n-1)} \quad \text { para } n>0, K_{b u l k}<0
$$

sendo, $C_{L}$ a concentração limite.

A parcela responsável pelo decréscimo do cloro na água, devido às reações que ocorrem com a parede $\left(\mathrm{K}_{\text {wall }}\right)$, é causada por reações com o próprio material da parede e ou com biofilme existente, e pode ser representada pela seguinte equação:

$$
r_{\text {wall }}=\left(\frac{A}{V}\right) K_{\text {wall }} C^{n}
$$

sendo, $K_{\text {wall }}$ o coeficiente de reação na parede e $(A / V)$ a área lateral por unidade de volume. Este último termo permite que a massa do reagente por unidade de área da parede passe a ser expressa por unidade de volume, sendo que o EPANET 2.0 limita a escolha da ordem da reação na parede $(n)$ de 0 ou 1 . Conforme a ordem, os $K_{\text {wall }}$ são expressos em massa/área/tempo ou em comprimento/tempo, respectivamente, e para reações de primeira ordem, limita-se a valores entre 0 e $-1,5 \mathrm{~m} /$ dia.

A área da tubulação disponível para reação e a taxa de transferência de massa entre o escoamento da água e a parede também influenciam a taxa de reação. O raio hidráulico, para uma tubulação circular, é igual ao raio dividido por dois. O efeito de transferência de massa pode ser representado por um coeficiente de transferência de massa cujo valor depende da difusão molecular das espécies reativas e do número de Reynolds do escoamento 
(ROSSMAN et al.,1993). Para leis cinéticas de $1^{\text {a }}$ ordem, a taxa de reação na tubulação pode ser expressa pela seguinte equação:

$$
r_{\text {wall }}=\frac{2 K_{\text {wall }} K_{f} C}{R\left(K_{\text {wall }}+K_{f}\right)}
$$

sendo, $K_{\text {wall }}$ o coeficiente de reação na parede (comprimento/tempo), $K_{f}$ o coeficiente de transferência de massa (comprimento/tempo) e $R$ o raio da tubulação.

Para reações cinéticas de ordem zero, a taxa de reação não pode ser superior à taxa e transferência de massa, sendo expressa por:

$$
r_{\text {wall }}=\operatorname{Min}\left(K_{\text {wall }}, K_{f} C\right)\left(\frac{2}{R}\right)
$$

$K_{\text {wall }}$ tem agora as unidades de massa/área/tempo.

Os coeficientes de transferência de massa são usualmente expressos em termos do número adimensional de Sherwood $(S h)$ :

$$
K_{f}=\operatorname{Sh} \frac{Y}{D}
$$

sendo, $Y$ a difusão molecular da espécie a ser transportada (comprimento ${ }^{2} /$ tempo) e $D$ o diâmetro da tubulação. Em regime laminar, o número de Sherwood médio ao longo do comprimento de uma tubulação pode ser expresso da seguinte forma:

$$
S h=3.65+\frac{0.0668\left(\frac{D}{L}\right) R_{\text {eynols }} S c}{1+0.04\left[\left(\frac{D}{L}\right) R_{\text {eynolds }} S c\right]^{\frac{2}{3}}}
$$

sendo, $R_{\text {eynolds }}$ o número de Reynolds e $S c$ o número de Schmidt (viscosidade cinemática da água dividida pela difusão molecular do químico). Para o escoamento turbulento, a correlação empírica de Notter e Sleicher (1971) pode ser utilizada:

$$
S h=0.0149 R_{\text {eynolds }}^{0.88} S c^{\frac{1}{3}}
$$




\subsection{ALGORITMOS GENÉTICOS (AGs)}

Os AGs são métodos estocásticos de otimização inspirados no mecanismo de evolução dos seres vivos. Representam matematicamente o fenômeno da adaptação como ele ocorre na natureza.

É muito comum se deparar com terminologias derivadas da genética nesse tipo de método de otimização, de forma que os principais termos são importados da biologia genética e representam operadores que se assemelham aos fenômenos da natureza. GOLDBERG (1989) e LACERDA \& CARVALHO (1999) são autores da literatura que listam os principais termos dos AGs que serão listados a seguir:

Cromossomo e Genoma: as duas terminologias representam a estrutura de dados que codifica uma solução para um problema, isto é, um cromossomo ou genoma representa um simples ponto no espaço de busca ou, ainda, uma possível solução para o problema;

Gene: é um parâmetro codificado no cromossomo, ou seja, ele representa um elemento do vetor solução, ou uma variável de decisão do problema;

Alelo: representa os possíveis valores que uma variável de decisão pode assumir;

Indivíduo: é um simples membro da população de soluções que corresponde a um valor de aptidão;

Genótipo: representa a informação contida no cromossomo ou genoma, ou variáveis de decisão que caracterizam completamente uma solução;

Fenótipo: representa o objeto, estrutura ou organismo construído a partir das informações do genótipo. É o cromossomo decodificado;

Epistasia: interação entre genes do cromossomo, representando a solução decodificada de forma que o valor de um gene influencia o valor de outro gene; 
Elitismo: é uma estratégia usada em AGs tradicionais e tem como fundamento a perpetuação da melhor solução para a próxima iteração sem alterações, isso tem como objetivo manter a característica do melhor cromossomo para que ele não sofra alterações com operadores de recombinação e mutação. Proposto por DEJONG (1995), o elitismo faz com que a solução seja encontrada mais rapidamente em comparação com AG sem elitismo, visto que o AG pode ocasionalmente encontrar máximos locais.

De acordo com a terminologia dos AGs, cada "cromossomo", referido como string, representa uma possível solução para o problema, sendo que uma população de “cromossomos" representa um conjunto de possíveis soluções (SOARES, 2003).

Os operadores comumente usados pelos AGs foram inspirados na genética: seleção, crossover ou recombinação e mutação, os quais são usados sistematicamente na procura de uma solução eficiente ou otimizada.

Dentre as vantagens dos AGs sobre os demais métodos de busca direta convencionais, é interessante citar que: buscam, a partir de uma população de pontos e não de um único ponto; são capazes de otimizar um número grande de variáveis; não necessitam de operadores matemáticos complexos como derivadas e integrais; fornecem uma nuvem de boas soluções não se restringindo a apenas uma; e principalmente, são capazes de "varrer" o espaço de soluções de maneira eficaz quando o número de variáveis de decisão do problema é grande. A deficiência do uso dos AGs reside no fato de serem lentos, pois são eficazes na avaliação do espaço de soluções e oscilam em torno da solução ótima. 


\subsection{PARTICLE SWARM OPTIMIZATION}

O Particle Swarm Optimization (PSO) é uma técnica de otimização estocástica baseada no comportamento de populações de peixes, aves e insetos, desenvolvida por EBERHART \& KENNEDY (1995). Tem muitas semelhanças com outros métodos da computação evolutiva tais como os AGs. No entanto, ao contrário dos AGs, o PSO não tem operadores evolutivos tais como mutação e recombinação; no PSO, as possíveis soluções, chamadas de "particles", percorrem o espaço de soluções seguindo o curso ótimo determinado pelas melhores soluções.

Comparado aos AGs, o PSO tem como vantagem, ser de fácil implementação e não precisar dos ajustes de tantos parâmetros, sendo aplicado com sucesso em diversos campos como: funções de otimização, treinamento de redes neurais artificiais, sistema fuzzy de controle e demais áreas em que os AGs também são aplicados.

O exemplo clássico da inspiração do PSO é a arrevoada de pássaros em procura de alimentos. Supondo que todos os pássaros não saibam onde está o alimento, mas sejam capazes de aprender a cada geração onde pode estar o alimento, a estratégia adotada é seguir o pássaro que está mais próximo do alimento. Sendo assim, cada pássaro representa uma solução do espaço de busca, sendo avaliado por uma função de otimização, alterando consequentemente a velocidade e direção conforme os resultados obtidos (EBERHART \& KENNEDY, 1995).

Assim sendo, o PSO é inicializado com um conjunto de soluções aleatórias que procura otimizar a função de otimização a cada iteração. A cada iteração, cada solução é atualizada com base nos dois melhores resultados. O primeiro deles é a melhor solução conseguida pela própria "particle", e o segundo é o melhor resultado obtido pelo grupo de soluções, ou seja, a melhor solução global já atingida. 
Depois de obtidos os melhores valores, cada solução (particle) sofre alteração em sua velocidade e direção conforme as equações:

$$
\begin{aligned}
& V_{s d}^{i}=a \cdot V_{s d}^{i-1}+\operatorname{rand}_{1} \cdot C_{\text {const. }} \cdot\left(P_{s d}^{*}-P_{s d}^{i-1}\right)+\operatorname{rand}_{2} \cdot C_{\text {const. }}\left(P_{g d}^{*}-P_{s d}^{i-1}\right) \\
& P_{s d}^{i}=P_{s d}^{i-1}+V_{s d}^{i}
\end{aligned}
$$

sendo, $a$ o fator que pondera a consideração da velocidade anterior, $V_{s d}$ a velocidade, $P_{s d}^{i-1} \mathrm{o}$ valor da variável na geração anterior (i-1), $P_{s d}^{*}$ o melhor valor da variável da melhor solução alcançada pelo próprio indivíduo, $P_{g d}^{*}$ o melhor valor da variável da melhor solução já alcançada pelo grupo, $i$ o índice de iteração, $s d$ e $g d$ denotam respectivamente o indivíduo e o melhor indivíduo e rand são números randômicos.

O PSO vem sendo utilizado em diversas áreas e, algumas vezes, em conjunto com outros métodos resultando nos chamados Modelos Híbridos de otimização.

ZEFERINO et al.(2006) usou o PSO para calibrar parâmetros de outro método de otimização chamado "Simulated Annealing". Assim, possibilitou que os parâmetros fossem calibrados de maneira criteriosa.

CHAU (2006) usou o PSO para treinar uma rede neural artificial. Em seu trabalho, ele utilizou esses dois métodos para a previsão de enxurradas e inundações, possibilitando a evacuação do local atingido por esses eventos.

JUNG \& KARNEY (2006) usaram o PSO conjuntamente com o AGs pra otimizar a seleção preliminar, a calibragem e a instalação de dispositivos hidráulicos para o controle da resposta no regime transiente de um sistema de oleodutos. A otimização tinha como objetivos: minimizar a carga hidráulica máxima atingida pelo golpe de aríete, maximizar a carga hidráulica mínima atingida pelo golpe de aríete e minimizar a diferença de carga hidráulica máxima e mínima atingida durante o golpe. 


\subsection{TRABALHOS RELACIONADOS À CALIBRAÇÃO DE QUALIDADE}

CASAGRANDE (1997) pesquisou o sistema de distribuição de água do bairro Jucu do município de Viana (ES), Brasil, para a calibração de qualidade. Usando o simulador EPANET 1.0 e dados de vazão, pressão e concentrações de cloro residual na rede, o pesquisador calibrou o sistema chegando a valores de $K_{\text {bulk }}$ e $K_{\text {wall }}\left(K_{\text {bulk }}=-0,191 / d\right.$ e $K_{\text {wall }}=$ $0,015 \mathrm{~m} / \mathrm{d})$ muito diferentes dos encontrado por ROSSMAN et al. (1993) $\left(\mathrm{K}_{\text {bulk }}=-0,55 / \mathrm{d}\right.$ e $\left.\mathrm{K}_{\text {wall }}=-0,15 \mathrm{~m} / \mathrm{d}\right)$ e KENNEDY et al. (1993) ( $\mathrm{K}_{\text {bulk }}$ variando de $-0,27 / \mathrm{d}$ a $\left.-0,51 / \mathrm{d}\right)$. Ele concluiu que os valores de $\mathrm{K}_{\text {bulk }}$ e $\mathrm{K}_{\text {wall }}$ são divergente entre os diversos experimentos já realizados devido ao fato de serem muito peculiares às características de cada sistema. Outra observação importante foi a necessidade de se ter um conhecimento profundo da rede hidráulica para que se possa calibrar a rede qualitativamente.

No trabalho de CASAGRANDE (1997) foram considerados valores globais para toda rede de $\mathrm{K}_{\text {bulk }}$ e $\mathrm{K}_{\text {wall, }}$ mesmo sabendo que possa haver diferenças na própria rede, pois sua rede era alimentada por mais de uma fonte de abastecimento e tinha diversos materiais. $\mathrm{O}$ valor de o $\mathrm{K}_{\text {bulk }}$ foi determinado em laboratório e o $\mathrm{K}_{\text {wall }}$ foi determinado por tentativa e erro.

HUA et al. (1998) pesquisaram os efeitos da temperatura e da concentração inicial sobre o decaimento de cloro em diferentes sistemas de distribuição. Determinaram os valores de $K_{\text {bulk }}$ para duas amostras, uma retiradas da saída da estação de tratamento de Frankley (Reino Unido) e outra de um TAP da Universidade de Birmingham (Reino Unido), cuja água também era originaria da estação de tratamento de Frankley, chegando a valores entre $-0,08$ a $-0,015$ /d para $\mathrm{K}_{\text {bulk. }}$ Os autores concluíram também que a combinação dos modelos de decaimento de primeira e segunda ordem descreve mais precisamente o comportamento do decaimento, do que somente o modelo de primeira ordem. 
VIEIRA (2002) estudou a rede de distribuição da costa da Caparica no Concelho de Almada (Lisboa/Portugal) para a determinação do decaimento de cloro. Para tanto seguiu a seguinte metodologia:

- Efetuou simulações usando somente o valor de $\mathrm{K}_{\text {bulk }}$ determinado em laboratório via "teste da garrafa", com as condições de concentração inicial e temperatura mais próxima das observadas na rede, para a qual o valor de $K_{\text {bulk }}$ foi igual a -0,024336 $\operatorname{dias}^{-1}$.

- Uma vez que o modelo não traduziu satisfatoriamente, ou melhor, não foi capaz de reproduzir o comportamento do decaimento de cloro considerando apenas o valor de $\mathrm{K}_{\text {bulk, }}$, efetuaram-se novas simulações introduzindo um $\mathrm{K}_{\text {wall }}$ não nulo. Testando os dois tipos de cinética para a reação do cloro com a parede: ordem zero e primeira ordem, o valor de $\mathrm{K}_{\text {wall }}$ foi ajustado até se obter uma concordância entre os valores de cloro resultantes do modelo e os determinados na rede.

A autora concluiu que, conforme a metodologia adotada, o valor que melhor ajustou os resultados do simulador foi o de $-0,0012 \mathrm{~m} /$ dia para $\mathrm{K}_{\text {wall }}$.

Neste mesmo estudo VIEIRA (2002) notou a influência de alguns parâmetros nos resultados do modelo de qualidade e no próprio comportamento do cloro na rede. Através da Figura 2.1, a metodologia seguida foi esquematizada, indicando-se os parâmetros estudados em cada fase e agrupando-se os parâmetros hidráulicos (extensão da rede, distribuição espacial de consumos e vazamentos na rede) e de qualidade (existência de decaimento do cloro em relação a $\left.\mathrm{K}_{\text {wall }}\right)$. 


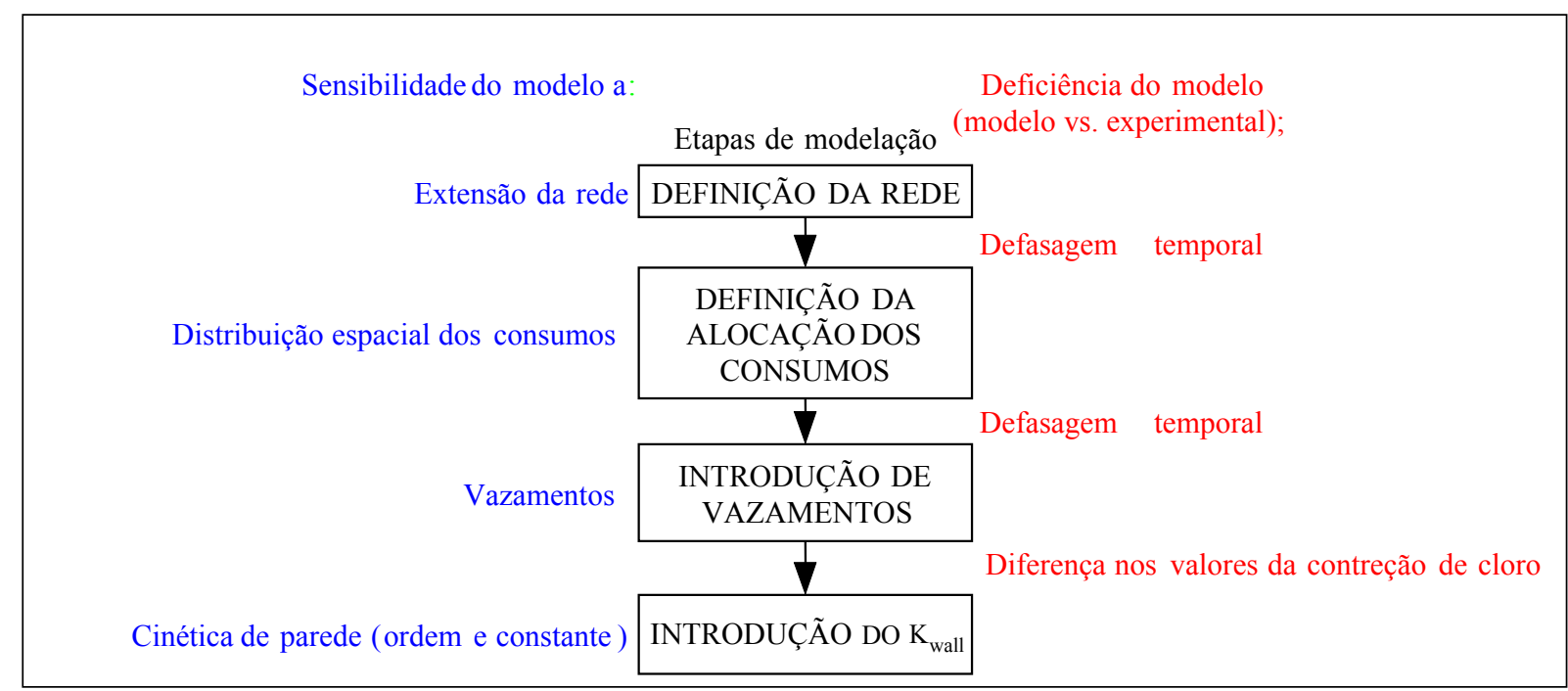

Fonte: Vieira (2002)

FIGURA 2.1 - Análise de sensibilidade do modelo a parâmetros hidráulicos e de qualidade

OZDEMIR \& UCAK (2002) aplicaram outro programa de simulação chamado DYNAQ, que foi testado em comparação ao EPANET 2.0 para a simulação da concentração de cloro. Eles usaram a justificativa de que, em algumas aplicações em rede reais, o modelo de qualidade usado pelo EPANET 2.0 não tem conseguido bons resultados na comparação das concentrações de cloro residual simuladas e observadas em nós com tempo de residência grandes. E concluíram que o EPANET 2.0 consegue uma melhor aproximação para a maioria dos nós da rede, contudo para os nós que apresentam os maiores tempo de residência, o DYNAQ tem melhor desempenho na comparação das concentrações observadas e simuladas.

HALLAM et al. (2002) desenvolveram uma metodologia para a determinação do $\mathrm{K}_{\text {wall }}$ em campo e em laboratório. Desta forma, conseguiram determinar grupos de tubos de mesmo $\mathrm{K}_{\text {wall }}$ para a rede de estudo, diferenciando os valores para os grupos dos tubos separados por tipo de material, idade e diâmetro.

CHEUNG (2005) desenvolveu outro modelo de calibração para os coeficientes cinéticos de decaimento de cloro, usando conjuntamente, o simulador EPANET 2.0 e o método de otimização AGs aplicado a duas redes de distribuição reais: uma rede composta por tubos de ferro e de mesmo diâmetro, e outra composta por tubos de diversos materiais e 
diâmetros. A calibração foi feita em duas fases, uma de determinação do coeficiente $\mathrm{K}_{\text {bulk }} \mathrm{em}$ laboratório através do teste da garrafa e a outra de ajuste dos coeficientes cinéticos através do uso dos AGs e do EPANET 2.0. Nesse trabalho, CHEUNG (2005) conclui que mesmo sendo determinado pelo teste da garrafa, é necessário que o coeficiente $K_{\text {bulk }}$ seja ajustado para a utilização nos modelos matemáticos.

MUNAVALLI \& KUMAR (2005) calibraram a rede estudada por ROSSMAN et al. (1994) considerando valores globais para toda a rede de $\mathrm{K}_{\text {bulk }}$ e $\mathrm{K}_{\text {wall. }}$ Para tanto, utilizaram o algoritmo de Gauss-Newton para minimizar a diferença das concentrações de cloro observadas e simuladas. $\mathrm{O}$ modelo de decaimento do $\mathrm{K}_{\text {wall }}$ foi assumido primeiramente como de primeira ordem e posteriormente de segunda ordem, chegando a valores de $-0,3654 \mathrm{~m} / \mathrm{d}$ e $-204,61 \mathrm{mg} / \mathrm{m}^{2} / \mathrm{d}$

MUNAVALLI \& KUMAR (2006) melhoraram o trabalho proposto anteriormente (MUNAVALLI \& KUMAR, 2005), substituindo o algoritmo de Gauss-Newton pelo o método estocástico de otimização, os AGs. Foi mantida a suposição de apenas conseguir encontrar valores globais de $\mathrm{K}_{\text {bulk }}$ e $\mathrm{K}_{\text {wall, }}$, sendo a inovação relacionada à determinação do coeficiente $\mathrm{K}_{\mathrm{wall}}$ para grupos de tubos com mesmas características.

DANIELI et al. (2006) calibraram um setor de rede real da cidade de Santa Maria (RS), Brasil. Foi utilizado o simulador EPANET 2.0 para as simulações hidráulicas e de qualidade. Nesse trabalho também é feita à calibração hidráulica, antes da calibração das concentrações de cloro residual. A metodologia da calibração qualitativa é feita em duas fases: na determinação em laboratório do $\mathrm{K}_{\text {bulk, }}$ sendo que a coleta da amostragem para essa determinação foi feita em um ponto intermediário da rede; e na avaliação do $\mathrm{K}_{\text {wall }}$ por tentativa e erro no simulador EPANET 2.0. Nos seus resultados foram obtidos valores iguais a $-0,1046 \mathrm{dia}^{-1}$ e 0 , para $\mathrm{K}_{\text {bulk }}$ e $\mathrm{K}_{\mathrm{wall}}$, respectivamente. 
SALGADO (2008) construiu e avaliou seu calibrador aplicando-o a três sistemas de distribuição de água para a determinação dos coeficientes cinéticos, considerando o vazamento. Os sistemas de Jucu no Brasil, Fouras na França, e um sistema hipotético foram alvos tanto da calibração hidráulica quanto da calibração de qualidade. 


\section{MATERIAIS E MÉTODOS}

O trabalho de pesquisa desenvolvido compreende diversas etapas como determinação laboratorial, campanhas de campo e simulação numérico-computacional.

As simulações numéricas reportadas neste trabalho foram realizadas no Laboratório de Simulação Numérica (LABSIN), que está devidamente equipado com: computadores; impressoras; Internet; softwares como o simulador hidráulico de qualidade EPANET 2.0 (ROSSMAN, 2000), desenvolvido pela US Environmental Protection Agency (EPA) e de domínio público; o compilador de linguagem de programação $C++$ Builder 5 e a Biblioteca GAlib ++(WALL, 1996) do departamento de Engenharia Mecânica do Massachusetts Institute of Technology (MIT), de distribuição livre e domínio público.

\subsection{SISTEMA DE DISTRIBUIÇÃO ALVO DO ESTUDO}

O setor piloto adotado para a realização dos estudos situa-se no município de São Carlos, Estado de São Paulo - Brasil. Trata-se de uma associação de moradores conhecida como Parque Fher, na região de Santa Felícia, assim como indicado na Figura 3.1.

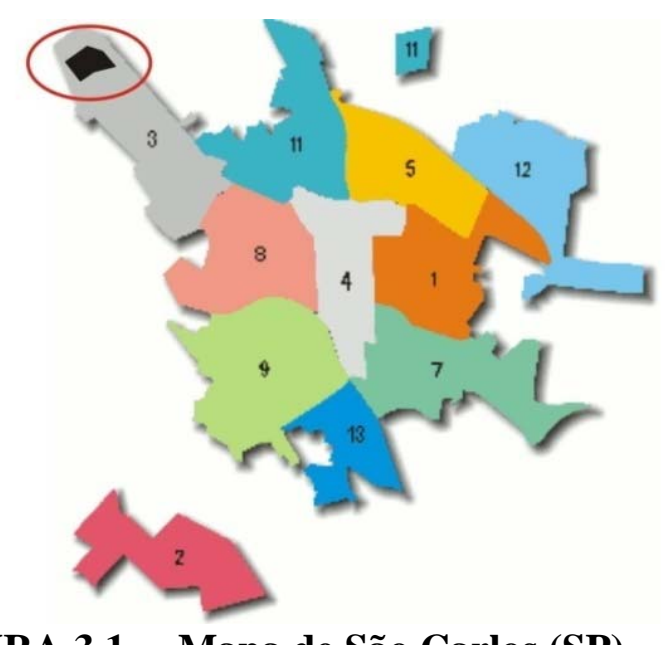

FIGURA 3.1 - Mapa de São Carlos (SP) 
A região de estudo é mostrada em detalhes na Figura 3.2 e é constituída predominantemente por residências familiares de padrão médio, com alguns estabelecimentos comerciais.

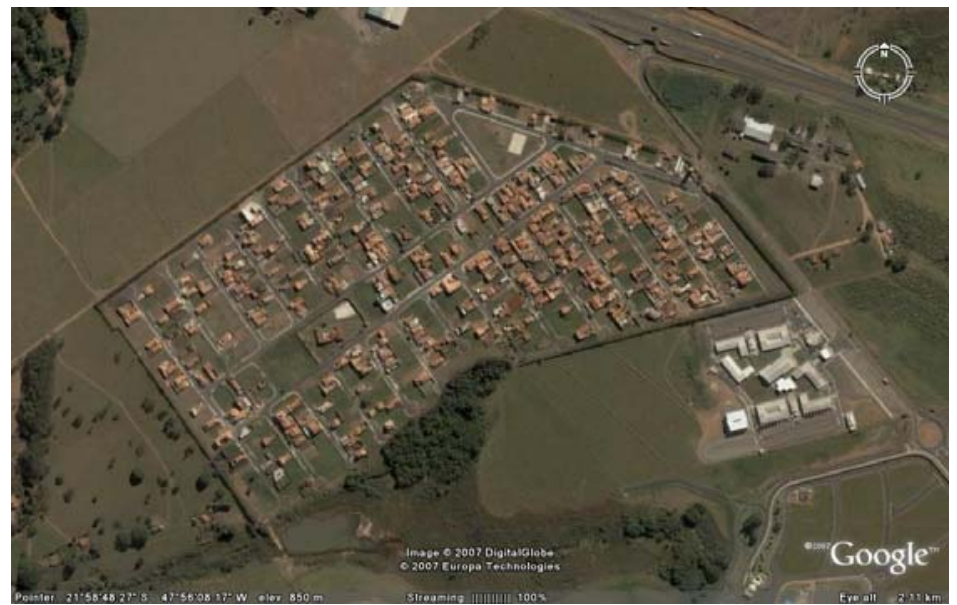

FIGURA 3.2 - Parque Fher (foto de satélite retirada do GoogleEarth)

A água do sistema de abastecimento do Parque Fehr é de origem subterrânea (poço profundo), sendo bombeada para o reservatório elevado de distribuição e simultaneamente misturada aos produtos químicos do tratamento simplificado (flúor, carbonato de cálcio e cloro). A Figura 3.3 mostra o reservatório e a bomba de adução da água subterrânea.

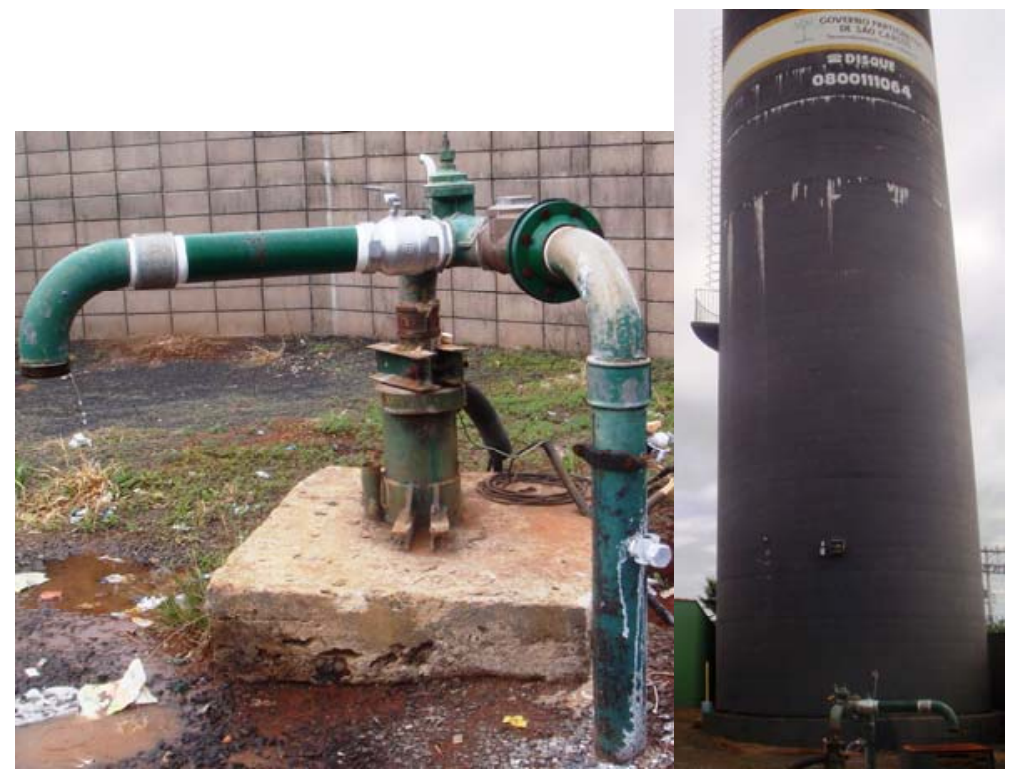

FIGURA 3.3 - Bomba de adução subterrânea e reservatório do Parque Fehr 
Deste reservatório existe uma única saída de água que alimenta o Parque Fehr diretamente e o reservatório de alimentação do Jardim Ipanema. A divisão da vazão para cada uma dessas regiões é subterrânea e ocorre na entrada do Parque Fehr. O acesso à tubulação que alimenta o Jardim Ipanema é permitido apenas no Posto de Visita (PV), conforme a Figura 3.4. Visto isso, a vazão do Parque Fehr foi determinada pela diferença entre a vazão da saída do reservatório (medida pela empresa administradora do sistema) e a vazão que vai para o reservatório do Jardim Ipanema (medida pela equipe de pesquisa).

O reservatório do Parque Fehr conta com um sistema de monitoramento contínuo de dados de nível do reservatório e vazões de entrada e saída que são enviados por um sistema de telemetria à central de operações do Serviço Autônomo de Água e Esgoto (SAAE) de São Carlos. Na saída do reservatório, há um medidor de vazão tipo hélice (Figura 3.5) e colar de tomada de pressão.

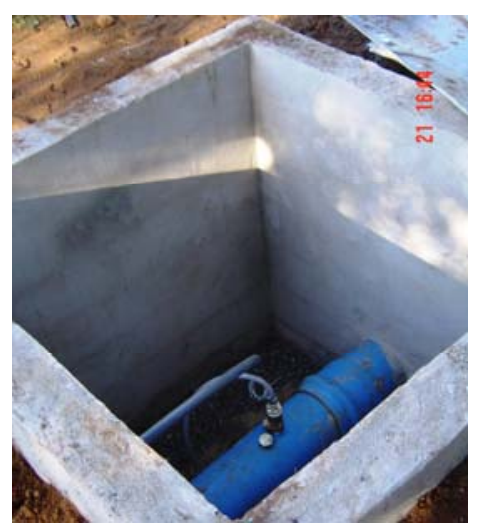

FIGURA 3.4 - PV da tubulação que abastece o Reservatório Ipanema.

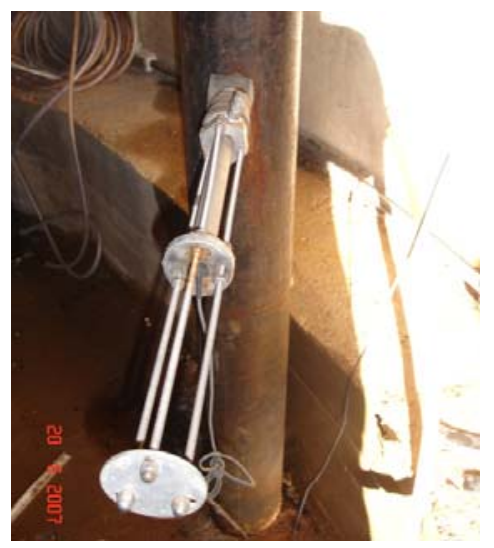


Os comprimentos e os diâmetros da rede foram determinados a partir do arquivo cadastral cedido pelo SAAE - São Carlos, segundo o qual foi possível determinar o traçado da rede, diâmetros, comprimentos e obter a primeira aproximação das cotas do terreno.

O sistema de distribuição de água do Parque Fehr tem 107 tubulações com uma extensão de aproximadamente $12 \mathrm{~km}$, o material dos tubos é o PVC e a rugosidade é desconhecida. Foram considerados 82 nós para a rede, alimentada por um único reservatório, com 553 hidrômetros instalados, servindo aproximadamente 1660 pessoas. O bairro corresponde a um loteamento de $412.739,57 \mathrm{~m}^{2}$, com 929 lotes distribuídos em 32 quadras. O sistema de distribuição tem o traçado apresentado na Figura 3.6.

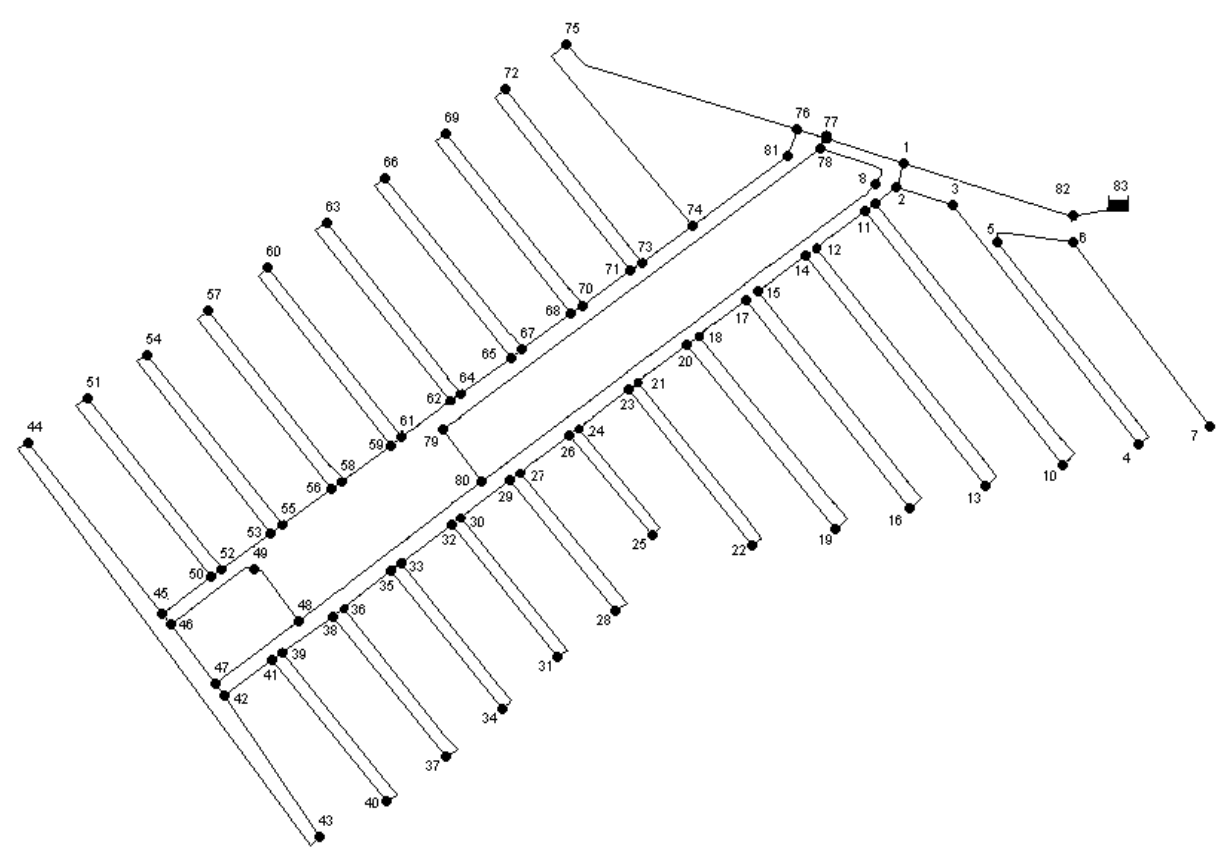

FIGURA 3.6 - Rede de distribuição de água

Para essa rede foram determinados os parâmetros hidráulicos e de qualidade da água, assumindo que $\mathrm{K}_{\text {bulk}}, \mathrm{K}_{\text {wall }}$, a rugosidade, o expoente e as constantes das equações de vazamento são parâmetros globais da rede. Assim, os coeficientes dos emissores resultam em diferentes valores para cada nó. 
Os consumos de referência foram determinados considerando-se a média dos três últimos meses de consumo de cada hidrômetro. A determinação do consumo de cada nó foi feita através da soma dos consumos médios dos hidrômetros que se localizavam na metade mais próxima dos tubos ligados ao nó, conforme o desenho esquemático (Figura 3.7).

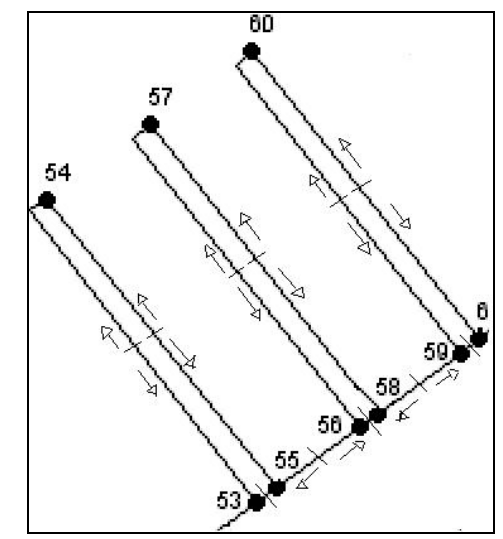

FIGURA 3.7 - Esquema de distribuição dos consumos para os nós.

Em relação às cotas do terreno, duas fontes de informação foram comparadas: o arquivo cadastral cedido pela empresa de água e a planta do projeto do loteamento do Parque Fehr apresentada à prefeitura de São Carlos. Realizada a comparação entre as duas fontes, percebeu-se a necessidade de um levantamento topográfico em campo, para determinação das diferenças entre as cotas dos pontos de monitoramento (pressão e concentração de cloro).

\subsection{MODELO INVERSO}

\subsubsection{Calibração hidráulica pelo modelo inverso}

Para a resolução do problema proposto, primeiramente existe a necessidade da simulação hidráulica, visto que as informações resultantes dessa fase foram posteriormente usadas na simulação da qualidade da água. Sendo assim, a precisão dos resultados era desejável para se evitar à propagação de erros de uma simulação para a outra. O modelo de 
calibração hidráulica usado neste trabalho foi o implementado por SOARES (2003) e adaptado à necessidade de avaliação dos coeficientes dos "emitters" por REIS et al. (2007).

Os dados de entrada necessários para a alimentação do modelo foram compostos pelos dados de observação das pressões, em alguns pontos, e de vazões, em certos trechos da rede, usualmente da saída dos reservatórios, dos níveis dos reservatórios e da vazão abastecida total na rede, para diversos padrões operacionais observados, correspondentes às condições de vazão abastecida máxima, média e mínima. Ainda constituíram dados de entrada para o modelo, os dados da rede propriamente dita como: comprimentos, diâmetros e rugosidades absolutas das tubulações, cotas topográficas e consumos de referência nos nós e suas ligações.

SOARES (2003) usou duas funções objetivos para fins de comparação, sendo que a primeira se baseava no quadrado das diferenças de valores observados e simulados de pressões e vazões ponderados e adimensionalizados pelo quadrado do somatório dos valores observados.

$$
\operatorname{Min}_{Z} F O_{1}=\sum_{t=1}^{n^{P D}}\left\{\sum_{j=1}^{n_{t}^{P}}\left[w_{j}^{P} \frac{\left(P_{t, j}-P_{t, j}^{*}\right)^{2}}{\left(\sum_{i=1}^{n_{t}^{P}} P_{t, i}^{*} / n_{t}^{P}\right)^{2}}\right]+\sum_{j=1}^{n_{t}^{Q}}\left[w_{j}^{Q} \frac{\left(Q_{t, j}-Q_{t, j}^{*}\right)^{2}}{\left(\sum_{i=1}^{n_{t}^{Q}} Q_{t, i}^{*} / n_{t}^{Q}\right)^{2}}\right]\right\}
$$

sendo, $n^{P D}$ o número de padrões de operacionais observados, $n^{P}$ o número de padrões operacionais em que há observações de pressões, $n^{Q}$ o número de padrões operacionais em que há observações de vazões. $w^{P}$ e $w^{Q}$ os pesos atribuídos às observações de pressões e vazões, respectivamente, $P$ as pressões simuladas, $P^{*}$ as pressões observadas, $Q$ as vazões simuladas, $Q^{*}$ as vazões observadas e $Z$ o conjunto de variáveis de decisão do problema, dado por:

$$
Z=Z_{1}=\left(\varepsilon_{1}, \ldots, \varepsilon_{n_{\varepsilon}}, D_{1}, \ldots, D_{n_{D}}, d_{1}, \ldots, d_{n_{d}}, z_{1}, \ldots, z_{n_{Z}}, \theta_{1}, \ldots, \theta_{n_{\theta}}, \beta 1, \ldots, \beta_{n_{\beta}}\right)
$$

sendo, $n_{\varepsilon}$ e $n_{D}$ o número de tubulações ou setores de tubulações com rugosidades absolutas e 
diâmetros homogêneos, respectivamente; $n_{d}$ e $n_{z}$ o número de nós ou setores com consumos e cotas topográficas homogêneos, respectivamente; e $n_{\theta}$ e $n_{\beta}$ o número de tubulações ou setores com coeficiente e expoente de vazamento homogêneos.

A outra função objetivo expressa o somatório dos quadrados das diferenças de valores observados e simulados de pressões e vazões para os diversos padrões operacionais observados.

$$
\operatorname{Min}_{Z} F O_{2}=\sum_{t=1}^{n^{P D}}\left\{\sum_{j=1}^{n_{t}^{P}}\left[\left(P_{t, j}-P_{t, j}^{*}\right)^{2}\right]+\sum_{j=1}^{n_{t}^{Q}}\left[\left(Q_{t . i}-Q_{t, i}^{*}\right)^{2}\right]\right\}
$$

SOARES (2003) observa que existe uma dificuldade na escolha dos pesos para a função 3.1, no que diz respeito à sua aplicação para algoritmos populacionais como os AGs. Em seu trabalho, a adoção de combinação de pesos foi feita na base da tentativa, ou seja, adotando-se pesos fixos para cada conjunto de medidas de tipos diferentes. No caso, um peso para o conjunto de medidas de pressão e outro peso para o conjunto de medidas de vazão, com análise dos desvios gerados.

Com o objetivo de simplificar, evitar o problema de adoção de pesos e consequentemente o questionamento sobre o valor adotado para os pesos, é proposta a alteração nos modelos inversos usados por SOARES (2003) gerando-se, assim, um terceiro modelo inverso, que subtrai os pesos da equação (3.1) mantendo os demais termos da equação.

$$
\operatorname{Min}_{Z} F O_{3}=\sum_{t=1}^{n^{P D}}\left\{\sum_{j=1}^{n_{t}^{P}}\left[\frac{\left(P_{t, j}-P_{t, j}^{*}\right)^{2}}{\left(\sum_{i=1}^{n_{t}^{P}} P_{t, i}^{*} / n_{t}^{P}\right)^{2}}\right]+\sum_{j=1}^{n_{t}^{Q}}\left[\frac{\left(Q_{t, j}-Q_{t, j}^{*}\right)^{2}}{\left(\sum_{i=1}^{n_{t}^{Q}} Q_{t, i}^{*} / n_{t}^{Q}\right)^{2}}\right]\right\}
$$

O processo de calibração com este modelo teve como variáveis de decisão a rugosidade absoluta $(\varepsilon)$ e os parâmetros do modelo de vazamento (dirigido pela pressão). Os 
valores dos coeficientes dos "emitters" $\left(K_{f s}\right)$ são conseqüência dos valores obtidos para a constante do modelo de vazamento.

\subsubsection{Calibração de qualidade pelo modelo inverso}

Para a calibração do modelo de qualidade foi também usada a técnica do modelo inverso. As equações que usadas foram testadas anteriormente por outros autores e produziram bons resultados com a aplicação dos Algoritmos Genéticos, como por exemplo, CHEUNG (2005) que usou a equação (3.5) e posteriormente MUNAVALLI \& KUMAR (2006) que usaram a equação (3.6), que é similar a (3.5), suprimido porém os pesos das observações. MUNAVALLI \& KUMAR (2005) também testaram a equação (3.5) anteriormente, usando Gauss-Newton como método de otimização.

Assim como na calibração hidráulica, a função objetivo na calibração da qualidade minimiza o somatório dos quadrados da diferenças, porém entre os valores de concentração de cloro simulados e os valores correspondentes observados na rede.

$$
M i{ }_{-} F O_{4}=\sum_{j=1}^{M} \sum_{k=1}^{N(j)} W_{j, k}\left[C^{*}{ }_{j, t k}-C_{j, t k}\right]^{2}
$$

$C_{j, t k}^{*}$ o valor da concentração de cloro observado no nó $j$ e no tempo $t_{k}(\mathrm{mg} / \mathrm{L}), C_{j, t k}$ o valor da concentração de cloro simulado para o nó $j$ e instante $t_{k}(\mathrm{mg} / \mathrm{L}), W_{j, k}$ o peso associado ao nó $j$ e instante $t_{k}$ e $N(j)$ o número de observações relativas ao nó $j$ avaliadas para instantes $t_{k}$ e $M \mathrm{o}$ número de nós observados.

Como mencionado anteriormente, a escolha dos pesos quando se adota Algoritmo Genético é alvo de muita discussão, por essa razão MUNAVALLI \& KUMAR (2006) usaram 
a equação (3.6), a qual é similar a equação (3.5) com a diferença presente no fato de subtrair o peso da equação (3.5).

$$
\text { Min_F } O_{5}=\sum_{j=1}^{M} \sum_{k=1}^{N(j)}\left[C^{*}{ }_{k, j}-C_{k, j}\right]^{2}
$$

$C^{*}{ }_{k, j}$ o valor de concentração de cloro observado $(\mathrm{mg} / \mathrm{L})$ no $k$-éssimo instante e no $j$-éssimo nó, $C_{k, j}$ o valor simulado da concentração de cloro $(\mathrm{mg} / \mathrm{L})$ no $k$-éssimo instante e no j-éssimo nó, $M$ o número de nós em que a concentração de cloro é observada e $N(j)$ o número de observações no $j$-éssimo nó que são observadas e comparadas com os respectivos valores simulados.

O peso da equação (3.5) tem como objetivo homogeneizar e diminuir os erros devidos a problemas na coleta de dados no campo. MUMANAVALLI \& KUMAR (2003) apresentaram algumas formas para adoção de pesos na calibração de qualidade usando o modelo inverso. A primeira avalia o peso através do inverso da média dos valores observados em campo para cada nó monitorado elevado a um expoente entre 1 e 2. Esse procedimento foi adotado neste trabalho por razões de simplicidade, da mesma forma que SALGADO (2008) o fez. Assim, os pesos foram calculados em conformidade com a equação (3.7).

$$
W_{j}=\left(\frac{1}{C_{J_{\text {medio }}}}\right)^{n}
$$

sendo, $C_{\text {Jmédio }}(\mathrm{mg} / \mathrm{L})$ a média da concentração de cloro residual monitorado no nó $j$ e $n$ varia entre 1 e 2 (neste estudo $n=2$ ).

A escolha desse tipo de peso é vantajosa, pois adimensionaliza a função objetivo transformando-a na equação (3.8).

$$
\operatorname{Min}_{-} F O_{6}=\sum_{j=1}^{M} \sum_{k=1}^{N(j)}\left[\frac{\left(C_{k, j}^{*}-C_{k, j}\right)^{2}}{\left(C_{\text {Jmédio }}\right)^{2}}\right]
$$


No processo de calibração de qualidade realizado neste trabalho, constituíram variáveis de decisão apenas as constantes $\mathrm{K}_{\text {bulk }}$ e $\mathrm{K}_{\text {wall }}$ globais, devido às características da rede, abastecida por uma única fonte de água e com todos os tubos do mesmo material e idade. Apesar da suposta homogeneidade de parâmetros de qualidade da rede usada neste trabalho, o calibrador de qualidade foi desenvolvido para considerar diversas fontes de abastecimento e diferentes materiais de tubulação, justificando-se o uso dos AGs para a resolução do problema inverso empregado na calibração de qualidade, visto que, AGs são capazes de buscar soluções otimizadas para problemas de otimização de variáveis de decisão numerosas.

\subsection{MODELO DE SIMULAÇÃO HIDRÁULICA}

O EPANET 2.0 simula redes hidráulicas através do Método Híbrido Nó-Malha que considera as equações da continuidade, da conservação da energia e a relação entre a vazão e a perda de carga. Autores como TODINI \& PILATI (1987) ${ }^{2}$ e SALGADO et al.(1988) ${ }^{3}$ apud ROSSMAN (2000) denominaram-no como "Método do Gradiente".

Partindo-se de uma rede com $N$ nós e $N F$ nós de carga hidráulica fixa, considerou-se que a relação da vazão $x$ perda de carga em um tubo entre os nós $i$ e $j$ pode se escrita pela equação (3.9).

$$
H_{i}-H_{j}=h_{i j}=r \cdot Q_{i j}^{n}+m \cdot Q_{i j}^{2}
$$

sendo, $H_{i}$ carga hidráulica no nó $i, h_{i j}$ a perda de carga total no trecho que liga os nós $i$ e $j, r$ o termo de perda de carga que depende da formulação utilizada, $Q_{i j}$ a vazão na tubulação, $n$ o

\footnotetext{
${ }^{2}$ TODINI, E.; PILATI, S. (1987). A gradient method for the analysis of pipe networks. International Conference on Computer Applications for Water Supply and Distribution, Leicester Polytechnic, UK, September 8-10.

${ }^{3}$ SALGADO, R.; TODINI, E.; O'CONNELL, P.E. (1988). Extending the gradient method to include pressure regulating valves in pipe networks. Proc. Inter. Symposium on Computer Modeling of Water Distribution Systems, University of Kentucky, May 12-13.
} 
expoente da formulação perda de carga $x$ vazão e $m$ o coeficiente de perda de carga localizada.

O próximo conjunto de equações refere-se à conservação de massa nos nós que é expressa pela equação (3.10).

$$
\sum_{j \in J_{i}} Q_{i j}-C_{i}=0 \quad \text { para } \mathrm{i}=1, \ldots, \mathrm{N}
$$

sendo, $C$ o consumo no nó $i$ e $J_{i}$ todos os nós conectados ao nó $i$. Desta forma, conhecendo-se a carga hidráulica nos $N F$ nós, pode se obter os valores de pressão e vazão na rede que satisfaçam as equações (3.9) e (3.10).

O Método do Gradiente arbitra uma solução inicial que não necessariamente satisfaz as equações de conservação de massa nos nós e posteriormente através da solução do sistema linear (3.11) são obtidas, a cada iteração, as novas cargas hidráulicas da rede.

$$
A \cdot H=F
$$

sendo, $A$ a matriz Jacobiana $(N \mathrm{x} N), H$ o vetor de incógnitas em termos da carga hidráulica e $F$ o vetor de balanço de massa mais um fator de correção da vazão.

Os elementos da diagonal da matriz Jacobiana são:

$$
A_{i i}=\sum_{j} x_{i j}
$$

por outro lado, os elementos não nulos fora da diagonal são:

$$
A_{i j}=-x_{i j}
$$

sendo, $x_{i j}$ o inverso da derivada da perda de carga total no tubo entre os nós $i$ e $j$ em relação à vazão, dada por:

$$
x_{i j}=\frac{1}{n \cdot r \cdot\left|Q_{i j}\right|^{n-1}+2 \cdot m \cdot\left|Q_{i j}\right|}
$$


$\mathrm{O}$ vetor $\mathrm{F}$ é composto pela parcela que obedece ao balanço de massa de cada nó adicionado a um fator de correção da vazão, escrito na forma da equação (3.15).

$$
F_{i}=\left(\sum_{j \in J_{i}} Q_{i j}-C_{i}\right)+\sum_{j \in J_{i}} y_{i j}+\sum_{f \in J_{f}} x_{i f} \cdot H_{f}
$$

sendo, o último termo aplicável a qualquer tubo que ligue um nó $i$ a um nó $f$ de carga hidráulica constante, $J_{f} \mathrm{o}$ conjunto de nós com carga hidráulica constante ligados ao nó $i$ e $y_{i j} \mathrm{o}$ fator de correção da vazão, dado pela equação (3.16).

$$
y_{i j}=x_{i j}\left(r\left|Q_{i j}\right|^{n}+m\left|Q_{i j}\right|^{2}\right) \operatorname{sgn}\left(Q_{i j}\right)
$$

sendo, $\operatorname{sgn}(\mathrm{x})$ é 1 se $\mathrm{x} \geq 0$ e -1 caso contrário.

Após terem sido calculadas as cargas hidráulicas nos nós, os novos valores das vazões nas tubulações foram obtidos de acordo com a expressão (3.17).

$$
Q_{i j}=Q_{i j}-\left\lfloor y_{i j}-x_{i j}\left(H_{i}-H_{j}\right)\right\rfloor
$$

Se a soma dos valores absolutos de todos os desvios da vazão total, assim calculadas para todas as tubulações, fosse superior à tolerância especificada, as equações (3.11) e (3.17) seriam resolvidas novamente.

A consideração do vazamento em rede é um problema, uma vez que é difícil calcular a parcela da vazão total abastecida, que é consumida por vazamentos. Desta forma, a consideração dos vazamentos é feita por uma suposição quanto à composição da vazão abastecida. Assim, mesmo sabendo que a vazão abastecida inclui consumos não autorizados de água, admite-se que a vazão total abastecida $(T S)$ possa ser subdividida em consumo total $(T D)$ e vazamentos $(V)$, e o balanço de massa correspondente passa ser escrito pela expressão (3.18):

$$
T S=T D+V
$$


Supondo-se que a distribuição espacial do consumo total seja conhecida e invariável no tempo, é admitido que o consumo nodal varia proporcionalmente, bastando que fatores horários (FT) sejam multiplicados ao longo das horas do dia pelo consumo de referência $\left(T S^{*}\right)$, geralmente estabelecido com base nos consumos mensais. Assim, a vazão abastecida (TD) pode ser expressa pela equação (3.19).

$$
T D=F T \cdot T S^{*}
$$

Substituindo (3.19) em (3.18) tem se a equação (3.20):

$$
T S=T S^{*} \cdot F T+V
$$

Logo, o fator multiplicador do consumo de referência pode ser determinado através da equação (3.20).

$$
F T=\frac{T S-V}{T S *}
$$

Para possibilitar que esse fator seja avaliado iterativamente, admite-se inicialmente que $\mathrm{FT}_{1}=1$ e o processo de cálculo do $F T$ só termina quando as diferenças entre as pressões $\left(\Delta_{l}\right)$ calculadas na iteração anterior e da última iteração, calculadas para cada nó, têm valor inferior à tolerância fixada, que neste trabalho foi de 0,01 . Satisfeita a primeira condição, ainda se verificam duas outras condições: a) a diferença em módulo entre o $F T$ calculado anteriormente e calculado na última iteração $\left(\Delta_{2}\right)$, que não pode ser maior a 0,01 , e b) o balanço de massas $\left(\Delta_{3}\right)$ que não pode ser maior que 0,1 .

O fluxograma da Figura 3.8 demonstra a estrutura do processo iterativo para o cálculo dos valores $F T$ s, avaliação hidráulica e cálculo dos parâmetros do modelo de vazamentos. Esta rotina de cálculo utilizada no presente trabalho foi semelhante à adotada por SOARES (2003) e igual à usada por REIS et al. (2007), autores que já comprovaram a eficácia do processo de cálculo. 
O processo iterativo tem início com o conhecimento prévio da vazão abastecida total (TS), sendo que esta informação pode ser obtida através do controle das vazões de entrada no setor de rede estudado.

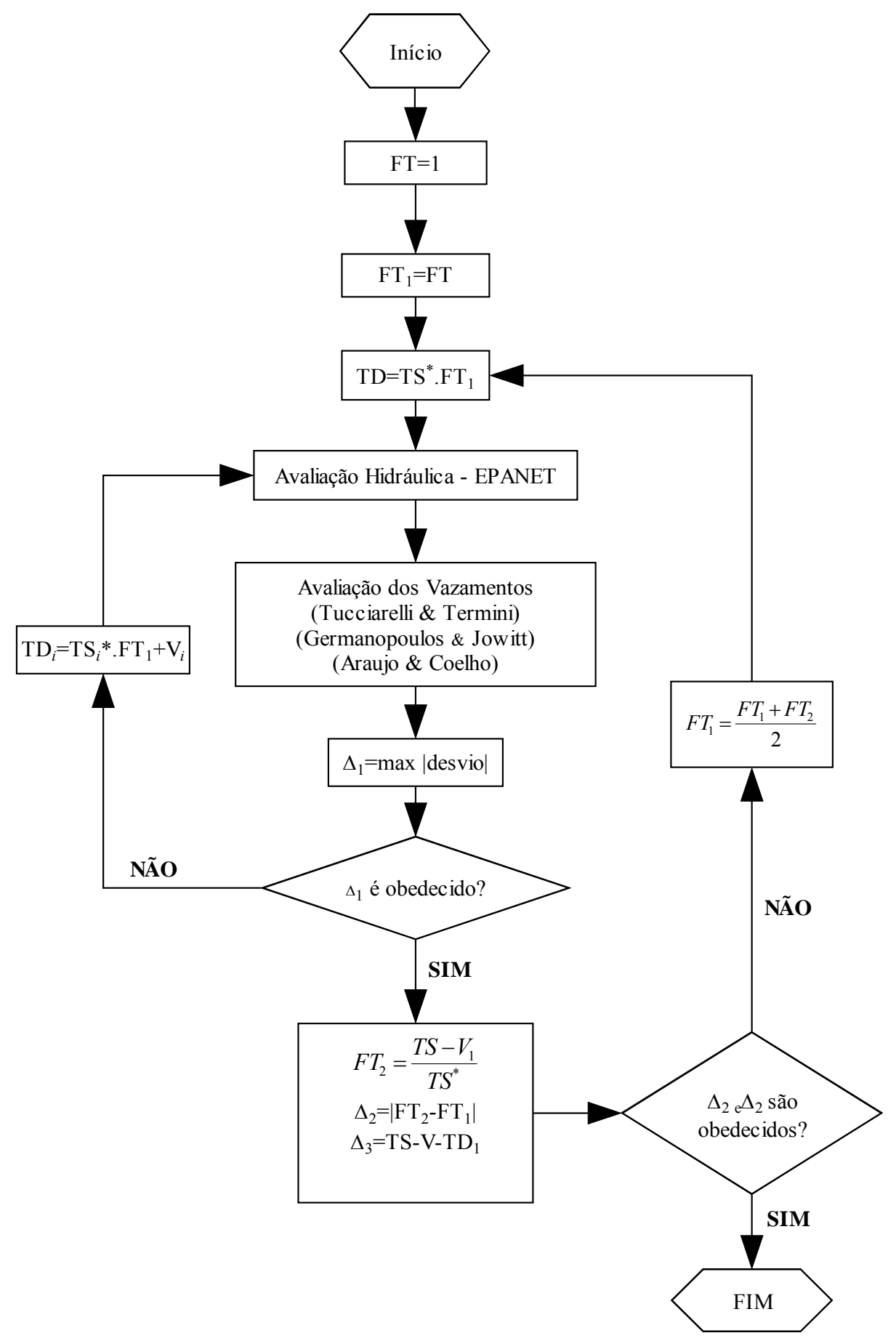

FIGURA 3.8 - Fluxograma do processo iterativo para avaliação hidráulica, determinação dos fatores de consumo e dos parâmetros do vazamento. 
Outras informações importantes para compor os dados de entrada são:

- A vazão de abastecimento de referência $\left(T S^{*}\right)$, que foi determinada através da média dos três últimos meses dos consumos mensais residências;

- A rugosidade absoluta e sua faixa de procura;

- A faixa de procura dos coeficientes e expoente da equação dos vários modelos de vazamentos;

- Pressões medidas em alguns nós;

- Níveis da carga hidráulica do reservatório;

- Além das características da rede, como diâmetros e comprimentos das tubulações, componentes hidráulicos e topografia.

\subsection{MODELOS DE VAZAMENTO EM FUNÇÃO DAS PRESSÕES NODAIS}

O EPANET 2.0 não considera os vazamentos diretamente em suas simulações. Contudo, apresenta a opção de associar a cada nó um "emitter", sendo esses "emitters" modelados segundo a lei dos orifícios, com descarga para a atmosfera. A vazão nessas condições obedece à equação (2.18).

$$
q_{f}=K_{f} P_{f}^{\beta}
$$

sendo, $q_{f}$ a vazão do "emitter" no nó, $P_{f}$ a pressão do nó com "emitter", $K_{f}$ o coeficiente do "emitter" e $\beta$ o expoente do "emitter".

Desta forma, a consideração do vazamento foi realizada através dos três modelos citados anteriormente (GERMANOPOULOS \& JOWITT, 1989; ARAUJO et al., 2006 e TUCCIARELLI et al. 1999). 
ARAUJO et al. (2006) consideraram esses "emitters" nos nós para impor vazamentos como uma função das pressões nodais. Em que o $K_{f}$ é o produto do coeficiente do vazamento pela área de influência de cada nó, sendo calculado pelo somatório da metade dos comprimentos dos tubos ligados ao nó, conforme a equação (3.22).

$$
K_{f_{i}}=c_{i} \cdot \sum_{j=1}^{m} 0,5 \cdot L_{i j}
$$

sendo, $c$ o coeficiente de vazamento por metro linear global (atribuído a todos os tubos) e $L_{i j} \mathrm{O}$ comprimento do tubo que liga o nó $i$ ao nó $j$ em metros. Ainda para a resolução da equação (2.18), os autores consideram o expoente $\beta$ como sendo fixo e de valor igual a 1,18 , como foi apresentado anteriormente.

O modelo de GERMANOPOULOS \& JOWITT (1989) calcula os $K_{f}$ de cada nó de forma similar ao modelo proposto ARAUJO et al. (2006), sendo que a diferença entre os dois modelos reside na consideração do expoente da equação (2.18), que para GERMANOPOULOS \& JOWITT (1989) deve ser calibrado dentro de uma faixa de busca, recomendada por GOODWIN (1980), entre 0,5 a 1,18. Para este trabalho foi considerado como sendo entre 0,5 a 1,20 .

TUCCIARELLI et al. (1999) consideram o vazamento como sendo função da unidade de área superficial das tubulações conectadas a um determinado nó, apresentando a equação (2.13) para avaliação dos vazamentos.

$$
q_{i}=\left(H_{i}-z_{i}\right)^{\beta} \sum_{j=1}^{M_{i}} \frac{\pi}{2} D_{i j} \theta_{i j} L_{i j}
$$

sendo, $\beta$ o expoente de perda, $\theta_{i j}$ a taxa de vazamento por unidade de superfície da tubulação ligando o nó $i$ ao $j, D_{i j}$ o diâmetro do tubo que liga o nó $i$ ao $j, L_{i j}$ o comprimento do tubo, $H$ a carga hidráulica e $z$ a cota topográfica. Assim, para possibilitar o uso modelo de TUCCIARELLI et al. (1999) em conjunto com o simulador EPANET 2.0, foi necessário que 
o coeficiente do "emitter" fosse expresso através da relação dada pela unidade de área superficial da tubulação, conforme a equação (3.23).

$$
K_{f}=\sum_{j=1}^{M_{i}} \frac{\pi}{2} D_{i j} \theta_{i j} L_{i j}
$$

TUCCIARELLI et al. (1999) também levam em consideração a mesma faixa de procura para o expoente $\beta$ proposta por GOODWIN (1980), alterada neste trabalho para a faixa 0,5 a 1,20 .

\subsection{INTERAÇÃO ENTRE OS MODELOS DE SIMULAÇÃO E OTIMIZAÇÃO}

\subsubsection{Calibração Hidráulica}

Para se atingir o objetivo final deste trabalho, que é a calibração dos parâmetros de qualidade, existe a necessidade de que o modelo hidráulico seja perfeitamente calibrado e represente o mais próximo possível o comportamento hidráulico da rede real, para então poder obter-se os parâmetros em termos do decaimento de cloro. Devido a essa necessidade, foi usada a rotina computacional em linguagem $C++$ desenvolvida por REIS et al. (2007), que utilizaram o simulador hidráulico EPANET 2.0 como módulo auxiliar para avaliação da rede e a biblioteca GAlib $C++$ para desenvolvimento do Algoritmos Genéticos. A modificação implementada, neste trabalho, no processo de calibração hidráulica usado por REIS et al. (2007), consiste no uso do PSO para a calibração dos parâmetros dos AGs. 
A calibração do modelo hidráulico utiliza o calibrador construído por SOARES (2003) e modificado por REIS et al. (2007), para o qual foi necessário a criação de três arquivos de dados:

Arquivo 1: dados observados de pressão, vazão, nível do reservatório, com as respectivas identificações de localização da medida (nó e tubulação), e a vazão abastecida total para cada padrão de consumo.

Arquivo 2: parâmetros estabelecidos para os AGs, e estabelece o tipo de $A G$ (geracional elitista ou Steady-State), o operador de seleção (Ordenamento, Roda da Roleta, Torneio, Uniforme, Amostragem Determinística e Stochastic Remainder Sampling - SRS), o número de cromossomos a serem substituídos (no caso do AG Steady-State), recombinação (Uniforme, Um Ponto, Dois Pontos, Aritmética e $B L X$ - $\alpha$ ), as probabilidades de recombinação e mutação, o tamanho da população, o número de gerações e a semente para geração de números aleatórios. Esse arquivo ainda continha informações relativas aos setores da rede de distribuição de água de rugosidades absolutas homogêneas, identificando as tubulações que compõem cada zona e intervalos de procura para cada parâmetro buscado.

Arquivo 3: dados de entrada para o simulador hidráulico EPANET 2.0 e os dados da rede como: consumos de referencia e cotas topográficas dos nós, nível do reservatório, comprimentos, diâmetros e rugosidades das tubulações, bombas, válvulas e regras de operação do sistema, além de opções quanto ao uso de equações e perda de carga (DarcyWeisbach, Hazen-Williams ou Chezy-Manning), unidades e tolerância.

Para a calibração dos parâmetros dos AGs, utilizou-se o PSO, que é uma técnica de otimização estocástica que possibilita a calibração dos parâmetros importantes para os AGs como o número de gerações, o tamanho da população, a taxa de recombinação e a taxa de mutação em um número reduzido de iterações. Observa-se que para essa busca foram fixados 
os tipos de AG, seleção e mutação. A Tabela 3.1 detalha as opções fixadas para a calibração dos AGs e os intervalos de procura para os parâmetros calibrados.

TABELA 3.1 - Parâmetros dos AGs fixados e intervalos de procura

\begin{tabular}{|c|c|}
\hline Tipo do AG & Geracional elitista \\
\hline Representação da solução & Real \\
\hline População de soluções & variando entre 20 e 50 \\
\hline Recombinação & dois pontos \\
\hline Probabilidade de recombinação & variando entre 0,5 e 0,9 \\
\hline Seleção & Stochastic Remainder Sampling-SRS \\
\hline Mutação & gaussiana \\
\hline Probabilidade de mutação & variando entre 0,01 e 0,25 \\
\hline Taxa de elitismo & variando entre 100 e 1000 \\
\hline Número de gerações & linear (c=1,5) \\
\hline Escalonamento &
\end{tabular}

O processo de calibração hidráulica com a utilização dos AGs, do PSO, juntamente com o simulador hidráulico está representado no fluxograma da Figura 3.9. 


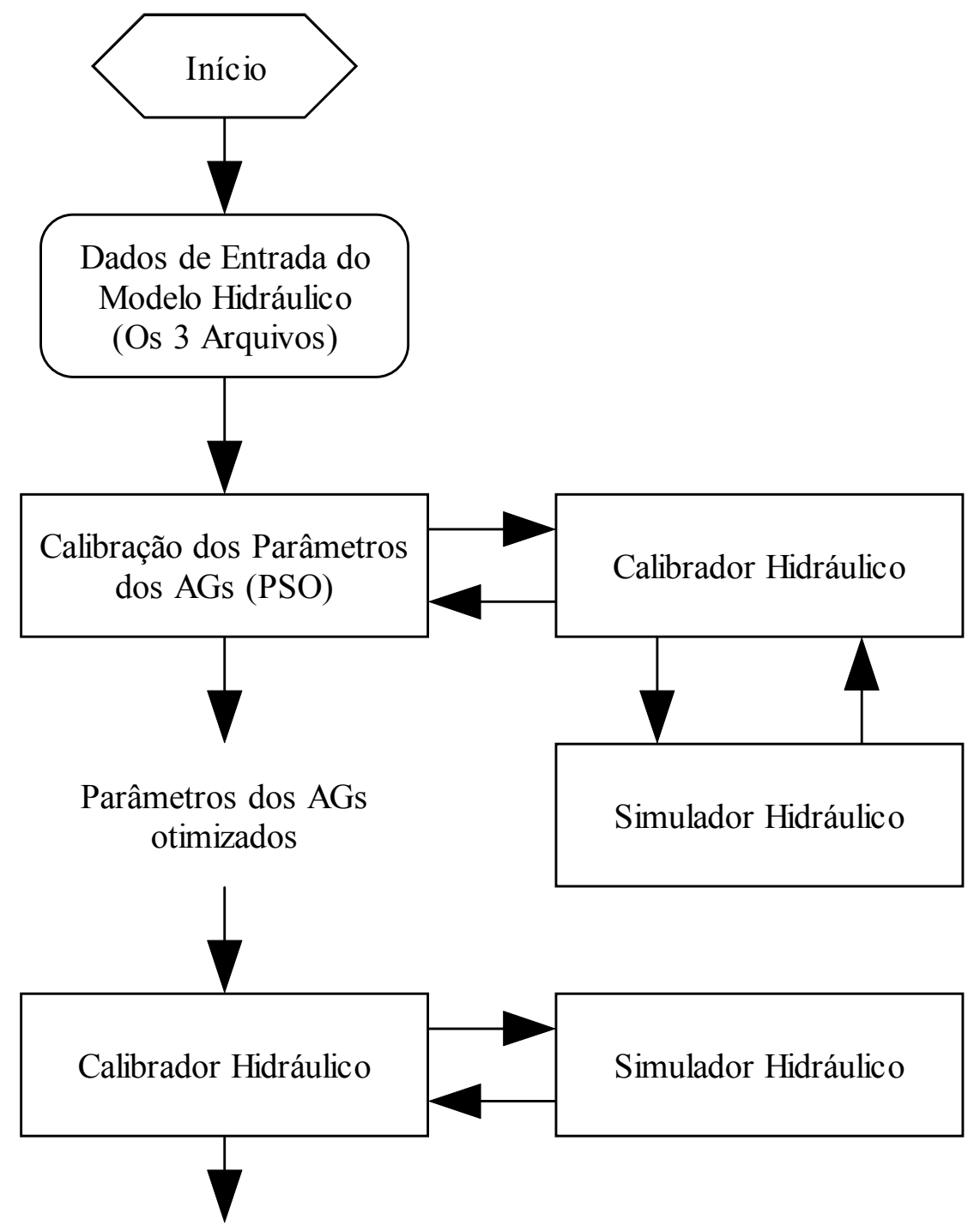

Resultados da Calibração

Hidráulica

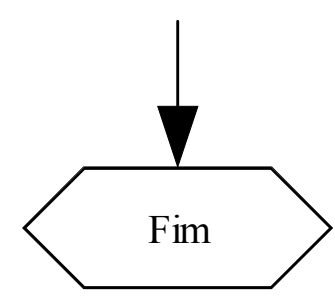

FIGURA 3.9 - Fluxograma do processo de calibração dos Parâmetros dos AGs mais a calibração Hidráulica

O processo de interação da rotina computacional (calibrador hidráulico), criada no $C++$ com os AGs, e o simulador hidráulico (EPANET 2.0) está representado na Figura 3.10. 


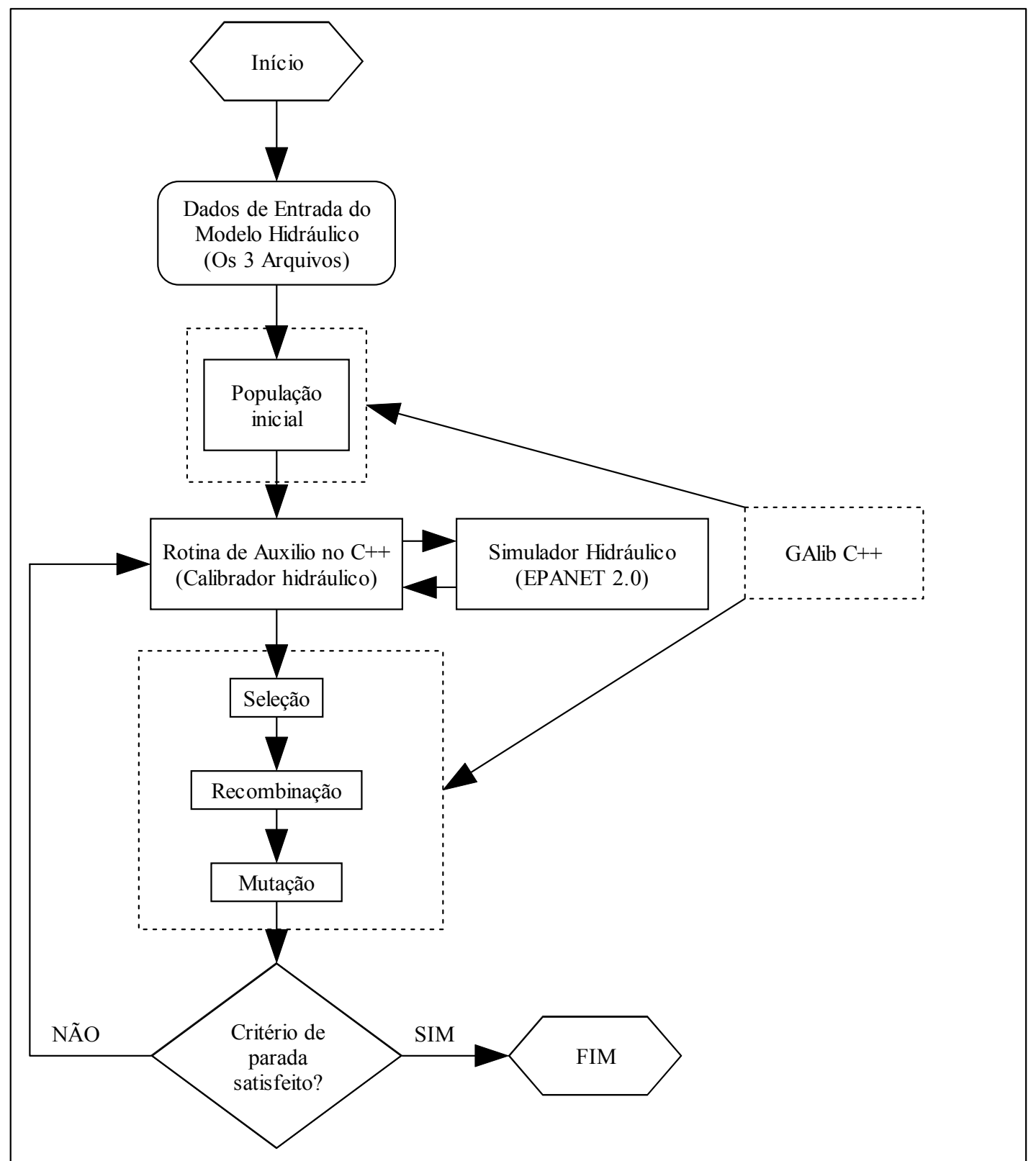

FIGURA 3.10 - Fluxograma do processo de interação da rotina no $\mathrm{C}++$ mais o simulador e os AGs

O critério de parada adotado para o uso dos AGs foi o número de gerações, assim como utilizado por SOARES (2003), que justifica que esta escolha devido à melhor utilização da biblioteca GAlib $\mathrm{C}++$, visto que outro critério demandaria um esforço computacional maior, devido à incompatibilidade da biblioteca com outras formas de convergência.

No caso do PSO, o critério de parada foi o número de iterações. Como o tempo computacional de cada iteração é elevado, por exigir diversas avaliações, este critério foi 
considerado como sendo mais coerente para este trabalho. Outro ponto importante é a fixação de algumas alternativas do modelo hidráulico. Assim, o único modelo de vazamento usado para calibrar os AGs foi o de TUCCIARELLI et al. (1999).

\subsubsection{Consideração do tempo de residência da água para cada nó observado}

Outra informação importante foi a consideração do tempo de residência da água em cada nó observado, pois a falta dessa análise no uso do EPANET 2.0 poderia gerar distorções na calibração de qualidade.

OZDEMIR \& UCAK (2002) solucionaram esse problema propondo outro simulador, o DYNAQ.

A proposta do presente trabalho foi utilizar o simulador EPANET 2.0, que é um simulador aberto ao uso, de distribuição gratuita e de fácil interação com outras rotinas de programa. No entanto, este simulador não é capaz de sincronizar automaticamente as concentrações de cloro simuladas com os dados observados em nós que tenham tempo de residência elevado. Este problema é conseqüência do modelo Lagrangeano dirigido pelo tempo (TDM).

A solução encontrada foi somar o tempo de residência máximo da água aos horários das observações. Essa determinação pode ser feita através da simulação no módulo de qualidade do EPANET 2.0 na opção "age".

Sendo assim, para a simulação do tempo de residência da água foram necessárias: todas as informações obtidas com a calibração hidráulica mais os dados de entrada da própria calibração hidráulica, os padrões de comportamento do reservatório e o cálculo dos FTs para cada hora do dia considerado. 
O fluxograma para a análise do tempo de residência, que possibilitou a calibração hidráulica, está representado na Figura 3.11.

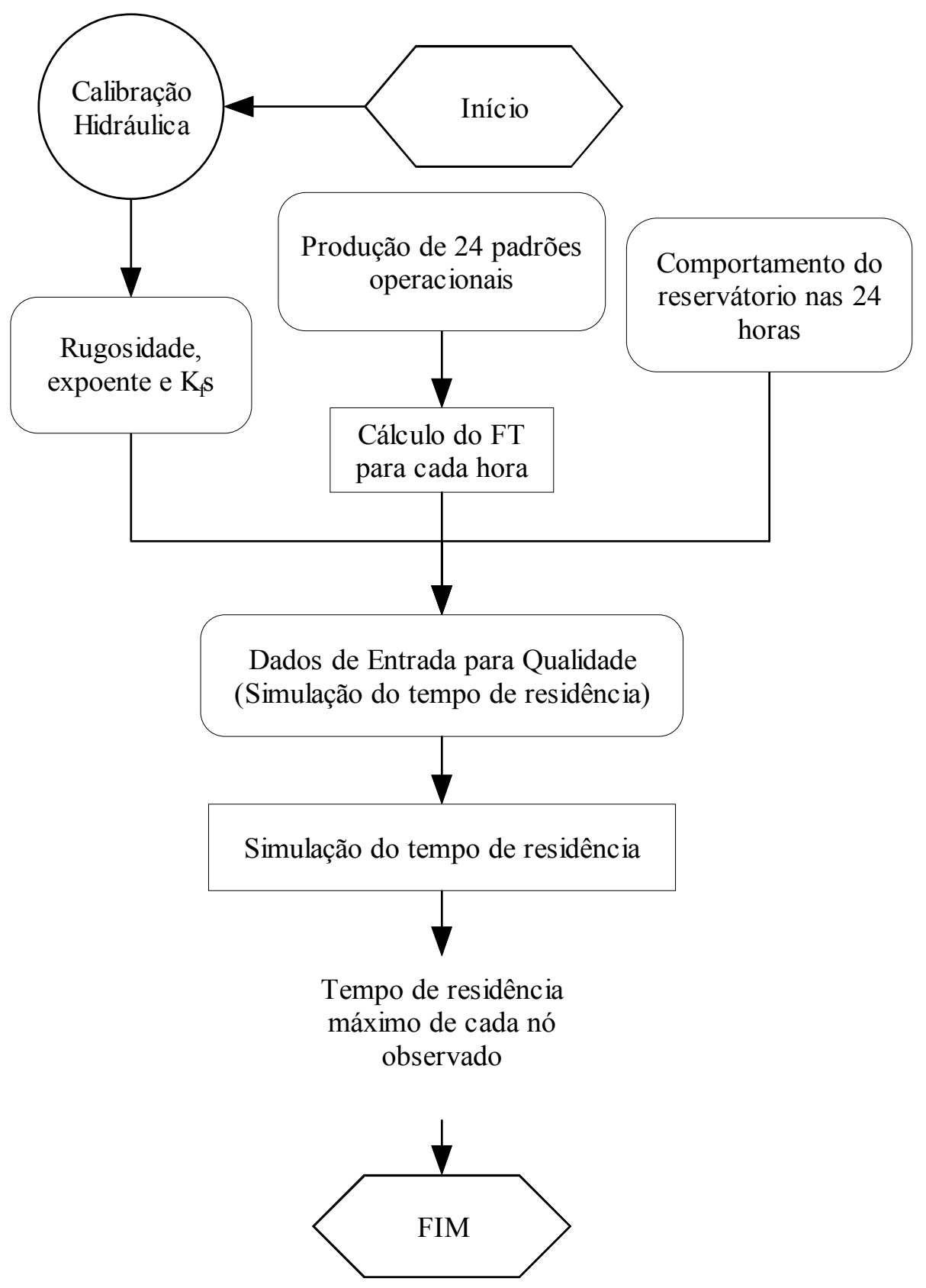

FIGURA 3.11 - Fluxograma da análise do tempo de residência d água nos nós observado 


\subsubsection{Calibração de qualidade da água}

Foi criada uma rotina computacional, em linguagem $C++$, utilizando o simulador hidráulico EPANET 2.0, como módulo auxiliar para avaliação da concentração de cloro na rede, e a biblioteca GAlib $C++$ para desenvolvimento do Algoritmos Genéticos.

A integração entre o modelo de qualidade e a ferramenta de calibração é baseada no processo proposto por SOARES (2003) para calibração de modelos hidráulicos, com base em três arquivos:

Arquivo 1: número de nós observados, os dados de concentração e o horário das medições realizadas.

Arquivo 2: parâmetros estabelecidos para os AGs, a serem definido, como: tipo do $A G$ (geracional elitista ou Steady-State), operador de seleção (Ordenamento, Roda da Roleta, Torneio, Uniforme, Amostragem Determinística e Stochastic Remainder Sampling - SRS), número de cromossomos a serem trocados (no caso do AG Steady-State), recombinação (Uniforme, Um Ponto, Dois Pontos, Aritmética e $B L X-\alpha$ ), probabilidades de recombinação e mutação, tamanho da população, número de gerações e semente aleatória. Esse arquivo ainda contém a informação da setorização da rede de distribuição, em relação às áreas de influência de mesmo $K_{\text {bulk }}$ e as áreas de influência de mesmo $K_{\text {wall, }}$ identificando as tubulações que compõem cada área e intervalos de busca das variáveis de decisão do problema ( $\mathrm{K}_{\text {bulk }}$ e $\left.\mathrm{K}_{\mathrm{wall}}\right)$.

Arquivo 3: dados de entrada do simulador hidráulico e de qualidade do EPANET 2.0; os dados da rede (consumos de base e cotas topográficas dos nós, nível de reservatórios, comprimentos, diâmetros e rugosidades das tubulações, bombas, válvulas e regras de operação do sistema); e opções quanto ao uso de equações e perda de carga (Darcy-Weisbach, Hazen-Williams ou Chezy-Manning), unidades e tolerância. 
O procedimento e a interação do calibrador de qualidade com a biblioteca da GAlib $C++$, estão representados na Figura 3.12. O critério de parada adotado foi o mesmo utilizado pelo calibrador hidráulico, que é o numero de gerações, isso em conseqüência das mesmas justificativas já apresentadas anteriormente.

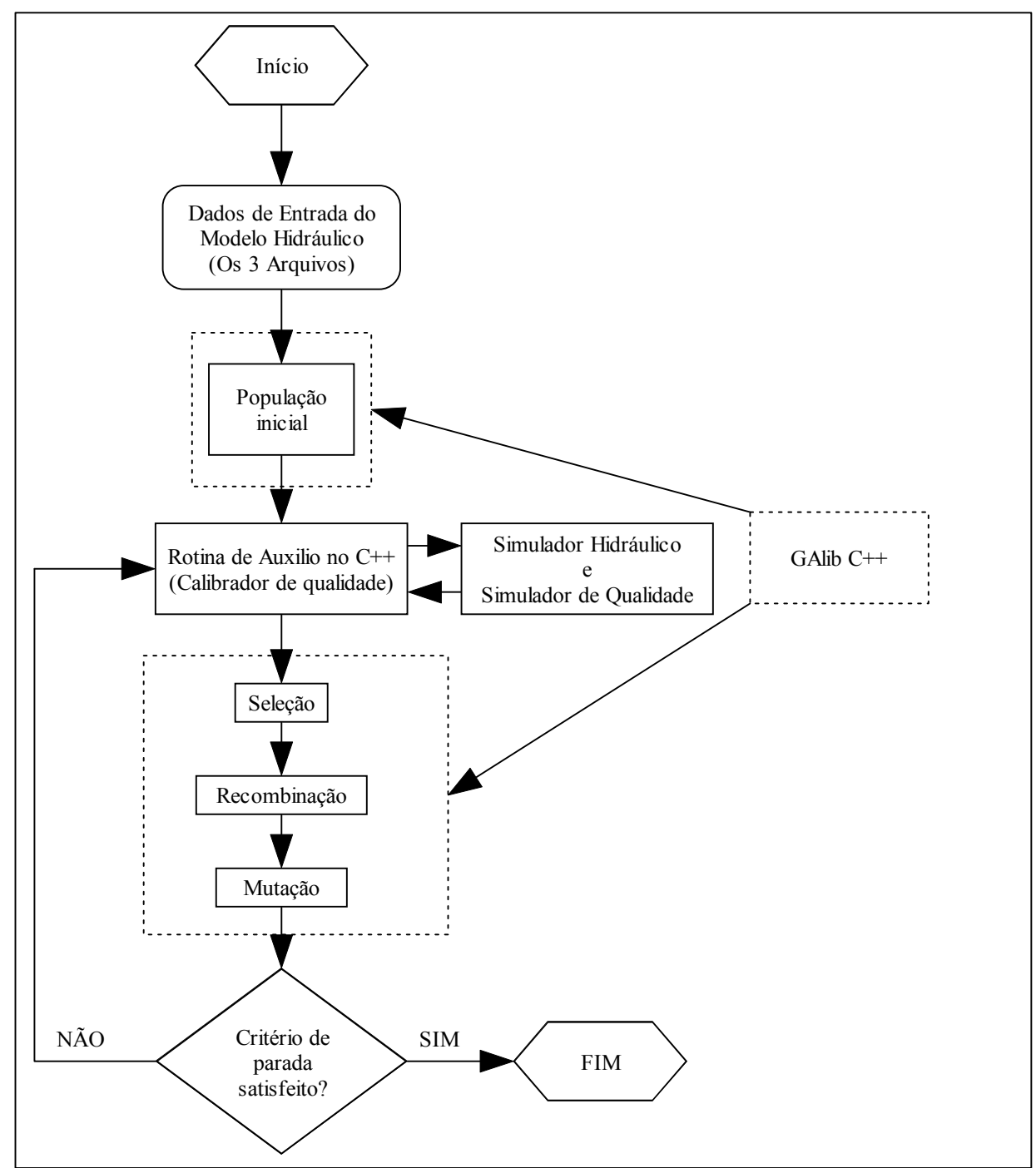

FIGURA 3.12 - Fluxograma do calibrador de qualidade e a interação com a GAlib C++. 


\subsection{EQUIPAMENTOS E PROCEDIMENTOS PARA CAMPANHA DE CAMPO}

\subsubsection{Monitoramento do cloro residual}

Foram usados para a medição pontual e contínua de cloro, duas sondas que medem simultaneamente a concentração de cloro residual livre, $\mathrm{pH}$ e temperatura da água, sendo uma instalada no ponto mais próximo à saída da desinfecção e a outra, no ponto extremo do sistema de distribuição real escolhido para o monitoramento.

As sondas utilizadas para a obtenção de dados de concentração de cloro em campo são compostas por conjunto de dispositivos (Tabela 3.2), que tem como objetivo o monitoramento autônomo de parâmetros importantes de qualidade da água no sistema de distribuição.

As sondas são dotadas de memória com capacidade de $384 \mathrm{MB}$, o que significa um armazenamento de 150.000 leituras para cada parâmetro individualmente. O intervalo de aquisição de dados pode variar conforme a necessidade do operador, implicando no intervalo de tempo em que deverá ser descarregada a memória. As sondas ainda são alimentadas por baterias, possibilitando autonomia ao equipamento, e podem ser descarregadas quando conectadas a um laptop, suprindo a necessidade de dados de entrada do modelo de qualidade.

O sensor de cloro livre tem como características:

- Escala de leitura de 0 a $3 \mathrm{mg} / \mathrm{L}$;

- A resolução da leitura $0,01 \mathrm{mg} / \mathrm{L}$;

- Acurácia de $\pm 15 \%$ da leitura ou $0,05 \mathrm{mg} / \mathrm{L}$, aquele que for maior; para manter a precisão especificada, a vazão na célula de fluxo tem que ser próxima de 500 $\mathrm{mL} / \mathrm{min}$ e o $\mathrm{pH}$ não mudar mais que $\pm 0,3$ unidades, caso o $\mathrm{pH}$ da água seja maior que 8,5 . 
TABELA 3.2 - Relação de equipamentos das sondas e suas respectivas funções

\begin{tabular}{|c|c|}
\hline Dispositivo & Função \\
\hline pH Probe Kit & Sensor de pH \\
\hline Calibration Cable & Cabo de conexão computador-sonda. Permite conectar a sonda direto ao \\
computador, programar e baixar os dados.
\end{tabular}

O modelo do aparelho usado nas medições de cloro foi o Hach, Chlorine Colorimeter Pocket II, modelo 58700-00. Ele é capaz de medir o cloro com precisão de duas casas decimais no modo "Low Range", abrangendo concentrações entre 0,02 a 2,00 mg/L (HACH, 2006). O Hach também foi utilizado para calibrar o medidor de cloro livre da sonda e medir o consumo de cloro livre na massa líquida.

\subsubsection{Determinação do decaimento de cloro na massa líquida}

Para a determinação do decaimento de cloro na massa líquida foi usado o "teste da garrafa", que consiste basicamente em coletar amostras de água clorada e verificar o decaimento do cloro residual em certos intervalos de tempo, obtendo o coeficiente $\mathrm{K}_{\text {bulk }}$ e sua respectiva ordem de decaimento. Para tanto foram usados os equipamentos listados na Tabela

\section{3 .}


TABELA 3.3 - Relação de equipamentos do "teste da garrafa”

\begin{tabular}{|c|c|}
\hline $\begin{array}{c}\text { Número de } \\
\text { equipamento }\end{array}$ & Equipamento \\
\hline 1 & Colorímetro de bolso( modelo HACH) \\
\hline 2 & 20 Frascos de 100 ml tipo Winkler na cor âmbar \\
\hline 3 & Mangueiras de água \\
\hline 4 & Pipeta volumétrica \\
\hline 5 & Pisseta com água destilada \\
\hline 6 & Planilha para anotação dos dados \\
\hline 7 & Caixa adaptada com entrada e saída de água \\
\hline
\end{tabular}

Na Figura 3.13 são apresentados os aparelhos que foram utilizados para a realização da pesquisa.

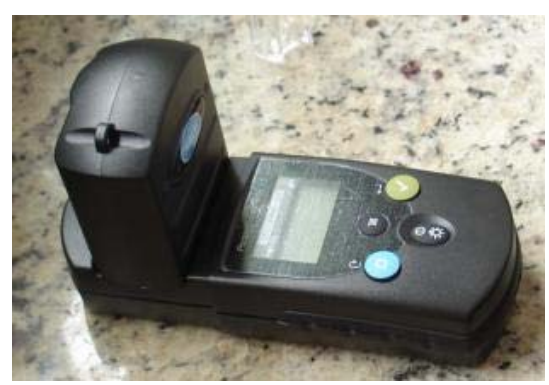

(1) Clorímetro de bolso

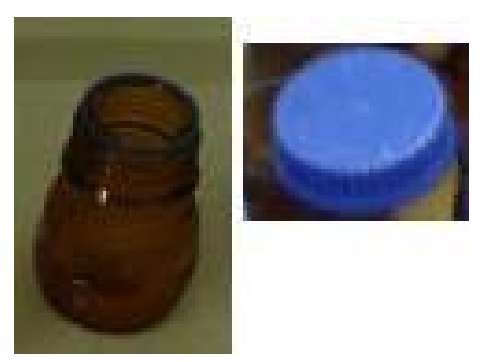

(2) Frasco coletor de amostra tipo Winkler

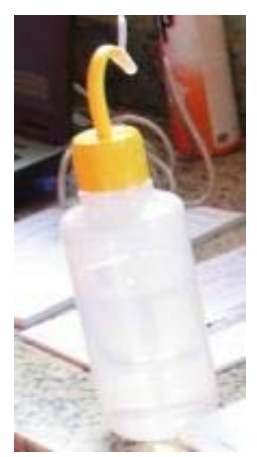

(5) Pisseta

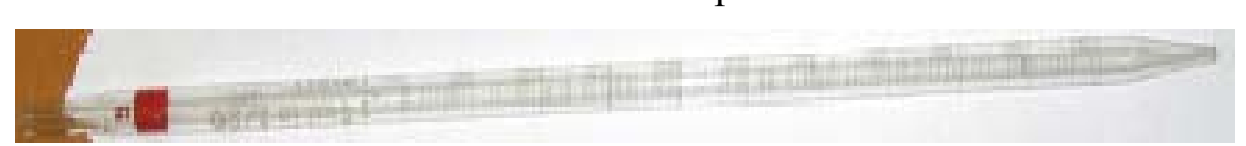

(4) Pipeta volumétrica
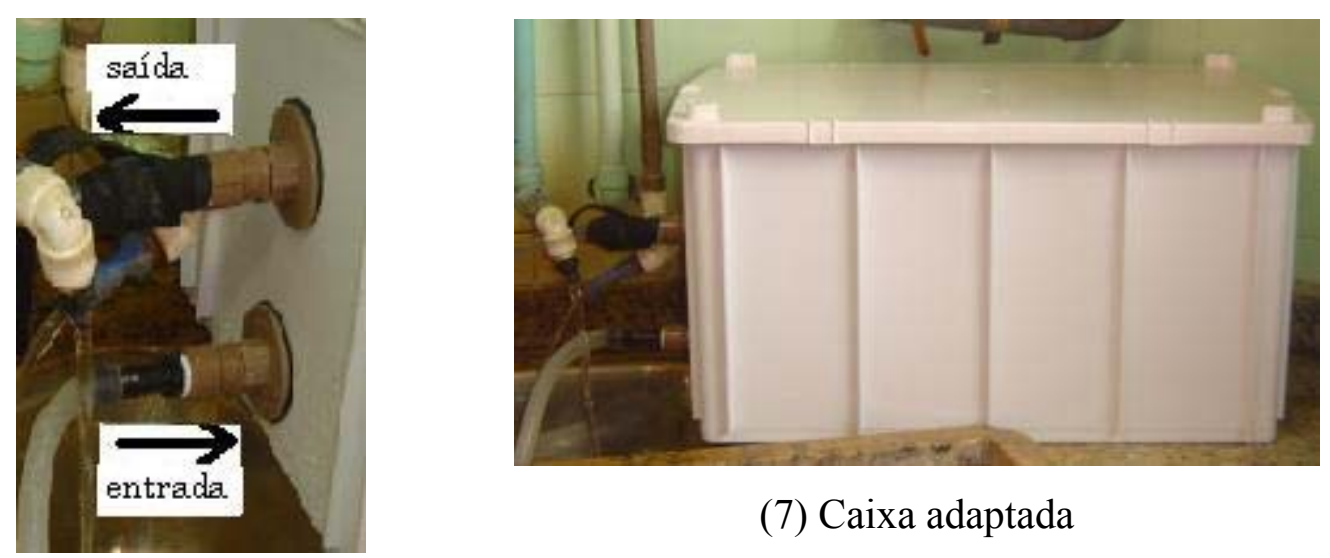

(7) Caixa adaptada

(3) Mangueiras

\section{FIGURA 3.13a - Equipamentos usados no "teste da garrafa"}


Na literatura não existem trabalhos e informações sobre o procedimento adotado para a realização do "teste da garrafa", sendo assim, foi desenvolvido um procedimento para o referido teste nesta pesquisa. Este procedimento foi resultado do trabalho conjunto de duas equipes de pesquisas: Universidade Federal do Mato Grosso do Sul e Universidade de São Paulo, participantes do projeto intitulado "Instrumentação de Redes Hidráulicas Reais para Avaliação Contínua de Parâmetros de Qualidade da Água”.

\section{- Procedimento}

\section{o Preparação dos utensílios}

Uma das preocupações desse procedimento foi tentar minimizar as interferências externas do processo de consumo de cloro residual na massa líquida, sendo necessário eliminar a demanda por cloro dos utensílios a serem utilizados no teste. Para isso, adotou-se o seguinte procedimento: no dia anterior ao teste, frascos destampados foram imersos na caixa adaptada, que estava conectada a uma mangueira que a alimentava continuamente com a água clorada a ser estudada. Assim buscou-se eliminar a demanda por cloro da caixa e dos frascos, minimizando-se as interferências no teste.

\section{o Coleta das amostras}

O procedimento de coleta das amostras consistiu em três etapas: a) esvaziar a caixa e os frascos que foram preparados no dia anterior; b) posicionar esses frascos adequadamente na caixa de modo a não flutuarem quando a mesma fosse preenchida com água; c) coletar as amostras ao mesmo tempo, para que tivessem a mesma concentração de cloro residual.

Após o preenchimento total dos frascos, eles foram tampados e imersos em uma caixa térmica com água. 


\section{o Medição do decaimento do cloro residual}

O procedimento de determinação do residual de cloro em intervalos de tempo préestimados utilizou como ferramenta: o colorímetro de bolso e o reagente DPD.

As amostragem foram realizadas em réplica e quando os valores diferiam, realizava-se uma terceira medida.

As amostras foram mantidas à temperatura constante no interior de uma estufa.

\section{o Limpeza dos utensílios}

Antes de cada medida, deve-se limpar as cubetas (pequeno frasco de $10 \mathrm{ml}$, que acompanha o colorímetro de bolso) de modo a eliminar eventuais resíduos das amostras anteriores. Foi adotado o seguinte procedimento:

1) 2 lavagens das cubetas com água de torneira (a cubeta do branco não precisa da lavagem com água de torneira, pois não contém resíduos do reagente DPD);

2) 2 lavagens das cubetas com água destilada;

3) 2 lavagens das cubetas com água do frasco que está sendo amostrado;

4) A pipeta também deve ser lavada com a água da amostra.

\section{o Medição}

Após a limpeza dos utensílios, seguiu-se o seguinte procedimento, a ser repetido para cada frasco amostrado:

1) Retirou-se $5 \mathrm{~mL}$ da amostra para o branco (amostra padrão), colocou-se no colorímetro, e zerou-se o colorímetro. É recomendável sempre utilizar a 
mesma cubeta como branco, para que esta não seja contaminada com o reagente DPD;

2) Retirou-se mais $5 \mathrm{~mL}$ da amostra e colocou em outra cubeta, adicionou-se o reagente DPD e misturou-se suavemente por 20 segundos. Depois disso, colocou-se a cubeta (amostra + reagente) no colorímetro e feita a medição. Esta medida deve ser feita no mínimo 2 vezes para confirmar o resultado.

Observações:

- Após adição do reagente DPD, deve-se efetuar a medida dentro de 1 minuto, e é necessário ao menos 2 pessoas para realizar a medição. Uma pessoa retira e coleta as amostras, enquanto a outra fica responsável pela utilização do colorímetro e pela limpeza das cubetas;

- O intervalo das medições depende da velocidade do decaimento de concentração observada. Após a $1^{\mathrm{a}}$ medida (concentração inicial de cloro), deve-se realizar as medidas seguintes a cada 15 minutos, pois o decaimento é bem rápido no início, e quando se perceber que o decaimento tornou-se mais lento, pode-se realizar as medições com intervalos maiores de tempo;

- Recomenda-se que os operadores estejam familiarizados com o procedimento, e que operador do colorímetro seja sempre o mesmo, para minimizar o erro nas medições;

- Antes de colocar a cubeta com a amostra no colorímetro, deve-se remover o excesso de água no exterior, principalmente na parte do "espelho". O “espelho" deve ser limpo na direção do comprimento. Não se deve tocar no "espelho";

- Deve-se eliminar as bolhas de ar que estejam no "espelho". 
Apesar da grande diversidade de leis de decaimento, a mais comumente utilizada em modelos computacionais é a de $1^{\mathrm{a}}$ ordem (simplicidade), na qual a velocidade de reação é proporcional à concentração de cloro, sendo este modelo também usado pelo EPANET 2.0. No entanto, a curva de decaimento do cloro residual apresenta duas fases distintas: a $1^{\text {a }}$ fase, durante a qual o decaimento é rápido (dura menos de $1 \mathrm{~h}$ ) e a $2^{\mathrm{a}}$ fase, com decaimento mais lento.

O modelo de decaimento de $1^{\mathrm{a}}$ ordem pode ser usado com o mínimo de erro, se a gama de tempo de percurso for superior ao tempo de decaimento da $1^{\text {a }}$ fase (VIEIRA et al., 2004). Caso contrário, seria mais adequado o uso de um modelo de $1^{\mathrm{a}}$ ordem limitada ou de ordem $\mathrm{n}$. Entretanto, só é usado o modelo de $1^{\mathrm{a}}$ ordem nas calibrações de qualidade.

O objetivo do "teste da garrafa" é determinar previamente o coeficiente $\mathrm{K}_{\text {bulk, }}$, contudo foi necessário o uso de outros métodos para sua determinação que consistiram em aproximar graficamente ou matematicamente os valores observados com os valores simulados, assim como o modelo em consideração que pode ser o modelos $1^{\text {a }}$ ordem, $1^{\text {a }}$ ordem limitada e ordem $\mathrm{n}(=2)$.

Para melhorar os resultados da minimização do somatório do quadrado das diferenças entre valores da concentração de cloro residual obtidos no colorímetro e os calculados via modelação (via “solver"), optou-se em não fixar a concentração inicial de cloro como sendo igual ao primeiro valor medido. Denominou-se este método de Minimização do Somatório dos Erros ao Quadrado (MSEQ).

Outro método também foi utilizado para se determinar o coeficiente $\mathrm{K}_{\text {bulk, }}$ este consistiu em: utilizar a escala logarítmica para o eixo da concentração de cloro, ou seja, linearizou-se as concentrações de cloro residual obtidas em campo aplicando-se o logaritmo neperiano à lei de decaimento de $1^{\mathrm{a}}$ ordem (ver Figura 3.13b). Assim, foi utilizada a linha de 
tendência exponencial, obtendo-se a equação de $1^{\mathrm{a}}$ ordem com o coeficiente $\mathrm{K}_{\text {bulk }}$ e sua respectiva concentração inicial. Denominou-se esse como Método Gráfico (MG).

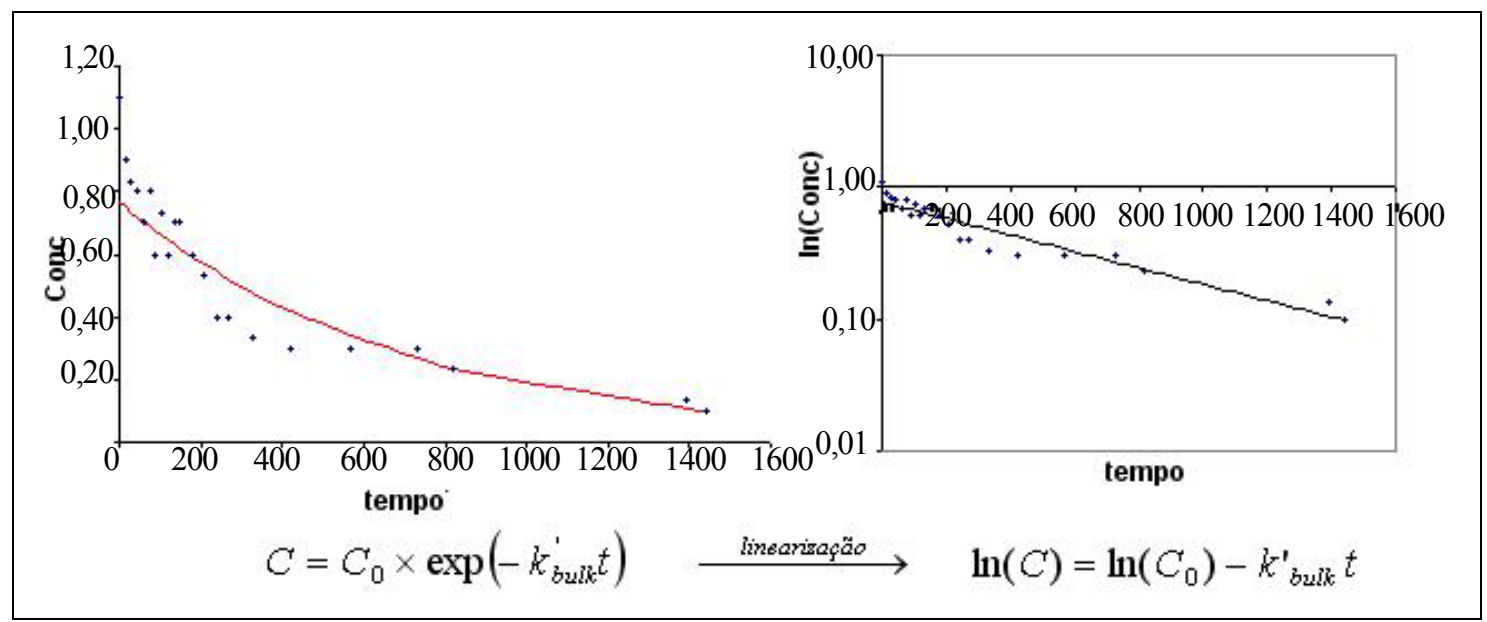

\section{FIGURA 3.13b - Gráfico de linearização}

O método gráfico utiliza o procedimento citado por Rossman (2000), no qual se assume que a reação seja de primeira ordem, sendo possível representar graficamente os valores de $\log (\mathrm{Ct} / \mathrm{C} 0)$ em função do tempo, sendo $\mathrm{Ct}$ a concentração no instante t e $\mathrm{C} 0$ a concentração no instante inicial. Deste modo, obtém-se uma reta, sendo o valor de $\mathrm{K}_{\text {bulk }}$ estimado a partir da sua declividade.

\subsubsection{Monitoramento de vazão e pressão}

Uma vez definido o setor a ser calibrado, iniciou-se o planejamento da campanha de campo. A aferição dos medidores de pressão e os testes dos medidores de vazão foram realizados antes da instalação dos aparelhos no campo. Foram utilizados medidores de pressão da METROLOG - Technolog modelo P

Para a aferição dos 7 medidores de pressão contou-se com o auxílio do técnico e professor responsável pelo Laboratório de Mecânica dos Solos do Departamento de Geotecnia 
da EESC - USP. Foi utilizado um aferidor de pressão ligado em série com um manômetro simples e o medidor de pressão. Foram então aplicadas pressões controladas eletronicamente pelo aferidor de pressão e realizadas as leitura de pressão, simultaneamente, nos 3 aparelhos ligados em série: aferidor, manômetro e medidor de pressão. As leituras online do medidor de pressão só podem ser feitas através do notebook a ele conectado e com uso do software PMAC Lite.

A partir dessas leituras, foram construídas curvas de calibração dos aparelhos que, quando analisadas, demonstraram que os medidores de pressão estão em perfeito estado de uso. As figuras 3.14, 3.15 e 3.16 mostram a correspondência das leituras realizadas entre os aparelhos.

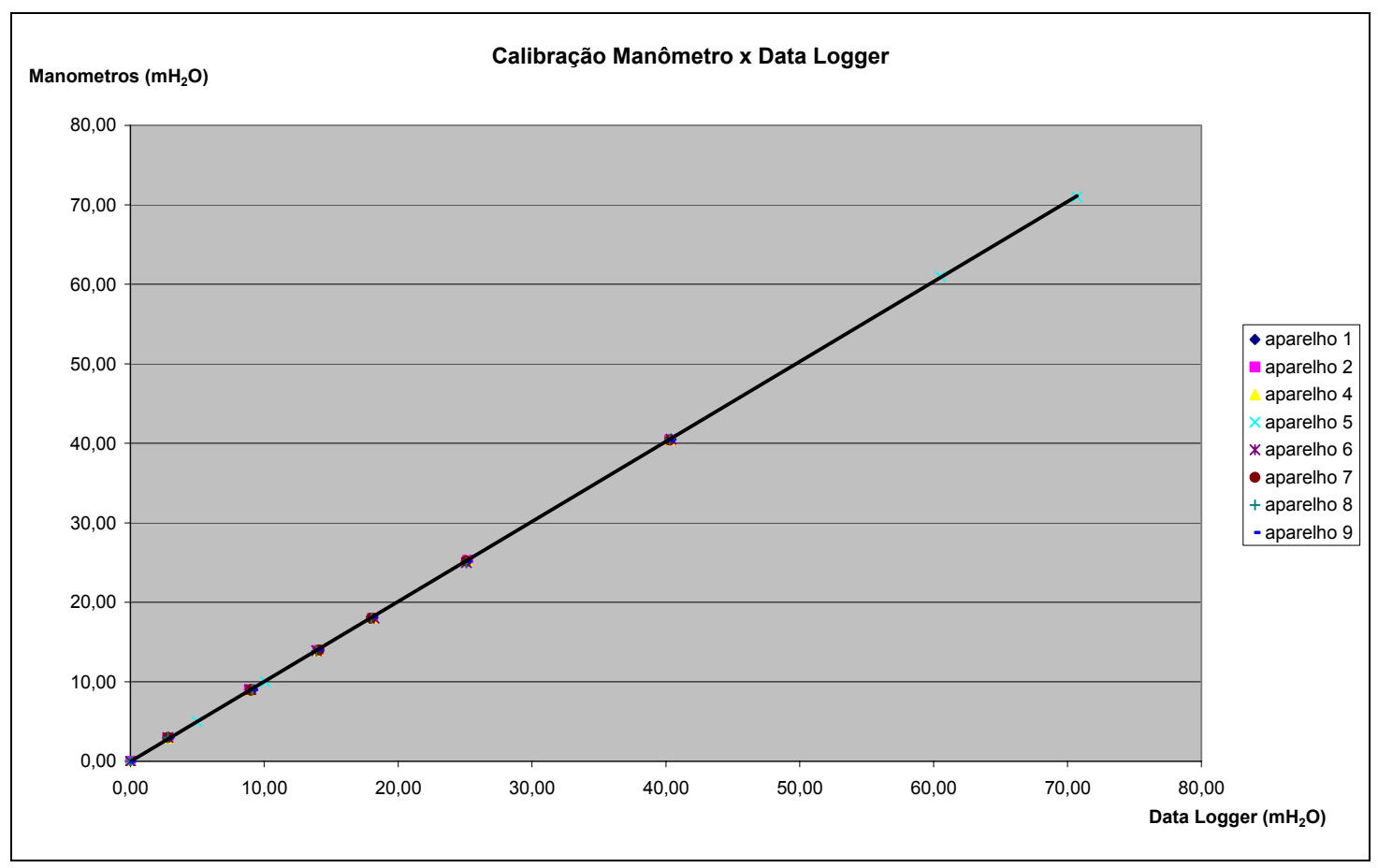

FIGURA 3.14 - Curva de Calibração do manômetro x Data Logger 


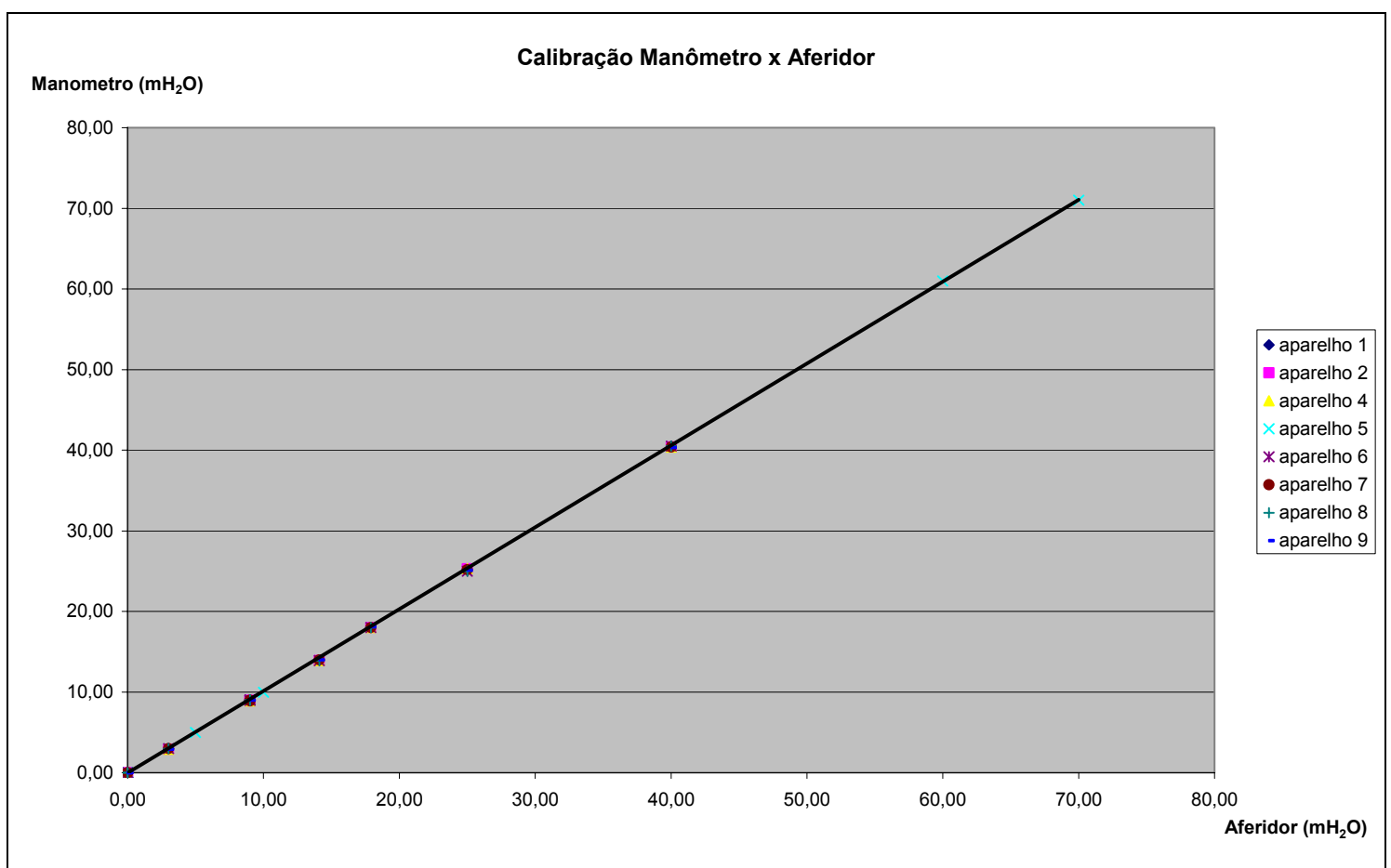

FIGURA 3.15 - Curva de Calibração do manômetro x Aferidor de pressão

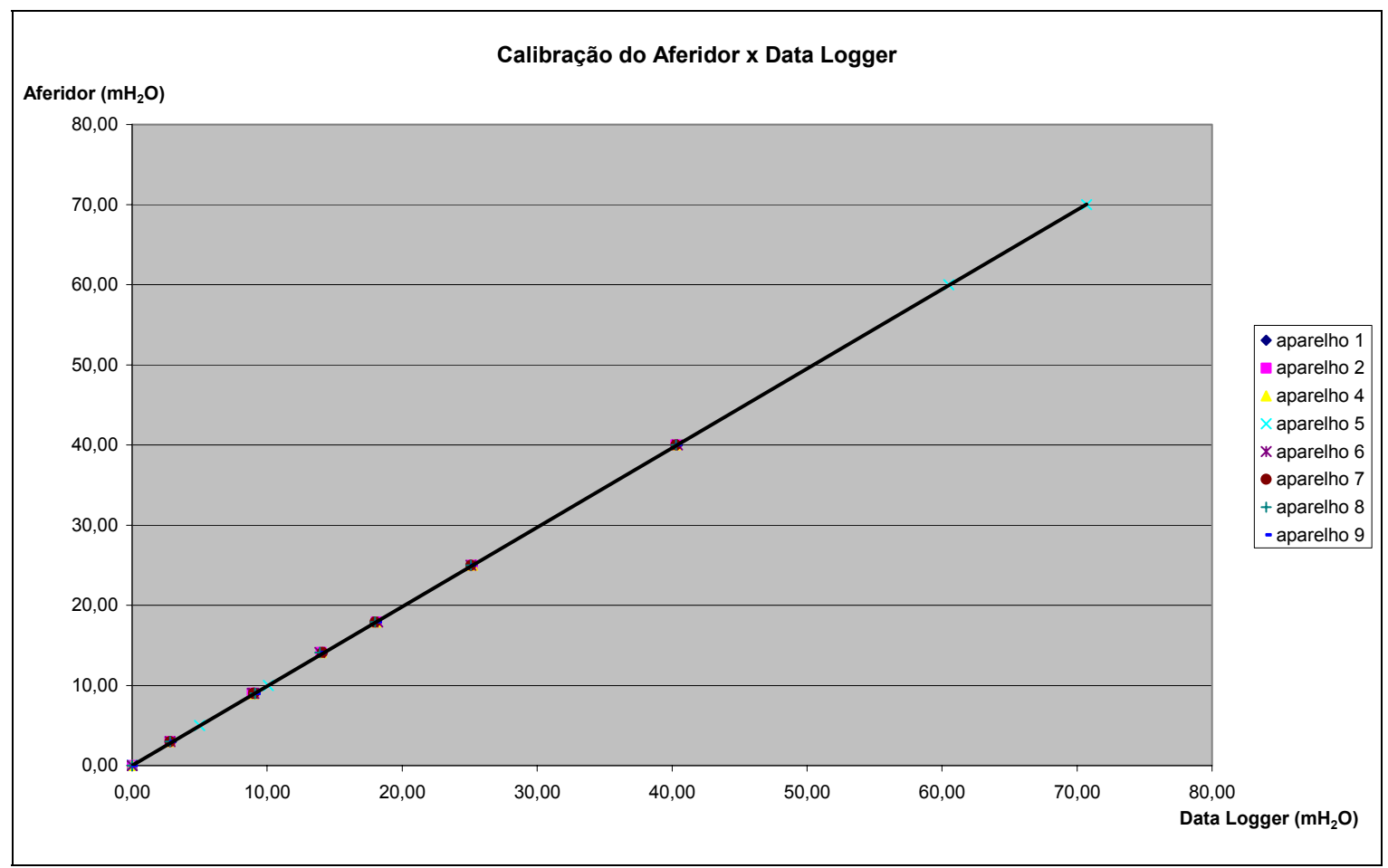

FIGURA 3.16 - Curva de Calibração do aferidor x Data Logger 
A vazão destinada ao reservatório Ipanema foi medida através do tubo pitot acoplado a maleta para medição de parâmetros hidráulicos (modelo MDH 600 do fabricante Lamon), trazida pelo grupo de pesquisa de Campo Grande - MS - Brasil.

A maleta Lamon (modelo MDH-600-300A) é desenvolvida com seu respectivo software para gerenciar a medição de vazão e pressão manométrica em redes de água através da pitometria.

\subsubsection{Levantamento topográfico}

Devido à divergência entre os dados topográficos do terreno obtidos junto ao SAAE e a prefeitura de São Carlos, para este estudo foi realizado um levantamento topográfico. Diante deste problema, de início foi proposto o levantamento de todos os nós considerados no modelo de simulação, porém isso não foi possível, devido à grande demanda de equipamentos necessários e a necessidade do acompanhamento do técnico do Departamento de Transportes para o uso dos mesmos. Tendo em vista essa limitação, foi proposto então o levantamento topográfico dos pontos de medição de pressão e os pontos vizinhos aos nós da respectiva quadra.

Para economizar o tempo e organizar o trabalho em campo, foi proposto $\mathrm{o}$ levantamento topográfico através de poligonal aberta passando por todos os pontos de interesse.

Para desenvolvimento desse levantamento foi empregada a Estação Total, aparelho capaz de determinar a diferença entre cotas topográficas com a precisão necessária nas leituras. Posteriormente, os dados foram carregados no computador e analisados, servindo para a retificação dos arquivos de entrada do calibrador hidráulico e conseqüentemente do calibrador de qualidade. 


\section{RESULTADOS E DISCUSSÕES}

\subsection{CAMPANHA DE CAMPO}

Com vistas à calibração dos parâmetros do modelo de decaimento de cloro para o setor relativo ao bairro de São Carlos chamado Parque Fehr, foi realizada uma campanha de campo em conjunto com a equipe da Universidade Federal de Mato Grosso do Sul no dia 22/06/2007 com duração de 24 horas.

Durante a campanha, foram realizadas medições simultâneas de cloro livre, pressão e vazão durante 24 horas em pontos estrategicamente determinados do sistema.

A rede de distribuição de água é apresentada de modo esquemático na Figura 4.1, em que as linhas azuis mais claras representam as tubulações em PVC Defofo (PVC rígido de diâmetro equivalente ao ferro fundido), com diâmetros de 110 e 85 milímetros; e as linhas mais escuras são as tubulações em PVC com diâmetro de 60 milímetros.

Durante o dia 20 de junho de 2007, foi realizada visita técnica ao setor para o levantamento das instalações físicas existentes, ocasião em que se verificaram as seguintes informações.

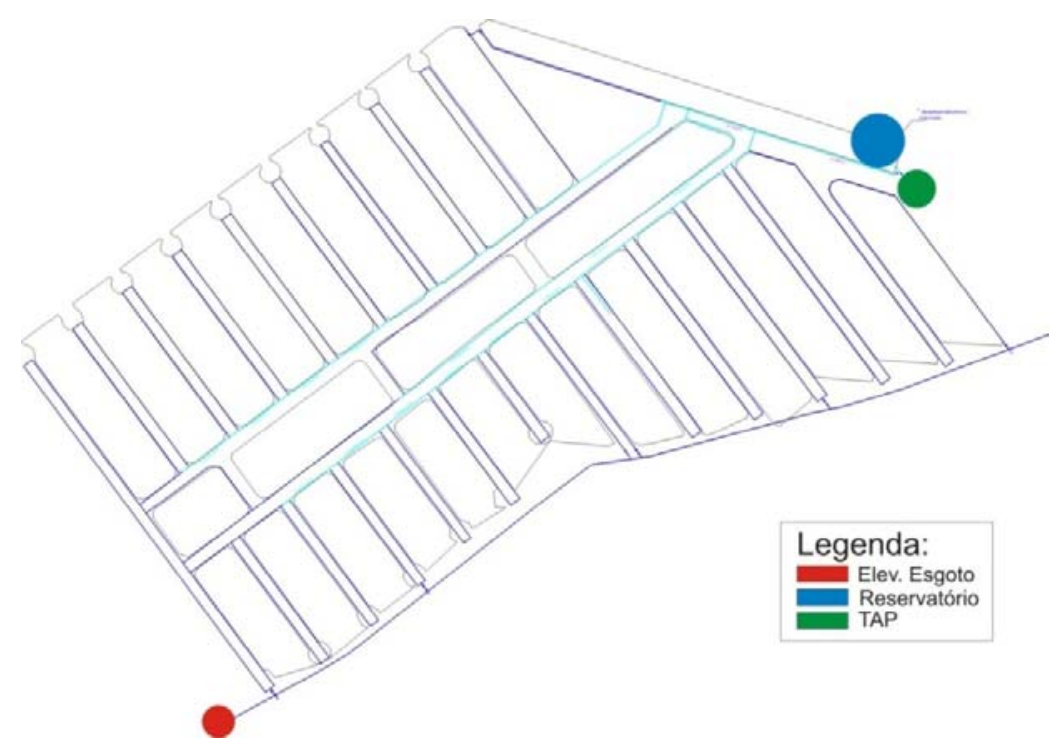

FIGURA 4.1 - Rede de distribuição de água e instalações 
Um reservatório elevado abastece o setor. A captação da água é subterrânea (poço profundo) e o tratamento realizado é do tipo simplificado, contanto com os processos de fluoretação, desinfecção e correção do pH. Parte da água do reservatório abastece o bairro vizinho (Jardim Ipanema). Nas imediações do reservatório está presente o poço/bomba (ponto de captação) e o reservatório elevado juntamente com as instalações necessárias para realizar o tratamento simplificado da água, conforme mostrado anteriormente na Figura 3.3.

O período considerado para a aquisição de dados para a calibração teve duração de 24 horas com início às 17h00min do dia 22 de junho de 2007 (sexta-feira).

\subsubsection{Monitoramento simultâneo da Vazão de entrada}

Devido a característica própria do sistema, para o qual não é possível determinar diretamente a vazão fornecida ao Parque Fehr, foi instalado um tubo de pitot acoplado a maleta para medição de parâmetros hidráulicos na linha que abastece o reservatório do Jardim Ipanema, imediatamente após a derivação para abastecimento do setor em estudo (Figura 4.2). Juntamente com o medidor de vazão, foi também instalado um medidor de pressão em outro TAP do mesmo tubo. Dessa forma, foi possível determinar a vazão que abastece o Jardim Ipanema e o nível aproximado do reservatório do Parque Fehr.

A maleta para medição de parâmetros hidráulicos foi programada para fazer medidas instantâneas em intervalos de 5 em 5 minutos, sendo os dados armazenados no próprio aparelho e depois transferidos para um computador. 


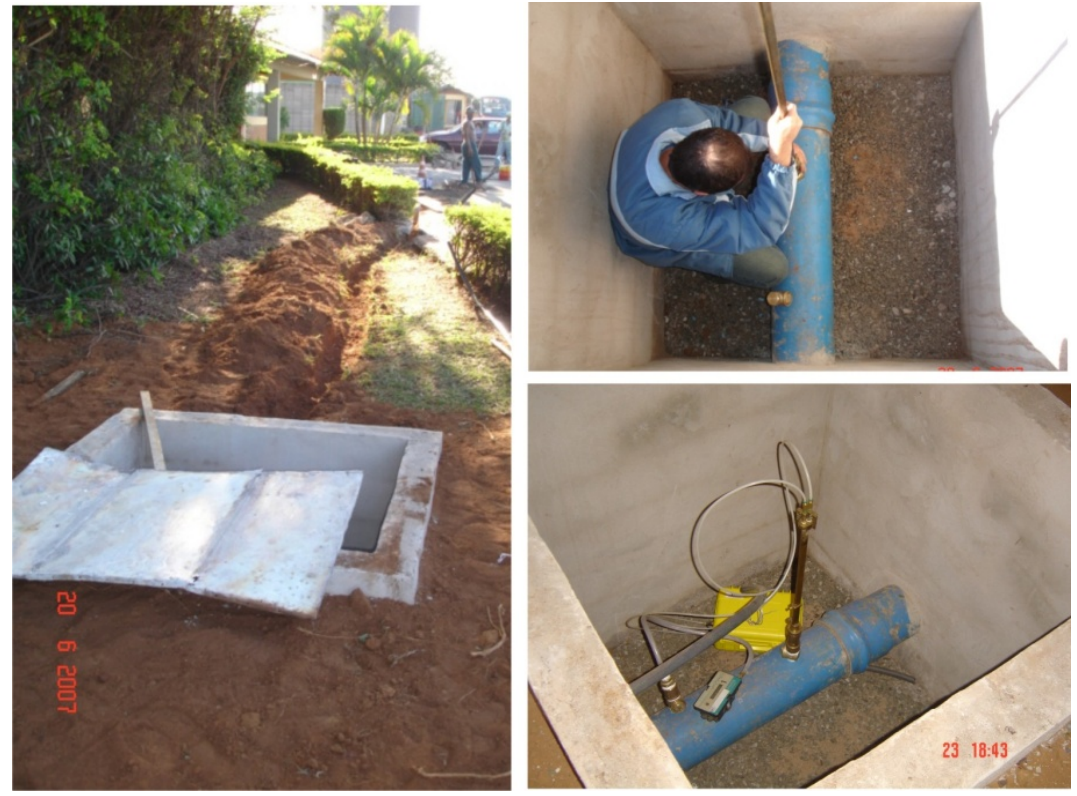

FIGURA 4.2 - Pontos de Medição de Vazão e Pressão

O resultado deste monitoramento é mostrado na Figura 4.3, onde são grafados os valores instantâneos de pressões e vazões, registrados durante o referido período, representados pelas linhas mais clara e mais escura, respectivamente.

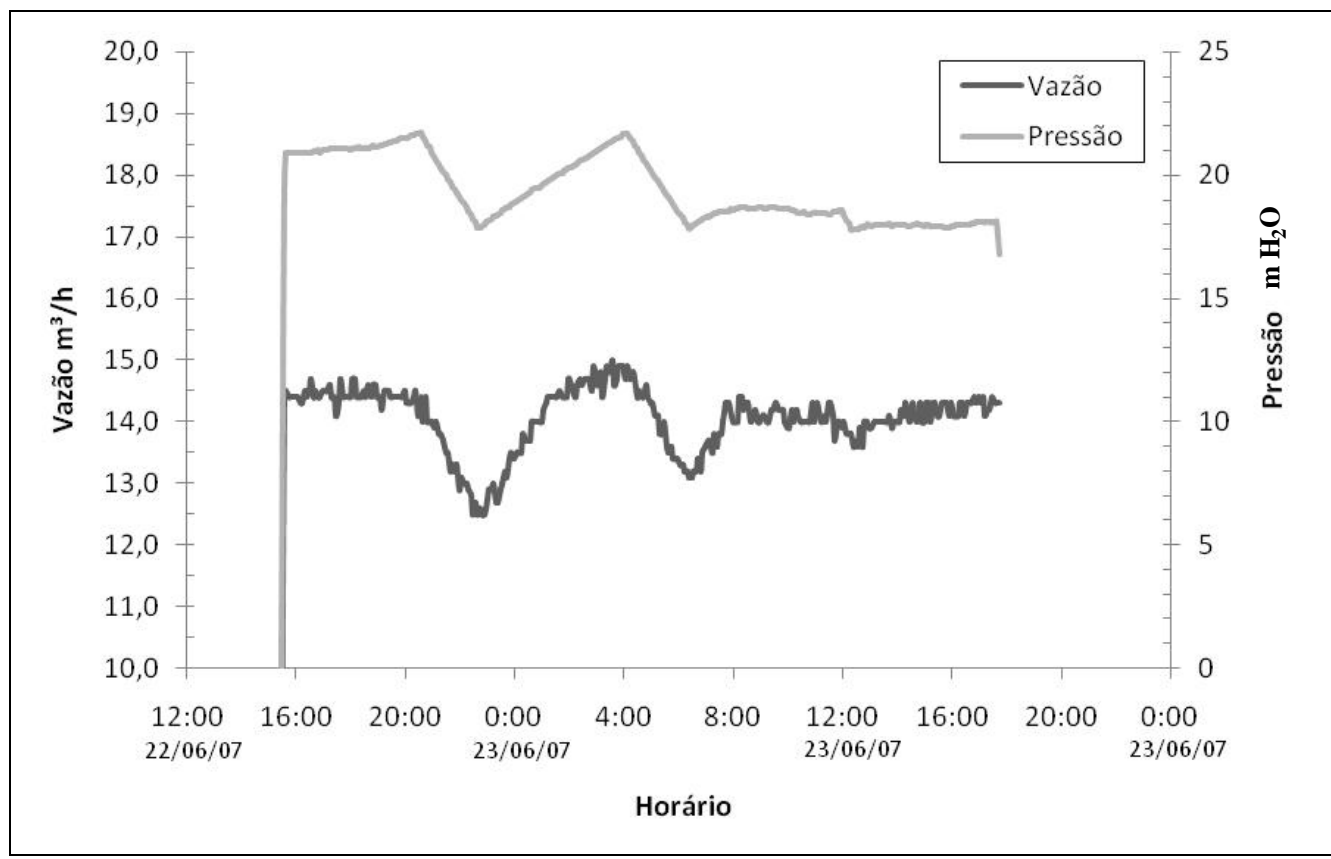

FIGURA 4.3 - Gráfico de Vazão e Pressão medidos no tubo que abastece o reservatório do Jardim Ipanema 
Durante o período de monitoramento houve desligamentos e acionamentos da bomba de recalque do poço para o reservatório. Tais manobras da bomba são perceptíveis na Figura 4.3, onde por volta das 20:36 horas do dia 22/06/2007 nota-se que há o desligamento da bomba que voltou a funcionar às 22:42 horas do mesmo dia. Posteriormente, pelo fato da bomba estar ligada na madrugada e não haver consumo residencial neste período, o reservatório atingiu facilmente seu volume máximo e a bomba voltou a ser desligada por volta das 4:09 horas do dia 23/06/2007, retornando a ser ligada por volta das 6:24 horas da manhã do dia 23/06/2007, pois o reservatório havia atingido o seu volume mínimo.

Os dados simultâneos da vazão de saída do reservatório, obtidos pelo medidor de vazão do tipo hélice da empresa de saneamento, foram obtidos posteriormente. Na Tabela 4.1 estão apresentados os valores monitorados da vazão de saída do reservatório durante o período considerado.

TABELA 4.1 - Vazão monitorada na saída do reservatório

\begin{tabular}{|c|c|c|}
\hline Dia & Horário & \begin{tabular}{|c|}
$\begin{array}{c}\text { Vazão Total } \\
\text { (L/s) }\end{array}$
\end{tabular} \\
\hline \multirow{7}{*}{$\begin{array}{c}22 / 6 / 2007 \\
\text { (sexta-feira) }\end{array}$} & 17h00min & 19,17 \\
\hline & 18h00min & 18,33 \\
\hline & 19h00min & 17,22 \\
\hline & $20 \mathrm{~h} 00 \mathrm{~min}$ & 15,00 \\
\hline & $21 \mathrm{~h} 00 \mathrm{~min}$ & 14,17 \\
\hline & $22 \mathrm{~h} 00 \mathrm{~min}$ & 14,17 \\
\hline & 23h00min & 14,17 \\
\hline \multirow{17}{*}{$\begin{array}{c}\text { 23/6/2007 } \\
\text { (sábado) }\end{array}$} & 00h00min & 14,17 \\
\hline & 01h00min & 14,44 \\
\hline & 02h00min & 14,72 \\
\hline & $03 \mathrm{~h} 00 \mathrm{~min}$ & 14,72 \\
\hline & 04h00min & 14,44 \\
\hline & 05h00min & 13,61 \\
\hline & 06h00min & 13,61 \\
\hline & 07h00min & 15,83 \\
\hline & 08h00min & 18,89 \\
\hline & 09h00min & 21,39 \\
\hline & 10h00min & 21,94 \\
\hline & $11 \mathrm{~h} 00 \mathrm{~min}$ & 20,28 \\
\hline & 12h00min & 18,89 \\
\hline & 13h00min & 19,44 \\
\hline & 14h00min & 20,00 \\
\hline & 15h00min & 21,11 \\
\hline & 16h00min & 9.17 \\
\hline
\end{tabular}


Os valores da Tabela 4.1 são os valores médios de cada hora do dia, esta simplificação foi feita, visto que o software usado pelo SAAE - São Carlos, que recebe as informações de vazão, só divulga os resultados para cada hora do dia, impossibilitando leituras de vazões em minutos. Desta forma, as leituras de vazão realizadas no tubo que abastece o Jardim Ipanema também foram transformadas em médias para cada hora do dia. A Tabela 4.2 mostra os valores da vazão de abastecimento de cada sistema e a vazão total de cada hora.

A curva de consumo do dia da aquisição de dados foi considerada válida, uma vez que o comportamento da vazão, ao longo do dia, foi semelhante ao esperado para uma rede de distribuição predominantemente residencial. Os valores foram baixos na madrugada e maiores durante o horário comercial, com picos às 10 horas da sexta feira (22/6/2007) e às 15 horas do sábado(23/6/2007).

TABELA 4.2 - Vazões de cada sistema de distribuição abastecido pelo reservatório

\begin{tabular}{|c|c|c|c|c|}
\hline Dia & Horário & $\begin{array}{l}\text { Vazão Total } \\
\text { (L/s) }\end{array}$ & $\begin{array}{c}\text { Vazão do } \\
\text { Jardim } \\
\text { Ipanema }(\mathrm{L} / \mathrm{s})\end{array}$ & $\begin{array}{l}\text { Vazão do } \\
\text { Parque } \\
\text { Fehr (L/s) }\end{array}$ \\
\hline \multirow{7}{*}{$\begin{array}{c}22 / 6 / 2007 \\
\text { (sexta-feira) }\end{array}$} & $17 \mathrm{~h} 00 \mathrm{~min}$ & 19,17 & 14,43 & 4,74 \\
\hline & 18h00min & 18,33 & 14,51 & 3,83 \\
\hline & 19h00min & 17,22 & 14,42 & 2,81 \\
\hline & $20 \mathrm{~h} 00 \mathrm{~min}$ & 15,00 & 14,23 & 0,78 \\
\hline & $21 \mathrm{~h} 00 \mathrm{~min}$ & 14,17 & 13,51 & 0,66 \\
\hline & $22 \mathrm{~h} 00 \mathrm{~min}$ & 14,17 & 12,73 & 1,44 \\
\hline & 23h00min & 14,17 & 13,06 & 1,11 \\
\hline \multirow{17}{*}{$\begin{array}{c}\text { 23/6/2007 } \\
\text { (sábado) }\end{array}$} & 00h00min & 14,17 & 13,78 & 0,38 \\
\hline & 01h00min & 14,44 & 14,41 & 0,04 \\
\hline & 02h00min & 15,00 & 14,77 & 0,23 \\
\hline & 03h00min & 14,72 & 14,57 & 0,16 \\
\hline & 04h00min & 14,44 & 13,75 & 0,69 \\
\hline & 05h00min & 13,89 & 13,75 & 0,14 \\
\hline & 06h00min & 13,61 & 13,28 & 0,34 \\
\hline & 07h00min & 15,83 & 13,89 & 1,94 \\
\hline & 08h00min & 18,89 & 14,16 & 4,73 \\
\hline & 09h00min & 21,39 & 14,12 & 7,27 \\
\hline & 10h00min & 21,94 & 14,06 & 7,89 \\
\hline & $11 \mathrm{~h} 00 \mathrm{~min}$ & 20,28 & 14,08 & 6,20 \\
\hline & $12 \mathrm{~h} 00 \mathrm{~min}$ & 18,89 & 13,81 & 5,08 \\
\hline & 13h00min & 19,44 & 13,99 & 5,45 \\
\hline & 14h00min & 20,00 & 14,12 & 5,88 \\
\hline & 15h00min & 21,11 & 14,23 & 6,89 \\
\hline & 16h00min & 20,56 & 14,25 & 6,31 \\
\hline
\end{tabular}




\subsubsection{Levantamento topográfico}

Como dito anteriormente, foi escolhida uma poligonal aberta para o levantamento topográfico, onde os pontos amarelos indicam a instalação da estação total para medição dos demais pontos (Figura 4.4). Os pontos verdes indicam os locais onde foram instalados os medidores de pressão, os pontos vermelhos são visadas da estação total nas esquinas das quadras e, por fim, os pontos azuis são os nós nos quais foram transferidas as medições de pressão, com o indicativo da diferença entre cotas do ponto de instalação do medidor de pressão e seu respectivo nó de transferência.

Na Figura 4.4 é possível ver todos os pontos que foram contemplados no levantamento topográfico.

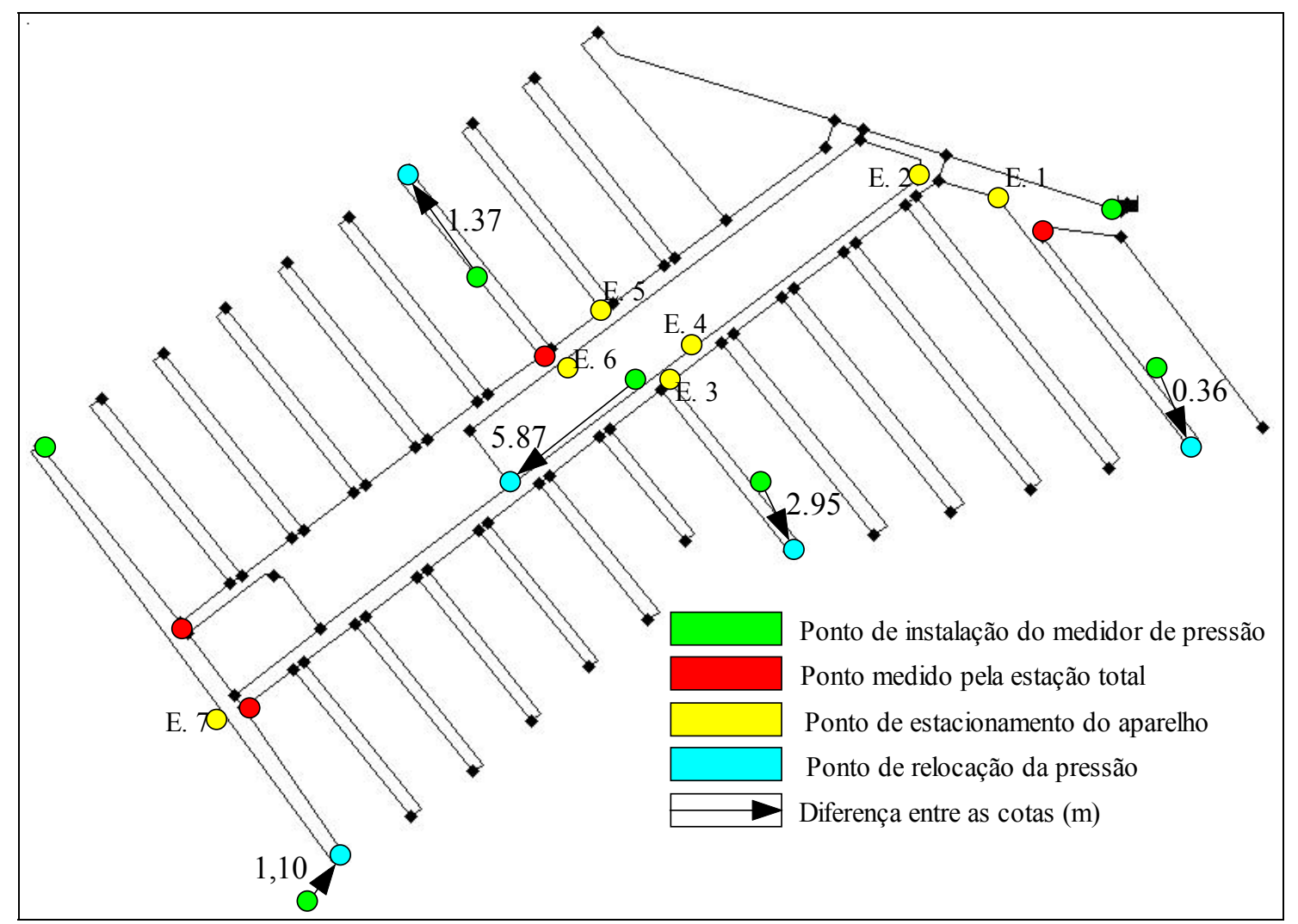

FIGURA 4.4 - Pontos nos quais realizou-se o levantamento topográfico 
No primeiro estacionamento da estação total (E.1) foram levantados os pontos:

- Reservatório.

- Nó 3 da rede que é esquina da Rua Mautílio Bruno.

- Aparelho instalado Rua Mautílio Bruno.

- O final da Rua Mautílio Bruno, para onde foi transferida a leitura do medidor de pressão.

- Sendo a última visada do aparelho feita no próximo estacionamento da estação total (E.2).

No segundo estacionamento da estação total (E.2) foram levantados os pontos:

- A leitura de ré no ponto E.1.

- A leitura de vante na esquina da Rua Antonio Genoveze, que também foi o ponto próximo do estacionamento da estação total.

No terceiro estacionamento da estação total (E.3) os pontos de visada foram:

- A leitura de ré no ponto E.2.

- O ponto de instalação do aparelho de pressão na Rua Antonio Genoveze.

- O final da Rua Antonio Genoveze para onde foi realocado as medições de pressões.

- A esquina da Rua Vitório Possa, que também foi o próximo ponto de estacionamento da estação total (E.4).

- O ponto de instalação do aparelho na Rua João Crnkovic.

- O nó 80 da rede para onde foi realocado o aparelho instalado na Rua João Crnkovic.

- O final da Rua João Crnkovic onde também foi o estacionada a estação total (E.7). 
No quarto estacionamento da estação total (E.4) os pontos de visada foram:

- A leitura de ré no ponto E.3.

- O ponto do próximo estacionamento (E.5).

No quinto estacionamento da estação total (E.5) foram levantados os pontos:

- A leitura de ré no ponto E.4.

- O ponto do próximo estacionamento (E.6).

No sexto estacionamento (E.6) foram visados os pontos:

- Da esquina da Rua Sebastião Conte.

- $\quad$ O ponto de medição do aparelho de pressão.

- O final da Rua Sebastião Conte, para onde foi realocado a medição de pressão do aparelho instalado nesta rua.

No último estacionamento (E.7) os pontos alvos foram:

- A leitura de ré no ponto E.3.

- A esquina da Rua Ernane Stefane com a Rua João Crnkovic.

- A esquina da Rua Ernane Stefane com a Carmem Aparecida Garcia.

- Os Extremos na Rua Ernane Stefane.

- O ponto de instalação do aparelho de pressão na Estação Elevatório de Esgoto.

A Tabela 4.6 mostra os valores das leituras realizadas com a estação total para todos os pontos levantados. 
TABELA 4.3 - Resultados do levantamento topográfico

\begin{tabular}{|c|c|}
\hline $\begin{array}{c}\text { Ponto } \\
\text { levantado }\end{array}$ & $\begin{array}{c}\text { Cota } \\
\text { topográfica }\end{array}$ \\
\hline nó 83 & 861,40 \\
\hline nó 5 & 861,40 \\
\hline P.2 & 861,00 \\
\hline nó 4 & 859,80 \\
\hline E.1 (nó 3) & 862,20 \\
\hline E.2 (nó 8) & 862,80 \\
\hline E.3 (nó 23) & 854,80 \\
\hline P.3 & 852,10 \\
\hline nó 22 & 849,10 \\
\hline E.4 & 865,20 \\
\hline E.5 (nó 68) & 857,80 \\
\hline E.6 & 854,80 \\
\hline nó 65 & 854,90 \\
\hline P.4 & 856,10 \\
\hline nó 66 & 857,50 \\
\hline P.5 & 855,00 \\
\hline nó 80 & 849,10 \\
\hline E.7 & 839,20 \\
\hline P.6 (nó 42) & 839,30 \\
\hline nó 45 & 842,80 \\
\hline nó 44 & 845,40 \\
\hline nó 43 & 828,90 \\
\hline P.7 & 827,80 \\
\hline
\end{tabular}

\subsubsection{Monitoramento da Pressão em pontos da rede}

Para o monitoramento de pressão em pontos da rede foram disponibilizados sete medidores de pressão, com o propósito de medir a carga hidráulica em cada ponto de medição. Todos foram programados para registrar medições de 3 em 3 minutos, armazenando os valores no próprio aparelho para depois serem transferidos para o computador.

Inicialmente foi proposto que os medidores fossem instalados diretamente na rede de distribuição de água e nas proximidades dos nós da rede, ou seja, esquinas das quadras do condomínio. Seguindo esse critério, foram escolhidos três pontos de descarga de ponta de rede do sistema de distribuição do Parque Fehr. No entanto, somente uma foi usada, as outras duas não foram aproveitadas, devido à presença de vazamentos no tubo de descarga em uma 
das pontas e a impossibilidade de acesso ao registro da descarga por falta de limpeza da caixa do registro, em outra.

Em substituição ao plano inicialmente proposto, novos pontos foram determinados tendo como critério de escolha razões como: difícil acesso de pessoas não autorizadas, representatividade do plano piezométrico da rede e mínima interferência de consumo.

Com base nesses critérios foram escolhidos os seguintes pontos (destacados na Figura 4.5) :

- a tubulação que liga o reservatório à saída da tubulação que vai para o Reservatório Ipanema, dentro da caixa recém construída pelo SAAE-São Carlos (P.1);

- na Rua Mautilio Bruno, onde existia um hidrômetro abandonado (P.2);

- na Rua Antônio Genoveze, em uma construção paralisada, em que existia outro hidrômetro abandonado (P.3);

- na Rua Sebastião Conti, em outro hidrômetro abandonado (P.4);

- na Avenida João Crnkovic, em uma construção paralisada (P.5); e

- dois pontos nas extremidades da Rua Ernane Stefane, um na parte alta da rua em um hidrômetro de uma construção paralisada no final da quadra (P.6) e outro na parte baixa, no ponto de descarga da rede (elevatória de esgoto, P.7).

Com esses sete medidores de pressão, foi possível obter um bom número de pontos observados em relação à pressão, já que o calibrador hidráulico exige pontos representativos de pressão nos nós.

A distribuição dos aparelhos para medir a pressão em pontos da rede pode ser observada na Figura 4.5, onde são apresentados todos os aparelhos medidores de pressão instalados em suas respectivas localizações. 


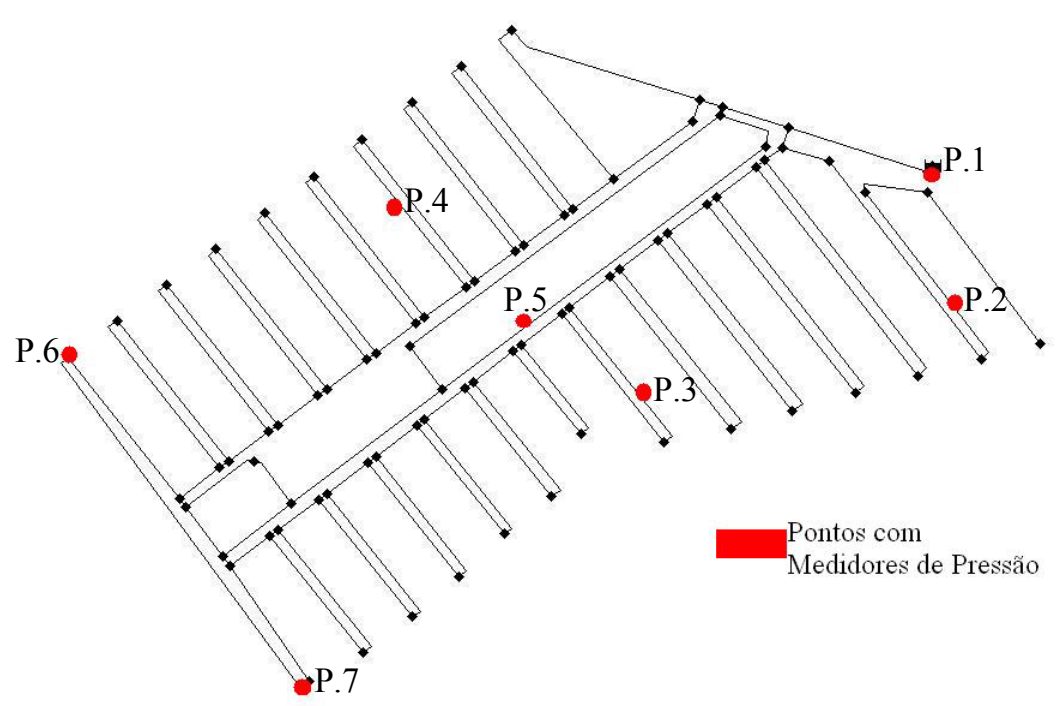

FIGURA 4.5 - Pontos onde foram instalados os medidores de pressão

Conforme discutido anteriormente, o calibrador hidráulico realiza comparações de valores de pressões apenas em nós de rede. Como pôde ser visto na Figura 4.5, alguns aparelhos não foram instalados em nós de rede. Para solucionar e simplificar o problema, foi somada ou subtraída a diferença entre as cotas do ponto medido e o nó mais próximo da medição, desta forma, foi possível considerar a medição como uma aproximação do valor observado para o nó mais próximo.

Com as informações do levantamento topográfico dos pontos significativos para a calibração hidráulica, tais como: pontos correspondentes aos cruzamentos de rua em que foram instalados os aparelhos medidores de pressão, pontos onde foram instalados os aparelhos e o ponto de medição do reservatório; foi possível realizar a transferência das medições de pressões para os nós. Assim, os pontos foram levantados a fim de se obter, com uma maior precisão, as diferenças de cotas entre eles. Um projeto de levantamento topográfico, que priorizava fornecer informação suficiente ao calibrador hidráulico sobre as cotas dos pontos de pressão medidos e possibilitar a transferência dos pontos medidos para os nós da rede, foi desenvolvido Feita a transferência dos pontos medidos na rede, foi possível utilizar o calibrador hidráulico. A Figura 4.6 mostra como ficaram os pontos medidos depois da transferência. 


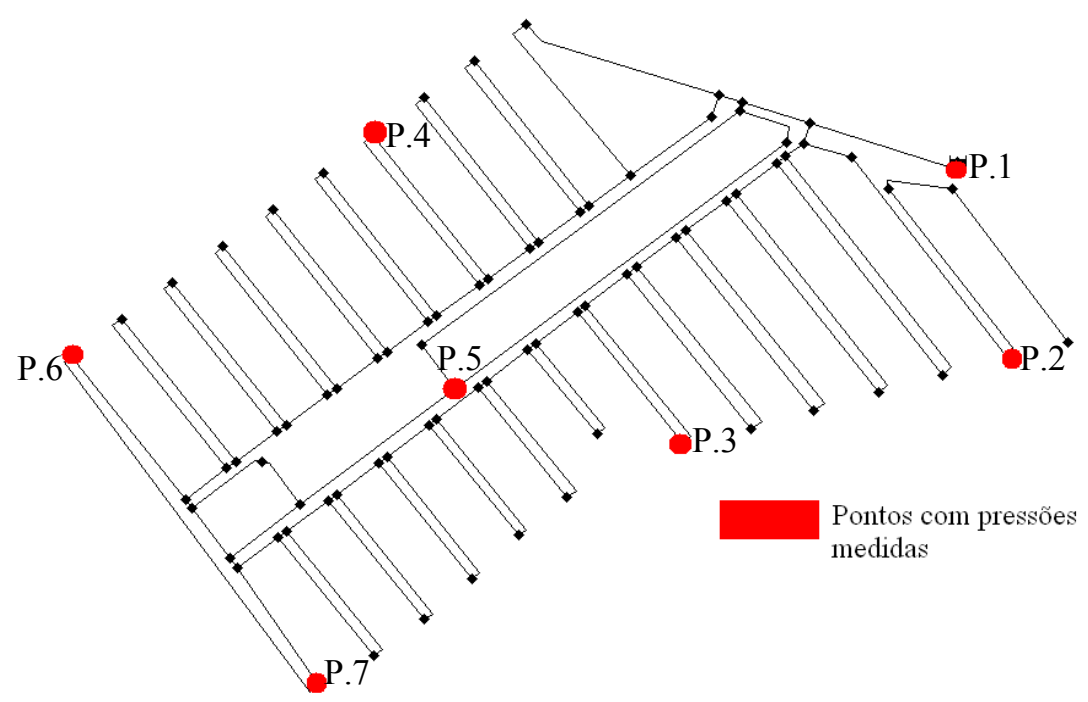

FIGURA 4.6 - Pontos considerados com pressões medidas

A Figura 4.7 mostra o comportamento das pressões, de todos os aparelhos instalados na rede, e do nível do reservatório. Esse comportamento é posterior a transferência das medições ao nós.

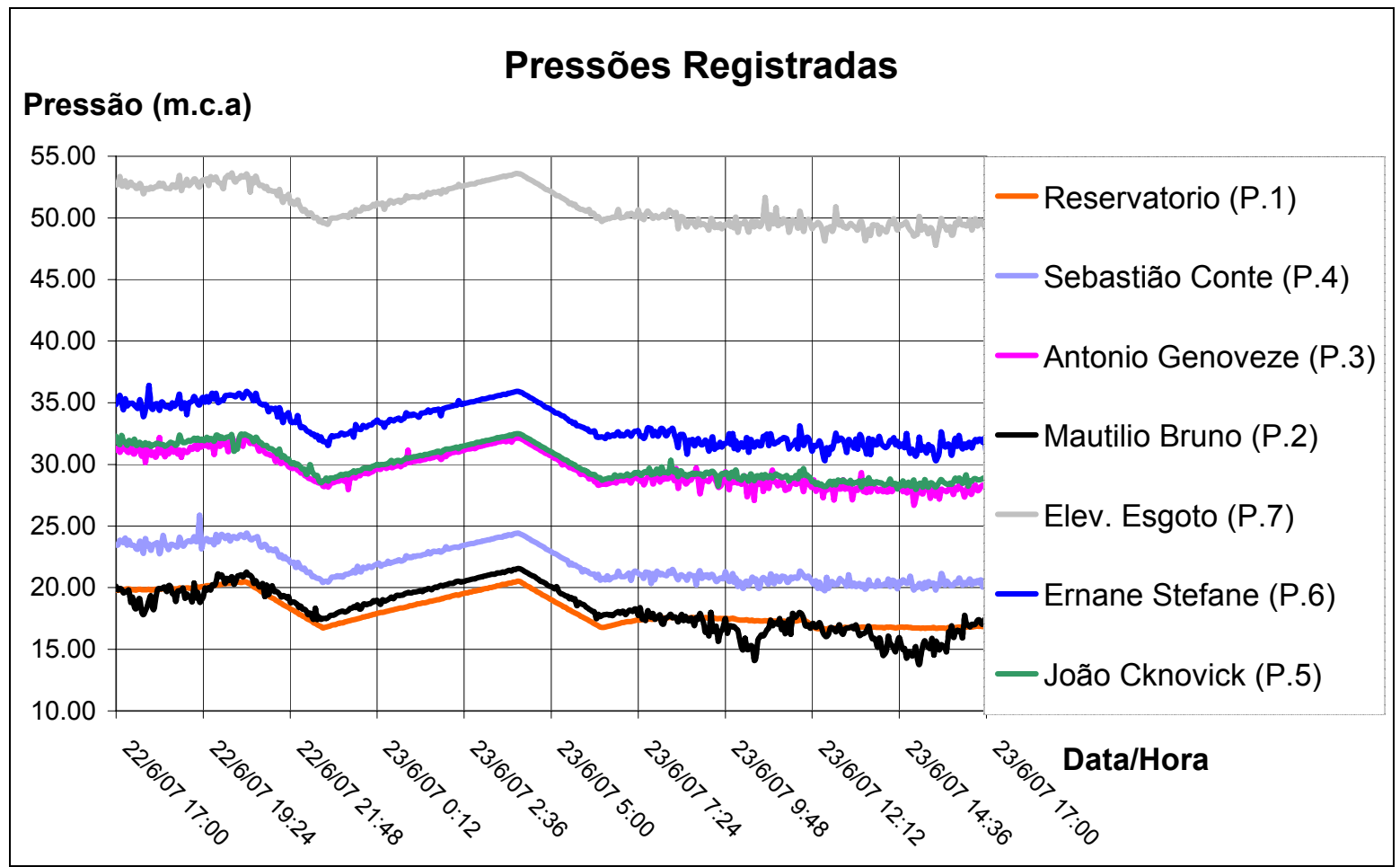

FIGURA 4.7 - Comportamento das pressões nos nós considerados 
Na Figura 4.7 pode se observar um comportamento semelhante registrado por todos os aparelhos, com pequenas oscilações em curtos períodos, bem como as manobras de desligamento e acionamento de bomba. No intervalo de tempo em que há manobras de desligamento e acionamento de bomba, não é possível se adquirir informações para a calibração hidráulica, pois o calibrador hidráulico somente calibra situações operacionais em que o nível do reservatório é relativamente constante durante um período de tempo (SOARES, 2003).

A Figura 4.8 mostra a enumeração adotada para todos os nós da rede considerada. 


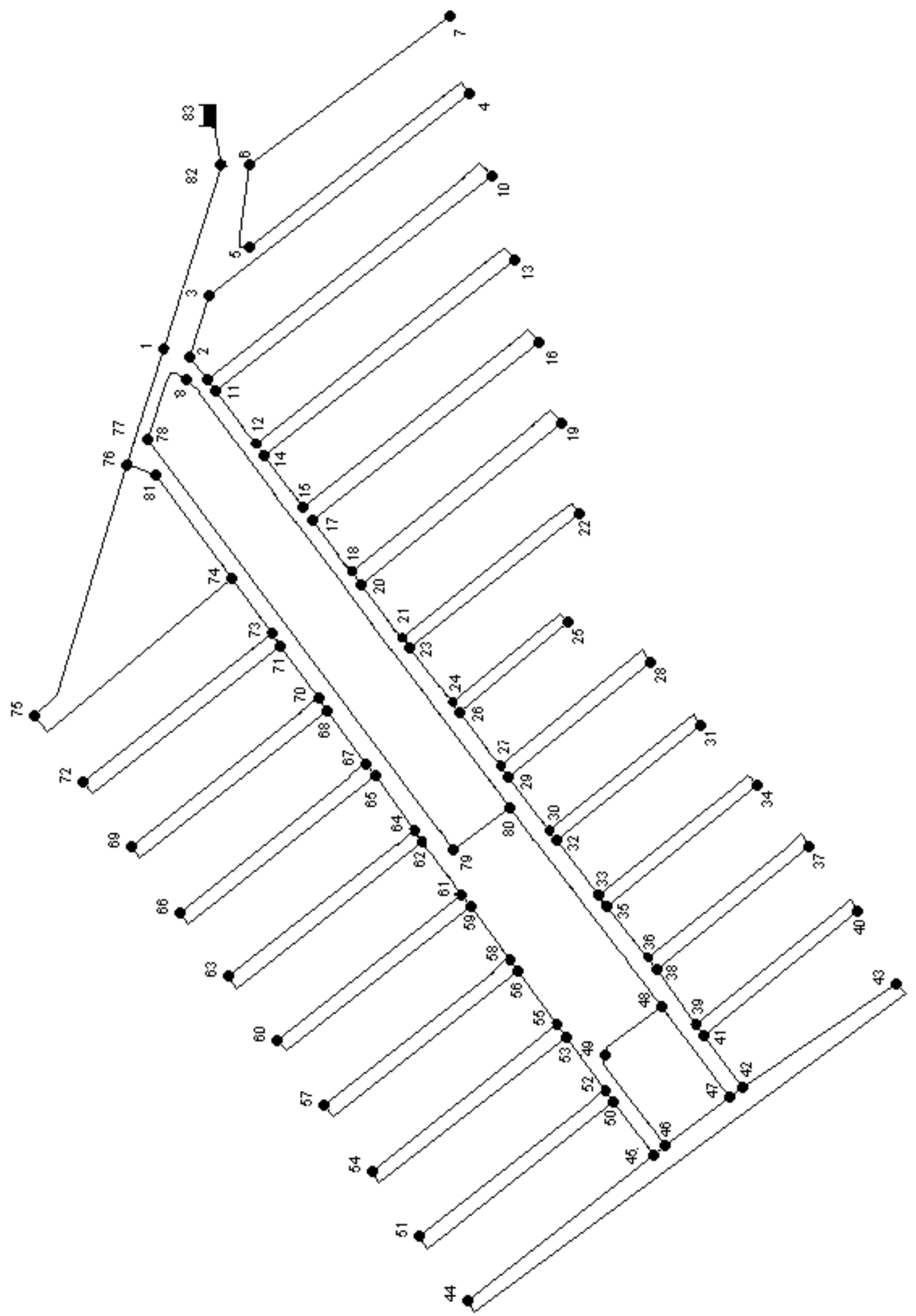

FIGURA 4.8 - Enumeração de todos os nós da rede do parque Fehr 
Na Tabela 4.3 são apresentados os valores das pressões médias horárias para todos os nós monitorados conforme o esquema da Figura 4.6.

TABELA 4.4 - Pressão dos nós para cada hora do dia

\begin{tabular}{|c|c|c|c|c|c|c|c|c|}
\hline \multirow{2}{*}{ Dia } & \multirow{2}{*}{ Horário } & \multicolumn{7}{|c|}{ Pressões nos nós $\left(\mathrm{mH}_{2} \mathrm{O}\right)$} \\
\hline & & $83(P .1)$ & 66 (P.4) & 22 (P.3) & 4 (P.2) & $43(P .7)$ & 44 (P.6) & 80 (P.5) \\
\hline \multirow{7}{*}{$\begin{array}{c}22 / 6 / 2007 \\
\text { (sexta-feira) }\end{array}$} & $17: 00$ & 19,85 & 23,51 & 31,12 & 19,10 & 53,69 & 34,92 & 31,78 \\
\hline & $18: 00$ & 19,90 & 23,49 & 31,05 & 19,56 & 53,72 & 34,79 & 31,72 \\
\hline & 19:00 & 20,13 & 23,96 & 31,51 & 19,90 & 54,01 & 35,25 & 32,06 \\
\hline & $20: 00$ & 20,29 & 24,07 & 31,75 & 20,71 & 54,26 & 35,55 & 32,06 \\
\hline & $21: 00$ & 18,86 & 22,70 & 30,40 & 19,47 & 53,01 & 34,18 & 30,88 \\
\hline & $22: 00$ & 17,23 & 21,03 & 28,76 & 17,87 & 51,29 & 32,48 & 29,21 \\
\hline & $23: 00$ & 17,35 & 21,23 & 28,91 & 18,26 & 51,46 & 32,67 & 29,32 \\
\hline \multirow{17}{*}{$\begin{array}{c}\text { 23/6/2007 } \\
\text { (sábado) }\end{array}$} & $0: 00$ & 18,09 & 21,98 & 29,74 & 19,07 & 52,27 & 33,48 & 30,09 \\
\hline & $1: 00$ & 18,77 & 22,70 & 30,44 & 19,81 & 52,95 & 34,17 & 30,77 \\
\hline & $2: 00$ & 19,45 & 23,36 & 31,04 & 20,47 & 53,63 & 34,87 & 31,43 \\
\hline & $3: 00$ & 20,12 & 24,03 & 31,74 & 21,14 & 54,31 & 35,53 & 32,11 \\
\hline & $4: 00$ & 19,89 & 23,80 & 31,52 & 20,94 & 54,08 & 35,30 & 31,88 \\
\hline & $5: 00$ & 18,25 & 22,11 & 29,85 & 19,25 & 52,39 & 33,62 & 30,22 \\
\hline & $6: 00$ & 17,02 & 20,93 & 28,60 & 17,91 & 51,22 & 32,42 & 29,01 \\
\hline & $7: 00$ & 17,37 & 21,03 & 28,80 & 17,88 & 51,30 & 32,52 & 29,29 \\
\hline & $8: 00$ & 17,55 & 21,02 & 28,86 & 17,47 & 51,05 & 32,23 & 29,37 \\
\hline & 9:00 & 17,53 & 20,83 & 28,67 & 16,90 & 50,54 & 31,72 & 29,17 \\
\hline & $10: 00$ & 17,36 & 20,48 & 28,36 & 15,73 & 50,72 & 31,76 & 29,00 \\
\hline & 11:00 & 17,30 & 20,79 & 28,46 & 17,24 & 50,74 & 31,89 & 29,05 \\
\hline & $12: 00$ & 16,81 & 20,39 & 28,09 & 16,72 & 50,48 & 31,56 & 28,58 \\
\hline & $13: 00$ & 16,79 & 20,28 & 28,08 & 16,43 & 50,31 & 31,66 & 28,56 \\
\hline & $14: 00$ & 16,78 & 20,40 & 28,00 & 15,13 & 50,38 & 31,66 & 28,42 \\
\hline & $15: 00$ & 16,73 & 20,28 & 27,76 & 15,12 & 50,13 & 31,28 & 28,42 \\
\hline & $16: 00$ & 16,82 & 20,40 & 28,01 & 16,88 & 50,48 & 31,64 & 28,71 \\
\hline
\end{tabular}

Como a calibração hidráulica é feita através de padrões operacionais que representam determinados intervalos de horários (nos quais o nível do reservatório pode ser considerado constante), neste trabalho, a escolha dos padrões operacionais foi realizada com base na análise da Figura 4.9. Com essa figura, é possível avaliar isoladamente o comportamento do nível do reservatório nas 24 horas. 


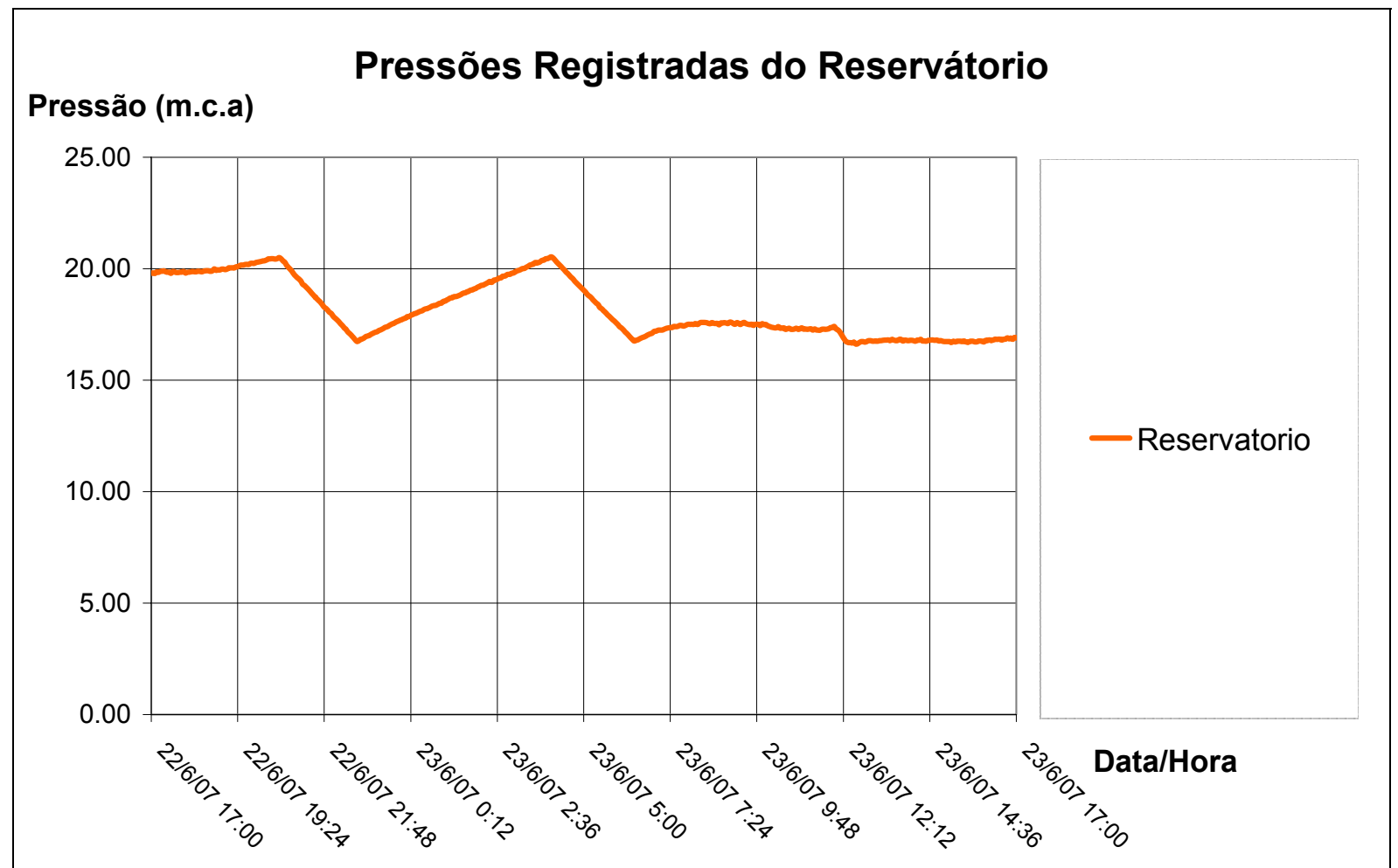

FIGURA 4.9 - Comportamento do nível do reservatório.

Assim, foi possível destacar três padrões operacionais em que o nível do reservatório é aproximadamente constante: o primeiro, para o intervalo das 17:00 às 20:00 do dia 22/06/2007; o segundo, para o intervalo das 8:00 às12:00 do dia 23/06/2007; e o terceiro, e último padrão operacional, para o intervalo das 13:00 às 15:00 do dia 23/06/2007. Porém, para simplificação do problema e redução do tempo de processamento computacional, só foram considerados os dois primeiros padrões operacionais, distintos entre si, retratando dois comportamentos bem diferentes da rede. O terceiro padrão foi excluído, uma vez que apresenta comportamento semelhante ao segundo padrão. A consideração desse terceiro padrão representaria uma informação repetitiva do ponto de vista da calibração hidráulica.

Desta forma, foi possível produzir os valores de entrada para os dois padrões operacionais considerados para a calibração hidráulica, esses valores são representados na Tabela 4.4. 
TABELA 4.5 - Valores das pressões e vazões para os dois padrões

\begin{tabular}{|c|c|c|c|c|c|c|c|c|}
\hline \multirow{2}{*}{$\begin{array}{c}\text { Padrões } \\
\text { Operacionais }\end{array}$} & 4 & 22 & 43 & 44 & 66 & 80 & 83 & \multirow{2}{*}{ Vazão (L/s) } \\
\cline { 2 - 9 } & 19,53 & 31,23 & 53,81 & 35,00 & 23,66 & 31,86 & 19,96 & 2,98 \\
\hline 1 & 16,83 & 28,59 & 50,76 & 31,90 & 20,78 & 29,15 & 17,43 & 6,18 \\
\hline 2 & 18,40 & & & & \\
\hline
\end{tabular}

Para a utilização dessas informações, no calibrador hidráulico, foi realizada a análise preliminar desses dados através da comparação entre os valores das pressões estáticas com as respectivas pressões dinâmicas de cada ponto (Tabela 4.5).

TABELA 4.6 - Comparação entre as pressões dinâmicas e estáticas dos pontos

\begin{tabular}{|c|c|c|c|c|c|c|c|c|}
\hline Padrão & Pontos & $\begin{array}{c}\text { Nível do } \\
\text { reservatório } \\
(\mathrm{m})\end{array}$ & $\begin{array}{c}\text { Cota dos } \\
\text { pontos } \\
(\mathrm{m})\end{array}$ & $\begin{array}{c}\text { Pressão } \\
\text { estática } \\
\left(\mathrm{mH}_{2} \mathrm{O}\right)\end{array}$ & $\begin{array}{c}\text { Pressão } \\
\text { dinâmica } \\
\left(\mathrm{mH}_{2} \mathrm{O}\right)\end{array}$ & Verificação & Valor & Diferença \\
\hline \multirow{6}{*}{1} & 4 & 881,36 & 859,80 & 21,56 & 19,53 & & & 2,03 \\
\cline { 2 - 10 } & 22 & 881,36 & 849,10 & 32,26 & 31,23 & & & 1,03 \\
\cline { 2 - 10 } & 43 & 881,36 & 828,90 & 52,46 & 53,81 & inconsistente & 1,35 & \\
\cline { 2 - 10 } & 44 & 881,36 & 845,40 & 35,96 & 35,00 & & & 0,96 \\
\cline { 2 - 10 } & 66 & 881,36 & 857,50 & 23,86 & 23,66 & & & 0,20 \\
\cline { 2 - 10 } & 80 & 881,36 & 849,10 & 32,26 & 31,86 & & & 0,40 \\
\hline \multirow{4}{*}{2} & 4 & 878,83 & 859,80 & 19,03 & 16,83 & & & 2,20 \\
\cline { 2 - 9 } & 22 & 878,83 & 849,10 & 29,73 & 28,59 & & & 1,14 \\
\cline { 2 - 9 } & 43 & 878,83 & 828,90 & 49,93 & 50,76 & inconsistente & 0,83 & \\
\cline { 2 - 9 } & 44 & 878,83 & 845,40 & 33,43 & 31,90 & & & 1,53 \\
\cline { 2 - 9 } & 66 & 878,83 & 857,50 & 21,33 & 20,78 & & & 0,55 \\
\cline { 2 - 9 } & 80 & 878,83 & 849,10 & 29,73 & 29,15 & & & 0,58 \\
\hline
\end{tabular}

A Tabela 4.5 possibilita a constatação de inconsistência dos valores de pressão dinâmica quando comparados às respectivas pressões estáticas do nó 43 (P.7). Por isso, os valores relativos ao nó 43 foram excluídos do conjunto de dados de entrada para a calibração hidráulica, pois poderiam interferir negativamente na calibração.

Fixada a cota de fundo do reservatório com o valor de 861,4 m (documento do SAAE - São Carlos), as cotas dos demais pontos aferidos por medidores de pressão e vazão foram determinadas através do uso da estação total, que determinou a diferença topográfica entre os pontos aferidos. A Figura 4.10 demonstra a cota de todos os pontos aferidos pela estação total. As cotas topográficas dos demais nós da rede foram obtidos através das informações 
cadastrais fornecidas pelo SAAE - São Carlos que tem como base um levantamento topográfico feito por fotos aéreas da cidade, segundo o qual o reservatório do Parque Fehr também apresenta cota fixa igual 861,4 m.

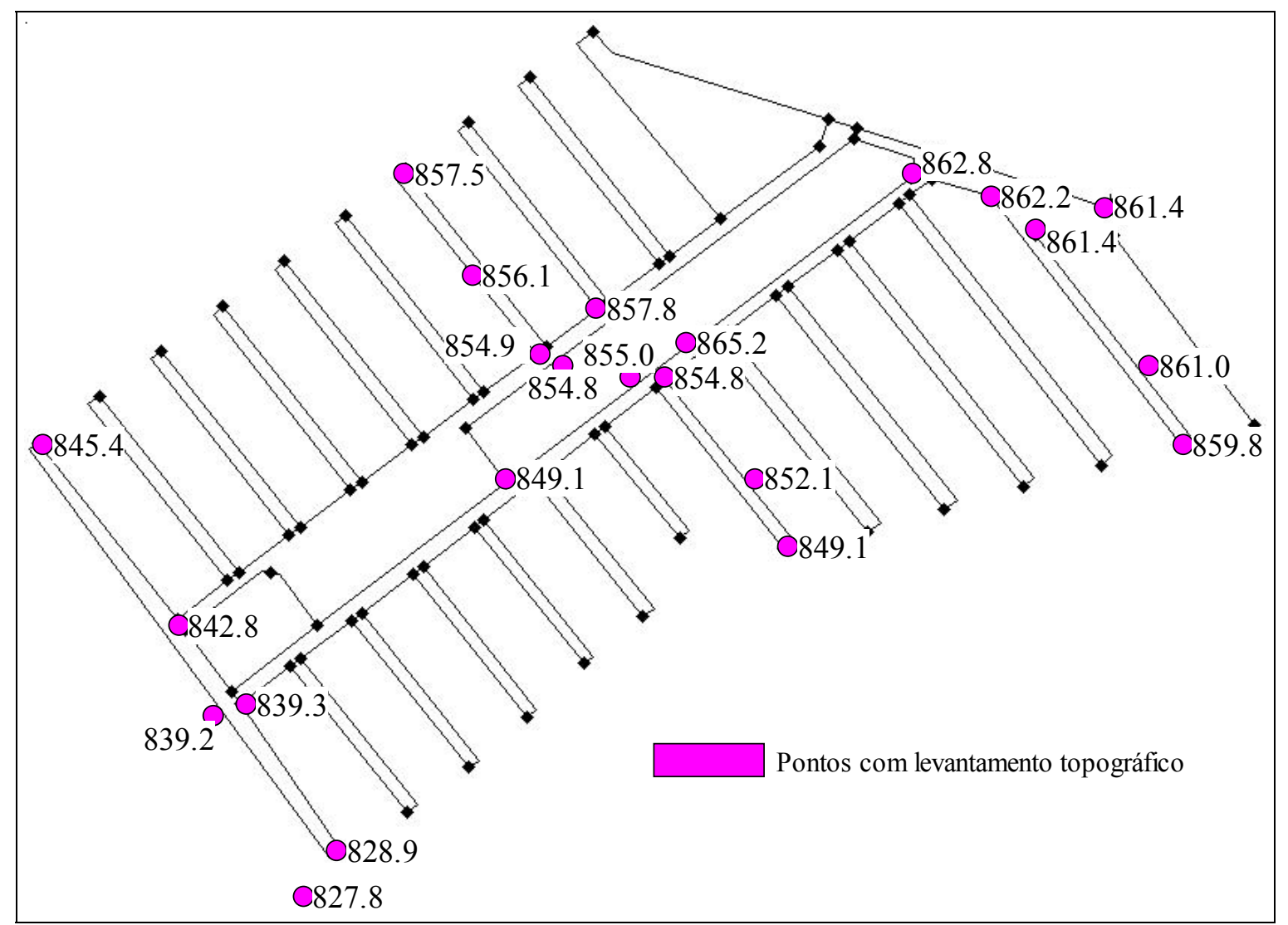

FIGURA 4.10 - Pontos com cotas nos quais realizou-se o levantamento topográfico

\subsubsection{Monitoramento contínuo e simultâneo do cloro residual}

As sondas foram instaladas em dois pontos do sistema de tal modo que fosse possível monitorar o residual de cloro em um ponto na entrada do setor (Ponto 1), e em outro, na extremidade do setor (Ponto 2), próximo à estação elevatório de esgoto existente (Figura 4.11). 


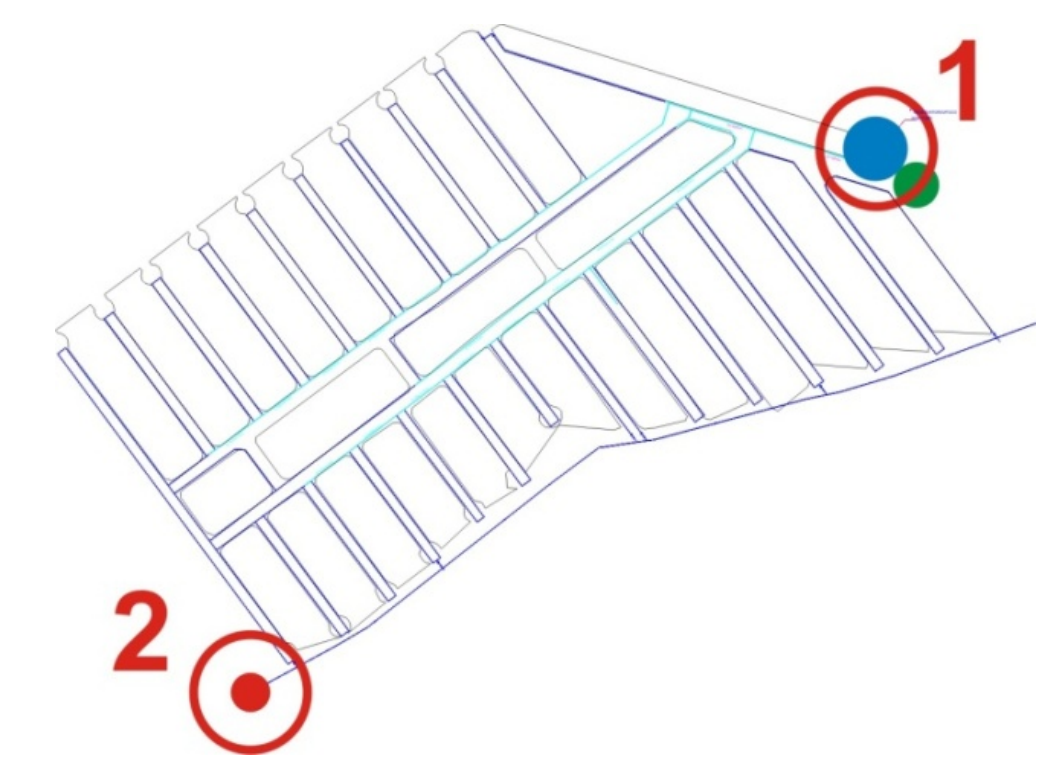

FIGURA 4.11 - Pontos de monitoramento do cloro residual

\section{- Calibração das Sondas}

Como descrito anteriormente, fez-se necessária à calibração dos sensores da sonda. Visto que o setor é abastecido diretamente pelo reservatório, o procedimento de calibração foi realizado com a água da saída do mesmo (Figura 4.12). As sondas foram monitoradas por um período de 3 horas para a ativação do sensor (Figura 4.12), e seus sensores calibrados com o auxílio do colorímetro Hach. Considerando-se a precisão do sensor de cloro, que é de mais ou menos $15 \%$ da leitura realizada ou $0,05 \mathrm{mg} / \mathrm{L}$, depende do que for maior (YSI, 2005), as concentrações determinadas pelas sondas equipararam-se às concentrações determinadas com o colorímetro da Hach. 


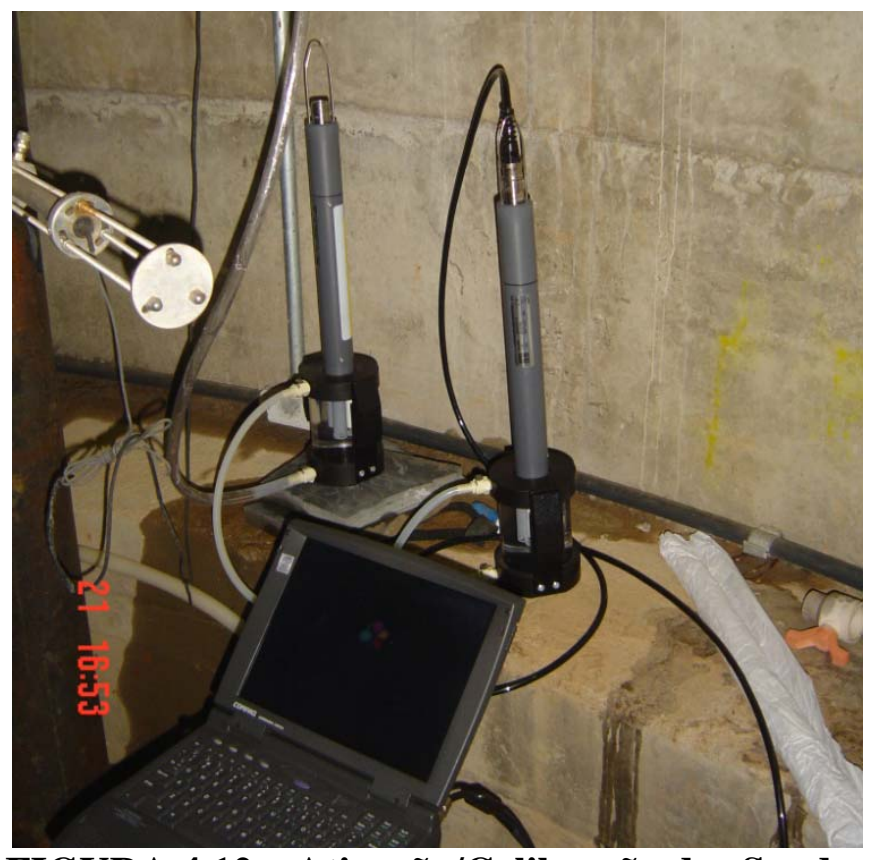

FIGURA 4.12 - Ativação/Calibração das Sondas

\section{- Ponto 1 - Reservatório}

Uma sonda foi instalada na saída do reservatório elevado (entrada do setor), através do colar de tomada já existente (Figura 4.13), e seguido o protocolo de calibração e ativação dos sensores. O controle da vazão foi dificultado, pois, conforme relatado anteriormente, nenhum dispositivo para controle eficiente da vazão foi adotado, a não ser o controle da abertura da torneira. Neste ponto, a sonda foi configurada para monitorar de 5 em 5 minutos os dados de temperatura, $\mathrm{pH}$ e concentração de cloro livre, garantindo um monitoramento contínuo do comportamento do cloro livre no ponto.

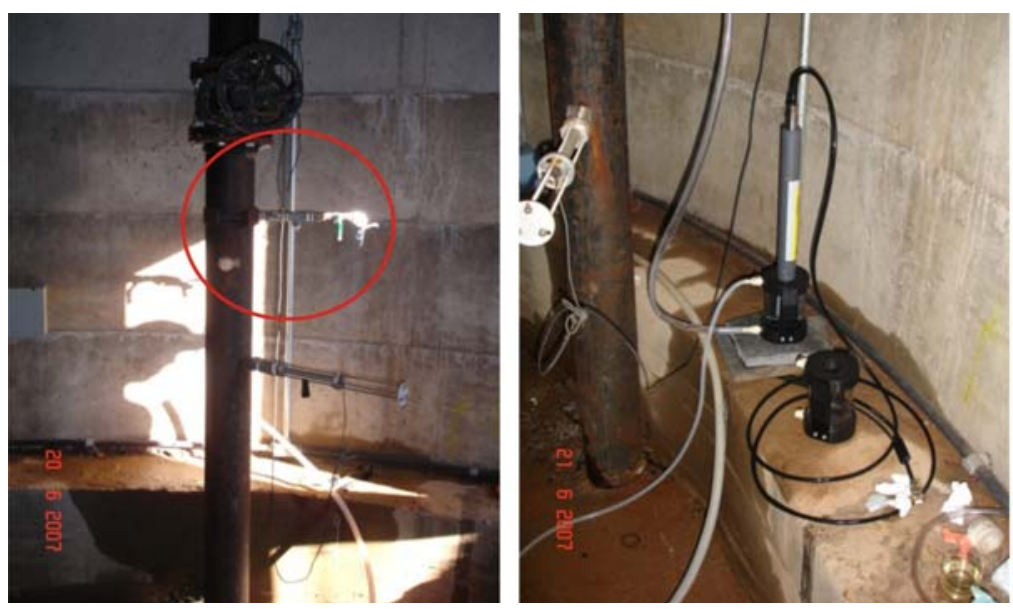

FIGURA 4.13 - Ponto de instalação da sonda (saída do reservatório) 
Na Figura 4.14 são mostrados os resultados do monitoramento. Observa-se uma descontinuidade nestes gráficos no período das 7:45 às 8:15 da manhã, período em que diariamente se efetua a preparação das soluções para o tratamento da água, tornando impraticável o monitoramento dos parâmetros.
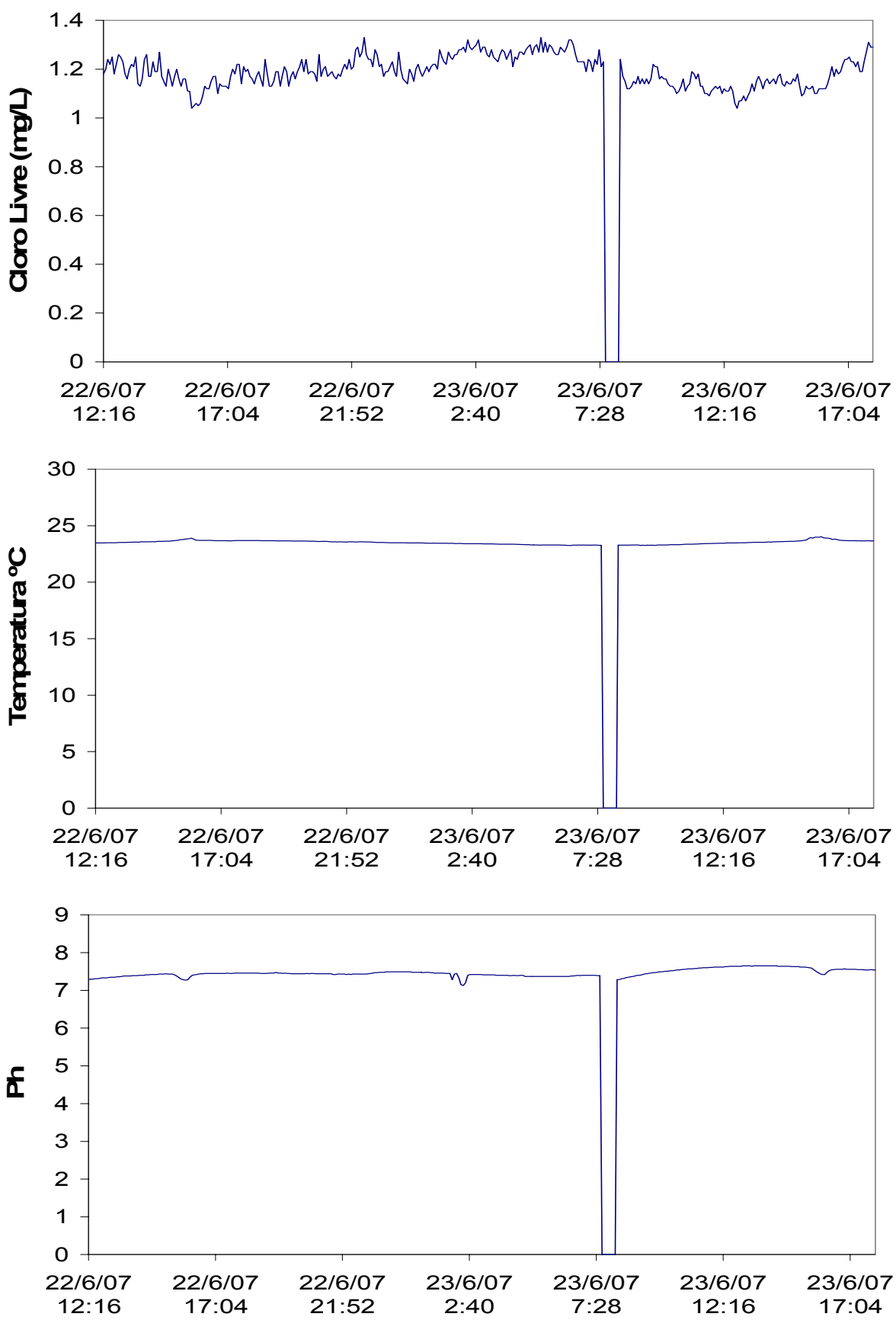

FIGURA 4.14 - Ponto de monitoramento 1 
Para que o EPANET 2.0 realizasse a simulação de qualidade da água, no período estendido e contínuo, foi necessário fornecer a concentração de cloro para cada hora do dia. Isto foi feito, fixando-se uma concentração inicial média do dia e variando este valor para cada hora do dia conforme os multiplicadores do padrão criado para a concentração de cloro (mesmo método adotado para a variação do nível do reservatório). A determinação da concentração média de cloro na entrada do sistema para cada hora do dia está apresentada na Tabela 4.7. Os resultados apresentados na Tabela 4.7 são resultantes da média aritmética de todas as leituras realizadas no intervalo de tempo considerado para cada hora do dia.

\section{TABELA 4.7 - Resultado das concentrações de cloro livre para cada hora do dia}

\begin{tabular}{|c|c|c|c|c|}
\hline \multirow{2}{*}{ Dia } & \multicolumn{2}{|c|}{ Hora } & \multirow{2}{*}{ Padrões } & \multirow{2}{*}{$\begin{array}{l}\text { Concentração do } \\
\text { cloro livre média } \\
(\mathrm{mg} / \mathrm{L})\end{array}$} \\
\hline & Inicio & Termino & & \\
\hline \multirow{7}{*}{$22 / 6 / 2007$} & $17: 00$ & $18: 00$ & 1 & 1,18 \\
\hline & $18: 00$ & 19:00 & 2 & 1,16 \\
\hline & $19: 00$ & $20: 00$ & 3 & 1,18 \\
\hline & $20: 00$ & $21: 00$ & 4 & 1,19 \\
\hline & $21: 00$ & $22: 00$ & 5 & 1,19 \\
\hline & $22: 00$ & $23: 00$ & 6 & 1,26 \\
\hline & $23: 00$ & $00: 00$ & 7 & 1,20 \\
\hline \multirow{17}{*}{ 23/6/2007 } & $00: 00$ & 01:00 & 8 & 1,19 \\
\hline & $01: 00$ & $02: 00$ & 9 & 1,24 \\
\hline & $02: 00$ & $03: 00$ & 10 & 1,29 \\
\hline & $03: 00$ & $04: 00$ & 11 & 1,26 \\
\hline & $04: 00$ & 05:00 & 12 & 1,27 \\
\hline & $05: 00$ & $06: 00$ & 13 & 1,29 \\
\hline & $06: 00$ & $07: 00$ & 14 & 1,27 \\
\hline & $07: 00$ & $08: 00$ & 15 & 1,23 \\
\hline & $08: 00$ & $09: 00$ & 16 & 1,15 \\
\hline & $09: 00$ & $10: 00$ & 17 & 1,17 \\
\hline & $10: 00$ & $11: 00$ & 18 & 1,13 \\
\hline & $11: 00$ & $12: 00$ & 19 & 1,14 \\
\hline & $12: 00$ & 13:00 & 20 & 1,10 \\
\hline & $13: 00$ & 14:00 & 21 & 1,13 \\
\hline & $14: 00$ & $15: 00$ & 22 & 1,20 \\
\hline & $15: 00$ & $16: 00$ & 23 & 1,12 \\
\hline & $16: 00$ & $17: 00$ & 24 & 1,18 \\
\hline
\end{tabular}

\section{- Ponto 2 - Estação Elevatória de Esgoto}

O ponto 2 de monitoramento do residual de cloro localiza-se em uma das extremidades da rede (ponta de rede), próximo à estação elevatório de esgoto. A sonda foi ligada diretamente a um terminal de descarga de rede existente nas proximidades da entrada 
da estação elevatória de esgoto (Figura 4.15), sendo calibrada com o auxílio do clororímetro de bolso e sua vazão controlada manualmente, neste ponto foi configurada para registrar de 5 em 5 minutos os dados de temperatura, pH e concentração de cloro livre, garantindo um monitoramento contínuo do comportamento do cloro livre no ponto.

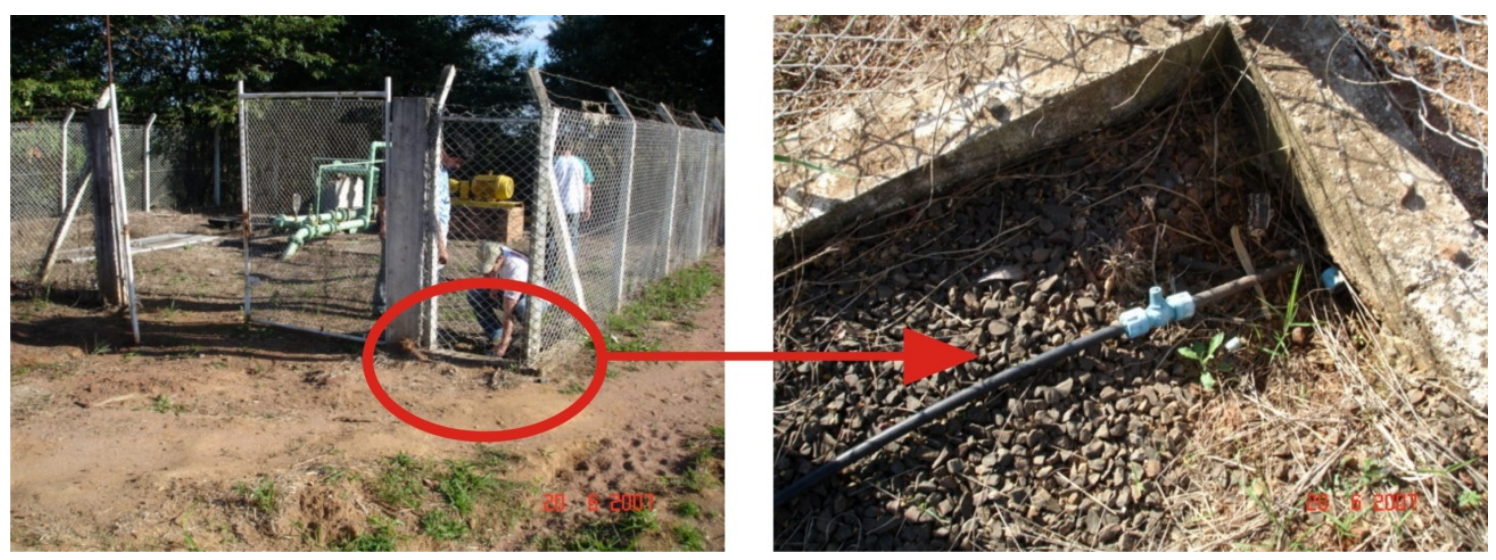

FIGURA 4.15 - Ponto de monitoramento 2

A Figura 4.16 mostra o local da instalação da sonda. O resultado do monitoramento neste ponto é mostrado na Figura 4.17. Pode-se observar que não houve variações significativas tanto no cloro residual, quanto no $\mathrm{pH}$ e na temperatura. Fato que pode ser justificado pelo fato da idade da rede de distribuição existente ser relativamente nova e a qualidade da água de abastecimento, de origem subterrânea, excelente.

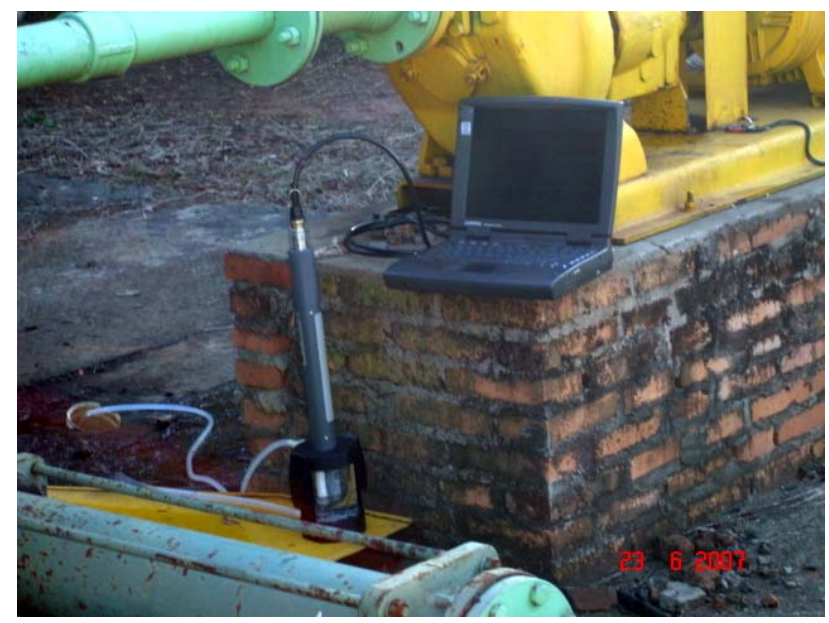

FIGURA 4.16 - Local de instalação da sonda 

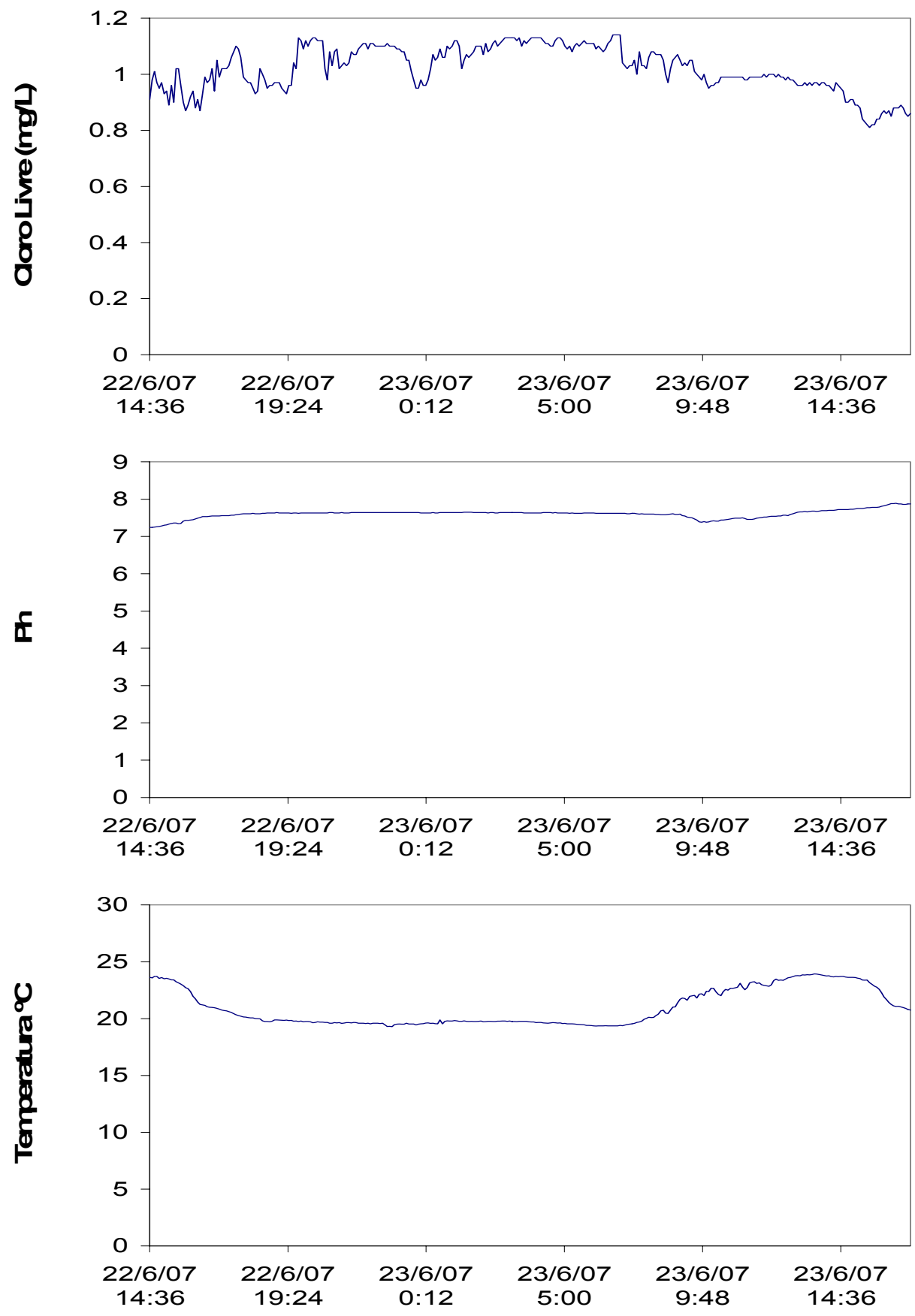

FIGURA 4.17 - Ponto de Monitoramento 2 (Estação Elevatória de Esgoto)

Como dito anteriormente, o calibrador de qualidade do sistema de distribuição considera concentrações de determinadas horas do dia, sendo assim a Tabela 4.8 mostra as concentrações médias para cada hora do dia. Os valores apresentados na Tabela 4.8 são as médias aritméticas de todas as leituras realizadas no intervalo de tempo considerado para cada hora do dia. 
TABELA 4.8 - Resultado das concentrações de cloro livre para cada hora do dia-Ponto 2

\begin{tabular}{|c|c|c|c|c|}
\hline \multirow{2}{*}{ Dia } & \multicolumn{2}{|c|}{ Hora } & \multirow{2}{*}{ Padrões } & \multirow{2}{*}{$\begin{array}{l}\text { Concentração do } \\
\text { cloro livre média } \\
(\mathrm{mg} / \mathrm{L})\end{array}$} \\
\hline & Início & Término & & \\
\hline \multirow{7}{*}{$22 / 6 / 2007$} & $17: 00$ & $18: 00$ & 1 & 0,96 \\
\hline & 18:00 & 19:00 & 2 & 0,97 \\
\hline & $19: 00$ & $20: 00$ & 3 & 1,01 \\
\hline & $20: 00$ & $21: 00$ & 4 & 1,09 \\
\hline & $21: 00$ & $22: 00$ & 5 & 1,06 \\
\hline & $22: 00$ & $23: 00$ & 6 & 1,10 \\
\hline & $23: 00$ & 00:00 & 7 & 1,04 \\
\hline \multirow{17}{*}{$23 / 6 / 2007$} & $00: 00$ & 01:00 & 8 & 1,03 \\
\hline & $01: 00$ & 02:00 & 9 & 1,08 \\
\hline & $02: 00$ & 03:00 & 10 & 1,10 \\
\hline & 03:00 & 04:00 & 11 & 1,12 \\
\hline & 04:00 & 05:00 & 12 & 1,12 \\
\hline & $05: 00$ & 06:00 & 13 & 1,10 \\
\hline & $06: 00$ & 07:00 & 14 & 1,11 \\
\hline & $07: 00$ & 08:00 & 15 & 1,04 \\
\hline & 08:00 & 09:00 & 16 & 1,04 \\
\hline & 09:00 & $10: 00$ & 17 & 1,02 \\
\hline & $10: 00$ & 11:00 & 18 & 0,98 \\
\hline & $11: 00$ & $12: 00$ & 19 & 0,99 \\
\hline & $12: 00$ & 13:00 & 20 & 0,99 \\
\hline & $13: 00$ & $14: 00$ & 21 & 0,97 \\
\hline & $14: 00$ & $15: 00$ & 22 & 0,94 \\
\hline & $15: 00$ & 16:00 & 23 & 0,95 \\
\hline & $16: 00$ & $17: 00$ & 24 & 0,96 \\
\hline
\end{tabular}

\subsection{CALIBRAÇÃO DOS PARÂMETROS DOS AGs}

Os parâmetros dos AGs foram estabelecidos através de um procedimento de busca de maneira a possibilitar o desempenho máximo. O PSO é então utilizado como método de otimização dos parâmetros dos AGs. Para tanto, é necessário estabelecer o tipo e os operadores de AGs a serem empregados, bem como a fixar os parâmetros para o PSO. As opções adotadas neste trabalho constam da Tabela 4.9.

Foi aplicada uma modificação no PSO original, que consiste na transformação da constante " $a$ " da equação 2.40 como uma função linearmente decrescente das gerações (iterações). Com essa modificação, a velocidade de convergência foi acelerada, diminuindo a 
influência da velocidade anterior de cada solução e aumentando a influência das melhores posições alcançadas individualmente e pelo grupo.

$$
a=w-i \cdot b
$$

TABELA 4.9 - Opções pré-fixadas para ambos os métodos de otimização

\begin{tabular}{|c|c|c|}
\hline $\begin{array}{c}\text { Método de } \\
\text { Otimização }\end{array}$ & Variável Fixada & Tipo ou Valor \\
\hline \multirow{4}{*}{ AGs } & Tipo de AG & Simples \\
\cline { 2 - 3 } & Seleção & SRS \\
\cline { 2 - 3 } & Recombinação & Aritmética \\
\cline { 2 - 3 } & Mutação & Distribuição Gaussiana \\
\hline \multirow{5}{*}{ PSO } & Tamanho da população & 30 \\
\cline { 2 - 3 } & Número de gerações & 10 \\
\cline { 2 - 3 } & Constantes C & 0.2 \\
\cline { 2 - 3 } & $w$ & 0.9 \\
\cline { 2 - 3 } & $w$ & 0,004 \\
\hline
\end{tabular}

Como o calibrador hidráulico permite diversos modelos de vazamento, para efeito da otimização dos parâmetros dos AGs via PSO, optou-se pelo modelo de vazamento de TUCCIARELLI et al (1999). Os parâmetros de busca dos AGs, bem como os intervalos de procura da rugosidade, do coeficiente teta e do expoente são apresentados na Tabela 4.10.

TABELA 4.10 - Intervalos de procura para a otimização dos AGs

\begin{tabular}{|c|c|c|c|}
\hline \multirow{2}{*}{$\begin{array}{c}\text { Modelo de } \\
\text { Vazamento }\end{array}$} & $\begin{array}{c}\text { Parâmetro de } \\
\text { Procura }\end{array}$ & \multicolumn{2}{|c|}{$\begin{array}{c}\text { Intervalo de } \\
\text { Procura }\end{array}$} \\
\cline { 3 - 4 } & & Mínimo & Maximo \\
\hline \multirow{4}{*}{ Tucciarelli et al. } & Rugosidade $(\varepsilon) \mathrm{mm}$ & 0,00150 & 0,01000 \\
\cline { 3 - 4 } & Coeficiente teta $(\theta)$ & 0,005 & 0,15 \\
\cline { 2 - 4 } & Expoente $(\beta)$ & 0,6 & 1,1 \\
\hline
\end{tabular}


Os arquivos usados para a calibração dos parâmetros dos AGs são apresentados no Apêndice A.

As variáveis que são objetivo da otimização por PSO são apresentadas na Tabela 4.11 com seus respectivos intervalos de procura.

TABELA 4.11 - Parâmetros Fixados para os dois métodos de otimização

\begin{tabular}{|c|c|c|c|}
\hline \multirow{2}{*}{$\begin{array}{l}\text { Método de } \\
\text { Otimização }\end{array}$} & Variável a ser otimizada & \multicolumn{2}{|c|}{ Intervalo de busca } \\
\cline { 3 - 4 } & & Mínimo & Máximo \\
\hline \multirow{4}{*}{ AGs } & Dimensão da População & 20 & 50 \\
\cline { 2 - 4 } & Número de Gerações & 100 & 1000 \\
\cline { 2 - 4 } & Taxa de Recombinação & 0,5 & 0,9 \\
\cline { 2 - 4 } & Taxa de Mutação & 0,01 & 0,25 \\
\hline
\end{tabular}

Cada solução da população do PSO (parâmetros do AG) foi avaliada via AG a partir de 5 populações iniciais distintas de soluções (5 sementes aleatórias: 200, 300, 700, 1000, 2000). O valor da função objetivo, associado a cada solução do PSO, foi determinado pela média aritmética dos melhores valores alcançados para a função objetivo no final das iterações de AG a partir de cada semente. A Tabela 4.12 apresenta os resultados obtidos com a calibração dos parâmetros dos AGs usando PSO.

TABELA 4.12 - Resultados obtidos da calibração dos parâmetros dos AGs

\begin{tabular}{|c|c|c|}
\hline $\begin{array}{c}\text { Método de } \\
\text { Otimização }\end{array}$ & Variável otimizada & Resultado \\
\hline \multirow{4}{*}{ AGs } & Dimensão da População & 48 \\
\cline { 2 - 3 } & Número de Gerações & 788 \\
\cline { 2 - 3 } & Taxa de Recombinação & 0,7 \\
\cline { 2 - 3 } & Taxa de Mutação & 0,04 \\
\hline
\end{tabular}

Na Tabela 4.13 são apresentados os melhores resultados obtidos com a calibração dos parâmetros dos AGs, enquanto que na Tabela 4.14 são apresentados os valores das funções objetivos das respectivas sementes da Tabela 4.13. 
TABELA 4.13 - Resultados obtidos com a calibração hidráulica depois da calibração dos parâmetros dos AGs.

\begin{tabular}{|c|c|c|c|c|c|c|c|c|c|c|c|c|c|}
\hline \multicolumn{2}{|c|}{ Padrões } & \multicolumn{5}{|c|}{ Valores simulados } & \multirow{4}{*}{ 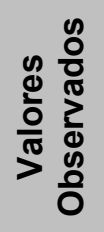 } & \multicolumn{5}{|c|}{ Valores simulados } & \multirow{4}{*}{ 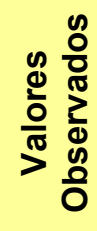 } \\
\hline & & \multirow{2}{*}{\multicolumn{5}{|c|}{$\frac{1}{2 m e}$}} & & & & 2 & & & \\
\hline \multirow{2}{*}{\multicolumn{2}{|c|}{$\begin{array}{l}\text { Variáveis } \\
\text { de estado }\end{array}$}} & & & & & & & & & Semen & & & \\
\hline & & 200 & 300 & 700 & 1000 & 2000 & & 200 & 300 & 700 & 1000 & 2000 & \\
\hline \multicolumn{2}{|c|}{$\begin{array}{c}\text { Vazão } \\
\text { (L/s) }\end{array}$} & 2,97 & 98 & 2,98 & 2,97 & 2,97 & 2,98 & 6,11 & 6,11 & 6,11 & 6,11 & 6,11 & 6,18 \\
\hline \multirow{5}{*}{ 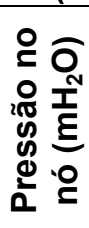 } & 04 & 21,41 & 21,41 & 21,41 & 21,41 & 21,41 & 19,53 & 18,76 & 18,76 & 18,76 & 18,76 & 18,76 & 16,83 \\
\hline & 22 & 32,11 & 32,11 & 32,11 & 32,11 & 32,11 & 31,23 & 29,49 & 29,49 & 29,49 & 29,49 & 29,49 & 28,59 \\
\hline & 44 & 35,78 & 35,78 & 35,78 & 35,78 & 35,78 & 35,00 & 33,08 & 33,08 & 33,08 & 33,08 & 33,08 & 31,90 \\
\hline & 66 & 23,70 & 23,70 & 23,70 & 23,70 & 23,70 & 23,66 & 21,05 & 21,05 & 21,05 & 21,05 & 21,05 & 20,78 \\
\hline & 80 & 32,14 & 32,14 & 32,14 & 32,14 & 32,14 & 31,86 & 29,58 & 29,58 & 29,58 & 29,58 & 29,58 & 29,15 \\
\hline \multicolumn{2}{|c|}{$\begin{array}{l}\text { Perdas } \\
\text { (L/s) }\end{array}$} & 0,71 & 0,69 & 0,69 & 0,75 & 0,81 & & 0,64 & 0,63 & 0,62 & 0,68 & 0,73 & \\
\hline
\end{tabular}

TABELA 4.14 - Valores da função objetivo e resultados para cada semente

\begin{tabular}{|c|c|c|c|c|c|}
\hline \multirow{2}{*}{ Função Objetivo $\left(.10^{-3}\right)$} & \multicolumn{5}{|c|}{ Semente } \\
\cline { 2 - 6 } & 200 & 300 & 700 & 1000 & 2000 \\
\cline { 2 - 6 } & 15,877 & 15,894 & 15,870 & 15,876 & 15,884 \\
\hline Rugosidade $(\varepsilon) \mathrm{mm}\left(.10^{-3}\right)$ & 9,50 & 4,68 & 9,10 & 9,28 & 9,93 \\
\hline Coeficiente teta $(\theta)\left(.10^{-8}\right)$ & 1,15 & 1,48 & 0,88 & 0,92 & 0,92 \\
\hline Expoente $(\beta)$ & 0,96 & 0,88 & 1,03 & 1,04 & 1,07 \\
\hline
\end{tabular}

\subsection{CALIBRAÇÕES HIDRÁULICAS PRELIMINARES}

O objetivo deste tópico foi avaliar os resultados obtidos com a calibração hidráulica e os valores das funções objetivos obtidas com a eventual exclusão de um ponto de observação, cujos dados podiam estar interferindo na calibração hidráulica, ou seja, prejudicando os resultados da calibração.

Assim, o primeiro alvo desta investigação foi o nó 4, localizado na rua Mautilio Bruno, pois, conforme a Tabela 4.13, foi o nó que apresentou a maior diferença entre os resultados simulados e os valores observados. Este resultado pode ser decorrente das oscilações de pressão que o nó 4 apresenta, diferentemente dos demais pontos de observação (Figura 4.7). Os comportamentos divergentes desta medição, em relação às demais medições, 
podem ser observados em horários como os do dia 23/06/2007, em que nos intervalos das 9:30 às 11:00 e das 14:00 às 16:00 (Figura 4.7) houve uma súbita queda de pressão que não ocorreu nos demais pontos medidos. Desta forma, a Tabela 4.15 apresenta os novos resultados obtidos com a exclusão da observação realizada no nó 4.

Para permitir a comparação entre os resultados obtidos com e sem o nó 4, as calibrações sem o nó 4 foram feitas com os mesmos intervalos de procura da calibração dos parâmetros dos AGs (Tabela 4.10), considerando o mesmo modelo de vazamento (TUCCIARELLI et al., 1999), e com os resultados obtidos da calibração dos parâmetros dos AGs (Tabela 4.12).

TABELA 4.15 - Resultados obtidos com a exclusão do ponto observado 4

\begin{tabular}{|c|c|c|c|c|c|c|c|c|c|c|c|c|c|}
\hline \multirow{2}{*}{\multicolumn{2}{|c|}{ Padrões }} & \multicolumn{5}{|c|}{ Valores simulados } & \multirow{4}{*}{ 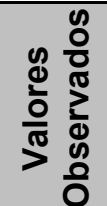 } & \multirow{2}{*}{\multicolumn{5}{|c|}{$\begin{array}{c}\text { Valores simulados } \\
2 \\
\end{array}$}} & \multirow{4}{*}{ 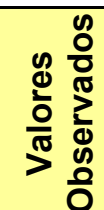 } \\
\hline & & \multirow{2}{*}{\multicolumn{5}{|c|}{$\frac{1}{e m e}$}} & & & & & & & \\
\hline \multirow{2}{*}{\multicolumn{2}{|c|}{$\begin{array}{l}\text { Variáveis } \\
\text { de estado }\end{array}$}} & & & & & & & & & ement & & & \\
\hline & & 200 & 300 & 700 & 1000 & 2000 & & 200 & 300 & 700 & 1000 & 2000 & \\
\hline \multicolumn{2}{|c|}{$\begin{array}{l}\text { Vazão } \\
\text { (L/s) }\end{array}$} & 2,98 & 2,97 & 2,98 & 2,97 & 2,97 & 2,98 & 6,12 & 6,11 & 6,11 & 6,11 & 6,11 & 6,18 \\
\hline \multirow{4}{*}{ 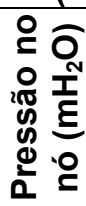 } & 22 & 32,11 & 32,11 & 32,11 & 32,11 & 32,11 & 31,23 & 29,48 & 29,48 & 29,48 & 29,48 & 29,48 & 28,59 \\
\hline & 44 & 35,77 & 35,77 & 35,77 & 35,77 & 35,77 & 35,00 & 33,07 & 33,07 & 33,07 & 33,07 & 33,07 & 31,90 \\
\hline & 66 & 23,70 & 23,70 & 23,70 & 23,70 & 23,70 & 23,66 & 21,05 & 21,05 & 21,05 & 21,05 & 21,05 & 20,78 \\
\hline & 80 & 32,13 & 32,13 & 32,13 & 32,13 & 32,13 & 31,86 & 29,57 & 29,57 & 29,57 & 29,57 & 29,57 & 29,15 \\
\hline \multicolumn{2}{|c|}{$\begin{array}{l}\text { Perdas } \\
\text { (L/s) }\end{array}$} & 1,03 & 1,34 & 1,02 & 1,36 & 1,39 & & 0,93 & 1,21 & 0,93 & 1,22 & 1,25 & \\
\hline
\end{tabular}

TABELA 4.16 - Valores da função objetivo e resultados para cada semente sem o nó 4

\begin{tabular}{|c|c|c|c|c|c|}
\hline \multirow{3}{*}{ Função Objetivo $\left(.10^{-3}\right)$} & \multicolumn{5}{|c|}{ Semente } \\
\cline { 2 - 6 } & 200 & 300 & 700 & 1000 & 2000 \\
\cline { 2 - 6 } & 4,836 & 4,842 & 4,844 & 4,851 & 4,832 \\
\hline Rugosidade $(\varepsilon) \mathrm{mm}\left(.10^{-3}\right)$ & 9,79 & 9,17 & 9,17 & 4,48 & 9,93 \\
\hline Coeficiente teta $(\theta)\left(.10^{-8}\right)$ & 1,14 & 1,43 & 1,31 & 1,49 & 1,45 \\
\hline Expoente $(\beta)$ & 1,07 & 1,08 & 1,03 & 1,08 & 1,09 \\
\hline
\end{tabular}

Os resultados das Tabelas 4.15 e 4.16 mostram que a função objetivo melhora significativamente com à exclusão do ponto observado 4, sendo assim, esse ponto não é mais considerado nas calibrações posteriores. Outra alteração importante pode ser verificada no 
valor total do vazamento, que sofreu uma alteração significativa para todas as sementes testadas.

A exclusão do ponto observado 4 não representou mudanças significativas na rugosidade, na vazão simulada e nos valores simulados de pressão dos nós $22,44,66,80$, contudo, o coeficiente $C$ e o expoente $\beta$ variaram substancialmente, determinando a alteração da ordem de grandeza do vazamento total da rede.

Visto que a exclusão do ponto observado 4 foi realizada, prosseguiu-se a investigação da exclusão de mais um ponto observado para a verificação dos resultados obtidos. $\mathrm{O}$ alvo seguinte da investigação foi o ponto 22. Ponto que apresenta maior diferença entre os valores das pressões observadas e simuladas, depois da exclusão do ponto 4. A Tabela 4.17 apresenta os resultados após a exclusão dos pontos 4 e 22 e a Tabela 4.18 apresenta os resultados das rugosidades e os valores da função objetivo para a comparação com os valores obtidos anteriormente.

TABELA 4.17 - Resultados obtidos com a exclusão dos pontos observados 4 e 22

\begin{tabular}{|c|c|c|c|c|c|c|c|c|c|c|c|c|c|}
\hline \multirow{2}{*}{\multicolumn{2}{|c|}{ Padrões }} & \multicolumn{5}{|c|}{ Valores simulados } & \multirow{4}{*}{ 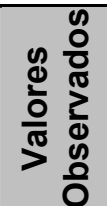 } & \multirow{3}{*}{\multicolumn{5}{|c|}{$\begin{array}{c}\text { Valores simulados } \\
2 \\
\text { Semente } \\
\end{array}$}} & \multirow{4}{*}{ 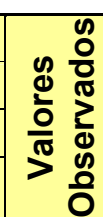 } \\
\hline & & \multirow{2}{*}{\multicolumn{5}{|c|}{$\frac{1}{1}$}} & & & & & & & \\
\hline \multirow{2}{*}{\multicolumn{2}{|c|}{$\begin{array}{l}\text { Variáveis } \\
\text { de estado }\end{array}$}} & & & & & & & & & & & & \\
\hline & & 200 & 300 & 700 & 1000 & 2000 & & 200 & 300 & 700 & 1000 & 2000 & \\
\hline \multicolumn{2}{|c|}{$\begin{array}{c}\text { Vazão } \\
\text { (L/s) }\end{array}$} & 2,98 & 2,97 & 2,98 & 2,97 & 2,97 & 2,98 & 6,11 & 6,11 & 6,11 & 6,11 & 6,11 & 6,18 \\
\hline \multirow{3}{*}{ 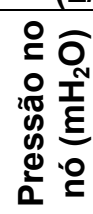 } & 44 & 35,77 & 35,77 & 35,77 & 35,77 & 35,77 & 35,00 & 33,07 & 33,07 & 33,07 & 33,07 & 33,07 & 31,90 \\
\hline & 66 & 23,70 & 23,70 & 23,70 & 23,70 & 23,70 & 23,66 & 21,05 & 21,05 & 21,05 & 21,05 & 21,05 & 20,78 \\
\hline & 80 & 32,13 & 32,13 & 32,13 & 32,14 & 32,13 & 31,86 & 29,57 & 29,57 & 29,57 & 29,57 & 29,57 & 29,15 \\
\hline \multicolumn{2}{|c|}{$\begin{array}{c}\text { Perdas } \\
\text { (L/s) }\end{array}$} & 1,03 & 1,02 & 1,02 & 1,00 & 1,39 & & 0,93 & 0,92 & 0,93 & 0,90 & 1,25 & \\
\hline
\end{tabular}

TABELA 4.18 - Valores da função objetivo e resultados sem os nós 4 e 22

\begin{tabular}{|c|c|c|c|c|c|}
\hline \multirow{3}{*}{ Função Objetivo $\left(.10^{-3}\right)$} & \multicolumn{5}{|c|}{ Semente } \\
\cline { 2 - 6 } & 200 & 300 & 700 & 1000 & 2000 \\
\cline { 2 - 6 } & 3,028 & 3,035 & 3,032 & 3,041 & 3,036 \\
\hline Rugosidade $(\varepsilon) \mathrm{mm}\left(.10^{-3}\right)$ & 9,64 & 6,38 & 9,17 & 9,30 & 6,00 \\
\hline Coeficiente teta $(\theta)\left(.10^{-8}\right)$ & 1,24 & 1,19 & 1,31 & 1,49 & 1,45 \\
\hline Expoente $(\beta)$ & 1,05 & 1,06 & 1,03 & 0,98 & 1,09 \\
\hline
\end{tabular}


Há uma diminuição no valor da função objetivo depois da exclusão dos pontos observados 4 e 22, contudo para completar a análise da calibração preliminar, também se testou a exclusão do ponto observado 44; ponto em que os valores simulados diferem dos valores observados quase que na mesma ordem de grandeza do ponto 22. Assim a Tabela 4.19 e a Tabela 2.20 apresentam os resultados com a exclusão dos pontos 4 e 44 .

TABELA 4.19 - Resultados obtidos com a exclusão dos pontos observados 4 e 44

\begin{tabular}{|c|c|c|c|c|c|c|c|c|c|c|c|c|c|}
\hline \multirow{2}{*}{\multicolumn{2}{|c|}{ Padrões }} & \multicolumn{5}{|c|}{ Valores simulados } & \multirow{4}{*}{ 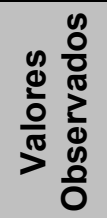 } & \multirow{2}{*}{\multicolumn{5}{|c|}{$\begin{array}{c}\text { Valores simulados } \\
2\end{array}$}} & \multirow{4}{*}{ 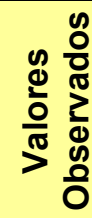 } \\
\hline & & \multirow{2}{*}{\multicolumn{5}{|c|}{$\frac{1}{\text { mente }}$}} & & & & & & & \\
\hline \multirow{2}{*}{\multicolumn{2}{|c|}{$\begin{array}{l}\text { Variáveis } \\
\text { de estado }\end{array}$}} & & & & & & & & & Semen & & & \\
\hline & & 200 & 300 & 700 & 1000 & 2000 & & 200 & 300 & 700 & 1000 & 2000 & \\
\hline \multicolumn{2}{|c|}{$\begin{array}{l}\text { Vazão } \\
\text { (L/s) }\end{array}$} & 2,98 & 2,98 & 2,98 & 2,94 & 2,97 & 2,98 & 6,12 & 6,11 & 6,11 & 6,11 & 6,11 & 6,18 \\
\hline \multirow{3}{*}{ 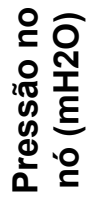 } & 22 & 32,11 & 32,11 & 32,11 & 32,11 & 32,11 & 35,00 & 29,48 & 29,49 & 29,48 & 29,49 & 29,48 & 31,90 \\
\hline & 66 & 23,70 & 23,70 & 23,70 & 23,70 & 23,70 & 23,66 & 21,05 & 21,05 & 21,05 & 21,05 & 21,05 & 20,78 \\
\hline & 80 & 32,13 & 32,14 & 32,13 & 32,14 & 32,14 & 31,86 & 29,57 & 29,58 & 29,57 & 29,58 & 29,57 & 29,15 \\
\hline \multicolumn{2}{|c|}{$\begin{array}{c}\text { Perdas } \\
(\mathrm{L} / \mathbf{s})\end{array}$} & 1,03 & 0,76 & 1,02 & 0,19 & 0,99 & & 0,93 & 0,68 & 0,93 & 0,18 & 0,89 & \\
\hline
\end{tabular}

TABELA 4.20 - Valores da função objetivo e resultados sem os nós 4 e 44

\begin{tabular}{|c|c|c|c|c|c|}
\hline \multirow{2}{*}{ Função Objetivo $\left(.10^{-3}\right)$} & \multicolumn{5}{|c|}{ Semente } \\
\cline { 2 - 6 } & 200 & 300 & 700 & 1000 & 2000 \\
\cline { 2 - 6 } & 2,648 & 2,668 & 2,652 & 2,659 & 2,654 \\
\hline Rugosidade $(\varepsilon) \mathrm{mm}\left(.10^{-3}\right)$ & 9,50 & 5,62 & 9,02 & 2,97 & 9,93 \\
\hline Coeficiente teta $(\theta)\left(.10^{-8}\right)$ & 1,06 & 0,79 & 1,31 & 1,03 & 1,12 \\
\hline Expoente $(\beta)$ & 1,10 & 1,09 & 1,03 & 1,10 & 1,07 \\
\hline
\end{tabular}

Os resultados obtidos com a exclusão do ponto 44 em combinação com o ponto 4 não apresentaram significativa diferença dos resultados obtidos com a exclusão dos pontos $22 \mathrm{em}$ combinação com o ponto 4. Esse resultado pode ser observado na Tabela 4.21 que apresenta o comparativo entre as sementes e as diferenças em relação aos resultados obtidos. 
TABELA 4.21 - Todos os resultados obtidos e seus comparativos

\begin{tabular}{|c|c|c|c|c|c|}
\hline & \multicolumn{5}{|c|}{ Semente } \\
\hline & 200 & 300 & 700 & 1000 & 2000 \\
\hline $\begin{array}{c}\text { Valores da função } \\
\text { Objetivo }\left(.10^{-3}\right) \\
\text { depois da exclusão } \\
\text { do nó } 4 . \\
\end{array}$ & 4,836 & 4,842 & 4,844 & 4,851 & 4,832 \\
\hline $\begin{array}{l}\text { Valores da função } \\
\text { Objetivo }\left(.10^{-3}\right) \\
\text { depois da exclusão } \\
\text { dos nós } 4 \text { e } 22 .\end{array}$ & 3,029 & 3,036 & 3,032 & 3,041 & 3,037 \\
\hline $\begin{array}{c}\text { Valores da função } \\
\text { Objetivo }\left(.10^{-3}\right) \\
\text { depois da exclusão } \\
\text { dos nós } 4 \text { e } 44 .\end{array}$ & 2,648 & 2,668 & 2,653 & 2,659 & 2,654 \\
\hline \multirow[t]{2}{*}{$\begin{array}{c}\text { Diferença entre as } \\
\text { melhores } \\
\text { sementes da } \\
\text { função objetivo } \\
\text { entre só } 4 \text { e } 4 \text { mais } \\
22 \\
\end{array}$} & 1,803 & & \multicolumn{2}{|c|}{$\begin{array}{l}\text { Diferença entre as } \\
\text { melhores sementes da } \\
\text { função objetivo entre } \\
\text { só } 4 \text { e } 4 \text { mais } 44\end{array}$} & 2,184 \\
\hline & \multicolumn{2}{|c|}{$\begin{array}{c}\text { Diferença entre as } \\
\text { duas Diferenças } \\
\text { calculadas }\end{array}$} & 0,380 & & \\
\hline
\end{tabular}

Sendo assim, a exclusão dos pontos 22 e 44 são discutíveis, visto que eles contribuem e interferem na função objetivo da mesma forma, uma vez que é pequena a diferença entre os resultados obtidos com a exclusão de cada um dos pontos. A disposição de informações ao calibrador melhora a resolução das variáveis do problema, por isso é importante manter como informação para o calibrador os pontos observados 22 e 44, visto que se fossem excluídos os dois pontos, o calibrador tornar-se-ia carente de informações para calibração hidráulica.

Como conclusão da análise feita sobre a exclusão dos eventuais pontos que estavam interferindo negativamente na calibração, somente o ponto 4 foi excluído para as futuras calibrações hidráulicas, pois é o ponto que, devido ao seu comportamento inconstante (Figura 4.7), não contribuiu na calibração hidráulica. 


\subsection{CALIBRAÇÃO HIDRÁULICA VARIANDO OS MODELOS DE}

\section{VAZAMENTO}

O vazamento representa a parcela de água que é perdida pelo sistema de distribuição por diversos motivos. Essa perda pode ser responsável por parte significativa da água disponibilizada para a distribuição e é de difícil quantificação. Diversos modelos de vazamento tentam representar a parcela de água perdida nas redes de distribuição de água, porém como esta grandeza é inviável de ser obtida em campo, torna-se difícil comparar os valores simulados pelos modelos de vazamento.

Devido à existência de diversos modelos de vazamento e ao desconhecimento de qual modelo é capaz de representar o vazamento de forma mais realística, este trabalho testou os modelos citados na literatura. A Figura 4.18 apresenta o fluxograma seguido na etapa de calibração hidráulica dos modelos.

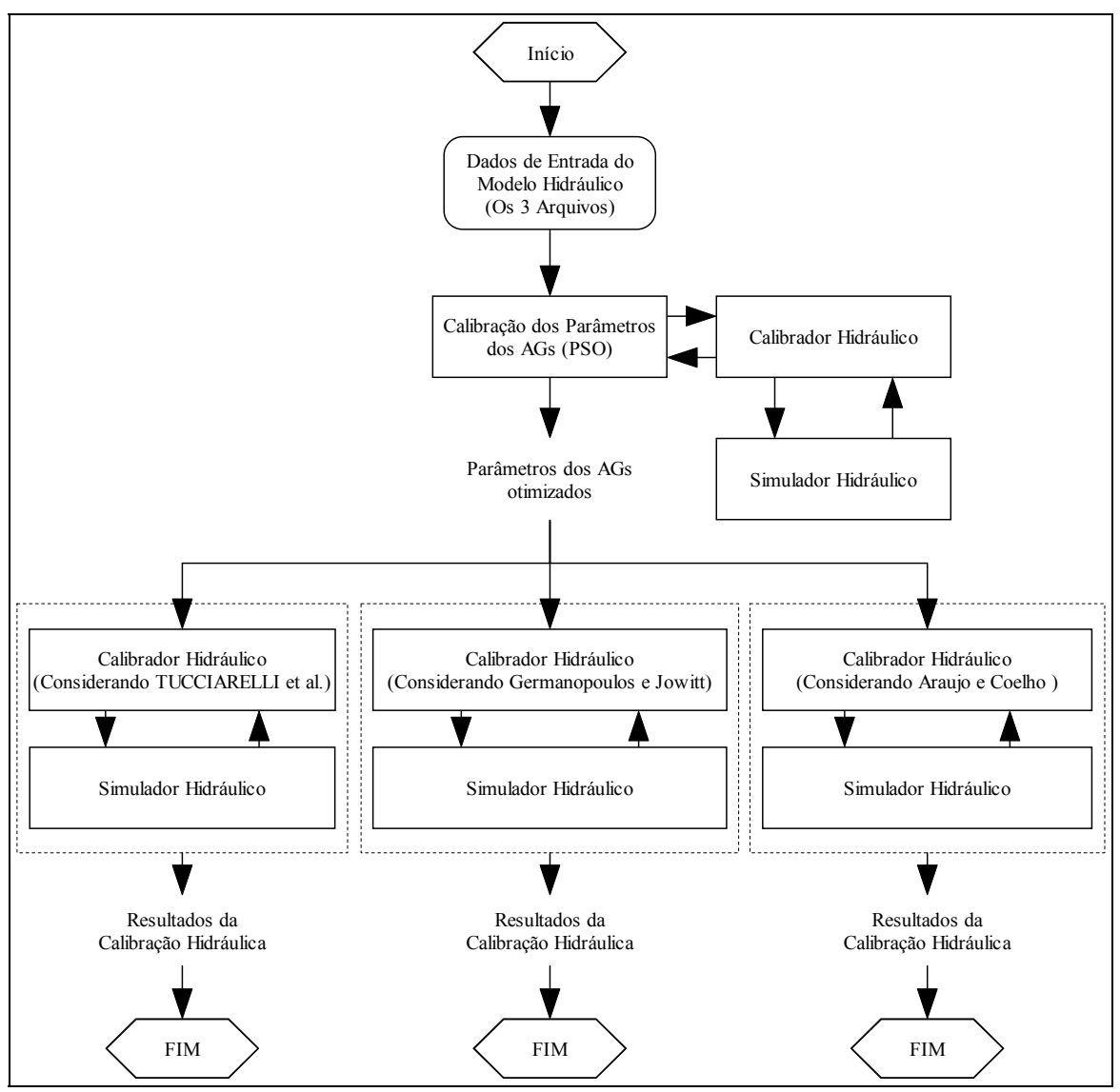

FIGURA 4.18 - Fluxograma das diversas calibrações hidráulicas 
Levando-se em consideração que existem parâmetros dos modelos de vazamento para os quais a literatura não fornece a faixa de variação $(C, \theta$ e $\beta)$, neste trabalho foram testadas diversas faixas de procura para todos os modelos de vazamento. Segundo GOODWIN apud ALONSO et al. (2000), resultados de uma experiência para a determinação do expoente $\beta$ sugeriram que o expoente varia entre 0,5 e 1,18. Contudo, foram testados outros intervalos a fim de se determinar valores para o expoente, mantendo a ordem de grandeza sugerida por GOODWIN. A Tabela 4.15 mostra todos os testes realizados com os modelos de vazamento e os respectivos intervalos de procura para os respectivos parâmetros.

TABELA 4.22 - Testes realizados e seus respectivos intervalos de procura

\begin{tabular}{|c|c|c|c|}
\cline { 3 - 4 } \multicolumn{2}{c|}{} & \multicolumn{2}{c|}{ Intervalos de procura para } \\
\hline Modelo & Teste & Coeficiente $\left(\mathrm{C} .10^{-5}\right.$ ou $\left.\theta .10^{-7}\right)$ & Expoente $(\beta)$ \\
\hline \multirow{2}{*}{ Araújo et al. } & T.1.A & $0,005-0,15$ & 1,18 \\
\cline { 2 - 2 } $\begin{array}{c}\text { Germanopoulos e } \\
\text { Jowitt }\end{array}$ & T.2.A & $0,005-0,47$ & 1,18 \\
\hline \multirow{3}{*}{$\begin{array}{c}\text { T.1.GJ } \\
\text { Tucciarelli et al. }\end{array}$} & T.2.GJ & $0,005-0,15$ & $0,05-1,2$ \\
\cline { 2 - 2 } & T.3.GJ & \multirow{2}{*}{$0,005-0,45$} & $0,5-1,2$ \\
\cline { 2 - 2 } & T.4.GJ & & $0,05-1,2$ \\
\cline { 2 - 2 } & T.1.T & \multirow{2}{*}{$0,005-0,15$} & $0,5-1,2$ \\
\cline { 2 - 2 } & T.2.T & & $0,05-1,2$ \\
\cline { 2 - 2 } & T.3.T & \multirow{2}{*}{$0,005-0,20$} & $0,05-1,2$ \\
\cline { 2 - 2 } & T.4.T & & $0,5-1,2$ \\
\hline
\end{tabular}

Esses intervalos foram estabelecidos para permitir a comparação dos resultados entre os modelos de vazamentos testados. Ao se observar a Tabela 4.22, pode se verificar que o expoente tem dois intervalos de procura e os coeficientes $C$ ou $\theta$ também, sendo assim, os testes foram realizados para todas as possíveis combinações de intervalos de procura. Cabe dizer que a determinação dos intervalos de procura $C$ ou $\theta$ possui limites em que há convergência do calibrador hidráulico.

Os resultados de cada teste são mostrados a seguir e serviram para a determinação dos multiplicadores do consumo de referência para cada hora do dia. Desta forma, cada teste realizado implica em uma calibração hidráulica seguida de calibração de qualidade, sendo assim, foram realizadas 10 calibrações hidráulicas seguidas de 10 calibrações de qualidade. 
Basicamente, os arquivos usados para cada calibração hidráulica foram os mesmos apresentados no Apêndice A, com pequenas alterações no arquivo de dados de campo do qual é excluído o ponto 4, e no arquivo dos AGs, no qual se alterou o modelo e os intervalos de procura para os respectivos parâmetros.

Alguns fatores multiplicativos do consumo de referência foram assumidos nulos pelo fato do calibrador hidráulico não convergir para situações em que as vazões abastecidas são muito baixas. Nesses casos, o pequeno valor de vazão abastecida pode ser atribuído quase integralmente aos vazamentos, resultando assim em fatores próximos de zero para determinados horários (madrugada).

\subsubsection{Resultados do Teste 1 do modelo Araújo et al. (T.1.A)}

Os resultados do teste T.1.A são apresentados nas Tabelas 4.23 e 4.24. A Tabela 4.23 apresenta os valores simulados (pressões, vazões e perdas), e os valores encontrados, enquanto que na Tabela 4.24 estão as variáveis de decisão e o valor das funções objetivo. Em destaque, está a semente com resultado da melhor função objetivo. A Tabela 4.26 apresenta os valores dos $K f$ s para o melhor resultado obtido (associado à semente aleatória em destaque).

TABELA 4.23 - Resultados obtidos no teste T.1.A

\begin{tabular}{|c|c|c|c|c|c|c|c|c|c|c|c|c|c|}
\hline \multirow{2}{*}{\multicolumn{2}{|c|}{ Padrões }} & \multicolumn{5}{|c|}{ Valores simulados } & \multirow{4}{*}{ 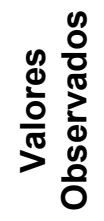 } & \multirow{3}{*}{\multicolumn{5}{|c|}{$\begin{array}{c}\text { Valores simulados } \\
2 \\
\text { Semente }\end{array}$}} & \multirow{4}{*}{ 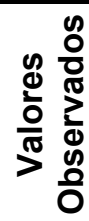 } \\
\hline & & \multirow{2}{*}{\multicolumn{5}{|c|}{$\frac{1}{\text { Semente }}$}} & & & & & & & \\
\hline \multirow{2}{*}{\multicolumn{2}{|c|}{$\begin{array}{c}\text { Variáveis } \\
\text { de } \\
\text { estado }\end{array}$}} & & & & & & & & & & & & \\
\hline & & 200 & 300 & 700 & 1000 & 2000 & & 200 & 300 & 700 & 1000 & 2000 & \\
\hline \multicolumn{2}{|c|}{$\begin{array}{l}\text { Vazão } \\
\text { (L/s) }\end{array}$} & 2,98 & 2,94 & 2,98 & 2,98 & 2,98 & 2,98 & 6,12 & 6,11 & 6,12 & 6,12 & 6,12 & 6,18 \\
\hline \multirow{4}{*}{ 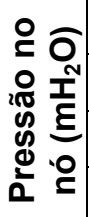 } & 22 & 32,11 & 32,11 & 32,11 & 2,11 & 32,11 & 31,23 & 29,48 & 29,49 & 29,48 & 29,48 & 29,48 & 28,59 \\
\hline & 44 & 35,77 & 79 & 35,77 &, 77 & 77 & 35,00 & 07 &, 09 & 33,07 & 33,07 &, 07 & 31,90 \\
\hline & 66 & 23,70 & 23,70 & 23,70 & 23,70 & 23,70 & 23,66 & 21,05 & 21,05 & 21,05 & 21,05 & 21,05 & 20,78 \\
\hline & 80 & 32,14 & 32,14 & 32,14 & 32,14 & 32,14 & 31,86 & 29,57 & 29,58 & 29,57 & 29,57 & 29,57 & 29,15 \\
\hline \multicolumn{2}{|c|}{$\begin{array}{l}\text { Perdas } \\
\text { (L/s) }\end{array}$} & 0,95 & 0,93 & 95 & 0,95 & 0,95 & & 0,85 & 0,83 & 0,85 & 0,85 & 0,85 & \\
\hline
\end{tabular}


TABELA 4.24 - Valores da função objetivo e resultados do teste T.1.A

\begin{tabular}{|c|c|c|c|c|c|}
\hline \multirow{3}{*}{ Função Objetivo $\left(.10^{-3}\right)$} & \multicolumn{5}{|c|}{ Semente } \\
\cline { 2 - 6 } & 200 & 300 & 700 & 1000 & 2000 \\
\cline { 2 - 6 } & 4,800 & 4,804 & 4,802 & 4,801 & 4,801 \\
\hline Rugosidade $(\varepsilon) \mathrm{mm}\left(.10^{-3}\right)$ & 9,79 & 9,42 & 9,17 & 9,68 & 9,52 \\
\hline Coeficiente $(C)\left(.10^{-6}\right)$ & 1,50 & 1,48 & 1,49 & 1,49 & 1,50 \\
\hline Expoente $(\beta)$ & 1,18 & 1,18 & 1,18 & 1,18 & 1,18 \\
\hline
\end{tabular}

O exame da Tabela 4.24 permite que se conclua que a semente aleatória 200 produziu melhor resultado para a busca, com resultados para a rugosidade e o coeficiente $C$ próximos ao limite superior do intervalo pré-estabelecido para a busca. A Tabela 4.23 mostra que os resultados da calibração hidráulica em termos das pressões e vazões são satisfatórios, visto que os resultados simulados, apesar de não serem semelhantes ao observados, são próximos.

A Tabela 4.25 apresenta os multiplicadores do consumo de referência para os resultados da melhor semente na calibração hidráulica (rugosidade, expoente e coeficiente $C$ ).

TABELA 4.25 - Multiplicadores do consumo de referência do teste T.1.A

\begin{tabular}{|c|c|c|c|}
\hline $\begin{array}{c}\text { Horas do } \\
\text { dia de } \\
\text { observação }\end{array}$ & $\begin{array}{c}\text { Multiplicadores } \\
\text { do consumo } \\
\text { de referência }\end{array}$ & $\begin{array}{c}\text { Horas do } \\
\text { dia de } \\
\text { observação }\end{array}$ & $\begin{array}{c}\text { Multiplicadores } \\
\text { do consumo } \\
\text { de referência }\end{array}$ \\
\hline $1^{\mathrm{a}}$ & 1,64 & $13^{\mathrm{a}}$ & 0 \\
\hline $2^{\mathrm{a}}$ & 1,24 & $14^{\mathrm{a}}$ & 0 \\
\hline $3^{\mathrm{a}}$ & 0,80 & $15^{\mathrm{a}}$ & 0,47 \\
\hline $4 \mathrm{a}$ & 0 & $16^{\mathrm{a}}$ & 1,67 \\
\hline $5^{\mathrm{a}}$ & 0 & $17^{\mathrm{a}}$ & 2,77 \\
\hline $6^{\mathrm{a}}$ & 0,26 & $18^{\mathrm{a}}$ & 3,04 \\
\hline $7^{\mathrm{a}}$ & 0,11 & $19^{\mathrm{a}}$ & 2,31 \\
\hline $8^{\mathrm{a}}$ & 0 & $20^{\mathrm{a}}$ & 1,83 \\
\hline $9^{\mathrm{a}}$ & 0 & $21^{\mathrm{a}}$ & 1,99 \\
\hline $10^{\mathrm{a}}$ & 0 & $22^{\mathrm{a}}$ & 2,18 \\
\hline $11^{\mathrm{a}}$ & 0 & $23^{\mathrm{a}}$ & 2,62 \\
\hline $12^{\mathrm{a}}$ & 0 & $24^{\mathrm{a}}$ & 2,37 \\
\hline
\end{tabular}


TABELA 4.26 - Valores dos $K f s$ para o T.1.A

\begin{tabular}{|c|c|c|c|c|c|c|c|}
\hline Nó & Kfs $\left(.10^{-4}\right)$ & Nó & Kfs $\left(.10^{-4}\right)$ & Nó & Kfs $\left(.10^{-4}\right)$ & Nó & Kfs $\left(.10^{-4}\right)$ \\
\hline 1 & 1,79 & 21 & 1,87 & 42 & 1,57 & 63 & 2,79 \\
\hline 2 & 0,69 & 22 & 2,73 & 43 & 4,24 & 64 & 1,86 \\
\hline 3 & 2,30 & 23 & 1,79 & 44 & 4,54 & 65 & 1,88 \\
\hline 4 & 3,59 & 24 & 1,32 & 45 & 1,86 & 66 & 2,81 \\
\hline 5 & 1,85 & 25 & 1,71 & 46 & 1,18 & 67 & 1,86 \\
\hline 6 & 1,62 & 26 & 1,32 & 47 & 1,21 & 68 & 1,88 \\
\hline 7 & 1,43 & 27 & 1,56 & 48 & 2,54 & 69 & 2,83 \\
\hline 8 & 3,57 & 28 & 2,18 & 49 & 1,08 & 70 & 1,88 \\
\hline 9 & 2,30 & 29 & 1,56 & 50 & 1,86 & 71 & 1,88 \\
\hline 10 & 4,10 & 30 & 1,56 & 51 & 2,80 & 72 & 2,83 \\
\hline 11 & 2,51 & 31 & 2,18 & 52 & 1,86 & 73 & 1,89 \\
\hline 12 & 2,34 & 32 & 1,56 & 53 & 1,86 & 74 & 2,58 \\
\hline 13 & 3,74 & 33 & 1,61 & 54 & 2,80 & 75 & 3,03 \\
\hline 14 & 2,33 & 34 & 2,28 & 55 & 1,86 & 76 & 1,94 \\
\hline 15 & 2,15 & 35 & 1,60 & 56 & 1,86 & 77 & 0,78 \\
\hline 16 & 3,38 & 36 & 1,63 & 57 & 2,80 & 78 & 3,50 \\
\hline 17 & 2,15 & 37 & 2,33 & 58 & 1,86 & 79 & 3,35 \\
\hline 18 & 1,98 & 38 & 1,63 & 59 & 1,86 & 80 & 4,93 \\
\hline 19 & 3,04 & 39 & 1,64 & 60 & 2,80 & 81 & 0,92 \\
\hline 20 & 2,00 & 40 & 2,34 & 61 & 1,86 & 82 & 1,11 \\
\hline & & 41 & 1,63 & 62 & 1,85 & & \\
\hline
\end{tabular}

\subsubsection{Resultados do Teste 2 do modelo Araújo et al. (T.2.A)}

O segundo teste realizado com o modelo de vazamento de ARAUJO et al. (2003) procurou explorar o limite superior do coeficiente $C$, visto que, no teste anterior os resultados ficaram próximos ao limite superior da faixa estabelecida para a busca. Os resultados são apresentados nas Tabelas 4.27 e 4.28. A Tabela 4.30 apresenta os valores dos $K f$ s para a melhor semente. 
TABELA 4.27 - Resultados obtidos no teste T.2.A

\begin{tabular}{|c|c|c|c|c|c|c|c|c|c|c|c|c|c|}
\hline \multirow{2}{*}{\multicolumn{2}{|c|}{ Padrões }} & \multicolumn{5}{|c|}{ Valores simulados } & \multirow{4}{*}{ 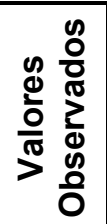 } & \multirow{3}{*}{\multicolumn{5}{|c|}{$\begin{array}{c}\text { Valores simulados } \\
2 \\
\text { Semente }\end{array}$}} & \multirow{4}{*}{ 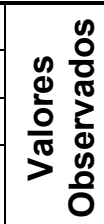 } \\
\hline & & \multirow{2}{*}{\multicolumn{5}{|c|}{$\frac{1}{\text { Semente }}$}} & & & & & & & \\
\hline \multirow{2}{*}{\multicolumn{2}{|c|}{$\begin{array}{c}\text { Variáveis } \\
\text { de } \\
\text { estado }\end{array}$}} & & & & & & & & & & & & \\
\hline & & 200 & 300 & 700 & 1000 & 2000 & & 200 & 300 & 700 & 1000 & 2000 & \\
\hline \multicolumn{2}{|c|}{$\begin{array}{c}\text { Vazão } \\
\text { (L/s) }\end{array}$} & 2,99 & 2,99 & 2,99 & 2,94 & 2,99 & 2,98 & 6,12 & 6,12 & 6,12 & 6,11 & 6,12 & 6,18 \\
\hline \multirow{4}{*}{ 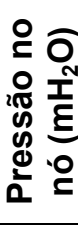 } & 22 & 32,09 & 32,09 & 32,09 & 32,11 & 32,09 & 31,23 & 29,46 & 29,46 & 29,46 & 29,49 & 29,46 & 28,59 \\
\hline & 44 & 35,73 & 35,73 & 35,73 & 35,79 & 35,73 & 35,00 & 33,01 & 33,01 & 33,01 & 33,09 & 33,01 & 31,90 \\
\hline & 66 & 23,70 & 23,70 & 23,70 & 23,70 & 23,70 & 23,66 & 21,04 & 21,04 & 21,05 & 21,05 & 21,04 & 20,78 \\
\hline & 80 & 32,11 & 32,11 & 32,11 & 32,14 & 32,11 & 31,86 & 29,55 & 29,55 & 29,55 & 29,58 & 29,55 & 29,15 \\
\hline \multicolumn{2}{|c|}{$\begin{array}{c}\text { Perdas } \\
\text { (L/s) }\end{array}$} & 2,97 & 2,94 & 2,97 & 2,93 & 2,93 & & 2,65 & 2,63 & 2,65 & 2,61 & 2,62 & \\
\hline
\end{tabular}

TABELA 4.28 - Valores da função objetivo e resultados do teste T.2.A

\begin{tabular}{|c|c|c|c|c|c|}
\hline \multirow{2}{*}{ Função Objetivo $\left(.10^{-3}\right)$} & \multicolumn{5}{|c|}{ Semente } \\
\cline { 2 - 6 } & 200 & 300 & 700 & 1000 & 2000 \\
\cline { 2 - 6 } & 4,460 & 4,467 & 4,462 & 4,469 & 4,470 \\
\hline Rugosidade $(\varepsilon) \mathrm{mm}\left(.10^{-3}\right)$ & 9,64 & 9,48 & 9,17 & 7,36 & 9,21 \\
\hline Coeficiente $(C)\left(.10^{-6}\right)$ & 4,69 & 4,65 & 4,68 & 4,67 & 4,63 \\
\hline Expoente $(\beta)$ & 1,18 & 1,18 & 1,18 & 1,18 & 1,18 \\
\hline
\end{tabular}

Novamente a semente que resultou em solução de menor valor para a função objetivo foi a 200 conforme a Tabela 4.28. Verificou-se também, que novamente o coeficiente $C$ convergiu para o limite superior do intervalo de procura, contudo, como houve a alteração do limite superior do coeficiente $C$, os resultados das variáveis de estado também se alteraram (Tabela 4.27), sendo a maior alteração observada no valor do total de perdas por vazamento. A função objetivo do teste T.2.A foi menor que a função objetivo do teste T.1.A. A Tabela 4.29 apresenta os multiplicadores do consumo de referência para os resultados obtidos com a melhor semente (rugosidade, expoente e coeficiente $C$ ). 
TABELA 4.29 - Multiplicadores do consumo de referência do teste T.2.A

\begin{tabular}{|c|c|c|c|}
\hline $\begin{array}{c}\text { Horas do } \\
\text { dia de } \\
\text { observação }\end{array}$ & $\begin{array}{c}\text { Multiplicadores } \\
\text { do consumo } \\
\text { de referência }\end{array}$ & $\begin{array}{c}\text { Horas do } \\
\text { dia de } \\
\text { observação }\end{array}$ & $\begin{array}{c}\text { Multiplicadores } \\
\text { do consumo } \\
\text { de referência }\end{array}$ \\
\hline $1^{\mathrm{a}}$ & 0,78 & $13^{\mathrm{a}}$ & 0 \\
\hline $2^{\mathrm{a}}$ & 0,38 & $14^{\mathrm{a}}$ & 0 \\
\hline $3^{\mathrm{a}}$ & 0 & $15^{\mathrm{a}}$ & 0 \\
\hline $4 \mathrm{a}$ & 0 & $16^{\mathrm{a}}$ & 0,89 \\
\hline $5^{\mathrm{a}}$ & 0 & $17^{\mathrm{a}}$ & 1,99 \\
\hline $6^{\mathrm{a}}$ & 0,02 & $18^{\mathrm{a}}$ & 2,27 \\
\hline $7^{\mathrm{a}}$ & 0,01 & $19^{\mathrm{a}}$ & 1,53 \\
\hline $8^{\mathrm{a}}$ & 0 & $20^{\mathrm{a}}$ & 1,07 \\
\hline $9^{\mathrm{a}}$ & 0 & $21^{\mathrm{a}}$ & 1,23 \\
\hline $10^{\mathrm{a}}$ & 0 & $22^{\mathrm{a}}$ & 1,42 \\
\hline $11^{\mathrm{a}}$ & 0 & $23^{\mathrm{a}}$ & 1,87 \\
\hline $12^{\mathrm{a}}$ & 0 & $24^{\mathrm{a}}$ & 1,61 \\
\hline
\end{tabular}

TABELA 4.30 - Valores dos $K f s$ para o T.2.A

\begin{tabular}{|c|c|c|c|c|c|c|c|}
\hline Nó & $K f s\left(.10^{-4}\right)$ & Nó & Kfs $\left(.10^{-4)}\right.$ & Nó & Kfs $\left(.10^{-4}\right)$ & Nó & Kfs $\left(.10^{-4}\right)$ \\
\hline 1 & 5,61 & \begin{tabular}{|l|}
21 \\
\end{tabular} & 5,84 & 42 & 4,93 & \begin{tabular}{|l|}
63 \\
\end{tabular} & 8,74 \\
\hline 2 & 2,17 & 22 & 8,54 & 43 & 13,29 & \begin{tabular}{|l|}
64 \\
\end{tabular} & 5,84 \\
\hline 3 & 7,21 & 23 & 5,60 & 44 & 14,21 & 65 & 5,88 \\
\hline 4 & 11,25 & 24 & 4,13 & 45 & 5,82 & 66 & 8,81 \\
\hline 5 & 5,80 & 25 & 5,35 & 46 & 3,70 & 67 & 5,84 \\
\hline 6 & 5,09 & 26 & 4,12 & 47 & 3,80 & 68 & 5,90 \\
\hline 7 & 4,48 & 27 & 4,87 & 48 & 7,95 & 69 & 8,87 \\
\hline 8 & 11,19 & 28 & 6,84 & 49 & 3,38 & \begin{tabular}{|l|}
70 \\
\end{tabular} & 5,88 \\
\hline 9 & 7,20 & \begin{tabular}{|l|}
29 \\
\end{tabular} & 4,87 & 50 & 5,84 & \begin{tabular}{|l|}
71 \\
\end{tabular} & 5,89 \\
\hline 10 & 12,85 & 30 & 4,88 & 51 & 8,76 & 72 & 8,87 \\
\hline 11 & 7,87 & 31 & 6,84 & 52 & 5,83 & 73 & 5,91 \\
\hline 12 & 7,33 & 32 & 4,88 & 53 & 5,83 & 74 & 8,07 \\
\hline 13 & 11,72 & 33 & 5,05 & 54 & 8,76 & 75 & 9,48 \\
\hline 14 & 7,31 & 34 & 7,14 & 55 & 5,84 & 76 & 6,06 \\
\hline 15 & 6,75 & 35 & 5,02 & 56 & 5,83 & 77 & 2,44 \\
\hline 16 & 10,60 & 36 & 5,11 & 57 & 8,76 & 78 & 10,98 \\
\hline 17 & 6,72 & \begin{tabular}{|l|}
37 \\
\end{tabular} & 7,31 & 58 & 5,83 & \begin{tabular}{|l|}
79 \\
\end{tabular} & 10,50 \\
\hline 18 & 6,21 & 38 & 5,11 & 59 & 5,82 & 80 & 15,44 \\
\hline 19 & 9,54 & 39 & 5,13 & 60 & 8,76 & \begin{tabular}{|l|}
81 \\
\end{tabular} & 2,87 \\
\hline 20 & 6,27 & 40 & 7,35 & 61 & 5,84 & 82 & 3,47 \\
\hline & & 41 & 5,11 & 62 & 5,81 & & \\
\hline
\end{tabular}




\subsubsection{Resultados do Teste 1 do modelo Germanopoulos e Jowitt (T.1.GJ)}

Neste primeiro teste com o modelo de GERMANOPOULOS \& JOWITT (1989), o objetivo foi explorar o mesmo intervalo de procura dado ao coeficiente $C$ do teste T.1.A, só que variando também o expoente $\beta$, já que o atual modelo permite essa variação. Neste primeiro teste (T.1.GJ) procurou-se aumentar o intervalo de procura do expoente diminuindo o limite inferior da procura sugerido por GOODWIN (1980). Os resultados são apresentados nas Tabelas 4.31 e 4.32. A Tabela 4.34 apresenta os valores dos $K f$ s para a melhor semente.

TABELA 4.31 - Resultados obtidos no teste T.1.GJ

\begin{tabular}{|c|c|c|c|c|c|c|c|c|c|c|c|c|c|}
\hline \multirow{2}{*}{\multicolumn{2}{|c|}{ Padrões }} & \multicolumn{5}{|c|}{ Valores simulados } & \multirow{4}{*}{ 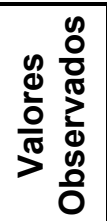 } & \multirow{3}{*}{\multicolumn{5}{|c|}{$\begin{array}{c}\text { Valores simulados } \\
\mathbf{2} \\
\text { Semente }\end{array}$}} & \multirow{4}{*}{ 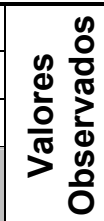 } \\
\hline & & \multirow{2}{*}{\multicolumn{5}{|c|}{1}} & & & & & & & \\
\hline \multirow{2}{*}{\multicolumn{2}{|c|}{$\begin{array}{c}\text { Variáveis } \\
\text { de } \\
\text { estado }\end{array}$}} & & & & & & & & & & & & \\
\hline & & 200 & 300 & 700 & 1000 & 2000 & & 200 & 300 & 700 & 1000 & 2000 & \\
\hline \multicolumn{2}{|c|}{$\begin{array}{c}\text { Vazão } \\
\text { (L/s) }\end{array}$} & 2,98 & 2,97 & 2,97 & 2,98 & 2,98 & 2,98 & 6,12 & 6,12 & 6,12 & 6,12 & 6,12 & 6,18 \\
\hline \multirow{4}{*}{ 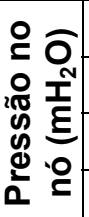 } & 22 & 32,11 & 32,11 & 32,11 & 32,11 & 32,11 & 31,23 & 29,48 & 29,48 & 29,49 & 29,48 & 29,48 & 28,59 \\
\hline & 44 & 35,77 & 35,77 & 35,77 & 35,77 & 35,77 & 35,00 & 33,07 & 33,07 & 33,08 & 3,07 & 33,07 & 31,90 \\
\hline & 66 & 23,70 & 23,70 & 23,70 & 23,70 & 23,70 & 23,66 & 21,05 & 21,05 & 21,05 & 21,05 & 21,05 & 20,78 \\
\hline & 80 & 32,14 & 32,14 & 32,14 & 32,14 & 32,13 & 31,86 & 29,57 & 29,58 & 29,58 & 29,57 & 29,57 & 29,15 \\
\hline \multicolumn{2}{|c|}{$\begin{array}{l}\text { Perdas } \\
\text { (L/s) }\end{array}$} & 0,80 & 0,73 & 0,73 & 0,93 & 0,95 & & 0,71 & 0,66 & 0,66 & 0,83 & 0,85 & \\
\hline
\end{tabular}

TABELA 4.32 - Valores da função objetivo e resultados do teste T.1.GJ

\begin{tabular}{|c|c|c|c|c|c|}
\hline \multirow{2}{*}{ Função Objetivo $\left(.10^{-3}\right)$} & \multicolumn{5}{|c|}{ Semente } \\
\cline { 2 - 6 } & 200 & 300 & 700 & 1000 & 2000 \\
\cline { 2 - 6 } & 4,827 & 4,842 & 4,846 & 4,810 & 4,801 \\
\hline Rugosidade $\left.(\varepsilon){\mathrm{mm}\left(.10^{-3}\right)}\right)$ & 9,79 & 9,17 & 9,17 & 7,84 & 9,21 \\
\hline Coeficiente $(C)\left(.10^{-6}\right)$ & 1,22 & 1,19 & 1,49 & 1,49 & 1,48 \\
\hline Expoente $(\beta)$ & 1,19 & 1,17 & 1,10 & 1,18 & 1,18 \\
\hline
\end{tabular}


Observando-se a Tabela 4.32 concluiu-se que a melhor semente foi a 2000 que apresentou também resultados para o coeficiente $C$ e rugosidade próximos ao limite superior dado ao intervalo de procura. O expoente não ficou tão próximo ao limite superior denunciando ser adequado este limite. Quanto às variáveis de estado, os resultados da Tabela 4.31 foram próximos aos encontrados para o teste T.1.A, desta forma conclui-se que, mesmo dada à liberdade de procura para o expoente $\beta$, os resultados dos testes T.1.A e T.1GJ são próximos. A Tabela 4.33 apresenta os multiplicadores do consumo de referência para os resultados obtidos com a melhor semente (rugosidade, expoente e coeficiente $C$ ).

TABELA 4.33 - Multiplicadores do consumo de referência do teste T.1.GJ

\begin{tabular}{|c|c|c|c|}
\hline $\begin{array}{c}\text { Horas do } \\
\text { dia de } \\
\text { observação }\end{array}$ & $\begin{array}{c}\text { Multiplicadores } \\
\text { do consumo } \\
\text { de referência }\end{array}$ & $\begin{array}{c}\text { Horas do } \\
\text { dia de } \\
\text { observação }\end{array}$ & $\begin{array}{c}\text { Multiplicadores } \\
\text { do consumo } \\
\text { de referência }\end{array}$ \\
\hline $1^{\mathrm{a}}$ & 1,64 & $1^{\mathrm{a}}$ & 0 \\
\hline $2^{\mathrm{a}}$ & 1,24 & $2^{\mathrm{a}}$ & 0 \\
\hline $3^{\mathrm{a}}$ & 0,80 & $3^{\mathrm{a}}$ & 0,47 \\
\hline $4 \mathrm{a}$ & 0 & $4 \mathrm{a}$ & 1,67 \\
\hline $5^{\mathrm{a}}$ & 0 & $5^{\mathrm{a}}$ & 2,77 \\
\hline $6^{\mathrm{a}}$ & 0,26 & $6^{\mathrm{a}}$ & 3,04 \\
\hline $7^{\mathrm{a}}$ & 0,11 & $7^{\mathrm{a}}$ & 2,31 \\
\hline $8^{\mathrm{a}}$ & 0 & $8^{\mathrm{a}}$ & 1,83 \\
\hline $9^{\mathrm{a}}$ & 0 & $9^{\mathrm{a}}$ & 1,99 \\
\hline $10^{\mathrm{a}}$ & 0 & $10^{\mathrm{a}}$ & 2,18 \\
\hline $11^{\mathrm{a}}$ & 0 & $11^{\mathrm{a}}$ & 2,62 \\
\hline $12^{\mathrm{a}}$ & 0 & $12^{\mathrm{a}}$ & 2,37 \\
\hline
\end{tabular}


TABELA 4.34 - Valores dos Kfs para o T.1.GJ

\begin{tabular}{|c|c|c|c|c|c|c|c|}
\hline Nó & Kfs $\left(.10^{-4}\right)$ & Nó & Kfs $\left(.10^{-4}\right)$ & Nó & Kfs $\left(.10^{-4}\right)$ & Nó & $\operatorname{Kfs}\left(.10^{-4}\right)$ \\
\hline 1 & 1,77 & 21 & 1,84 & 42 & 1,55 & 63 & 2,76 \\
\hline 2 & 0,68 & 22 & 2,69 & 43 & 4,19 & 64 & 1,84 \\
\hline 3 & 2,27 & 23 & 1,77 & 44 & 4,48 & 65 & 1,85 \\
\hline 4 & 3,55 & 24 & 1,30 & 45 & 1,84 & 66 & 2,78 \\
\hline 5 & 1,83 & 25 & 1,69 & 46 & 1,17 & 67 & 1,84 \\
\hline 6 & 1,60 & 26 & 1,30 & 47 & 1,20 & 68 & 1,86 \\
\hline 7 & 1,41 & 27 & 1,54 & 48 & 2,51 & 69 & 2,80 \\
\hline 8 & 3,53 & 28 & 2,16 & 49 & 1,06 & 70 & 1,85 \\
\hline 9 & 2,27 & 29 & 1,54 & 50 & 1,84 & 71 & 1,86 \\
\hline 10 & 4,05 & 30 & 1,54 & 51 & 2,76 & 72 & 2,80 \\
\hline 11 & 2,48 & 31 & 2,16 & 52 & 1,84 & 73 & 1,86 \\
\hline 12 & 2,31 & 32 & 1,54 & 53 & 1,84 & 74 & 2,55 \\
\hline 13 & 3,69 & 33 & 1,59 & 54 & 2,76 & 75 & 2,99 \\
\hline 14 & 2,30 & 34 & 2,25 & 55 & 1,84 & 76 & 1,91 \\
\hline 15 & 2,13 & 35 & 1,58 & 56 & 1,84 & 77 & 0,76 \\
\hline 16 & 3,34 & 36 & 1,61 & 57 & 2,76 & 78 & 3,46 \\
\hline 17 & 2,12 & 37 & 2,31 & 58 & 1,84 & 79 & 3,31 \\
\hline 18 & 1,96 & 38 & 1,61 & 59 & 1,84 & 80 & 4,87 \\
\hline 19 & 3,01 & 39 & 1,62 & 60 & 2,76 & 81 & 0,91 \\
\hline 20 & 1,98 & 40 & 2,32 & 61 & 1,84 & 82 & 1,09 \\
\hline & & 41 & 1,61 & 62 & 1,83 & & \\
\hline
\end{tabular}

\subsubsection{Resultados do Teste 2 do modelo Germanopoulos e Jowitt (T.2.GJ)}

No segundo teste, considerando o modelo GERMANOPOULOS \& JOWITT (1989), houve apenas a alteração do limite inferior do expoente $\beta$, visto que, no teste anterior T.1.GJ, o resultado para o expoente ficou distante do limite inferior. O intervalo para o coeficiente $C$ foi o mesmo utilizado no teste anterior (T.1.GJ) para permitir a comparação dos resultados. Os resultados são apresentados nas Tabelas 4.35 e 4.36 . 
TABELA 4.35 - Resultados obtidos no teste T.2.GJ

\begin{tabular}{|c|c|c|c|c|c|c|c|c|c|c|c|c|c|}
\hline & \multicolumn{5}{|c|}{ Valores simulados } & \multirow{4}{*}{ 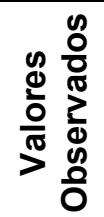 } & \multirow{3}{*}{\multicolumn{5}{|c|}{$\begin{array}{c}\text { Valores simulados } \\
\mathbf{2} \\
\text { Semente }\end{array}$}} & \multirow{4}{*}{ 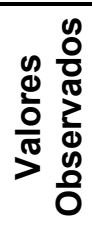 } \\
\hline & & \multirow{2}{*}{\multicolumn{5}{|c|}{$\begin{array}{c}1 \\
\text { Semente } \\
\end{array}$}} & & & & & & & \\
\hline \multirow{2}{*}{\multicolumn{2}{|c|}{$\begin{array}{c}\text { Padrōes } \\
\text { Variáveis } \\
\text { de } \\
\text { estado } \\
\end{array}$}} & & & & & & & & & & & & \\
\hline & & & & \multirow{2}{*}{$\begin{array}{l}200 \\
6,12 \\
\end{array}$} & \multirow{2}{*}{$\begin{array}{r}300 \\
6,12 \\
\end{array}$} & \multirow{2}{*}{\begin{tabular}{|l|}
700 \\
6,12
\end{tabular}} & \multirow{2}{*}{$\begin{array}{l}1000 \\
6,11 \\
\end{array}$} & \multirow{2}{*}{\begin{tabular}{|l|}
2000 \\
6,12 \\
\end{tabular}} & \\
\hline \multicolumn{2}{|c|}{$\begin{array}{l}\text { Vazão } \\
\text { (L/s) }\end{array}$} & \multirow{2}{*}{$\begin{array}{l}2,97 \\
32,11\end{array}$} & \multirow{2}{*}{\begin{tabular}{c|}
2,97 \\
32,11 \\
\end{tabular}} & \multirow{2}{*}{\begin{tabular}{|c|}
2,98 \\
32,11 \\
\end{tabular}} & \multirow{2}{*}{$\begin{array}{l}2,94 \\
32,11\end{array}$} & \multirow{2}{*}{$\begin{array}{l}2,98 \\
32,11\end{array}$} & \multirow{2}{*}{\begin{tabular}{|c|}
2,98 \\
31,23 \\
\end{tabular}} & & & & & & \multirow{2}{*}{$\begin{array}{l}6,18 \\
28,59 \\
\end{array}$} \\
\hline \multirow{4}{*}{ 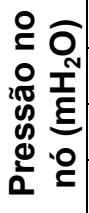 } & 22 & & & & & & & 29,48 & 29,48 & 29,48 & 29,49 & 29,48 & \\
\hline & 44 & 77 & 35,77 & 3 & 35,78 & 35,77 & 35,00 & 33,07 & 33,07 & 33,07 & 33,09 & 33,07 & 31,90 \\
\hline & 66 & 3,70 & 23,70 & 23,70 & 3,70 & 3,70 & 23,66 & 1,05 & 1,05 & 21,05 & 21,05 & 21,05 & 20,78 \\
\hline & 80 & ,14 &, 14 & 32,14 & 14 &, 13 & 31,86 &, 57 & 29,57 & 29,57 & 29,58 & 29,57 & 29,15 \\
\hline \multicolumn{2}{|c|}{$\begin{array}{l}\text { Perdas } \\
\text { (L/s) }\end{array}$} & 0, & 0,92 & 0,81 & 0,09 & $0, \subseteq$ & & 0, & 0,82 & 0,73 & 0,09 & 0,87 & \\
\hline
\end{tabular}

TABELA 4.36 - Valores da função objetivo e resultados do teste T.2.GJ

\begin{tabular}{|c|c|c|c|c|c|}
\hline \multirow{2}{*}{ Função Objetivo $\left(.10^{-3}\right)$} & \multicolumn{5}{|c|}{ Semente } \\
\cline { 2 - 6 } & 200 & 300 & 700 & 1000 & 2000 \\
\cline { 2 - 6 } & 4,809 & 4,813 & 4,828 & 4,806 & 4,798 \\
\hline Rugosidade $(\varepsilon){\mathrm{mm}\left(.10^{-3}\right)}^{-9,79}$ & 7,84 & 7,82 & 5,55 & 8,08 \\
\hline Coeficiente $(C)\left(.10^{-6}\right)$ & 1,38 & 1,43 & 1,25 & 1,49 & 1,48 \\
\hline Expoente $(\beta)$ & 1,19 & 1,18 & 1,19 & 1,18 & 1,19 \\
\hline
\end{tabular}

Conforme a Tabela 4.36 observou-se uma pequena melhora na função objetivo em relação ao teste T.1.GJ. Outro comportamento que também se pôde notar foi a convergência do expoente $\beta$ para o limite superior, contudo a rugosidade alterou-se e ficou mais distante do limite superior, enquanto que no coeficiente $C$ não houve alteração significativa. Em relação às variáveis de estado, houve pequenas alterações (Tabela 4.35). A Tabela 4.37 apresenta os multiplicadores do consumo de referência para os resultados obtidos com a melhor semente (rugosidade, expoente e coeficiente $C$ ). A Tabela 4.38 apresenta os valores dos $K f$ s para a melhor semente. 
TABELA 4.37 - Multiplicadores do consumo de referência do teste T.2.GJ

\begin{tabular}{|c|c|c|c|}
\hline $\begin{array}{c}\text { Horas do } \\
\text { dia de } \\
\text { observação }\end{array}$ & $\begin{array}{c}\text { Multiplicadores } \\
\text { do consumo } \\
\text { de referência }\end{array}$ & $\begin{array}{c}\text { Horas do } \\
\text { dia de } \\
\text { observação }\end{array}$ & $\begin{array}{c}\text { Multiplicadores } \\
\text { do consumo } \\
\text { de referência }\end{array}$ \\
\hline $1^{\mathrm{a}}$ & 1,63 & $1^{\mathrm{a}}$ & 0 \\
\hline $2^{\mathrm{a}}$ & 1,23 & $2^{\mathrm{a}}$ & 0 \\
\hline $3^{\mathrm{a}}$ & 0,79 & $3^{\mathrm{a}}$ & 0,47 \\
\hline $4 \mathrm{a}$ & 0 & $4 \mathrm{a}$ & 1,66 \\
\hline $5^{\mathrm{a}}$ & 0 & $5^{\mathrm{a}}$ & 2,76 \\
\hline $6^{\mathrm{a}}$ & 0,25 & $6^{\mathrm{a}}$ & 3,04 \\
\hline $7^{\mathrm{a}}$ & 0,11 & $7^{\mathrm{a}}$ & 2,30 \\
\hline $8^{\mathrm{a}}$ & 0 & $8^{\mathrm{a}}$ & 1,83 \\
\hline $9^{\mathrm{a}}$ & 0 & $9^{\mathrm{a}}$ & 1,99 \\
\hline $10^{\mathrm{a}}$ & 0 & $10^{\mathrm{a}}$ & 2,17 \\
\hline $11^{\mathrm{a}}$ & 0 & $11^{\mathrm{a}}$ & 2,61 \\
\hline $12^{\mathrm{a}}$ & 0 & $12^{\mathrm{a}}$ & 2,36 \\
\hline
\end{tabular}

TABELA 4.38 - Valores dos Kfs para o T.2.GJ

\begin{tabular}{|c|c|c|c|c|c|c|c|}
\hline Nó & $K f s\left(.10^{-4}\right)$ & Nó & Kfs $\left(.10^{-4}\right)$ & Nó & Kfs $\left(.10^{-4}\right)$ & Nó & Kfs $\left(.10^{-4}\right)$ \\
\hline 1 & 1,77 & 21 & 1,84 & 42 & 1,55 & 63 & 2,75 \\
\hline 2 & $0,60,8$ & 22 & 2,69 & 43 & 4,19 & 64 & 1,84 \\
\hline 3 & 2,27 & 23 & 1,76 & 44 & 4,47 & 65 & 1,85 \\
\hline 4 & 3,54 & 24 & 1,30 & 45 & 1,83 & 66 & 2,77 \\
\hline 5 & 1,83 & 25 & 1,68 & 46 & 1,17 & 67 & 1,84 \\
\hline 6 & 1,60 & 26 & 1,30 & 47 & 1,20 & 68 & 1,86 \\
\hline 7 & 1,41 & 27 & 1,53 & \begin{tabular}{|l|}
48 \\
\end{tabular} & 2,50 & 69 & 2,79 \\
\hline 8 & 3,52 & 28 & 2,15 & 49 & 1,06 & 70 & 1,85 \\
\hline 9 & 2,27 & 29 & 1,53 & 50 & 1,84 & 71 & 1,85 \\
\hline 10 & 4,05 & 30 & 1,54 & 51 & 2,76 & 72 & 2,79 \\
\hline 11 & 2,48 & 31 & 2,15 & 52 & 1,84 & 73 & 1,86 \\
\hline 12 & 2,31 & 32 & 1,54 & 53 & 1,84 & 74 & 2,54 \\
\hline 13 & 3,69 & 33 & 1,59 & 54 & 2,76 & 75 & 2,98 \\
\hline 14 & 2,30 & 34 & 2,25 & 55 & 1,84 & 76 & 1,91 \\
\hline 15 & 2,13 & 35 & 1,58 & 56 & 1,84 & 77 & 0,76 \\
\hline 16 & 3,34 & 36 & 1,61 & 57 & 2,76 & 78 & 3,46 \\
\hline 17 & 2,12 & 37 & 2,30 & 58 & 1,83 & 79 & 3,31 \\
\hline 18 & 1,96 & 38 & 1,61 & 59 & 1,83 & 80 & 4,86 \\
\hline 19 & 3,00 & 39 & 1,62 & 60 & 2,76 & 81 & 0,91 \\
\hline 20 & 1,98 & 40 & 2,31 & 61 & 1,84 & 82 & 1,09 \\
\hline & & 41 & 1,61 & \begin{tabular}{|l|}
62 \\
\end{tabular} & 1,83 & & \\
\hline
\end{tabular}




\subsubsection{Resultados do Teste 3 do modelo Germanopoulos e Jowitt (T.3.GJ)}

Neste teste T.3.GJ foram testadas as reações dos resultados com a alteração do intervalo de procura do coeficiente $C$, para tanto houve um acréscimo no limite superior, visto que os resultados anteriores convergiram para o limite dado. Ainda neste teste, foi adotado o mesmo intervalo de procura do expoente $\beta$ do teste T.1.GJ para permitir a comparação dos resultados. Os resultados são apresentados nas Tabelas 4.39 e 4.40.

TABELA 4.39 - Resultados obtidos no teste T.3.GJ

\begin{tabular}{|c|c|c|c|c|c|c|c|c|c|c|c|c|c|}
\hline \multirow{2}{*}{\multicolumn{2}{|c|}{ Padrões }} & \multicolumn{5}{|c|}{ Valores simulados } & \multirow{4}{*}{ 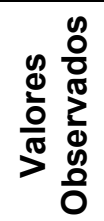 } & \multirow{3}{*}{\multicolumn{5}{|c|}{$\begin{array}{c}\text { Valores simulados } \\
\mathbf{2} \\
\text { Semente }\end{array}$}} & \multirow{4}{*}{ 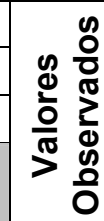 } \\
\hline & & \multirow{2}{*}{\multicolumn{5}{|c|}{$\frac{1}{\text { Semente }}$}} & & & & & & & \\
\hline \multirow{2}{*}{\multicolumn{2}{|c|}{$\begin{array}{c}\text { Variáveis } \\
\text { de } \\
\text { estado }\end{array}$}} & & & & & & & & & & & & \\
\hline & & 200 & 300 & 700 & 1000 & 2000 & & 200 & 300 & 700 & 1000 & 2000 & \\
\hline \multicolumn{2}{|c|}{$\begin{array}{c}\text { Vazão } \\
\text { (L/s) }\end{array}$} & 2,98 & 2,98 & 2,94 & 2,94 & 2,98 & 2,98 & 6,12 & 6,12 & 6,11 & 11 & 6,13 & 6,18 \\
\hline \multirow{4}{*}{ 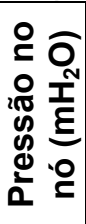 } & 22 & 32,10 & 32,10 & 32,11 & 32,11 & 32,09 & 31,23 & 29,47 & 29,47 & 29,49 & 29,49 & 29,46 & 28,59 \\
\hline & 44 & 35,75 & 35,75 & 35,79 & 35,79 & 35,74 & 35,00 & 33,04 & 33,04 & 33,09 & 33,09 & 33,02 & 31,90 \\
\hline & 66 & 23,70 & 23,70 & 23,70 & 23,70 & 23,70 & 23,66 & 21,05 & 21,05 & 21,05 & 21,05 & 21,05 & 20,78 \\
\hline & 80 & 32,12 & 32,12 & 32,14 & 32,14 & 32,12 & 31,86 & 29,56 & 29,56 & 29,58 & 29,58 & 29,55 & 29,15 \\
\hline \multicolumn{2}{|c|}{$\begin{array}{l}\text { Perdas } \\
\text { (L/s) }\end{array}$} & 2,31 & 2,19 & 0,06 & 0,06 & 2,71 & & 2,07 & 1,95 & 0,06 & 0,06 & 2,42 & \\
\hline
\end{tabular}

TABELA 4.40 - Valores da função objetivo e resultados do teste T.3.GJ

\begin{tabular}{|c|c|c|c|c|c|}
\hline \multirow{3}{*}{ Função Objetivo $\left(.10^{-3}\right)$} & \multicolumn{5}{|c|}{ Semente } \\
\cline { 2 - 6 } & 200 & 300 & 700 & 1000 & 2000 \\
\cline { 2 - 6 } & 4,584 & 4,597 & 4,503 & 4,536 & 4,484 \\
\hline Rugosidade $(\varepsilon){\mathrm{mm}\left(.10^{-3}\right)}^{6,16}$ & 9,83 & 7,01 & 9,30 & 9,21 \\
\hline Coeficiente $(C)\left(.10^{-6}\right)$ & 4,14 & 3,55 & 4,17 & 4,48 & 4,36 \\
\hline Expoente $(\beta)$ & 1,14 & 1,17 & 1,18 & 1,14 & 1,17 \\
\hline
\end{tabular}

Novamente a semente 2000 foi a de melhor resultado, mostrando, segundo a Tabela 4.40, que a rugosidade e o coeficiente $C$ convergiram para os seus respectivos limites superiores. No entanto, em relação à função objetivo, houve uma melhora substancial quando comparada aos dois testes realizados anteriormente (T.1.GJ e T.2.GJ). Na Tabela 4.39 é possível observar também um acréscimo nas perdas e uma melhor aproximação dos valores 
simulados das variáveis de estado em relação aos valores observados. A Tabela 4.41 apresenta os multiplicadores do consumo de referência para os resultados obtidos com a melhor semente (rugosidade, expoente e coeficiente $C$ ). A Tabela 4.42 apresenta os valores dos $K f$ s para a melhor semente.

TABELA 4.41 - Multiplicadores do consumo de referência do teste T.3.GJ

\begin{tabular}{|c|c|c|c|}
\hline $\begin{array}{c}\text { Horas do } \\
\text { dia de } \\
\text { observação }\end{array}$ & $\begin{array}{c}\text { Multiplicadores } \\
\text { da consumo } \\
\text { de referência }\end{array}$ & $\begin{array}{c}\text { Horas do } \\
\text { dia de } \\
\text { observação }\end{array}$ & $\begin{array}{c}\text { Multiplicadores } \\
\text { da consumo } \\
\text { de referência }\end{array}$ \\
\hline $1^{\text {a }}$ & 0,89 & $1^{\mathrm{a}}$ & 0 \\
\hline $2^{\mathrm{a}}$ & 0,49 & $2^{\mathrm{a}}$ & 0 \\
\hline $3^{\mathrm{a}}$ & 0,03 & $3^{\mathrm{a}}$ & 0,01 \\
\hline $4 \mathrm{a}$ & 0 & $4 \mathrm{a}$ & 0,99 \\
\hline $5^{\mathrm{a}}$ & 0 & $5^{\mathrm{a}}$ & 2,09 \\
\hline $6^{\mathrm{a}}$ & 0,02 & $6^{\mathrm{a}}$ & 2,37 \\
\hline $7^{\mathrm{a}}$ & 0,01 & $7^{\mathrm{a}}$ & 1,64 \\
\hline $8^{\mathrm{a}}$ & 0 & $8^{\mathrm{a}}$ & 1,17 \\
\hline $9^{\mathrm{a}}$ & 0 & $9^{\mathrm{a}}$ & 1,33 \\
\hline $10^{\mathrm{a}}$ & 0 & $10^{\mathrm{a}}$ & 1,52 \\
\hline $11^{\mathrm{a}}$ & 0 & $11^{\mathrm{a}}$ & 1,96 \\
\hline $12^{\mathrm{a}}$ & 0 & $12^{\mathrm{a}}$ & 1,71 \\
\hline
\end{tabular}

TABELA 4.42 - Valores dos $K f s$ para o T.3.GJ

\begin{tabular}{|c|c|c|c|c|c|c|c|}
\hline Nó & Kfs $\left(.10^{-4}\right)$ & Nó & $K f s\left(.10^{-4}\right)$ & Nó & Kfs $\left(.10^{-4}\right)$ & Nó & Kfs $\left(.10^{-4}\right)$ \\
\hline 1 & 5,22 & 21 & 5,44 & 42 & 4,59 & 63 & 8,14 \\
\hline 2 & 2,02 & 22 & 7,95 & 43 & 12,37 & 64 & 5,44 \\
\hline 3 & 6,72 & 23 & 5,21 & 44 & 13,23 & 65 & 5,47 \\
\hline 4 & 10,47 & 24 & 3,84 & 45 & 5,42 & 66 & 8,20 \\
\hline 5 & 5,40 & 25 & 4,98 & 46 & 3,45 & 67 & 5,43 \\
\hline 6 & 4,74 & 26 & 3,84 & 47 & 3,53 & 68 & 5,49 \\
\hline 7 & 4,17 & 27 & 4,53 & 48 & 7,40 & 69 & 8,26 \\
\hline 8 & 10,41 & 28 & 6,37 & 49 & 3,14 & 70 & 5,47 \\
\hline 9 & 6,70 & 29 & 4,54 & 50 & 5,43 & 71 & 5,48 \\
\hline 10 & 11,96 & 30 & 4,54 & 51 & 8,15 & 72 & 8,26 \\
\hline 11 & 7,32 & 31 & 6,37 & 52 & 5,43 & 73 & 5,50 \\
\hline 12 & 6,83 & 32 & 4,54 & 53 & 5,43 & 74 & 7,52 \\
\hline 13 & 10,91 & 33 & 4,70 & 54 & 8,15 & 75 & 8,82 \\
\hline 14 & 6,80 & 34 & 6,65 & 55 & 5,43 & 76 & 5,64 \\
\hline 15 & 6,28 & 35 & 4,67 & 56 & 5,43 & 77 & 2,27 \\
\hline 16 & 9,86 & 36 & 4,76 & 57 & 8,15 & 78 & 10,22 \\
\hline 17 & 6,26 & 37 & 6,81 & 58 & 5,42 & 79 & 9,78 \\
\hline 18 & 5,78 & 38 & 4,76 & 59 & 5,42 & 80 & 14,37 \\
\hline 19 & 8,88 & 39 & 4,78 & 60 & 8,15 & 81 & 2,68 \\
\hline 20 & 5,84 & 40 & 6,84 & 61 & 5,43 & 82 & 3,23 \\
\hline & & 41 & 4,76 & 62 & 5,40 & & \\
\hline
\end{tabular}




\subsubsection{Resultados do Teste 4 do modelo Germanopoulos e Jowitt (T.4.GJ)}

No quarto e último teste, considerando-se o modelo GERMANOPOULOS \& JOWITT (1989), foi alterado o intervalo do expoente $\beta$ com o objetivo de melhorar a função objetivo e testar o comportamento dos resultados com essa alteração. O intervalo de procura do coeficiente $C$ continua sendo o mesmo do teste T.3.GJ. Os resultados são apresentados nas Tabelas 4.43 e 4.44 .

TABELA 4.43 - Resultados obtidos no teste T.4.GJ

\begin{tabular}{|c|c|c|c|c|c|c|c|c|c|c|c|c|c|}
\hline \multirow{2}{*}{\multicolumn{2}{|c|}{ Padrões }} & \multicolumn{5}{|c|}{ Valores simulados } & \multirow{4}{*}{ 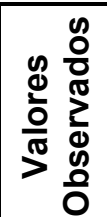 } & \multirow{3}{*}{\multicolumn{5}{|c|}{\begin{tabular}{|c|} 
Valores simulados \\
2 \\
Semente
\end{tabular}}} & \multirow{4}{*}{ 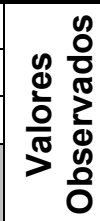 } \\
\hline & & \multirow{2}{*}{\multicolumn{5}{|c|}{1}} & & & & & & & \\
\hline \multirow{2}{*}{\multicolumn{2}{|c|}{$\begin{array}{l}\text { Variáveis } \\
\text { de } \\
\text { estado }\end{array}$}} & & & & & & & & & & & & \\
\hline & & 200 & 300 & 700 & 1000 & 2000 & & 200 & 300 & 700 & 1000 & 2000 & \\
\hline \multicolumn{2}{|c|}{$\begin{array}{c}\text { Vazão } \\
\text { (L/s) }\end{array}$} & 2,98 & 2,94 & 2,99 & 2,98 & 2,99 & 2,98 & 6,12 & 6,11 & 6,12 & 6,13 & 6,12 & 6,18 \\
\hline \multirow{4}{*}{ 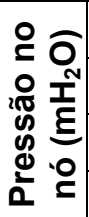 } & 22 & 32,10 & 32,11 & 32,09 & 32,09 & 32,09 & 31,23 & 29,47 & 29,49 & 29,46 & 29,46 & 29,46 & 28,59 \\
\hline & 44 & 35,75 & 35,79 & 35,74 & 35,74 & 35,73 & 35,00 & 33,03 & 33,09 & 33,02 & 33,02 & 33,01 & 31,90 \\
\hline & 66 & 23,70 & 23,70 & 23,70 & 23,70 & 23,70 & 23,66 & 21,05 & 21,05 & 21,05 & 21,05 & 21,05 & 20,78 \\
\hline & 80 & 32,12 & 32,14 & 32,12 & 32,12 & 32,11 & 31,86 & 29,55 & 29,58 & 29,55 & 29,55 & 29,55 & 29,15 \\
\hline \multicolumn{2}{|c|}{$\begin{array}{c}\text { Perdas } \\
\text { (L/s) }\end{array}$} & 2,45 & 0,03 & 2,91 & 2,69 & 2,95 & & 2,19 & 0,02 & 2,60 & 2,41 & 2,64 & \\
\hline
\end{tabular}

TABELA 4.44 - Valores da função objetivo e resultados do teste T.4.GJ

\begin{tabular}{|c|c|c|c|c|c|}
\hline \multirow{2}{*}{ Função Objetivo $\left(.10^{-3}\right)$} & \multicolumn{5}{|c|}{ Semente } \\
\cline { 2 - 6 } & 200 & 300 & 700 & 1000 & 2000 \\
\cline { 2 - 6 } & 4,534 & 4,550 & 4,478 & 4,495 & 4,466 \\
\hline Rugosidade $(\varepsilon){\mathrm{mm}\left(.10^{-3}\right)}^{9,79}$ & 7,42 & 7,01 & 6,97 & 7,81 \\
\hline Coeficiente $(C)\left(.10^{-6}\right)$ & 3,72 & 4,45 & 4,48 & 4,47 & 4,49 \\
\hline Expoente $(\beta)$ & 1,19 & 1,14 & 1,19 & 1,17 & 1,19 \\
\hline
\end{tabular}

A Tabela 4.44 revela o mesmo comportamento do coeficiente $C$ em ficar perto do limite superior do intervalo de procura, sem significante alteração do valor da função objetivo e com uma pequena aproximação do expoente para o limite superior. Na Tabela 4.43 foi possível observar as variáveis de estado que também não sofreram grandes alterações em relação ao teste anterior (T.3.GJ). A Tabela 4.45 apresenta os multiplicadores do consumo de 
referência para os resultados obtidos com a melhor semente (rugosidade, expoente e coeficiente $C$ ) e a Tabela 4.46, os valores dos $K f$ s para a melhor semente.

TABELA 4.45 - Multiplicadores do consumo de referência do teste T.4.GJ

\begin{tabular}{|c|c|c|c|}
\hline $\begin{array}{c}\text { Horas do } \\
\text { dia de } \\
\text { observação }\end{array}$ & $\begin{array}{c}\text { Multiplicadores } \\
\text { do consumo } \\
\text { de referência }\end{array}$ & $\begin{array}{c}\text { Horas do } \\
\text { dia de } \\
\text { observação }\end{array}$ & $\begin{array}{c}\text { Multiplicadores } \\
\text { do consumo } \\
\text { de referência }\end{array}$ \\
\hline $1^{\mathrm{a}}$ & 0,78 & $1^{\mathrm{a}}$ & 0 \\
\hline $2^{\mathrm{a}}$ & 0,38 & $2^{\mathrm{a}}$ & 0 \\
\hline $3^{\mathrm{a}}$ & 0,00 & $3^{\mathrm{a}}$ & 0,03 \\
\hline $4 \mathrm{a}$ & 0 & $4 \mathrm{a}$ & 0,90 \\
\hline $5^{\mathrm{a}}$ & 0 & $5^{\mathrm{a}}$ & 1,20 \\
\hline $6^{\mathrm{a}}$ & 0,02 & $6^{\mathrm{a}}$ & 2,28 \\
\hline $7^{\mathrm{a}}$ & 0 & $7^{\mathrm{a}}$ & 1,54 \\
\hline $8^{\mathrm{a}}$ & 0 & $8^{\mathrm{a}}$ & 1,08 \\
\hline $9^{\mathrm{a}}$ & 0 & $9^{\mathrm{a}}$ & 1,24 \\
\hline $10^{\mathrm{a}}$ & 0 & $10^{\mathrm{a}}$ & 1,43 \\
\hline $11^{\mathrm{a}}$ & 0 & $11^{\mathrm{a}}$ & 1,87 \\
\hline $12^{\mathrm{a}}$ & 0 & $12^{\mathrm{a}}$ & 1,62 \\
\hline
\end{tabular}

TABELA 4.46 - Valores dos $K f s$ para o T.4.GJ

\begin{tabular}{|c|c|c|c|c|c|c|c|}
\hline Nó & $K f s\left(.10^{-4}\right)$ & Nó & $K f s\left(.10^{-4}\right)$ & Nó & $K f s\left(.10^{-4}\right)$ & Nó & Kfs $\left(.10^{-4}\right)$ \\
\hline 1 & 5,38 & 21 & 5,60 & 42 & 4,72 & 63 & 8,38 \\
\hline 2 & 2,08 & 22 & 8,18 & \begin{tabular}{|l|}
43 \\
\end{tabular} & 12,74 & 64 & 5,60 \\
\hline 3 & 6,92 & 23 & 5,37 & 44 & 13,62 & 65 & 5,64 \\
\hline 4 & 10,78 & 24 & 3,96 & 45 & 5,58 & 66 & 8,44 \\
\hline 5 & 5,56 & 25 & 5,13 & 46 & 3,55 & 67 & 5,60 \\
\hline 6 & 4,88 & 26 & 3,95 & 47 & 3,64 & 68 & 5,66 \\
\hline 7 & 4,30 & 27 & 4,67 & 48 & 7,62 & 69 & 8,50 \\
\hline 8 & 10,72 & 28 & 6,55 & 49 & 3,24 & 70 & 5,64 \\
\hline 9 & 6,90 & 29 & 4,67 & 50 & 5,59 & 71 & 5,65 \\
\hline 10 & 12,32 & 30 & 4,68 & 51 & 8,39 & 72 & 8,50 \\
\hline 11 & 7,54 & 31 & 6,56 & 52 & 5,59 & 73 & 5,66 \\
\hline 12 & 7,03 & 32 & 4,68 & 53 & 5,59 & 74 & 7,74 \\
\hline 13 & 11,23 & 33 & 4,84 & 54 & 8,39 & 75 & 9,09 \\
\hline 14 & 7,01 & 34 & 6,85 & 55 & 5,59 & 76 & 5,81 \\
\hline 15 & 6,47 & 35 & 4,81 & 56 & 5,59 & 77 & 2,34 \\
\hline 16 & 10,16 & 36 & 4,90 & 57 & 8,39 & 78 & 10,52 \\
\hline 17 & 6,44 & 37 & 7,01 & 58 & 5,58 & 79 & 10,07 \\
\hline 18 & 5,95 & 38 & 4,90 & 59 & 5,58 & 80 & 14,80 \\
\hline 19 & 9,14 & 39 & 4,92 & 60 & 8,39 & 81 & 2,75 \\
\hline 20 & 6,01 & 40 & 7,04 & 61 & 5,60 & 82 & 3,33 \\
\hline & & 41 & 4,90 & 62 & 5,57 & & \\
\hline
\end{tabular}




\subsubsection{Resultados do Teste 1 do modelo Tucciarelli et al. (T.1.T)}

Neste primeiro teste com o modelo de TUCCIARELLI (1999), o objetivo foi explorar os mesmos intervalos de procura dados ao coeficiente $C$ e ao expoente $\beta$ do teste T.1.GJ, permitindo comparar os resultados. Os resultados são apresentados nas Tabelas 4.47 e 4.48.

TABELA 4.47 - Resultados obtidos no teste T.1.T

\begin{tabular}{|c|c|c|c|c|c|c|c|c|c|c|c|c|c|}
\hline \multirow{2}{*}{\multicolumn{2}{|c|}{ Padrões }} & \multicolumn{5}{|c|}{ Valores simulados } & \multirow{4}{*}{ 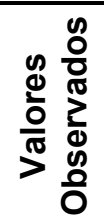 } & \multirow{3}{*}{\multicolumn{5}{|c|}{$\begin{array}{c}\text { Valores simulados } \\
\mathbf{2} \\
\text { Semente }\end{array}$}} & \multirow{4}{*}{ 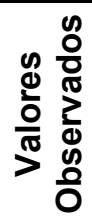 } \\
\hline & & \multirow{2}{*}{\multicolumn{5}{|c|}{1}} & & & & & & & \\
\hline \multirow{2}{*}{\multicolumn{2}{|c|}{$\begin{array}{l}\text { Variáveis } \\
\text { de } \\
\text { estado }\end{array}$}} & & & & & & & & & & & & \\
\hline & & 200 & 300 & 700 & 1000 & 2000 & & 200 & 300 & 700 & 1000 & 2000 & \\
\hline \multicolumn{2}{|c|}{$\begin{array}{c}\text { Vazão } \\
\text { (L/s) }\end{array}$} & 2,97 & 2,94 & 2,94 & 2,97 & 2,97 & 2,98 & 6,11 & 6,11 & 6,11 & 6,11 & 6,11 & 6,18 \\
\hline \multirow{4}{*}{ 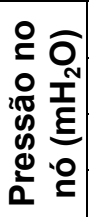 } & 22 & 32,10 & 32,11 & 32,11 & 32,10 & 32,10 & 31,23 & 29,48 & 29,49 & 29,49 & 29,48 & 29,48 & 28,59 \\
\hline & 44 & 35,77 & 35,78 & 35,78 & 35,76 & 35,76 & 35,00 & 33,06 & 3,09 & 33,09 & 33,06 & 33,05 & 31,90 \\
\hline & 66 & 23,70 & 23,70 & 23,70 & 23,70 & 23,70 & 23,66 & 21,05 & 21,05 & 21,05 & 21,05 & 21,05 & 20,78 \\
\hline & 80 & 32,13 & 32,14 & 32,14 & 32,13 & 32,13 & 31,86 & 29,57 & 29,58 & 29,58 & 29,57 & 29,56 & 29,15 \\
\hline \multicolumn{2}{|c|}{$\begin{array}{l}\text { Perdas } \\
\text { (L/s) }\end{array}$} & 1,55 & 0,06 & 0,06 & 1,70 & 1,94 & & 1,38 & 0,06 & 0,05 & 1,52 & 1,73 & \\
\hline
\end{tabular}

TABELA 4.48 - Valores da função objetivo e resultados do teste T.1.T

\begin{tabular}{|c|c|c|c|c|c|}
\hline \multirow{3}{*}{ Função Objetivo $\left(.10^{-3}\right)$} & \multicolumn{5}{|c|}{ Semente } \\
\cline { 2 - 6 } & 200 & 300 & 700 & 1000 & 2000 \\
\cline { 2 - 6 } & 4,811 & 4,825 & 4,757 & 4,789 & 4,734 \\
\hline Rugosidade $(\varepsilon) \mathrm{mm}\left(.10^{-3}\right)$ & 9,50 & 9,17 & 9,17 & 8,87 & 8,18 \\
\hline Coeficiente teta $(\theta)\left(.10^{-8}\right)$ & 1,16 & 1,19 & 1,49 & 1,49 & 1,48 \\
\hline Expoente $(\beta)$ & 1,19 & 1,17 & 1,16 & 1,14 & 1,18 \\
\hline
\end{tabular}

Para o teste T.1.T a melhor semente foi a 2000, que na Tabela 4.48 apresentou o coeficiente $\theta$ tento a mesma tendência do coeficiente $C$ (sempre ficar perto do limite superior do intervalo de procura), contudo a rugosidade e o expoente $\beta$ não ficaram tão próximos do limite superior do intervalo de procura. Na Tabela 4.47, pôde-se observar que as variáveis de estado simuladas estão próximas dos valores observados. No entanto, quando comparados os valores das perdas em relação ao teste T.1.GJ, conclui-se que o modelo de TUCCIARELLI et al. (1999) resulta em valores mais altos para as perdas. A Tabela 4.49 apresenta os 
multiplicadores do consumo de referência para os resultados obtidos com a melhor semente(rugosidade, expoente e coeficiente $\theta$ ) e a Tabela 4.50 , os valores dos $K f$ s para a melhor semente.

TABELA 4.49 - Multiplicadores do consumo de referência do teste T.1.T

\begin{tabular}{|c|c|c|c|}
\hline $\begin{array}{c}\text { Horas do } \\
\text { dia de } \\
\text { observação }\end{array}$ & $\begin{array}{c}\text { Multiplicadores } \\
\text { do consumo } \\
\text { de referência }\end{array}$ & $\begin{array}{c}\text { Horas do } \\
\text { dia de } \\
\text { observação }\end{array}$ & $\begin{array}{c}\text { Multiplicadores } \\
\text { do consumo } \\
\text { de referência }\end{array}$ \\
\hline $1^{\text {a }}$ & 1,22 & $13^{\text {a }}$ & 0 \\
\hline $2^{\text {a }}$ & 0,82 & $14^{\mathrm{a}}$ & 0 \\
\hline $3^{\mathrm{a}}$ & 0,37 & $15^{\mathrm{a}}$ & 0,09 \\
\hline $4 a$ & 0 & $16^{\mathrm{a}}$ & 1,28 \\
\hline $5^{\mathrm{a}}$ & 0 & $17^{\mathrm{a}}$ & 2,39 \\
\hline $6^{\mathrm{a}}$ & 0,04 & $18^{\mathrm{a}}$ & 2,67 \\
\hline $7^{\mathrm{a}}$ & 0,02 & $19^{\mathrm{a}}$ & 1,93 \\
\hline $8^{\mathrm{a}}$ & 0 & $20^{\mathrm{a}}$ & 1,46 \\
\hline $9^{\mathrm{a}}$ & 0 & $21^{\mathrm{a}}$ & 1,62 \\
\hline $10^{\mathrm{a}}$ & 0 & $22^{\mathrm{a}}$ & 1,81 \\
\hline $11^{\mathrm{a}}$ & 0 & $23^{\mathrm{a}}$ & 2,25 \\
\hline $12^{\mathrm{a}}$ & 0 & $24^{\mathrm{a}}$ & 2,00 \\
\hline
\end{tabular}

TABELA 4.50 - Valores dos $K f s$ para o T.1.T

\begin{tabular}{|c|c|c|c|c|c|c|c|}
\hline Nó & $K f s\left(.10^{-4}\right)$ & Nó & $K f s\left(.10^{-4}\right)$ & Nó & Kfs $\left(.10^{-4}\right)$ & Nó & Kfs $\left(.10^{-4}\right)$ \\
\hline 1 & 8,64 & 21 & 3,83 & 42 & 2,92 & 63 & 5,19 \\
\hline 2 & 1,79 & 22 & 5,07 & 43 & 7,89 & 64 & 4,13 \\
\hline 3 & 4,28 & 23 & 3,68 & 44 & 8,43 & 65 & 4,22 \\
\hline 4 & 6,68 & 24 & 2,81 & 45 & 3,46 & 66 & 5,23 \\
\hline 5 & 3,44 & 25 & 3,17 & 46 & 2,20 & 67 & 4,18 \\
\hline 6 & 3,02 & 26 & 2,81 & 47 & 2,25 & 68 & 4,23 \\
\hline 7 & 2,66 & 27 & 3,25 & 48 & 4,72 & 69 & 5,26 \\
\hline 8 & 9,41 & 28 & 4,06 & 49 & 2,00 & 70 & 4,21 \\
\hline 9 & 4,65 & 29 & 3,25 & 50 & 3,46 & 71 & 4,21 \\
\hline 10 & 7,63 & 30 & 3,25 & 51 & 5,20 & 72 & 5,26 \\
\hline 11 & 5,38 & 31 & 4,06 & 52 & 3,76 & 73 & 4,24 \\
\hline 12 & 5,08 & 32 & 3,26 & 53 & 3,82 & 74 & 6,54 \\
\hline 13 & 6,96 & 33 & 3,36 & 54 & 5,20 & 75 & 5,63 \\
\hline 14 & 5,05 & 34 & 4,24 & 55 & 3,82 & 76 & 4,15 \\
\hline 15 & 4,72 & 35 & 3,34 & 56 & 3,82 & 77 & 3,41 \\
\hline 16 & 6,29 & 36 & 3,33 & 57 & 5,20 & 78 & 6,95 \\
\hline 17 & 4,69 & 37 & 4,34 & 58 & 3,81 & 79 & 6,23 \\
\hline 18 & 4,32 & 38 & 3,03 & 59 & 3,81 & 80 & 1,15E-03 \\
\hline 19 & 5,66 & 39 & 3,05 & 60 & 5,20 & 81 & 3,13 \\
\hline 20 & 4,10 & 40 & 4,36 & 61 & 3,82 & 82 & 5,50 \\
\hline & & 41 & 3,03 & 62 & 3,80 & & \\
\hline
\end{tabular}




\subsubsection{Resultados do Teste 2 do modelo Tucciarelli et al. (T.2.T)}

No teste T.2.T foram feitas as mesmas alterações do teste T.2.GJ, pois com isso esperava-se, ao mesmo tempo, observar o comportamento dos resultados com a alteração e ainda permitir que os resultados dos dois testes fossem comparados. Os resultados do teste T.2.T são apresentados nas Tabelas 4.51 e 4.52. A Tabela 4.54 apresenta os valores dos $K f \mathrm{~s}$ para a melhor semente.

TABELA 4.51 - Resultados obtidos no teste T.2.T

\begin{tabular}{|c|c|c|c|c|c|c|c|c|c|c|c|c|c|}
\hline \multirow{2}{*}{\multicolumn{2}{|c|}{ Padrões }} & \multicolumn{5}{|c|}{ Valores simulados } & \multirow{4}{*}{ 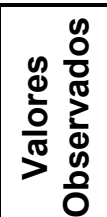 } & \multirow{3}{*}{\multicolumn{5}{|c|}{$\begin{array}{c}\text { Valores simulados } \\
\mathbf{2} \\
\text { Semente }\end{array}$}} & \multirow{4}{*}{ 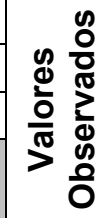 } \\
\hline & & \multirow{2}{*}{\multicolumn{5}{|c|}{1}} & & & & & & & \\
\hline \multirow{2}{*}{\multicolumn{2}{|c|}{$\begin{array}{c}\text { Variáveis } \\
\text { de } \\
\text { estado }\end{array}$}} & & & & & & & & & & & & \\
\hline & & 200 & 300 & 700 & 1000 & 2000 & & 200 & 300 & 700 & 1000 & 2000 & \\
\hline \multicolumn{2}{|c|}{$\begin{array}{c}\text { Vazão } \\
\text { (L/s) }\end{array}$} & 2,97 & 2,97 & 2,97 & 2,97 & 2,97 & 2,98 & 6,11 & 6,11 & 6,11 & 6,11 & 6,11 & 6,18 \\
\hline \multirow{4}{*}{ 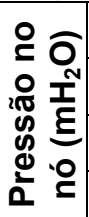 } & 22 & 32,10 & 32,10 & 32,10 & 32,10 & 32,10 & 31,23 & 29,48 & 29,48 & 29,48 & 29,48 & 29,48 & 28,59 \\
\hline & 44 & 35,77 & 35,77 & 35,76 & 35,76 & 35,76 & 35,00 & 33,06 & 33,06 & 33,05 & 33,05 & 33,05 & 31,90 \\
\hline & 66 & 23,70 & 23,70 & 23,70 & 23,70 & 23,70 & 23,66 & 21,05 & 21,05 & 21,05 & 21,05 & 21,05 & 20,78 \\
\hline & 80 & 32,13 & 32,13 & 32,13 & 32,13 & 32,13 & 31,86 & 29,57 & 29,57 & 29,56 & 29,56 & 29,56 & 29,15 \\
\hline \multicolumn{2}{|c|}{$\begin{array}{l}\text { Perdas } \\
\text { (L/s) }\end{array}$} & 1,55 & 1,56 & 1,89 & 1,96 & 1,98 & & 1,38 & 1,39 & 1,69 & 1,75 & 1,77 & \\
\hline
\end{tabular}

TABELA 4.52 - Valores da função objetivo e resultados do teste T.2.T

\begin{tabular}{|c|c|c|c|c|c|}
\hline \multirow{3}{*}{ Função Objetivo $\left(.10^{-3}\right)$} & \multicolumn{5}{|c|}{ Semente } \\
\cline { 2 - 6 } & 200 & 300 & 700 & 1000 & 2000 \\
\cline { 2 - 6 } & 4,812 & 4,811 & 4,746 & 4,726 & 4,725 \\
\hline Rugosidade $(\varepsilon) \mathrm{mm}\left(.10^{-3}\right)$ & 8,65 & 9,48 & 7,01 & 9,72 & 8,18 \\
\hline Coeficiente teta $(\theta)\left(.10^{-8}\right)$ & 1,15 & 1,19 & 1,42 & 1,49 & 1,48 \\
\hline Expoente $(\beta)$ & 1,19 & 1,18 & 1,19 & 1,18 & 1,19 \\
\hline
\end{tabular}

Neste teste (T.2.T), através da Tabela 4.52 observou-se pouca modificação dos resultados em função da alteração do intervalo de procura do expoente $\beta$, quando comparado com o teste T.1.T, uma vez que na função objetivo quase não há alteração, assim como no coeficiente $\theta$ e na rugosidade. Também houve pouca alteração nos valores das variáveis de estado simuladas segundo a Tabela 4.51. 
Desta forma, observa-se que o modelo de TUCCIARELLI et al (1999) é menos dependente do expoente $\beta$ que o modelo de GERMANOPOULOS \& JOWITT(1989), assim como o modelo ARÁUJO et al. (2003), pois a alteração do seu valor pouco interferiu nos resultados finais. A Tabela 4.53 apresenta os multiplicadores do consumo de referência para os resultados obtidos com a melhor semente (rugosidade, expoente e coeficiente $\theta$ ).

TABELA 4.53 - Multiplicadores do consumo de referência do teste T.2.T

\begin{tabular}{|c|c|c|c|}
\hline $\begin{array}{c}\text { Horas do } \\
\text { dia de } \\
\text { observação }\end{array}$ & $\begin{array}{c}\text { Multiplicadores } \\
\text { do consumo } \\
\text { de referência }\end{array}$ & $\begin{array}{c}\text { Horas do } \\
\text { dia de } \\
\text { observação }\end{array}$ & $\begin{array}{c}\text { Multiplicadores } \\
\text { do consumo } \\
\text { de referência }\end{array}$ \\
\hline $1^{\mathrm{a}}$ & 1,19 & $13^{\mathrm{a}}$ & 0 \\
\hline $2^{\mathrm{a}}$ & 0,80 & $14^{\mathrm{a}}$ & 0 \\
\hline $3^{\mathrm{a}}$ & 0,35 & $15^{\mathrm{a}}$ & 0,07 \\
\hline $4 \mathrm{a}$ & 0 & $16^{\mathrm{a}}$ & 1,27 \\
\hline $5^{\mathrm{a}}$ & 0 & $17^{\mathrm{a}}$ & 2,37 \\
\hline $6^{\mathrm{a}}$ & 0,03 & $18^{\mathrm{a}}$ & 2,65 \\
\hline $7^{\mathrm{a}}$ & 0,01 & $19^{\mathrm{a}}$ & 1,92 \\
\hline $8^{\mathrm{a}}$ & 0 & $20^{\mathrm{a}}$ & 1,45 \\
\hline $9^{\mathrm{a}}$ & 0 & $21^{\mathrm{a}}$ & 1,61 \\
\hline $10^{\mathrm{a}}$ & 0 & $22^{\mathrm{a}}$ & 1,80 \\
\hline $11^{\mathrm{a}}$ & 0 & $23^{\mathrm{a}}$ & 2,24 \\
\hline $12^{\mathrm{a}}$ & 0 & $24^{\mathrm{a}}$ & 1,98 \\
\hline
\end{tabular}

TABELA 4.54 - Valores dos $K f s$ para o T.2.T

\begin{tabular}{|c|c|c|c|c|c|c|c|}
\hline Nó & Kfs $\left(.10^{-4}\right)$ & Nó & Kfs $\left(.10^{-4}\right)$ & Nó & Kfs $\left(.10^{-4}\right)$ & Nó & Kfs $\left(.10^{-4}\right)$ \\
\hline 1 & 8,64 & 21 & 3,83 & 42 & 2,92 & 63 & 5,19 \\
\hline 2 & 1,79 & 22 & 5,07 & 43 & 7,89 & 64 & 4,13 \\
\hline 3 & 4,28 & 23 & 3,68 & 44 & 8,43 & 65 & 4,22 \\
\hline 4 & 6,68 & 24 & 2,81 & 45 & 3,46 & 66 & 5,23 \\
\hline 5 & 3,44 & 25 & 3,17 & 46 & 2,20 & 67 & 4,18 \\
\hline 6 & 3,02 & 26 & 2,81 & \begin{tabular}{|l|}
47 \\
\end{tabular} & 2,25 & 68 & 4,23 \\
\hline 7 & 2,66 & 27 & 3,25 & 48 & 4,72 & 69 & 5,26 \\
\hline 8 & 9,41 & 28 & 4,06 & \begin{tabular}{|l|}
49 \\
\end{tabular} & 2,00 & 70 & 4,21 \\
\hline 9 & 4,65 & 29 & 3,25 & 50 & 3,46 & 71 & 4,21 \\
\hline 10 & 7,63 & 30 & 3,25 & 51 & 5,20 & 72 & 5,26 \\
\hline 11 & 5,38 & 31 & 4,06 & 52 & 3,76 & 73 & 4,24 \\
\hline 12 & 5,08 & 32 & 3,26 & 53 & 3,82 & 74 & 6,54 \\
\hline 13 & 6,96 & 33 & 3,36 & \begin{tabular}{|l|}
54 \\
\end{tabular} & 5,20 & 75 & 5,63 \\
\hline 14 & 5,05 & 34 & 4,24 & 55 & 3,82 & 76 & 4,15 \\
\hline 15 & 4,72 & 35 & 3,34 & \begin{tabular}{|l|}
56 \\
\end{tabular} & 3,82 & 77 & 3,41 \\
\hline 16 & 6,29 & 36 & 3,33 & 57 & 5,20 & 78 & 6,95 \\
\hline 17 & 4,69 & 37 & 4,34 & \begin{tabular}{|l|}
58 \\
\end{tabular} & 3,81 & 79 & 6,23 \\
\hline 18 & 4,32 & 38 & 3,03 & 59 & 3,81 & 80 & 11,55 \\
\hline 19 & 5,66 & 39 & 3,05 & 60 & 5,20 & 81 & 3,13 \\
\hline 20 & 4,10 & 40 & 4,36 & 61 & 3,82 & 82 & 5,50 \\
\hline & & 41 & 3,03 & 6 & 3,80 & & \\
\hline
\end{tabular}




\subsubsection{Resultados do Teste 3 do modelo Tucciarelli et al. (T.3.T)}

No teste T.3.T foi realizado a alteração do intervalo de procura do coeficiente $\theta$ para analisar os resultados obtidos e compará-los aos resultados obtidos anteriormente, para tanto houve um acréscimo no limite superior do coeficiente $\theta$ e manteve-se o mesmo intervalo de procura para o expoente $\beta$ do teste T.1.T. Os resultados do teste T.3.T são apresentados nas Tabelas 4.55 e 4.56. A Tabela 4.58 apresenta os valores dos $K f$ s para a melhor semente.

TABELA 4.55 - Resultados obtidos no teste T.3.T

\begin{tabular}{|c|c|c|c|c|c|c|c|c|c|c|c|c|c|}
\hline & \multicolumn{5}{|c|}{ Valores simulados } & \multirow{4}{*}{ 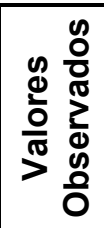 } & \multicolumn{5}{|c|}{ Valores simulados } & \multirow{4}{*}{ 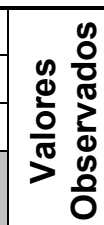 } \\
\hline & & \multirow{2}{*}{\multicolumn{5}{|c|}{$\frac{1}{\text { Semente }}$}} & & \multirow{2}{*}{\multicolumn{5}{|c|}{$\frac{2}{\text { Semente }}$}} & \\
\hline \multirow{2}{*}{\multicolumn{2}{|c|}{$\begin{array}{c}\text { Padroes } \\
\text { Variáveis } \\
\text { de } \\
\text { estado } \\
\end{array}$}} & & & & & & & & & & & & \\
\hline & & 200 & 300 & 700 & 1000 & 2000 & & 200 & 300 & 700 & 1000 & 2000 & \\
\hline \multicolumn{2}{|c|}{$\begin{array}{c}\text { Vazão } \\
\text { (L/s) }\end{array}$} & 2,97 & 6 & 2,97 & 2,97 & 2,97 & 2,98 & 6,11 & 6,11 & 6,11 & 6,11 & 6,11 & 6,18 \\
\hline \multirow{4}{*}{ 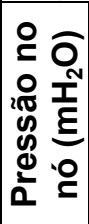 } & 22 & 32,10 & 32,10 & 32,10 & 32,10 & 32,10 & 31,23 & 29,48 & 29,47 & 29,47 & 29,47 & 29,47 & 28,59 \\
\hline & 44 & 35,76 & 35,75 & 35,75 & 35,75 & 35,75 & 35,00 & 33,05 & 33,04 & 33,04 & 33,04 & 33,04 & 31,90 \\
\hline & 66 & 23,70 & 23,70 & 23,70 & 23,70 & 23,70 & 23,66 & 21,05 & 21,05 & 21,05 & 21,05 & 21,05 & 20,78 \\
\hline & 80 & 32,13 & 32,12 & 32,12 & 32,12 & 32,12 & 31,86 & 29,56 & 29,56 & 29,55 & 29,56 & 29,55 & 29,15 \\
\hline \multicolumn{2}{|c|}{$\begin{array}{l}\text { Perdas } \\
\text { (L/s) }\end{array}$} & 1,88 & 2,35 & 2,45 & 2,49 & 2, & & 1,69 & 2,10 & 2,19 & 2,23 & 2,31 & \\
\hline
\end{tabular}

TABELA 4.56 - Valores da função objetivo e resultados do teste T.3.T

\begin{tabular}{|c|c|c|c|c|c|}
\hline \multirow{2}{*}{ Função Objetivo $\left(.10^{-3}\right)$} & \multicolumn{5}{|c|}{ Semente } \\
\cline { 2 - 6 } & 200 & 300 & 700 & 1000 & 2000 \\
\cline { 2 - 6 } & 4,755 & 4,694 & 4,673 & 4,654 & 4,636 \\
\hline Rugosidade $(\varepsilon) \mathrm{mm}\left(.10^{-3}\right)$ & 8,02 & 6,15 & 6,77 & 9,68 & 8,18 \\
\hline Coeficiente teta $(\theta)\left(.10^{-8}\right)$ & 1,65 & 1,91 & 1,99 & 1,95 & 1,97 \\
\hline Expoente $(\beta)$ & 1,14 & 1,16 & 1,16 & 1,18 & 1,18 \\
\hline
\end{tabular}

$\mathrm{Na}$ Tabela 4.55 observou-se o mesmo comportamento dos demais testes realizados, nos quais houve aumento das perdas. A melhor semente foi a 2000 (Tabela 4.56), em que os resultados obtidos mostraram que o coeficiente $\theta$ converge para o limite superior do intervalo de procura e o expoente $\beta$ e a rugosidade estão mais distantes dos limites do intervalo de procura. Em termos do valor da função objetivo, houve uma pequena melhora, contudo não 
foi possível dizer o que tenha contribuído substancialmente para isso. A Tabela 4.57 apresenta os multiplicadores do consumo de referência para os resultados obtidos com a melhor semente.

TABELA 4.57 - Multiplicadores do consumo de base do teste T.3.T

\begin{tabular}{|c|c|c|c|}
\hline $\begin{array}{c}\text { Horas do } \\
\text { dia de } \\
\text { observação }\end{array}$ & $\begin{array}{c}\text { Multiplicadores } \\
\text { do consumo } \\
\text { de referência }\end{array}$ & $\begin{array}{c}\text { Horas do } \\
\text { dia de } \\
\text { observação }\end{array}$ & $\begin{array}{c}\text { Multiplicadores } \\
\text { do consumo } \\
\text { de referência }\end{array}$ \\
\hline $1^{\mathrm{a}}$ & 0,94 & $13^{\mathrm{a}}$ & 0 \\
\hline $2^{\mathrm{a}}$ & 0,54 & $14^{\mathrm{a}}$ & 0 \\
\hline $3^{\mathrm{a}}$ & 0,09 & $15^{\mathrm{a}}$ & 0,01 \\
\hline $4 \mathrm{a}$ & 0 & $16^{\mathrm{a}}$ & 1,03 \\
\hline $5^{\mathrm{a}}$ & 0 & $17^{\mathrm{a}}$ & 2,14 \\
\hline $6^{\mathrm{a}}$ & 0,01 & $18^{\mathrm{a}}$ & 2,42 \\
\hline $7^{\mathrm{a}}$ & 0 & $19^{\mathrm{a}}$ & 1,69 \\
\hline $8^{\mathrm{a}}$ & 0 & $20^{\mathrm{a}}$ & 1,22 \\
\hline $9^{\mathrm{a}}$ & 0 & $21^{\mathrm{a}}$ & 1,38 \\
\hline $10^{\mathrm{a}}$ & 0 & $22^{\mathrm{a}}$ & 1,57 \\
\hline $11^{\mathrm{a}}$ & 0 & $23^{\mathrm{a}}$ & 2,01 \\
\hline $12^{\mathrm{a}}$ & 0 & $24^{\mathrm{a}}$ & 1,75 \\
\hline
\end{tabular}

TABELA 4.58 - Valores dos $K f s$ para o T.3.T

\begin{tabular}{|c|c|c|c|c|c|c|c|}
\hline Nó & Kfs $\left(.10^{-4}\right)$ & Nó & Kfs $\left(.10^{-4}\right)$ & Nó & Kfs $\left(.10^{-4}\right)$ & Nó & Kfs $\left(.10^{-4}\right)$ \\
\hline 1 & 11,51 & 21 & 5,10 & 42 & 3,90 & 63 & 6,92 \\
\hline 2 & 2,38 & 22 & 6,76 & 43 & 10,52 & 64 & 5,51 \\
\hline 3 & 5,71 & 23 & 4,91 & 44 & 11,24 & \begin{tabular}{|l|}
65 \\
\end{tabular} & 5,62 \\
\hline 4 & 8,90 & 24 & 3,74 & 45 & 4,61 & \begin{tabular}{|l|}
66 \\
\end{tabular} & 6,97 \\
\hline 5 & 4,59 & 25 & 4,23 & 46 & 2,93 & \begin{tabular}{|l|}
67 \\
\end{tabular} & 5,57 \\
\hline 6 & 4,03 & 26 & 3,74 & 47 & 3,00 & \begin{tabular}{|l|}
68 \\
\end{tabular} & 5,63 \\
\hline 7 & 3,55 & 27 & 4,33 & 48 & 6,29 & 69 & 7,02 \\
\hline 8 & 12,54 & 28 & 5,41 & 49 & 2,67 & 70 & 5,61 \\
\hline 9 & 6,20 & 29 & 4,34 & 50 & 4,62 & 71 & 5,62 \\
\hline 10 & 10,17 & 30 & 4,34 & 51 & 6,93 & 72 & 7,02 \\
\hline 11 & 7,18 & 31 & 5,41 & 52 & 5,01 & 73 & 5,65 \\
\hline 12 & 6,77 & 32 & 4,34 & 53 & 5,09 & 74 & 8,72 \\
\hline 13 & 9,27 & 33 & 4,48 & 54 & 6,93 & 75 & 7,50 \\
\hline 14 & 6,74 & 34 & 5,65 & 55 & 5,10 & 76 & 5,54 \\
\hline 15 & 6,30 & 35 & 4,45 & 56 & 5,10 & 77 & 4,55 \\
\hline 16 & 8,38 & 36 & 4,44 & 57 & 6,93 & 78 & 9,27 \\
\hline 17 & 6,26 & 37 & 5,79 & 58 & 5,09 & 79 & 8,31 \\
\hline 18 & 5,76 & 38 & 4,04 & 59 & 5,08 & 80 & 15,39 \\
\hline 19 & 7,55 & 39 & 4,06 & 60 & 6,93 & 81 & 4,17 \\
\hline 20 & 5,46 & 40 & 5,81 & 61 & 5,10 & 82 & 7,33 \\
\hline & & 41 & 4,04 & 62 & 5,07 & & \\
\hline
\end{tabular}




\subsubsection{Resultados do Teste 4 do modelo Tucciarelli et al. (T.4.T)}

No último teste considerando o modelo TUCCIARELLI (1999) foi alterado o intervalo do expoente $\beta$, tentando-se melhorar a função objetivo e testar o comportamento dos resultados com essa alteração. $\mathrm{O}$ intervalo de procura do coeficiente $\theta$ continuou sendo o mesmo do teste T.3.T. Os resultados são apresentados nas Tabelas 4.59 e 4.60. A Tabela 4.62 apresenta os valores dos $K f$ s para a melhor semente.

TABELA 4.59 - Resultados obtidos no teste T.4.T

\begin{tabular}{|c|c|c|c|c|c|c|c|c|c|c|c|c|c|}
\hline \multirow{2}{*}{\multicolumn{2}{|c|}{ Padrões }} & \multicolumn{5}{|c|}{ Valores simulados } & \multirow{4}{*}{ 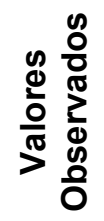 } & \multirow{3}{*}{\multicolumn{5}{|c|}{$\begin{array}{c}\text { Valores simulados } \\
2 \\
\text { Semente }\end{array}$}} & \multirow{4}{*}{ 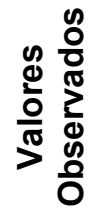 } \\
\hline & & \multirow{2}{*}{\multicolumn{5}{|c|}{1}} & & & & & & & \\
\hline \multirow{2}{*}{\multicolumn{2}{|c|}{$\begin{array}{c}\text { Variáveis } \\
\text { de } \\
\text { estado }\end{array}$}} & & & & & & & & & & & & \\
\hline & & 200 & 300 & 700 & 1000 & 2000 & & 200 & 300 & 700 & 1000 & 2000 & \\
\hline \multicolumn{2}{|c|}{$\begin{array}{c}\text { Vazão } \\
\text { (L/s) }\end{array}$} & 2,96 & 2,97 & 2,97 & 2,96 & 2,94 & 2,98 & 6,11 & 6,11 & 6,11 & 6,11 & 6,11 & 6,18 \\
\hline \multirow{4}{*}{ 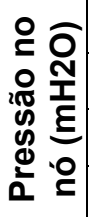 } & 22 & 32,10 & 32,10 & 32,10 & 32,10 & 32,11 & 31,23 & 29,47 & 29,47 & 29,47 & 29,47 & 29,49 & 28,59 \\
\hline & 44 & 35,76 & 35,76 & 35,75 & 35,76 & 35,78 & 35,00 & 33,04 & 33,05 & 33,04 & 33,05 & 33,09 & 31,90 \\
\hline & 66 & 23,70 & 23,70 & 23,70 & 23,70 & 23,70 & 23,66 & 21,05 & 21,05 & 21,05 & 21,05 & 21,05 & 20,78 \\
\hline & 80 & 32,12 & 32,12 & 32,12 & 32,12 & 32,14 & 31,86 & 29,56 & 29,56 & 29,56 & 29,56 & 29,58 & 29,15 \\
\hline \multicolumn{2}{|c|}{$\begin{array}{l}\text { Perdas } \\
\text { (L/s) }\end{array}$} & 2,25 & 2,07 & 2,47 & 2,21 & 0,26 & & 2,01 & 1,85 & 2,20 & 1,97 & 0,25 & \\
\hline
\end{tabular}

TABELA 4.60 - Valores da função objetivo e resultados do teste T.4.T

\begin{tabular}{|c|c|c|c|c|c|}
\hline \multirow{3}{*}{ Função Objetivo $\left(.10^{-3}\right)$} & \multicolumn{5}{|c|}{ Semente } \\
\cline { 2 - 6 } & 200 & 300 & 700 & 1000 & 2000 \\
\cline { 2 - 6 } & 4,697 & 4,707 & 4,621 & 4,713 & 4,661 \\
\hline Rugosidade $(\varepsilon){\mathrm{mm}\left(.10^{-3}\right)}$ & 9,83 & 9,17 & 7,01 & $6,93 \mathrm{E}$ & 9,20 \\
\hline Coeficiente teta $(\theta)\left(.10^{-8}\right)$ & 1,66 & 1,58 & 1,86 & 1,68 & 1,97 \\
\hline Expoente $(\beta)$ & 1,19 & 1,18 & 1,19 & 1,18 & 1,19 \\
\hline
\end{tabular}

Observando a Tabela 4.60, a melhor semente foi a 700, a qual apresentou os resultados para rugosidade e expoente $\beta$ mais distantes dos respectivos limites dos intervalos de procura e o valor da função objetivo pouco diferente do teste T.3.T. Os valores simulados estão próximos aos valores observados, sendo que as perdas são significativamente altas para este 
teste. Tabela 4.61 apresenta os multiplicadores do consumo de referência para os resultados obtidos com a melhor semente.

TABELA 4.61 - Multiplicadores do consumo de referência do teste T.4.T

\begin{tabular}{|c|c|c|c|}
\hline $\begin{array}{c}\text { Horas do } \\
\text { dia de } \\
\text { observação }\end{array}$ & $\begin{array}{c}\text { Multiplicadores } \\
\text { do consumo } \\
\text { de referência }\end{array}$ & $\begin{array}{c}\text { Horas do } \\
\text { dia de } \\
\text { observação }\end{array}$ & $\begin{array}{c}\text { Multiplicadores } \\
\text { do consumo } \\
\text { de referência }\end{array}$ \\
\hline $1^{\mathrm{a}}$ & 0,91 & $13^{\mathrm{a}}$ & 0 \\
\hline $2^{\mathrm{a}}$ & 0,52 & $14^{\mathrm{a}}$ & 0 \\
\hline $3^{\mathrm{a}}$ & 0,06 & $15^{\mathrm{a}}$ & 0,01 \\
\hline $4 \mathrm{a}$ & 0 & $16^{\mathrm{a}}$ & 1,01 \\
\hline $5^{\mathrm{a}}$ & 0 & $17^{\mathrm{a}}$ & 2,12 \\
\hline $6^{\mathrm{a}}$ & 0,01 & $18^{\mathrm{a}}$ & 2,40 \\
\hline $7^{\mathrm{a}}$ & 0 & $19^{\mathrm{a}}$ & 1,67 \\
\hline $8^{\mathrm{a}}$ & 0 & $20^{\mathrm{a}}$ & 1,20 \\
\hline $9^{\mathrm{a}}$ & 0 & $21^{\mathrm{a}}$ & 1,36 \\
\hline $10^{\mathrm{a}}$ & 0 & $22^{\mathrm{a}}$ & 1,55 \\
\hline $11^{\mathrm{a}}$ & 0 & $23^{\mathrm{a}}$ & 1,99 \\
\hline $12^{\mathrm{a}}$ & 0 & $24^{\mathrm{a}}$ & 1,74 \\
\hline
\end{tabular}

TABELA 4.62 - Valores dos $K f$ s para o T.4.T

\begin{tabular}{|c|c|c|c|c|c|c|c|}
\hline Nó & $K f s\left(.10^{-4}\right)$ & Nó & $K f s\left(.10^{-4}\right)$ & Nó & $K f s\left(.10^{-4}\right)$ & Nó & Kfs $\left(.10^{-4}\right)$ \\
\hline 1 & 10,87 & 21 & 4,82 & 42 & 3,68 & 63 & 6,53 \\
\hline 2 & 2,25 & 22 & 6,38 & \begin{tabular}{|l|}
43 \\
\end{tabular} & 9,93 & 64 & 5,20 \\
\hline 3 & 5,39 & 23 & 4,64 & 44 & 10,62 & 65 & 5,31 \\
\hline 4 & 8,41 & 24 & 3,54 & 45 & 4,35 & 66 & 6,58 \\
\hline 5 & 4,33 & 25 & 4,00 & 46 & 2,77 & 67 & 5,26 \\
\hline 6 & 3,80 & 26 & 3,53 & 47 & 2,84 & 68 & 5,32 \\
\hline 7 & 3,35 & 27 & 4,09 & 48 & 5,94 & 69 & 6,63 \\
\hline 8 & 11,84 & 28 & 5,11 & 49 & 2,52 & 70 & 5,30 \\
\hline 9 & 5,86 & 29 & 4,09 & 50 & 4,36 & 71 & 5,30 \\
\hline 10 & 9,60 & 30 & 4,10 & 51 & 6,54 & 72 & 6,63 \\
\hline 11 & 6,78 & 31 & 5,11 & 52 & 4,73 & 73 & 5,33 \\
\hline 12 & 6,40 & 32 & 4,10 & 53 & 4,81 & 74 & 8,23 \\
\hline 13 & 8,76 & 33 & 4,23 & 54 & 6,54 & 75 & 7,08 \\
\hline 14 & 6,36 & 34 & 5,34 & 55 & 4,81 & 76 & 5,23 \\
\hline 15 & 5,95 & 35 & 4,20 & 56 & 4,81 & 77 & 4,29 \\
\hline 16 & 7,92 & 36 & 4,19 & 57 & 6,54 & 78 & 8,75 \\
\hline 17 & 5,91 & 37 & 5,46 & 58 & 4,80 & 79 & 7,85 \\
\hline 18 & 5,44 & 38 & 3,82 & 59 & 4,80 & 80 & 14,54 \\
\hline 19 & 7,13 & 39 & 3,84 & 60 & 6,54 & 81 & 3,94 \\
\hline 20 & 5,16 & 40 & 5,49 & 61 & 4,82 & 82 & 6,92 \\
\hline & & 41 & 3,82 & 62 & 4,79 & & \\
\hline
\end{tabular}




\subsection{ANÁLISE DO TEMPO DE RESIDÊNCIA DE CADA TESTE}

OZDEMIR \& UCAK (2002) afirmam que o EPANET 2.0 tem a deficiência em comparar dados de concentração de cloro em nós que tenham tempo de residência da água elevado. Esse resultado também foi observado por VIEIRA (2002) em suas análises do comportamento do decaimento de cloro em redes de distribuição de água. Segundo esse autor, de acordo com a modificação de alguns parâmetros hidráulicos observa-se um defasamento temporal que dificulta a comparação entre as concentrações de cloro observadas e simuladas.

COELHO (2005) sugere que para se comparar os dados de concentração de cloro observados com os dados simulados, é imprescindível levar em consideração o tempo necessário para a simulação tornar-se cíclica, ou seja, repetitiva em um dado período de tempo. O tempo de residência da água também deve ser considerado para permitir a comparação.

A solução adotada para possibilitar a calibração de qualidade foi somar o tempo de residência máximo da água aos horários das observações, ocorrendo, assim, a sincronização das concentrações observadas com as simuladas. Este procedimento é justificado pelo fato do EPANET 2.0 usar o modelo TDM para as simulações de qualidade. A adoção deste modelo causa a defasagem temporal das concentrações de cloro observadas na rede em nós distantes da entrada do sistema. Sendo assim, o EPANET 2.0 só pode ser usado para comparar concentrações de cloro observadas com as simuladas, depois de ocorrer uma sincronização.

Como um dos dois pontos de instalação das sondas é ponta de rede, consequentemente, este apresentou um tempo de residência elevado e, sendo assim, todas as análises de tempo de residência foram feitas somente para esse nó.

No entanto, foram necessárias: todas as informações obtidas com a calibração hidráulica; os dados de entrada da própria calibração hidráulica; o padrão de comportamento 
do reservatório; e o cálculo dos multiplicadores do consumo de referência para cada hora do dia considerado. A estrutura dos arquivos usados para as análises do tempo de residência está representada no Apêndice B, sendo que, para cada teste são alteradas as informações de rugosidade, multiplicadores do consumo de referência e $K_{f} \mathrm{~s}$, em conformidade com o modelo de vazamento e as faixas de pesquisa de parâmetros calibrados.

Como o nível médio do reservatório é $18.1 \mathrm{~m}$ e a sua cota é 861.4 , os valores apresentados na terceira coluna da Tabela 4.63 são referentes à soma da pressão medida no reservatório mais sua cota. A quarta coluna da Tabela 4.63 é resultado da divisão do nível médio de cada hora pelo nível médio do dia todo. O padrão de comportamento do nível do reservatório foi usado para todos os testes.

TABELA 4.63 - Padrão do comportamento do nível do reservatório

\begin{tabular}{|c|c|c|c|}
\hline $\begin{array}{l}\text { Horas do dia } \\
\text { de observação }\end{array}$ & $\begin{array}{l}\text { Pressão medida } \\
\left(\mathrm{mH}_{2} \mathrm{O}\right)\end{array}$ & $\begin{array}{l}\text { Carga Hidráulica do } \\
\text { Reservatório }\left(\mathrm{mH}_{2} \mathrm{O}\right)\end{array}$ & $\begin{array}{c}\text { Padrão do Comportamento } \\
\text { do reservatório }\end{array}$ \\
\hline $1^{\mathrm{a}}$ & 19.85 & 881.25 & 1.001986 \\
\hline $2^{a}$ & 19.90 & 881.30 & 1.002045 \\
\hline $3^{\mathrm{a}}$ & 20.13 & 881.53 & 1.002303 \\
\hline $4^{a}$ & 20.29 & 881.69 & 1.002495 \\
\hline $5^{a}$ & 18.86 & 880.26 & 1.000863 \\
\hline $6^{a}$ & 17.23 & 878.63 & 0.999014 \\
\hline $7^{\mathrm{a}}$ & 17.35 & 878.75 & 0.999146 \\
\hline $8^{\mathrm{a}}$ & 18.09 & 879.49 & 0.999989 \\
\hline $9^{a}$ & 18.77 & 880.17 & 1.000762 \\
\hline $10^{a}$ & 19.45 & 880.85 & 1.001536 \\
\hline $11^{a}$ & 20.12 & 881.52 & 1.002294 \\
\hline $12^{a}$ & 19.89 & 881.29 & 1.002039 \\
\hline $13^{a}$ & 18.25 & 879.65 & 1.000165 \\
\hline $14^{\mathrm{a}}$ & 17.02 & 878.42 & 0.998770 \\
\hline $15^{a}$ & 17.37 & 878.77 & 0.999168 \\
\hline $16^{a}$ & 17.55 & 878.95 & 0.999374 \\
\hline $17^{a}$ & 17.53 & 878.93 & 0.999348 \\
\hline $18^{a}$ & 17.36 & 878.76 & 0.999153 \\
\hline $19^{a}$ & 17.30 & 878.70 & 0.999091 \\
\hline $20^{a}$ & 16.81 & 878.21 & 0.998536 \\
\hline $21^{a}$ & 16.79 & 878.19 & 0.998507 \\
\hline $22^{a}$ & 16.78 & 878.18 & 0.998502 \\
\hline $23^{a}$ & 16.73 & 878.13 & 0.998441 \\
\hline $24^{\mathrm{a}}$ & 16.82 & 878.22 & 0.998458 \\
\hline Médias & 18.1 & 879.5 & \\
\hline
\end{tabular}




\subsubsection{Resultados para o tempo de residência do teste T.1.A}

A Figura 4.19 apresenta o resultado da simulação feita para a determinação do tempo de residência da água do nó 43 para o teste T.1.A. O valor determinado na simulação é próximo ao de 13 horas, assim, para as simulações de qualidade, os horários das observações no nó 43 foi acrescido de 13 horas. Outra observação importante foi o tempo de simulação necessário para se observar o começo de um período cíclico, pois a calibração de qualidade só pôde ser feita depois de observado o período cíclico hidraulicamente. Desta forma, ao se observar a Figura 4.19, conclui-se que o tempo de residência em um período de 24 horas tornou-se cíclico após 24 horas de simulação.

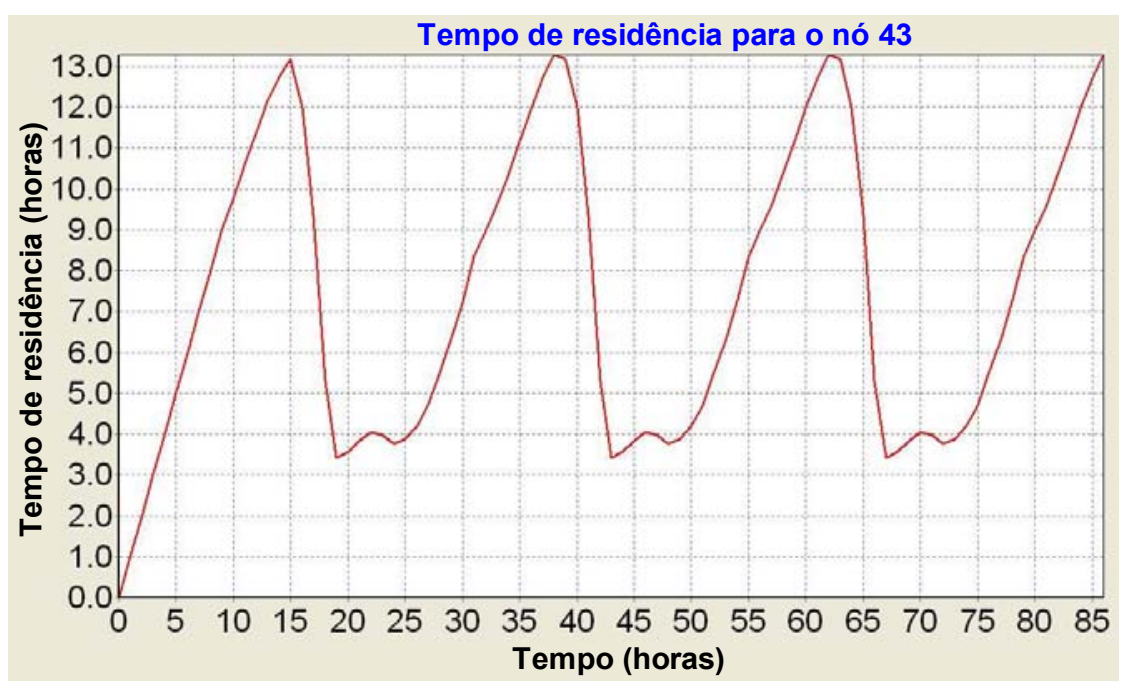

FIGURA 4.19 - Tempo de residência do nó 43 no teste T.1.A

\subsubsection{Resultados para o tempo de residência do teste T.2.A}

Para o teste T.2.A, o simulador EPANET 2.0 produziu a Figura 4.20, a qual apresenta o resultado da simulação feita para a determinação do tempo de residência da água do nó 43 . O valor determinado na simulação foi próximo ao de 9 horas para o tempo máximo de residência da água. O tempo necessário para se observar períodos cíclicos foi de 24 horas. 
Este resultado, se comparado com o do teste anterior (T.1.A), mostra bem a interferência da mudança dos valores dos parâmetros hidráulicos (rugosidade, coeficiente dos “emitters" e expoente), já que o comportamento representado na Figura 4.20 foi bem distinto do comportamento da Figura 4.19.

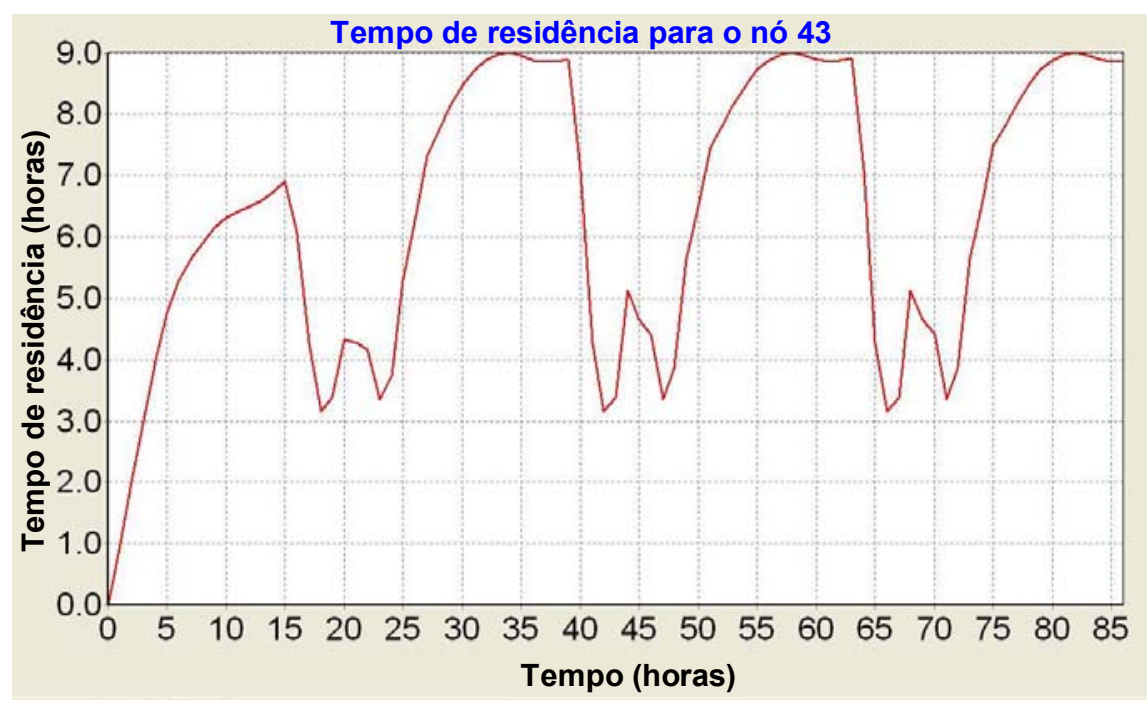

FIGURA 4.20 - Tempo de residência do nó 43 no teste T.2.A

\subsubsection{Resultados para o tempo de residência do teste T.1.GJ}

As informações obtidas no teste T.1.GJ tiveram como resultado a Figura 4.21 na simulação do tempo de residência da água para o nó 43. O valor do tempo de residência máximo atingido nesta simulação pelo nó 43 foi próximo ao de 13 horas.

Em comparação ao teste T.1.A, o qual admitiu-se o mesmo intervalo de procura para o coeficiente $C$ porém com expoente $\beta$ fixo, os dois testes apresentaram comportamentos para o tempo de residência do nó 43 parecidos. Esse resultado é interessante, visto que, mesmo dada a liberdade de procura para o expoente $\beta$ no teste T.1.GJ, os dois testes obtiveram resultados semelhantes para o tempo de residência do nó 43 . 
O tempo de simulação necessário do EPANET 2.0 para que o tempo de residência da água fosse repetitivo em períodos cíclicos foi de 24 horas, assim como os testes anteriores (T.1.A, T.2.A).

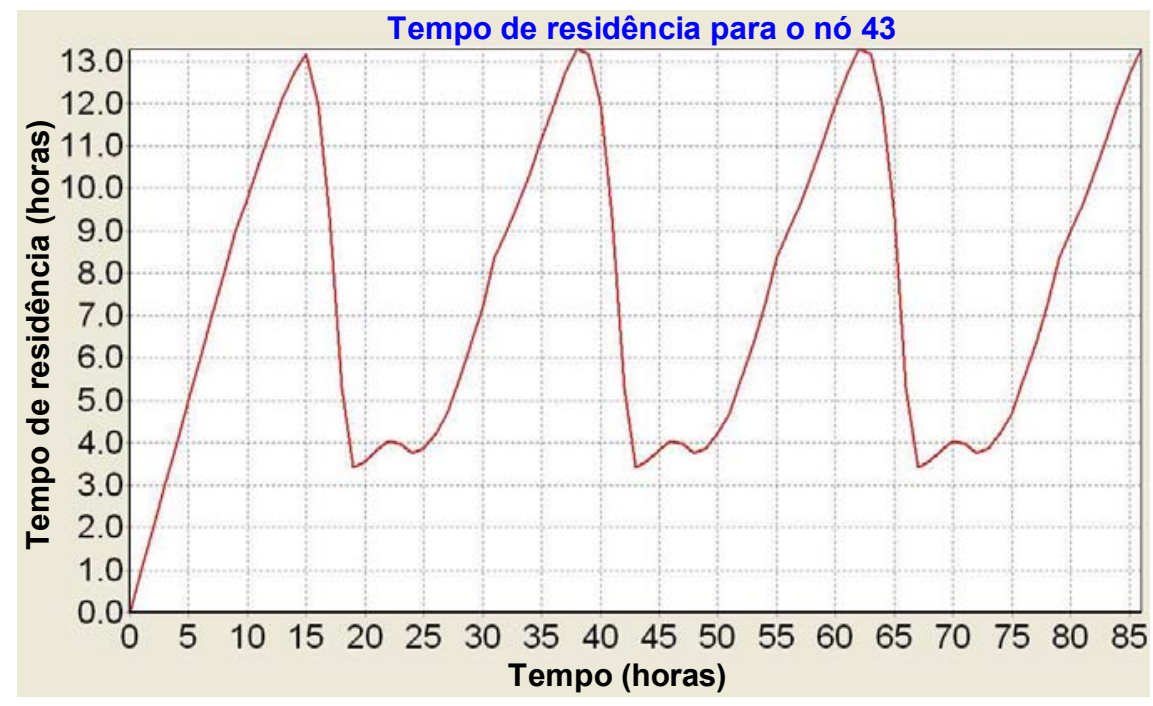

FIGURA 4.21 - Tempo de residência do nó 43 no teste T.1.GJ

\subsubsection{Resultados para o tempo de residência do teste T.2.GJ}

Para o teste T.2.GJ, o resultado da simulação feita para a determinação do tempo de residência da água no nó 43 é apresentado na Figura 4.22. O valor determinado na simulação para o tempo de residência máximo da água foi próximo de 13 horas. O comportamento deste teste foi próximo ao do teste anterior (T.1.GJ), demonstrando que a diminuição do intervalo de procura do expoente $\beta$ pouco interferiu nos resultados. Foram necessárias 24 horas para se observar períodos cíclicos. 


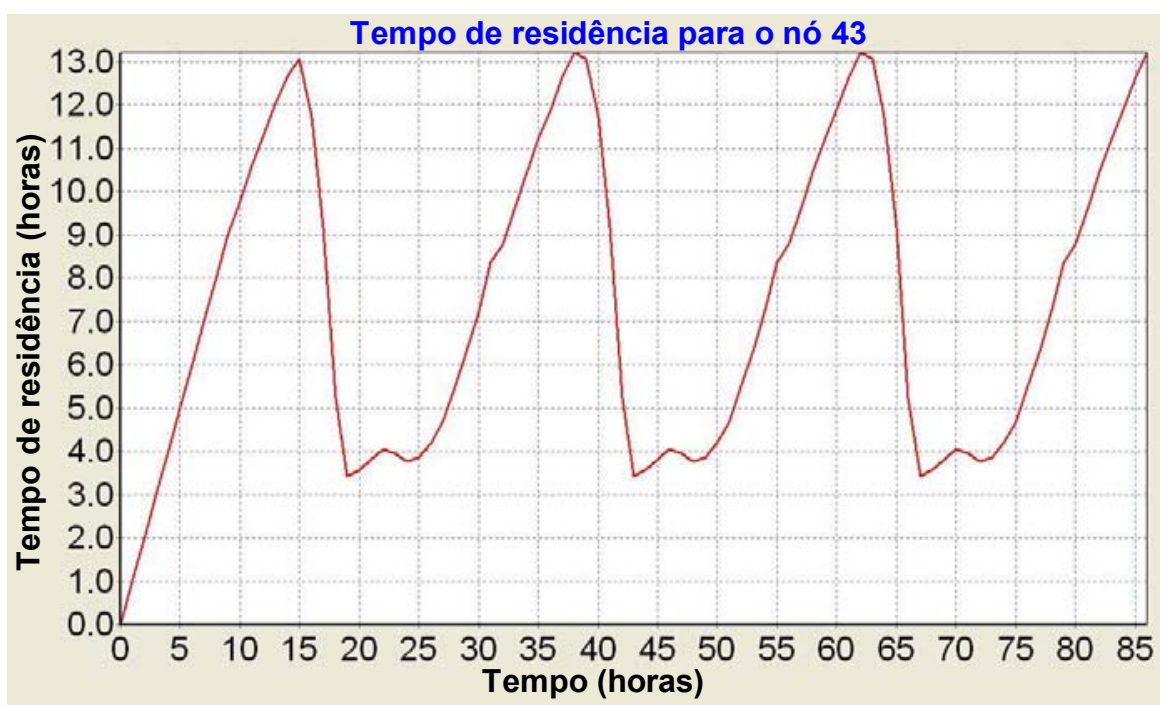

FIGURA 4.22 - Tempo de residência do nó 43 no teste T.2.GJ

\subsubsection{Resultados para o tempo de residência do teste T.3.GJ}

A Figura 4.23 apresenta o resultado da simulação realizada para determinação do tempo de residência da água no nó 43 com os resultados do T.3.GJ. O valor determinado na simulação para o tempo máximo de residência foi próximo de 10 horas e a repetição do comportamento do tempo de residência no período de 24 horas só ocorreu depois de 48 horas de simulação, sendo assim, a calibração de qualidade só pôde ocorrer depois de 48 horas de simulação.

Outra alteração importante dos resultados foi em relação ao próprio comportamento do tempo de residência do teste T.3.GJ, quando comparado com o teste T.1.GJ e o teste T.2.GJ. Esses dois testes anteriores apresentaram comportamentos semelhantes pois tinham o mesmo intervalo de procura para o coeficiente $C$, no entanto, ocorrendo a alteração no intervalo de procura também ocorreu a alteração no comportamento do tempo de residência, da mesma forma que foi observado nos testes T.1.A e T.2.A. 


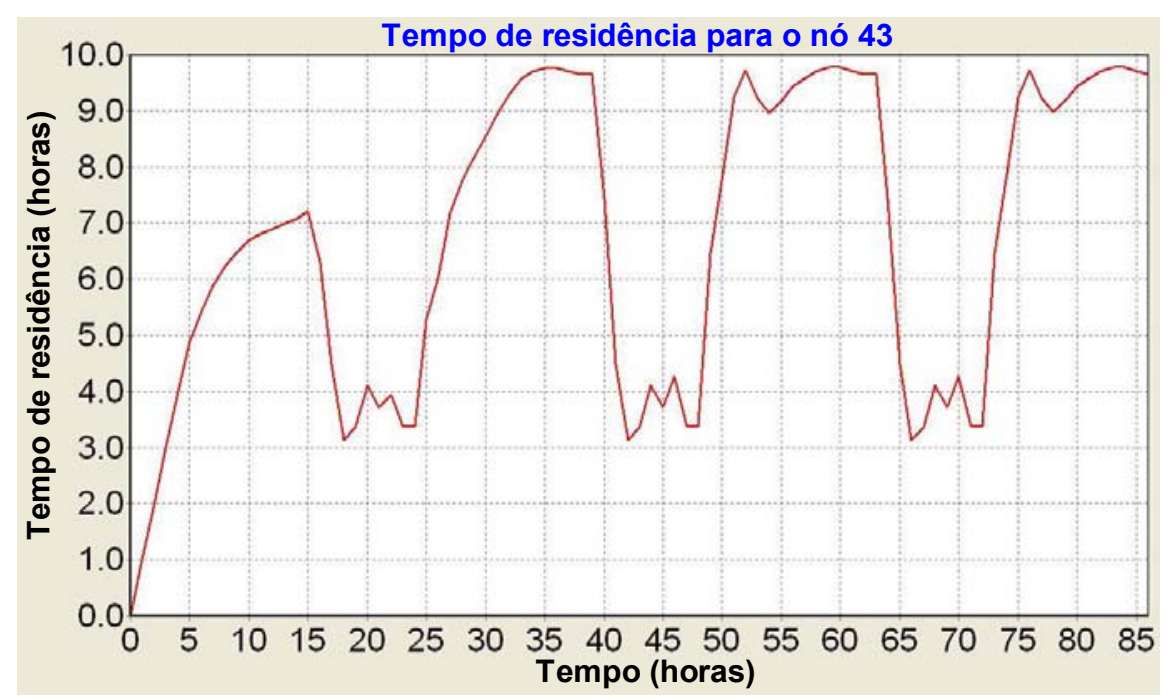

FIGURA 4.23 - Tempo de residência do nó 43 no teste T.3.GJ

\subsubsection{Resultados para o tempo de residência do teste T.4.GJ}

Para o teste T.4.GJ, o resultado da simulação realizada para a determinação do tempo de residência da água do nó 43 é apresentado na Figura 4.24. O valor determinado na simulação para o tempo de residência máximo da água foi próximo ao de 9 horas. O comportamento deste teste foi próximo ao do teste anterior (T.3.GJ), com uma pequena alteração nos patamares superiores do gráfico do tempo de residência. No entanto, da mesma forma que nos testes T.1.GJ e T.2.GJ, a alteração do intervalo de procura dos expoente $\beta$ pouco interferiu quando se considerou o mesmo intervalo de procura para o coeficiente $C$. $\mathrm{O}$ período de repetição cíclica da rede só aconteceu depois de 48 horas, consequentemente determinou o começo da calibração de qualidade. 


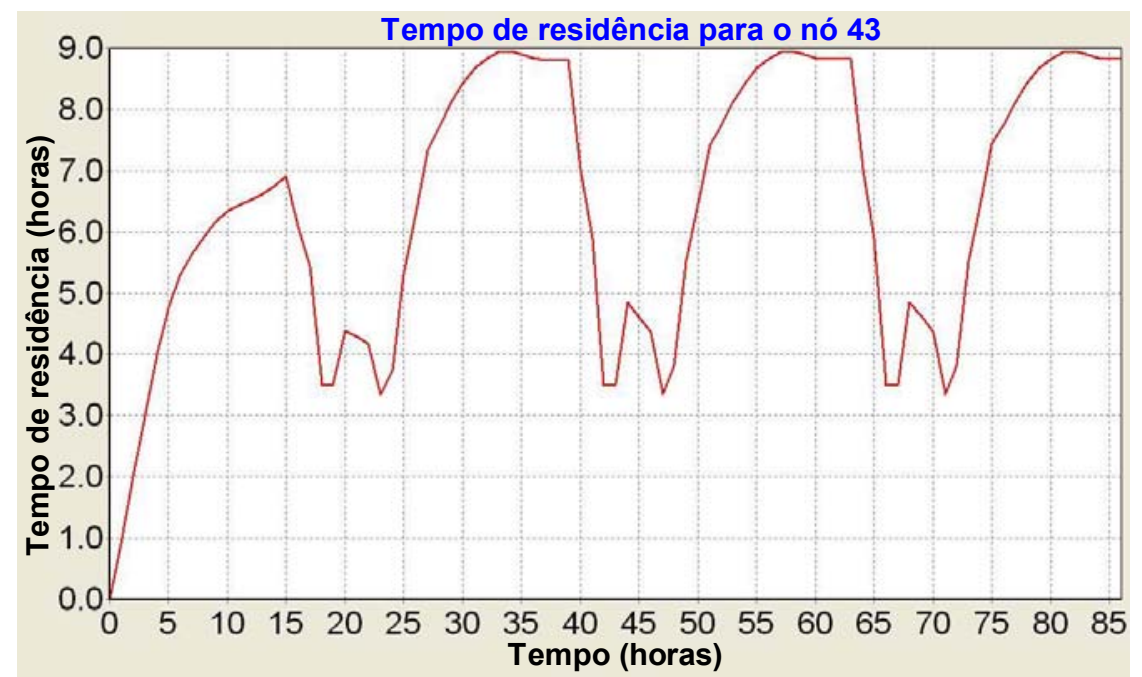

FIGURA 4.24 - Tempo de residência do nó 43 no teste T.4.GJ

\subsubsection{Resultados para o tempo de residência do teste T.1.T}

Os resultados do teste T.1.T para a simulação da determinação do tempo de residência da água do nó 43 são apresentados na Figura 4.25 e Figura 4.26. A Figura 4.25 apresenta o período de tempo necessário para que o tempo de residência da água se tornasse repetitivo. Através dessa figura, pode se concluir que somente após 168 horas de simulação, o tempo de residência tornou-se cíclico.

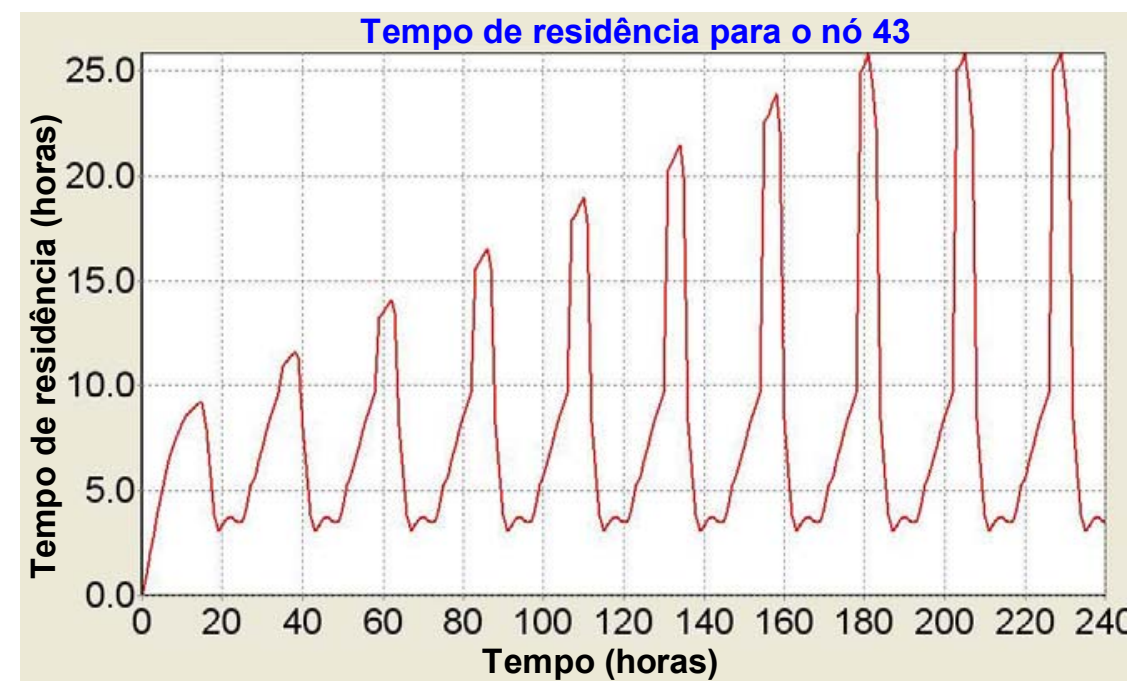

FIGURA 4.25 - Tempo de residência do nó 43 no teste T.1.T 
Na Figura 4.26 é possível observar em destaque o período de simulação entre 168 e 240 horas. Neste intervalo, ficou evidente que o valor máximo atingido pelo tempo de residência foi de 26 horas. Além disso, o comportamento do tempo de residência do teste T.1.T foi bem distinto dos demais testes já realizados, uma vez que apresentou picos mais agudos e o próprio valor máximo foi superior aos demais testes já realizados. Sendo assim, é difícil de se estabelecer algum comparativo do desempenho deste com os demais modelos, quando se leva em consideração somente os resultados da calibração hidráulica e a análise do tempo de residência da água.

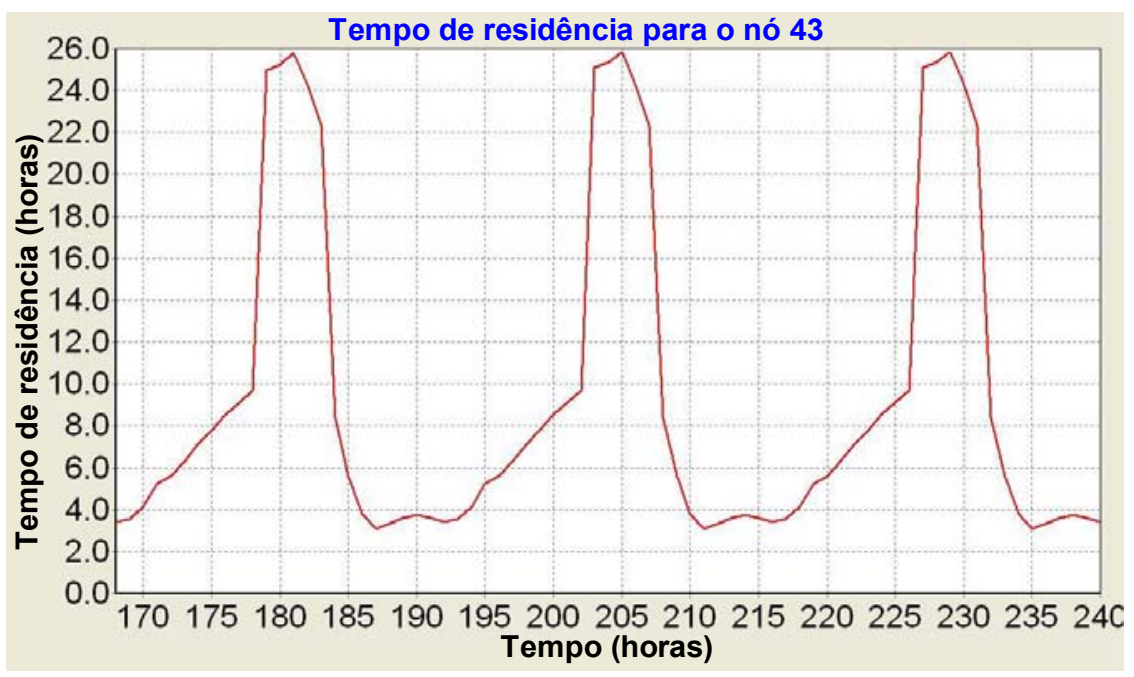

FIGURA 4.26 - Tempo de residência do nó 43 no teste T.1.T em destaque

\subsubsection{Resultados para o tempo de residência do teste T.2.T}

Os resultados da simulação do tempo de residência da água do teste T.2.T são apresentados na Figura 4.27 e Figura 4.28. O tempo de simulação necessário para a repetição cíclica do comportamento hidráulico foi de no mínimo 144 horas, ou seja, depois deste tempo os resultados para o tempo de residência foram os mesmos, conforme a Figura 4.27. 


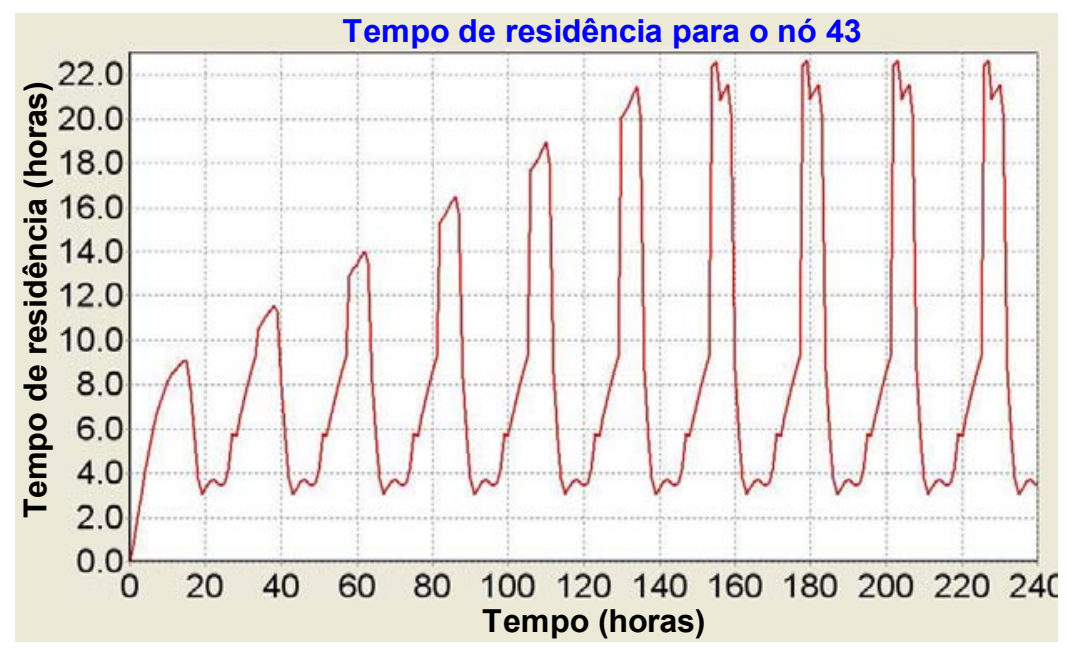

FIGURA 4.27 - Tempo de residência do nó 43 no teste T.2.T

Na Figura 4.28 destacou-se o período de simulação compreendido entre a hora 168 e 240, no qual foi possível determinar o tempo máximo de residência da água próximo de 22 horas.

Ao se comparar os resultados deste teste com o teste anterior (T.1.T), foi possível concluir que, para o modelo de TUCCIARELLI et al. (1999), a alteração do intervalo de procura para o expoente $\beta$ interferiu substancialmente no resultado da simulação do tempo de residência da água, já que o valor atingido anteriormente era de 26 horas e neste teste passou a ser de 22 horas. Este comportamento não foi observado nos modelos de vazamento usados anteriormente (ARAUJO et al., 2006; GEMANOPOULOS \& JOWITT, 1984)

Outra comparação deste teste e com o anterior (T.1.T) está relacionada ao tempo necessário para o comportamento cíclico. No T.2.T, o tempo para o comportamento cíclico diminuiu 24 horas, já que neste foram necessários 144 horas e no anterior, 168 horas. 


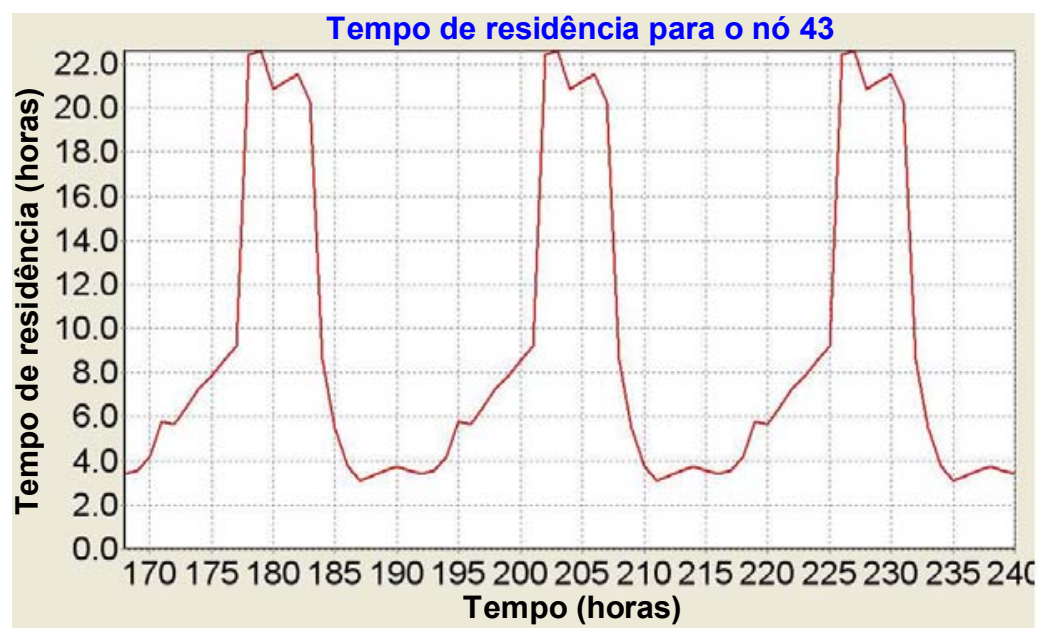

FIGURA 4.28 - Tempo de residência do nó 43 no teste T.2.T em destaque

\subsubsection{Resultados para o tempo de residência do teste T.3.T}

O resultado da simulação do tempo de residência do teste T.3.T do nó 43 é apresentado através da Figura 4.29. O valor determinado na simulação para o tempo máximo foi próximo de 12 horas.

Neste teste, é possível observar que o tempo de simulação foi menor que nos demais testes já realizados. Acredita-se que isto seja resultado da alteração do intervalo de procura do coeficiente $\theta$. Outra alteração em relação aos demais testes do mesmo modelo de vazamento foi percebida no valor máximo do tempo de residência que é muito menor do que nos demais testes.

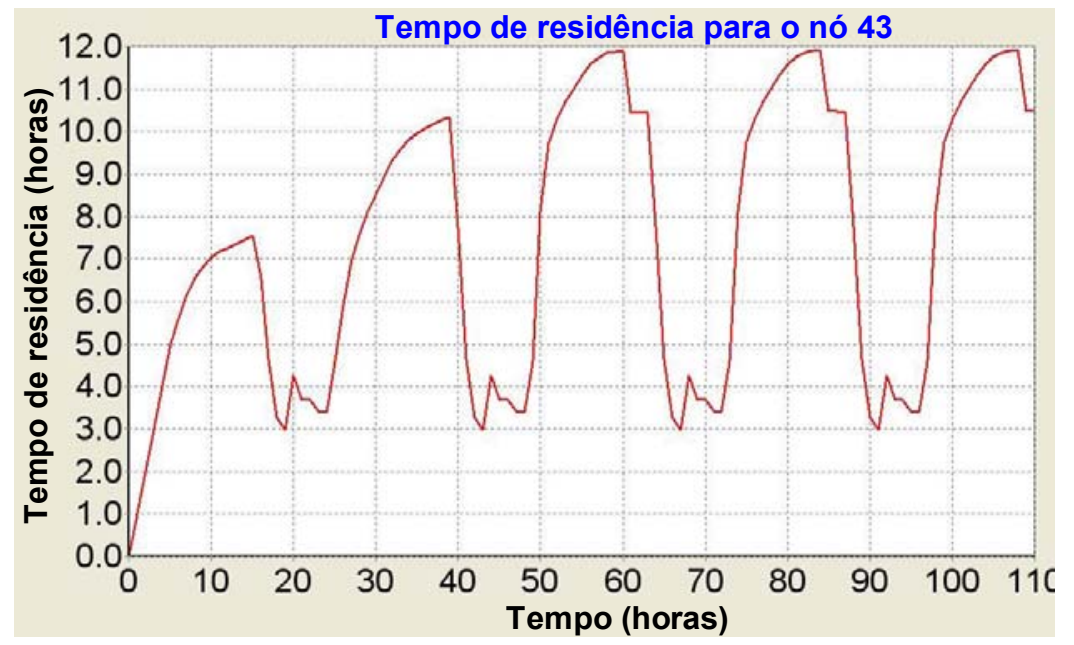

FIGURA 4.29 - Tempo de residência do nó 43 no teste T.3.T 


\subsubsection{Resultados para o tempo de residência do teste T.4.T}

O teste T.4.T tem seu resultado de simulação do tempo de residência do nó 43 apresentado na Figura 4.30. O valor máximo determinado na simulação foi próximo ao de 12 horas. Os resultados apresentados neste teste não se diferem em muito dos apresentados pelo teste T.3.T, revelando que a alteração do intervalo de procura do expoente $\beta$ pouco interferiu nos resultados finais quando considerado este intervalo de procura para o coeficiente $\theta$.

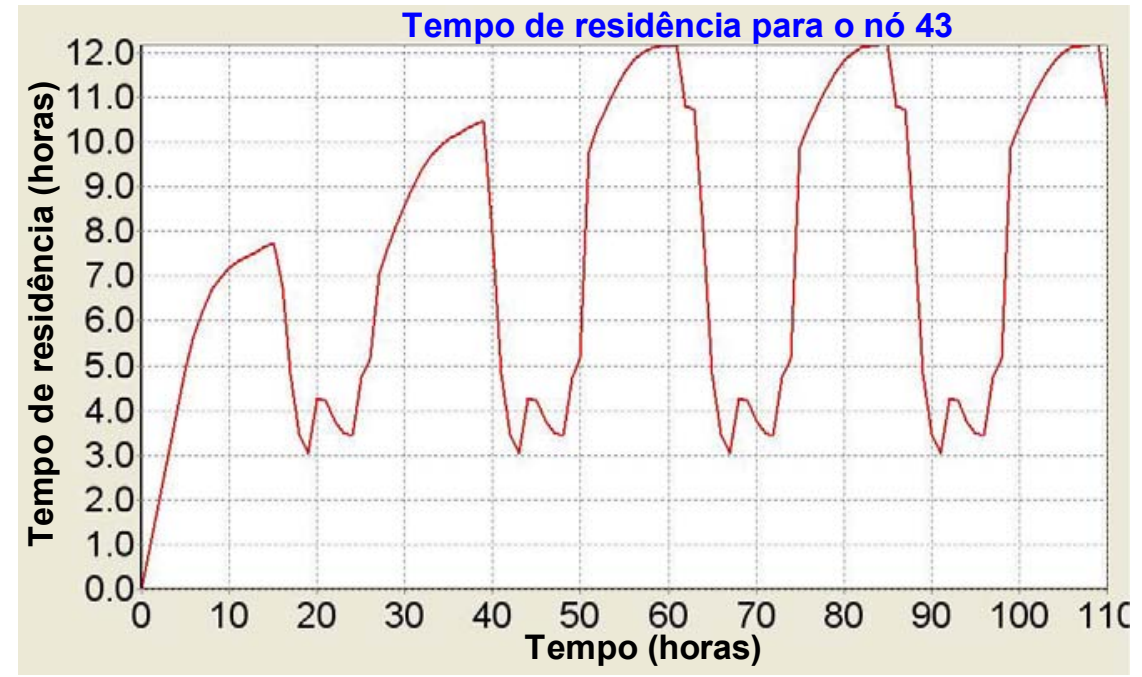

FIGURA 4.30 - Tempo de residência do nó 43 no teste T.4.T

\subsection{DETERMINAÇÃO DO K $\mathrm{BULK}_{\mathrm{B}}$ PELO “TESTE DA GARRAFA”}

Os resultados das determinações realizadas para o "teste da garrafa" são apresentados na Tabela 4.64. Este teste teve como objetivo final determinar o coeficiente $\mathrm{K}_{\text {bulk }}$ que foi usado como valor inicial do coeficiente no simulador de qualidade, e serviu como um guia auxiliar na determinação do intervalo de procura do $\mathrm{K}_{\text {bulk }}$ no calibrador de qualidade.

Nas primeiras duas colunas, encontram-se os horários das medições, assim como o intervalo desde a $1^{\mathrm{a}}$ medição. As colunas seguintes são preenchidas com as concentrações de cloro residual determinadas e as respectivas médias. 
Nas demais colunas da Tabela 4.64, encontram-se os valores esperados para as concentrações de cloro residual, segundo o modelo de decaimento de $1^{\text {a }}$ ordem pelas aproximações da Minimização do Somatório dos Erros ao Quadrado (MSEQ) e Método Gráfico (MG). Os valores dos coeficientes cinéticos foram ajustados com o auxílio da ferramenta de otimização "solver", de modo a minimizar o somatório dos quadrados das diferenças entre os valores determinado e o modelado.

O coeficiente obtido para o modelo de $1^{\mathrm{a}}$ ordem foi $\mathrm{K}_{\text {bulk, } 1^{\mathrm{a}}}=-0.019 \mathrm{dia}^{-1}$ pela aproximação MSEQ e $\mathrm{K}_{\text {bulk, } 1^{a}}=-0.0231$ dia $^{-1}$ pela aproximação MG. Estes valores não podem ser comparados com valores de outros estudos, pois há influência de diversos fatores, tais como: qualidade da água, origem da água e o tipo de matéria orgânica presente.

Praticamente não se observou decaimento do cloro residual durante o período de $24 \mathrm{~h}$, ao longo do qual foram realizadas as determinações em laboratório. $\mathrm{O}$ valor da concentração permaneceu muito próximo ao da concentração inicial, sugerindo que água subterrânea era isenta de matéria orgânica.

O teste realizado pode ser considerado à temperatura constante, pois se conservaram as amostras em uma caixa térmica, onde a temperatura variou no máximo $2,5^{\circ} \mathrm{C}$, inferior à variação de temperatura em uma estufa.

Os valores encontrados serviram como bom parâmetro para determinação do intervalo de procura do coeficiente $K_{\text {bulk }}$ para o calibrador de qualidade, mas este intervalo não deve ser muito próximo aos valores encontrados, uma vez que o teste ainda não é padronizado e sua metodologia não é consagrada, tornando-o impreciso e sujeito as falhas.

A Figura 4.31a apresenta o comparativo dos resultados obtidos através dos dois métodos de aproximação (MSEQ e MG) para o modelo de primeira ordem. 
TABELA 4.64 - Tabela com os resultados do "teste de garrafa"

Data 23/3/2007 a 25/03/2007

Amostra ETA

Local EESC - LPB

Temperatura: $23,5^{\circ} \mathrm{C}$

\begin{tabular}{|c|c|c|c|c|c|c|c|c|}
\hline & $n^{0}$ & Horário & $\begin{array}{c}\Delta \mathrm{t} \\
\text { (h:min) } \\
\end{array}$ & $\begin{array}{c}\Delta t \\
\text { (dia) }\end{array}$ & $\begin{array}{l}\Delta \mathrm{t} \\
(\mathrm{h}) \\
\end{array}$ & $\begin{array}{c}\Delta t \\
(\min ) \\
\end{array}$ & $\begin{array}{c}{[\mathrm{C}]} \\
\left(\mathrm{mg} \mathrm{Cl}_{2} / \mathrm{L}\right) \\
\end{array}$ & $\ln (C)$ \\
\hline \multirow{20}{*}{ 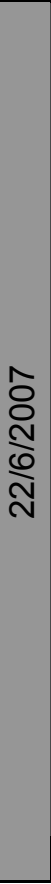 } & \multirow[b]{2}{*}{1} & $11: 37$ & $0: 00$ & 0,00 & 0,00 & 0 & 1,02 & 0,02 \\
\hline & & $11: 39$ & $0: 02$ & 0,00 & 0,03 & 2 & 1,01 & 0,01 \\
\hline & \multirow[b]{3}{*}{2} & $11: 54$ & $0: 17$ & 0,01 & 0,28 & 17 & 0,88 & $-0,13$ \\
\hline & & $11: 56$ & $0: 19$ & 0,01 & 0,32 & 19 & 0,95 & $-0,05$ \\
\hline & & $12: 00$ & $0: 23$ & 0,02 & 0,38 & 23 & 0,98 & $-0,02$ \\
\hline & \multirow[b]{2}{*}{3} & $12: 08$ & $0: 31$ & 0,02 & 0,52 & 31 & 0,99 & $-0,01$ \\
\hline & & $12: 11$ & $0: 34$ & 0,02 & 0,57 & 34 & 1,01 & 0,01 \\
\hline & \multirow[b]{3}{*}{4} & $12: 41$ & $1: 04$ & 0,04 & 1,07 & 64 & 1,01 & 0,01 \\
\hline & & $12: 44$ & 1:07 & 0,05 & 1,12 & 67 & 0,96 & $-0,04$ \\
\hline & & $12: 47$ & $1: 10$ & 0,05 & 1,17 & 70 & 1,01 & 0,01 \\
\hline & \multirow[b]{2}{*}{5} & $13: 43$ & $2: 06$ & 0,09 & 2,10 & 126 & 1,01 & 0,01 \\
\hline & & $13: 47$ & $2: 10$ & 0,09 & 2,17 & 130 & 1,02 & 0,02 \\
\hline & \multirow[b]{2}{*}{6} & $15: 05$ & $3: 28$ & 0,14 & 3,47 & 208 & 0,99 & $-0,01$ \\
\hline & & $15: 13$ & $3: 36$ & 0,15 & 3,60 & 216 & 0,97 & $-0,03$ \\
\hline & \multirow[b]{2}{*}{7} & $17: 05$ & $5: 28$ & 0,23 & 5,47 & 328 & 0,94 & $-0,06$ \\
\hline & & $17: 20$ & $5: 43$ & 0,24 & 5,72 & 343 & 0,93 & $-0,07$ \\
\hline & \multirow[b]{2}{*}{8} & $21: 24$ & $9: 47$ & 0,41 & 9,78 & 587 & 0,94 & $-0,06$ \\
\hline & & 21:27 & $9: 50$ & 0,41 & 9,83 & 590 & 0,92 & $-0,08$ \\
\hline & \multirow[b]{2}{*}{9} & $0: 13$ & $12: 36$ & 0,53 & 12,60 & 756 & 0,96 & $-0,04$ \\
\hline & & $0: 17$ & $12: 40$ & 0,53 & 12,67 & 760 & 0,99 & $-0,01$ \\
\hline \multirow{4}{*}{ 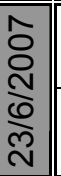 } & \multirow[b]{2}{*}{10} & $9: 17$ & $21: 40$ & 0,90 & 21,67 & 1300 & 0,90 & $-0,11$ \\
\hline & & $9: 23$ & $21: 46$ & 0,91 & 21,77 & 1306 & 0,95 & $-0,05$ \\
\hline & \multirow[b]{2}{*}{11} & $15: 25$ & $27: 48$ & 1,16 & 27,80 & 1668 & 0,98 & $-0,02$ \\
\hline & & $15: 29$ & $27: 52$ & 1,16 & 27,87 & 1672 & 1,02 & 0,02 \\
\hline
\end{tabular}

\begin{tabular}{|c|c|c|c|}
\hline \multicolumn{4}{|c|}{ kbulk $1^{\text {a }}$ ordem } \\
\hline \multicolumn{2}{|c|}{ MSEQ } & \multicolumn{2}{|c|}{ MG } \\
\hline$\overline{k_{\text {bulk }}=}$ & $-0,019$ & $\overline{\mathrm{k}_{\text {bulk }}=}$ & $=0,0231$ \\
\hline $\mathrm{C}_{0}=$ & 0,98 & $\mathrm{C}_{0}=$ & 0,98 \\
\hline $\begin{array}{c}\mathrm{C}] \\
\left(\mathrm{mg} \mathrm{Cl}_{2} / \mathrm{L}\right)\end{array}$ & $\left|\mathrm{C}_{\exp }-\mathrm{C}_{\text {mod }}\right|^{2}$ & $\begin{array}{c}\mathrm{C}] \\
\left(\mathrm{mg} \mathrm{Cl}_{2} / \mathrm{L}\right)\end{array}$ & $\left|C_{\text {exp }}-C_{\text {mod }}\right|^{2}$ \\
\hline 0,98 & 0,002 & 0,98 & 0,002 \\
\hline 0,98 & 0,001 & 0,98 & 0,001 \\
\hline 0,98 & 0,010 & 0,98 & 0,009 \\
\hline 0,98 & 0,001 & 0,98 & 0,001 \\
\hline 0,98 & 0,000 & 0,98 & 0,000 \\
\hline 0,98 & 0,000 & 0,98 & 0,000 \\
\hline 0,98 & 0,001 & 0,98 & 0,001 \\
\hline 0,98 & 0,001 & 0,98 & 0,001 \\
\hline 0,98 & 0,000 & 0,98 & 0,000 \\
\hline 0,98 & 0,001 & 0,98 & 0,001 \\
\hline 0,98 & 0,001 & 0,98 & 0,001 \\
\hline 0,98 & 0,002 & 0,98 & 0,002 \\
\hline 0,98 & 0,000 & 0,97 & 0,000 \\
\hline 0,98 & 0,000 & 0,97 & 0,000 \\
\hline 0,97 & 0,001 & 0,97 & 0,001 \\
\hline 0,97 & 0,002 & 0,97 & 0,002 \\
\hline 0,97 & 0,001 & 0,97 & 0,001 \\
\hline 0,97 & 0,003 & 0,97 & 0,002 \\
\hline 0,97 & 0,000 & 0,97 & 0,000 \\
\hline 0,97 & 0,000 & 0,97 & 0,001 \\
\hline 0,96 & 0,004 & 0,96 & 0,003 \\
\hline 0,96 & 0,000 & 0,96 & 0,000 \\
\hline 0,96 & 0,001 & 0,95 & 0,001 \\
\hline 0,96 & 0,004 & 0,95 & 0,005 \\
\hline$\sum=$ & 0,036 & & 0,164 \\
\hline
\end{tabular}




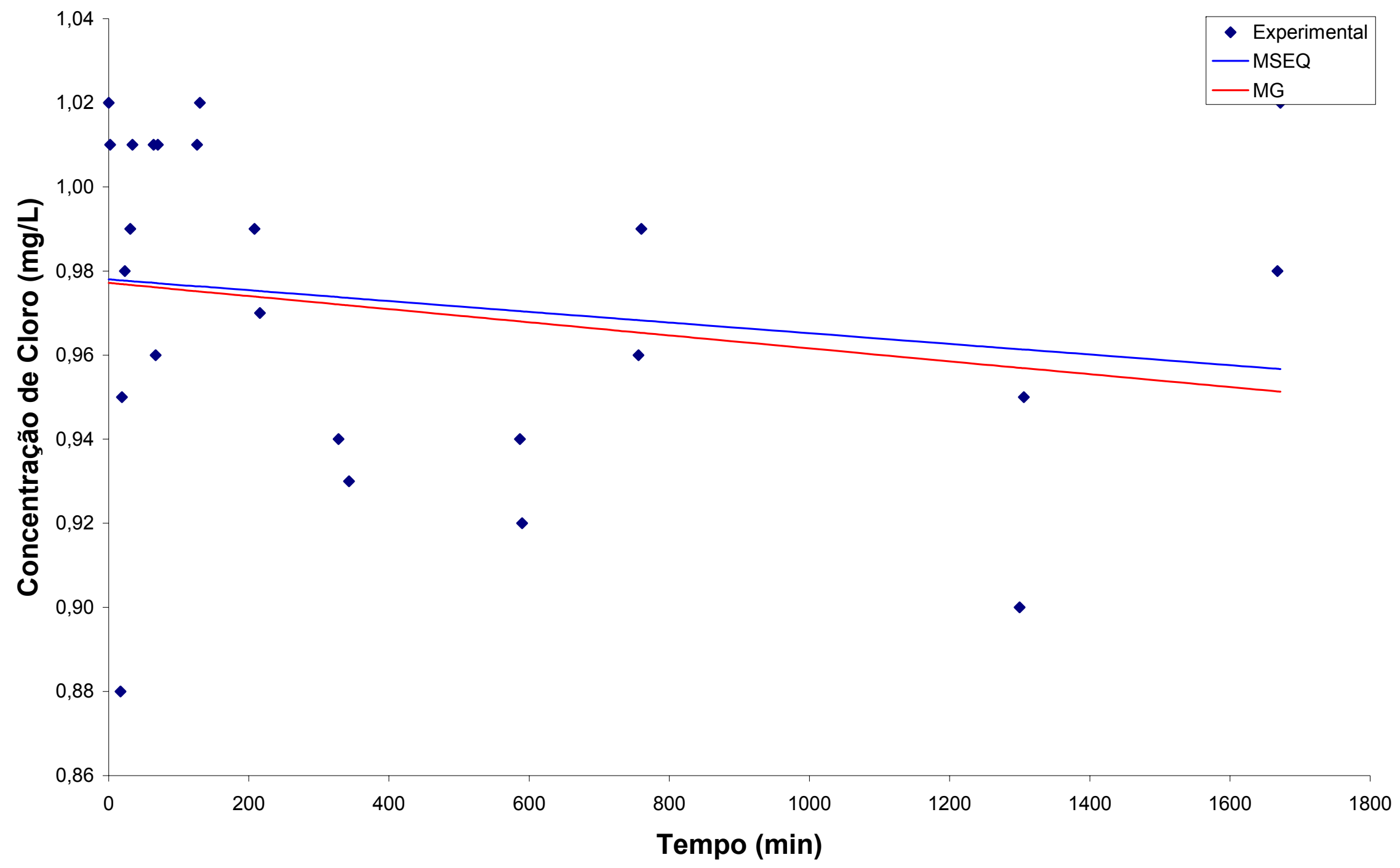

FIGURA 4.31 - Gráfico dos dados observados e calibrados 


\subsection{ARQUIVOS PARA CALIBRAR O DECAIMENTO DE CLORO}

Após realizadas todas as calibrações hidráulicas para os diversos modelos de vazamento, foi possível usar o calibrador de qualidade, uma vez que a distribuição das concentrações de cloro, por toda a rede, é função de fatores resultantes da calibração hidráulica (velocidade nos tubos, tempo de residência da água e distribuição das vazões na rede).

O calibrador de qualidade utiliza as mesmas informações exigidas pelo calibrador hidráulico acrescidas das informações obtidas pelo próprio calibrador hidráulico (rugosidade, coeficientes dos "emitters" e o expoente geral dos "emitters"), além dos dados de entrada de qualidade. Estes dados são: concentração inicial de cloro nos pontos observados; concentração inicial de cloro na saída do reservatório que abastece o sistema; as ordens de reação das equações e os valores iniciais dos coeficientes de calibração ( $K_{\text {bulk }}$ e $\left.K_{\text {wall }}\right)$ usadas pelo modelo proposto pelo EPANET 2.0; e o período da simulação, com seus respectivos passos de tempo de hidráulica e qualidade. Também são necessários padrões de consumo, de nível de reservatório e concentração que abastece o sistema, além da determinação dos tempos de residência da água nos nós observados.

\subsubsection{Construção do arquivo de qualidade .inp}

Os dados de entrada do arquivo inp são todos os que já existiam no arquivo .inp da calibração hidráulica acrescidos de outras informações necessárias para o calibrador de qualidade da água:

- A ordem de reação $\left(\mathrm{K}_{\text {bulk }}\right.$ e $\left.\mathrm{K}_{\text {wall }}\right)$, que no caso foi adotada como de primeira ordem para ambos;

- Os coeficientes globais de reação $\mathrm{K}_{\text {bulk }}$ e $\mathrm{K}_{\text {wall, }}$ adotados conforme o que a literatura recomenda. A literatura indica que para o PVC (material das 
tubulações do Parque Fher), o $\mathrm{K}_{\text {wall }}$ deve ter valor baixo e que a idade da rede desse material pouco influi nas mudanças de suas características em relação a esse parâmetro. Uma primeira aproximação para o valor de $\mathrm{K}_{\text {bulk }}$ foi feita através do "teste da garrafa". O teste de decaimento do cloro realizado no dia da campanha de campo indicou o valor do $\mathrm{K}_{\text {bulk }}$, sendo por volta de $-0.02 \mathrm{dia}^{-1}$.

- Concentração média de cloro na saída do Reservatório que abastece o sistema, que foi considerada como a concentração constante de abastecimento do reservatório.

- Fatores Multiplicativos do consumo de referência determinados pelo calibrador hidráulico previamente calibrado para o período de 24 horas correspondente à campanha de campo realizada (varia conforme o teste realizado).

- Fatores Multiplicativos da Concentração de Cloro na entrada do sistema, durante o período de 24 horas.

- Fatores Multiplicativos do Nível do Reservatório para o período de 24 horas (Tabela 4.63).

- Duração da simulação igual ao último instante em que se registrou concentração de cloro residual

- Indicar o tipo de análise de qualidade pretendida nas opções (cloro mg/l)

- O expoente dos "emitters" (varia conforme o teste realizado).

- Todos os coeficientes dos “emitters" determinados para cada nó na calibração hidráulica (varia conforme o teste realizado).

- E, por último a alteração da rugosidade do antigo arquivo .inp do calibrador hidráulico, para a rugosidade obtida como resultado da calibração hidráulica (varia conforme o teste realizado). 
- As informações relativas aos nós e trechos da rede, carga hidráulica do reservatório, e opções de unidades e fórmula de perda de carga continuam da mesma forma.

Os multiplicadores da concentração foram criados para retratar o comportamento da concentração de cloro na entrada da rede. Seu cálculo foi feito através da divisão do valor médio de cada hora do dia pelo valor médio do dia todo. Desta forma, a concentração na entrada da rede pôde ser representada de maneira fidedigna ao longo do período considerado. A partir da Tabela 4.7 foi possível determinar a média da concentração de entrada do dia considerado e determinar os multiplicadores da concentração de entrada (Tabela 4.65). O arquivo inp resultante dessas considerações pode ser consultado no Apêndice $C$, lembrando que alguns valores são alterados conforme o teste considerado no modelo hidráulico (modelo de vazamento e faixa para os parâmetros).

TABELA 4.65 - Cálculo dos multiplicadores da concentração de cloro

\begin{tabular}{|c|c|c|c|c|c|}
\hline \multirow{2}{*}{ Dia } & \multicolumn{2}{|c|}{ Hora } & \multirow{2}{*}{ Padrões } & \multirow{2}{*}{$\begin{array}{l}\text { Concentração do } \\
\text { cloro livre média } \\
\text { (ma/L) }\end{array}$} & \multirow{2}{*}{$\begin{array}{c}\text { Multiplicadores da } \\
\text { concentração de } \\
\text { cloro }\end{array}$} \\
\hline & Inicio & Termino & & & \\
\hline \multirow{7}{*}{$22 / 6 / 2007$} & $17: 00$ & 18:00 & 1 & 1.18 & 0.985643 \\
\hline & $18: 00$ & 19:00 & 2 & 1.16 & 0.973105 \\
\hline & 19:00 & $20: 00$ & 3 & 1.18 & 0.987733 \\
\hline & $20: 00$ & $21: 00$ & 4 & 1.19 & 0.998181 \\
\hline & $21: 00$ & $22: 00$ & 5 & 1.19 & 0.997485 \\
\hline & $22: 00$ & $23: 00$ & 6 & 1.26 & 1.053210 \\
\hline & $23: 00$ & $00: 00$ & 7 & 1.20 & 0.999575 \\
\hline \multirow{18}{*}{ 23/6/2007 } & $00: 00$ & 01:00 & 8 & 1.19 & 0.992609 \\
\hline & 01:00 & $02: 00$ & 9 & 1.24 & 1.037886 \\
\hline & $02: 00$ & 03:00 & 10 & 1.29 & 1.078287 \\
\hline & 03:00 & 04:00 & 11 & 1.26 & 1.052514 \\
\hline & $04: 00$ & $05: 00$ & 12 & 1.27 & 1.058783 \\
\hline & 05:00 & 06:00 & 13 & 1.29 & 1.074107 \\
\hline & 06:00 & 07:00 & 14 & 1.27 & 1.060809 \\
\hline & 07:00 & $08: 00$ & 15 & 1.23 & 1.028134 \\
\hline & 08:00 & 09:00 & 16 & 1.15 & 0.964978 \\
\hline & 09:00 & $10: 00$ & 17 & 1.17 & 0.977284 \\
\hline & $10: 00$ & $11: 00$ & 18 & 1.13 & 0.944546 \\
\hline & $11: 00$ & $12: 00$ & 19 & 1.14 & 0.948725 \\
\hline & $12: 00$ & 13:00 & 20 & 1.10 & 0.917380 \\
\hline & $13: 00$ & $14: 00$ & 21 & 1.13 & 0.941063 \\
\hline & $14: 00$ & $15: 00$ & 22 & 1.20 & 1.004634 \\
\hline & $15: 00$ & $16: 00$ & 23 & 1.12 & 0.938277 \\
\hline & $16: 00$ & $17: 00$ & 24 & 1.18 & 0.985054 \\
\hline & & & Média do dia & 1.20 & \\
\hline
\end{tabular}




\subsubsection{Construção do arquivo com as observações de cloro .in}

$\mathrm{O}$ arquivo com as observações de cloro in contém informações relativas ao número de nós observados, a duração do período de observação e, para cada nó observado, o valor da concentração nas diversas horas do período de observação.

Como não é possível comparar diretamente os dados observados com os dados simulados no período considerado (devido ao fato do simulador EPANET 2.0 considerar o modelo Lagrangeano dirigido pelo tempo - TDM) para sincronizar os dados observados com os dados simulados, foi realizada a defasagem do momento da observação nos nós, através da soma do tempo máximo de residência do nó observado nos horários das observações. Assim, obteve-se um novo horário de observação que tem como objetivo levar em consideração o tempo em que um volume de água, que entra na rede, leva para chegar a um determinado nó, possibilitando, assim, a comparação entre o simulado e observado. $\mathrm{O}$ exemplo do arquivo .in resultante pode ser consultado no Apêndice $\mathrm{C}$, lembrando que os valores das horas observadas são alterados a cada teste.

\subsubsection{Construção do arquivo .in dos AGs para a calibração de qualidade}

$\mathrm{O}$ arquivo .in dos AGs para a calibração de qualidade foi semelhante ao usado pelo calibrador hidráulico, mudando-se apenas as considerações dos intervalos de procura que passam a ser de apenas dois intervalos de procura, sendo um para $\mathrm{K}_{\text {bulk }}$ e outro para $\mathrm{K}_{\text {wall. }}$.

Como o $\mathrm{K}_{\text {bulk }}$ foi pré-determinado pelo "teste da garrafa", optou-se em considerar o intervalo de procura para o coeficiente próximo ao valor determinado pelo o experimento. 
Para $\mathrm{K}_{\text {wall, }}$ o intervalo de procura variou entre -0.1 a $0.00 \mathrm{~m} /$ dia, pois os resultados encontrados por CASAGRANDE (1997) e VIEIRA (2002) estão próximos a esta faixa de procura. O arquivo .in dos AGs resultante pode ser consultado no Apêndice C.

\subsection{RESULTADOS OBTIDOS DA CALIBRAÇÃO QUALIDADE}

Calibrando-se hidraulicamente essa rede foi possível determinar o valor das variáveis de reação da água $K_{\text {bulk }}$ e $K_{\text {wall. }}$.

O EPANET 2.0 possibilita a análise gráfica comparativa dos valores observados com o simulado. Para tanto, é necessário atribuir os valores das variáveis calibradas no simulador e criar um arquivo com os valores observados (arquivo *. DAT) que tem as mesmas informações do arquivo de campo do calibrador.

Foram realizadas 3 calibrações de qualidade com diferentes intervalos de procura para $\mathrm{K}_{\text {wall }} \mathrm{e} \mathrm{K}_{\text {bulk, }}$ considerando todos os resultados dos testes da calibração hidráulica. As 3 calibrações de qualidade só se diferem entre si em relação aos intervalos de procura de $\mathrm{K}_{\text {wall }} \mathrm{e}$ $\mathrm{K}_{\text {bulk, }}$ e a dimensão da população dos AGs.

A Tabela 4.66 apresenta os resultados obtidos da calibração de qualidade para todos os testes da calibração hidráulica, considerando os intervalos de procura e os valores iniciais indicados na Tabela 4.67. Na Tabela 4.68 está representada a configuração dos AGs usados e os valores para seus parâmetros. 
TABELA 4.66 - Resultados da $1^{\text {a }}$ calibração para $K_{\text {bulk }}$ e $K_{\text {wall }}$ considerando todos os testes

\begin{tabular}{|c|c|c|c|c|c|c|c|c|c|c|c|c|c|}
\hline & \multicolumn{2}{|c|}{200} & \multicolumn{2}{|c|}{300} & \multicolumn{2}{|c|}{700} & \multicolumn{2}{|c|}{1000} & \multicolumn{2}{|c|}{2000} & \multicolumn{2}{|c|}{ Melhor semente } \\
\hline & & $\mathrm{K}_{\text {bulk }}$ & $\mathrm{K}_{\text {wall }}$ & $\mathrm{K}_{\text {bulk }}$ & $\mathrm{K}_{\text {wall }}$ & $\mathrm{K}_{\text {bulk }}$ & $\mathrm{K}_{\text {wall }}$ & $\mathrm{K}_{\text {bulk }}$ & $\mathrm{K}_{\text {wall }}$ & $\mathrm{K}_{\text {bulk }}$ & $\mathrm{K}_{\text {wall }}$ & $\mathrm{K}_{\text {bulk }}$ & $\mathrm{K}_{\text {wall }}$ \\
\hline & Resu & $-0,0217$ & $-0,0089$ & $-0,0112$ & $-0,0100$ & $-0,0127$ & $-0,0100$ & $-0,0131$ & $-0,0099$ & $-0,0114$ & $-0,0099$ & $-0,0114$ & $-0,00$ \\
\hline & Função Objetivo & \multicolumn{2}{|c|}{0,0706513} & \multicolumn{2}{|c|}{0,0690678} & \multicolumn{2}{|c|}{0,0693311} & \multicolumn{2}{|c|}{0,0690710} & \multicolumn{2}{|c|}{0,0689624} & \multicolumn{2}{|c|}{0,0689624} \\
\hline \multirow{2}{*}{ T.2.A } & Resultados &, 0322 & $-0,0099$ & $-0,0136$ & $-0,0100$ & $\mid-0,0104$ & $-0,0100$ & $-0,0141$ & $\mid-0,0098$ & $-0,0105$ & $-0,0091$ & $-0,0104$ & $-0,0100$ \\
\hline & Função Objetivo & \multicolumn{2}{|c|}{0,0779564} & \multicolumn{2}{|c|}{0,0777625} & \multicolumn{2}{|c|}{0,0773481} & \multicolumn{2}{|c|}{0,0777311} & \multicolumn{2}{|c|}{0,0779340} & \multicolumn{2}{|c|}{0,0773481} \\
\hline \multirow{2}{*}{ T.1.GJ } & Resultados &, 0114 & $-0,0100$ & $-0,0112$ & $-0,0100$ & 0,0127 & $-0,0100$ & $-0,0089$ & $\mid-0,0099$ & $-0,0114$ & $-0,0099$ & $-0,0089$ & $-0,0099$ \\
\hline & Função Objetivo & \multicolumn{2}{|c|}{0,0693384} & \multicolumn{2}{|c|}{0,0693087} & \multicolumn{2}{|c|}{0,0695729} & \multicolumn{2}{|c|}{0,0687946} & \multicolumn{2}{|c|}{0,0687965} & \multicolumn{2}{|c|}{0,0687946} \\
\hline \multirow{2}{*}{ T.2.GJ } & Resultados & 0,0016 & $-0,0100$ & $-0,0300$ & $\mid-0,0086$ & 0,0008 & $\mid-0,0097$ & $-0,0110$ & $\mid-0,0094$ & $-0,0400$ & $-0,0089$ & $-0,0110$ & $-0,0094$ \\
\hline & Função Objetivo & \multicolumn{2}{|c|}{0,0688877} & \multicolumn{2}{|c|}{0,0717141} & \multicolumn{2}{|c|}{0,0686822} & 0,068 & 80727 & $0,06 \mathrm{~s}$ & 6966 & 0,06 & 30727 \\
\hline & Resu & $-0,0400$ & $-0,0100$ & $-0,0400$ & $-0,0100$ & $-0,0400$ & $-0,0100$ & $-0,0400$ & $\mid-0,0100$ & $-0,0400$ & $-0,0100$ & $-0,0400$ & 100 \\
\hline 1.J. & Função & 0,097 & 77692 & 0,09 & 769 & 0,097 & 776 & 0,097 & 776 & 0,097 & 776 & 0,09 & 776 \\
\hline & Res & 0,0400 & $-0,0100$ & $-0,0400$ & $-0,0100$ & $-0,0400$ & $-0,0100$ & $-0,0400$ & $-0,0100$ & $-0,0400$ & $-0,0100$ & $-0,0400$ & $-0,0100$ \\
\hline 1. & Funçã & 0,08 & 19653 & 0,08 & 1965 & 0,08 & 1965 & 0,08 & 1965 & 0,08 & 96 & 0,08 & 196 \\
\hline & os &, 0122 & $-0,0076$ & $-0,0112$ & $-0,0086$ & $-0,0008$ & $-0,0076$ & $-0,0048$ & $-0,0079$ & $-0,0025$ & $\mid-0,0073$ & $-0,0008$ & $-0,0076$ \\
\hline & Funçã & 1,29 & 44300 & 1,29 & 0200 & 1,29 & 25200 & 1,293 & 3110 & 1,292 & 26400 & 1,29 & 25200 \\
\hline & Resul &, 0122 & $-0,0076$ & $-0,0080$ & $-0,0085$ & $-0,0008$ & $-0,0076$ & $-0,0048$ & $\mid-0,0082$ & $-0,0061$ & $-0,0073$ & $-0,0008$ & $-0,0076$ \\
\hline & Função Objetivo & 1,337 & 71100 & 1,33 & 0300 & 1,33 & 37200 & 1,335 & 50800 & 1,335 & 0000 & 1,33 & 37200 \\
\hline & Resultados & 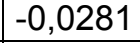 & $-0,0100$ & $-0,0112$ & $-0,0086$ & $\mid-0,0008$ & $-0,0076$ & $-0,0048$ & $\mid-0,0079$ & $-0,0025$ & $-0,0073$ & $\mid-0,0281$ & $-0,0100$ \\
\hline & Função Objetivo & 1091 & 18300 & 129 & 0200 & 1,29 & 25200 & 1,293 & 31100 & 1,292 & 26400 & 1,09 & 18300 \\
\hline & Resultados &, 0290 & $-0,0100$ & $-0,0312$ & $-0,0100$ & $-0,0400$ & $\mid-0,0097$ & $-0,0184$ & $\mid-0,0099$ & $-0,0305$ & $-0,0100$ & 0,0400 & $-0,0097$ \\
\hline & Função Objetivo & $1,09 c$ & 00900 & 1,09 & 1000 & 1,08 & 99300 & 1,09 & 03500 & 1,090 & 0900 & 108 & \\
\hline
\end{tabular}

TABELA 4.67 - Intervalos usados para $1^{\text {a }}$ calibração

\begin{tabular}{|c|c|c|}
\hline \multirow{2}{*}{} & \multicolumn{2}{|c|}{ Intervalos de procura } \\
\cline { 2 - 3 } & Kbulk & Kwall \\
\hline Mínimo & -0.040 & -0.010 \\
\hline Máximo & 0.000 & 0.000 \\
\hline Valores iniciais & -0.0231 & -0.005 \\
\hline
\end{tabular}


TABELA 4.68 - Parâmetros, valores e tipo de AGs usados na $1^{\text {a }}$ calibração

\begin{tabular}{|c|c|}
\hline Tipo do AG & Geracional elitista \\
\hline Representação da solução & Real \\
\hline População de soluções & 20 \\
\hline Recombinação & dois pontos \\
\hline Probabilidade de recombinação & 0.7 \\
\hline Seleção & Stochastic Remainder Sampling-SRS \\
\hline Mutação & gaussiana \\
\hline Probabilidade de mutação & 0.04 \\
\hline Taxa de elitismo & 0.3 \\
\hline Número de gerações & 100 \\
\hline Escalonamento & linear $(\mathrm{c}=1,5)$ \\
\hline
\end{tabular}

Nesta primeira calibração, foi possível analisar os resultados das melhores sementes para os diversos testes realizados com os modelos de vazamento. Na Tabela 4.65, é possível verificar distintas soluções para todos os testes, mostrando a influência dos parâmetros hidráulicos sobre os resultados da calibração de qualidade, visto que, a calibração de qualidade é predominantemente regida pelo comportamento hidráulico da rede.

Assim, é possível concluir que, os modelos de GERMANOPOULOS \& JOWITT (1989) e ARAUJO et al. (2003) são os modelos de vazamento que melhor contribuem para a calibração de qualidade, com resultados muito próximos nos testes T.1.A e T.2.GJ. Observouse também que, apesar da liberdade dada ao expoente $\beta$ no teste T.2.GJ, os AGs foram capazes de convergir para uma solução muito próxima à encontrada para o teste T.1.A, no qual o expoente fixo é igual a 1,18.

Os resultados encontrados para o modelo de TUCCIARELLI et al.(1999) não foram satisfatórios, pois todos os teste realizados mostraram que os resultados obtidos não se aproximaram dos modelos de vazamento com melhor desempenho, deixando transparecer uma possível deficiência deste modelo na representação e calibração de redes reais.

Como, em diversas calibrações realizadas, os coeficientes convergiram para os limites dados para os intervalos de procura de $K_{\text {bulk }}$ e $K_{\text {wall, }}$ foi realizada uma nova calibração de 
qualidade com pequenas alterações tanto nos intervalos de procura quanto na população dos AGs.

A Tabela 4.69 mostra os novos limites de procura para $\mathrm{K}_{\text {bulk }}$ e $\mathrm{K}_{\text {wall, }}$, e seus valores iniciais (os mesmo da calibração anterior). O tipo, os parâmetros e os valores dos AGs usados na segunda calibração de qualidade, no qual só muda o valor da população, estão representados na Tabela 4.70 .

TABELA 4.69 - Intervalos usados para $2^{\text {a }}$ calibração

\begin{tabular}{|c|c|c|}
\hline \multirow{2}{*}{} & \multicolumn{2}{|c|}{ Intervalos de procura } \\
\cline { 2 - 3 } & Kbulk & Kwall \\
\hline Mínimo & -0.040 & -0.015 \\
\hline Máximo & -0.005 & 0.000 \\
\hline Valores iniciais & -0.0231 & -0.005 \\
\hline
\end{tabular}

TABELA 4.70 - Parâmetros, valores e tipo de AGs usados na $2^{\mathrm{a}}$ calibração

\begin{tabular}{|c|c|}
\hline Tipo do AG & Geracional elitista \\
\hline Representação da solução & Real \\
\hline População de soluçães & 100 \\
\hline Recombinação & dois pontos \\
\hline Probabilidade de recombinação & 0.7 \\
\hline Seleção & Stochastic Remainder Sampling-SRS \\
\hline Mutação & gaussiana \\
\hline Probabilidade de mutação & 0.04 \\
\hline Taxa de elitismo & 0.3 \\
\hline Número de gerações & 100 \\
\hline Escalonamento & linear $(c=1,5)$ \\
\hline
\end{tabular}

Nesta calibração optou-se por uma população maior, visto que também houve um acréscimo no intervalo de procura de $\mathrm{K}_{\text {wall }}$. Esperou-se assim que, apesar do crescimento do espaço de possível soluções dos AGs, o acréscimo da população fosse capaz de percorrer todas as possíveis soluções e até mesmo melhorar a solução anterior.

Os resultados da $2^{\mathrm{a}}$ calibração realizada para todos os testes de vazamento estão apresentados na Tabela 4.71 . 
TABELA 4.71 - Resultados da $2^{\mathrm{a}}$ calibração para $K_{\text {bulk }}$ e $K_{\text {wall }}$ considerando todos os testes

\begin{tabular}{|c|c|c|c|c|c|c|c|c|c|c|c|c|c|}
\hline & & \multicolumn{2}{|c|}{200} & \multicolumn{2}{|c|}{300} & \multicolumn{2}{|c|}{700} & \multicolumn{2}{|c|}{1000} & \multicolumn{2}{|c|}{2000} & \multicolumn{2}{|c|}{ Melhor semente } \\
\hline & & $\mathrm{K}_{\text {bulk }}$ & wall & $K_{\text {bulk }}$ & $\mathrm{K}_{\text {wall }}$ & $K_{\text {bulk }}$ & $\mathrm{K}_{\text {wall }}$ & $\mathrm{K}_{\text {bulk }}$ & $\mathrm{K}_{\text {wall }}$ & $\mathrm{K}_{\text {bulk }}$ & $\mathrm{K}_{\text {wall }}$ & $\mathrm{K}_{\text {bulk }}$ & $\mathrm{K}_{\text {wall }}$ \\
\hline \multirow{2}{*}{ T.1.A } & os & 0,0086 & $-0,0101$ &, 0110 & $-0,0100$ & $-0,0068$ & $\mid-0,0101$ & 0,0147 & $-0,0099$ & $-0,0400$ & $\mid-0,0078$ & $-0,0400$ & $-0,00$ \\
\hline & Função Objetivo & \multicolumn{2}{|c|}{0,0691059} & \multicolumn{2}{|c|}{0,0690424} & \multicolumn{2}{|c|}{0,0688971} & \multicolumn{2}{|c|}{0,0692362} & \multicolumn{2}{|c|}{0,0688910} & \multicolumn{2}{|c|}{0,0688910} \\
\hline \multirow{2}{*}{ T.2.A } & Resultados & 0229 & $-0,01$ & 0067 & $\mid-0,0128$ & $-0,0120$ & $-0,01$ & 0120 & $-0, C$ & $-0,0316$ & $-0,0110$ & $-0,0316$ & \\
\hline & Funçã & \multicolumn{2}{|c|}{0,0775296} & \multicolumn{2}{|c|}{0,0794285} & \multicolumn{2}{|c|}{0,0776420} & \multicolumn{2}{|c|}{0,0776420} & \multicolumn{2}{|c|}{0,0773112} & \multicolumn{2}{|c|}{0,077311} \\
\hline \multirow{2}{*}{ T.1.GJ } & $\operatorname{Res}$ &, 0400 & $-0,0077$ & 0057 & $-0,0100$ & $-0,0080$ & $-0,0$ & $-0,0094$ & $-0, C$ & \begin{tabular}{|l|}
$-0,0400$ \\
\end{tabular} & $-0,0$ & $-0,0057$ & \\
\hline & Funça & \multicolumn{2}{|c|}{0,0694859} & \multicolumn{2}{|c|}{0,0687210} & \multicolumn{2}{|c|}{0,0692773} & \multicolumn{2}{|c|}{0,0689909} & \multicolumn{2}{|c|}{0,0695029} & \multicolumn{2}{|c|}{0,068721} \\
\hline \multirow{2}{*}{ T.2.GJ } & $\operatorname{Re}$ &, 0157 & $-0,0093$ &, 0219 & $\mid-0,0092$ & $-0,0125$ & $\mid-0,0$ & $-0,0094$ & $-0,0095$ & $|-0,0110|$ & 094 & $\mid-0,0110$ & \\
\hline & Funçấ & \multicolumn{2}{|c|}{0,0682604} & \multicolumn{2}{|c|}{0,0686070} & \multicolumn{2}{|c|}{0,0686838} & 0,068 & 30865 & 0,067 & 796 & 0,067 & 9 \\
\hline & &, 0203 & $\mid-0,0112$ &, 0235 & $\mid-0,0114$ & $-0,0400$ & -0, & $-0,0400$ & $-0,0110$ & $\mid-0,0316$ & & $\mid-0,0316$ & \\
\hline 1.0 .00 & Funç & 0,0 & 3841 & 0,093 & 382 & 0,093 & 362 & 0,093 & 352 & 0,093 & 344 & 0,093 & 1 \\
\hline & &, 0177 & $-0,0112$ &, 0208 & -0, & $-0,0091$ & -0, & $-0,0385$ & 110 & $\mid-0,0356$ & 110 & $-0,0385$ & -0 \\
\hline & Funçã & 0.077 & 7284 & 0,077 & 719 & 0,077 & 705 & 0,076 & $\$ 19$ & 0,076 & 331 & 0,076 & 19 \\
\hline & Res & ,0051 & $-0,0074$ & $-0,0063$ & $\mid-0,0076$ & $-0,0114$ & $\mid-0,0076$ & $-0,0059$ & $-0,0073$ & $|-0,0067|$ & $|-0,0077|$ & $-0,0059$ & $-0,0073$ \\
\hline & Funçấ & 1.248 & 96100 & $1,24 \mathrm{c}$ & 997 & 1,250 & 091 & 1,249 & 34700 & 1,250 & 00100 & 1,249 & 4700 \\
\hline & Res & 0,0114 & $-0,0081$ & $-0,0056$ & $\mid-0,0076$ & $-0,0133$ & $-0,0082$ & $-0,0062$ & $-0,0083$ & $-0,0062$ & $-0,0083$ & $\mid-0,0062$ & $-0,0083$ \\
\hline & Funça & & 19600 & 1,230 & 881 & 1,232 & 239 & 1,230 & 12 & 1,231 & 0300 & 1,230 & 1200 \\
\hline & $\mathrm{Re}$ & 0078 & $-0, c$ & $-0,0244$ & \begin{tabular}{|l|}
$-0,0106$ \\
\end{tabular} & $-0,0287$ & \begin{tabular}{|l|}
$-0,0105$ \\
\end{tabular} & $-0,0221$ & 106 & $\mid-0,0076$ & $\mid-0,0112$ & $\mid-0,0287$ & $-0,0105$ \\
\hline & Funç & & 737 & 1,047 & 729 & 1,047 & 116 & 1,047 & 21 & 1,047 & 58 & 1,047 & 1600 \\
\hline & &, 0246 & $-0,0101$ & $-0,0373$ & $-0,0095$ & $-0,0400$ & $\mid-0,0098$ & $-0,0400$ & 091 & $\mid-0,0400$ & $\mid-0,0093$ & $\mid-0,0373$ & $-0,0095$ \\
\hline & unção Objetivo & 1,046 & 68200 & 1,046 & 54900 & 1,046 & 6400 & 1,046 & 66500 & 1,046 & 6400 & 1,046 & 4900 \\
\hline
\end{tabular}


$\mathrm{Na}$ Tabela 4.71, é possível observar que a função objetivo de cada teste obteve melhores resultados com os intervalos de procura do $\mathrm{K}_{\text {bulk }}$ e $\mathrm{K}_{\text {wall }}$ determinados pela Tabela 4.69. Analisando-se os resultados da segunda calibração de qualidade, também é possível perceber que o intervalo adotado para $\mathrm{K}_{\text {wall }}$ nesta calibração é satisfatório, pois nenhum resultado entre as melhores sementes apresentou valor para $\mathrm{K}_{\text {wall }}$ igual ao limite adotado na procura, o que significa que os melhores resultados realmente estão na faixa adotada para o coeficiente. Com relação aos resultados obtidos para o coeficiente $\mathrm{K}_{\text {bulk, }}$, ainda existe uma oscilação entre os valores observados, denunciando que este coeficiente teve pouca influência no decaimento do cloro na água. Fato que provavelmente está relacionado às características hidráulicas da rede e às características da própria água, que determinam que o coeficiente $\mathrm{K}_{\text {bulk }}$ não seja expressivo no consumo de cloro.

Uma das possíveis razões da melhor otimização para todos os testes é o aumento da população dos AGs, no entanto este aumento ocorreu com o objetivo de tentar compensar o acréscimo do intervalo de procura do coeficiente do $\mathrm{K}_{\text {wall. }}$.

Outra alteração relevante, realizada na segunda calibração de qualidade, foi à adoção do valor máximo para $\mathrm{K}_{\text {bulk }}$ igual $-0.005 \mathrm{dia}^{-1}$, pois assim evitou-se que os valores de $\mathrm{K}_{\text {bulk }}$ convergissem para valores muito inferiores aos encontrados no "teste da garrafa".

Nas duas calibrações, o melhor resultado foi obtido pelo teste T.2.GJ seguido dos testes T.1.GJ e T.1.A. Em função deste resultado, é possível afirmar que o modelo GERMANOPOULOS E JOWITT (1998) foi o que melhor representou o vazamento. Contudo, quando analisados os resultados hidráulicos na Tabela 4.35, verificou-se que a semente 1000 está em desacordo com as demais, pois o resultado para a perda total é fora da ordem de grandeza das demais sementes. Isto pode ser atribuído ao alto grau de indeterminação do problema de otimização e representa um perigo para a calibração hidráulica, visto que pode mascarar o verdadeiro valor das perdas totais. 
Nota-se também que, para a rede de distribuição de água do Parque Fehr, o parâmetro dominante na representação do decaimento de cloro livre é o $\mathrm{K}_{\text {wall, }}$, pois pequenas alterações em seu valor produziram resultados distintos, no entanto, o mesmo não ocorreu com o coeficiente $\mathrm{K}_{\text {bulk. }}$ Esta discussão é resultante dos valores encontrados para as duas calibrações, na medida que, em todos os testes, foi verificado um $\mathrm{K}_{\text {wall }}$ próximo ao valor de $-0,01 \mathrm{~m} / \mathrm{dia}$. $\mathrm{O}$ mesmo não ocorreu para $\mathrm{K}_{\text {bulk, }}$ em que se verificou uma variação brusca para cada teste e calibração.

Levando-se em consideração o melhor resultado obtido pela função objetivo usada na calibração de qualidade, que ocorreu na segunda calibração de qualidade no teste T.2.GJ, pôde-se determinar os coeficientes resultantes da calibração de qualidade, os quais foram iguais $-0,0110 \mathrm{dia}^{-1}$ e $-0,0094 \mathrm{~m} /$ dia, para $\mathrm{K}_{\text {bulk }}$ e $\mathrm{K}_{\text {wall }}$ respectivamente. Ao se analisar o

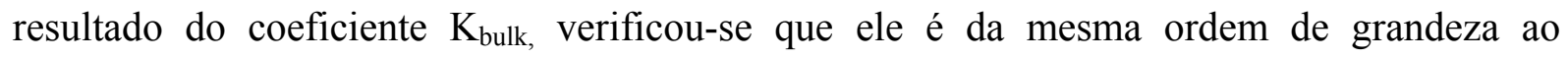
encontrado pelo "teste da garrafa", na medida em que as aproximações feitas pelos métodos MSEQ e MG determinaram valores iguais a $-0,019 \mathrm{dia}^{-1}$ e $-0,0231 \mathrm{dia}^{-1}$, respectivamente.

Como o coeficiente $K_{\text {wall }}$ não permite a comparação entre o experimental e o calibrado, a comparação realizada foi feita através dos resultados obtidos por CASAGRANDE (1997) $\left(\mathrm{K}_{\mathrm{wall}}=-0,015 \mathrm{~m} / \mathrm{dia}\right)$ e VIEIRA (2002) $\left(\mathrm{K}_{\mathrm{wall}}=-0,0012 \mathrm{~m} / \mathrm{dia}\right)$. Foi também verificado, que o resultado obtido neste trabalho é mais próximo ao encontrado por CASAGRANDE (1997).

Por fim, foi realizada mais uma calibração de qualidade com a finalidade de se testar: a) se os valores encontrados anteriormente são encontrados outra vez em intervalos de procura maiores; b) se há alteração no modelo que melhor irá representar o vazamento.

Para a terceira calibração de qualidade, foram adotados os intervalos de procura identificados na Tabela 4.72. Os parâmetros dos AGs usados são apresentados na Tabela 4.73. 
TABELA 4.72 - Intervalos usados para $3^{\text {a }}$ calibração

\begin{tabular}{|c|c|c|}
\hline \multirow{2}{*}{} & \multicolumn{2}{|c|}{ Intervalos de procura } \\
\cline { 2 - 3 } & $\mathrm{K}_{\text {bulk }}$ & $\mathrm{K}_{\text {wall }}$ \\
\hline Mínimo & -0.10 & -0.20 \\
\hline Máximo & 0.00 & 0.00 \\
\hline Valores iniciais & -0.023 & -0.005 \\
\hline
\end{tabular}

TABELA 4.73 - Parâmetros, valores e tipo de AGs usados na $3^{\text {a }}$ calibração

\begin{tabular}{|c|c|}
\hline Tipo do AG & Geracional elitista \\
\hline Representação da solução & Real \\
\hline População de soluções & 300 \\
\hline Recombinação & dois pontos \\
\hline Probabilidade de recombinação & 0.7 \\
\hline Seleção & Stochastic Remainder Sampling-SRS \\
\hline Mutação & gaussiana \\
\hline Probabilidade de mutação & 0.04 \\
\hline Taxa de elitismo & 0.3 \\
\hline Número de gerações & 100 \\
\hline Escalonamento & linear $(\mathrm{c}=1,5)$ \\
\hline
\end{tabular}

Nesta terceira calibração de qualidade houve um acréscimo no número da população das soluções, possibilitando que os AGs fossem capazes de otimizar e encontrar a melhor solução em um espaço de possíveis soluções maior. Os resultados para a terceira calibração de qualidade são apresentados na Tabela 4.74 . 
TABELA 4.74 - Resultados da $3^{\text {a }}$ calibração para $K_{\text {bulk }}$ e $K_{\text {wall }}$ considerando todos os testes

\begin{tabular}{|c|c|c|c|c|c|c|c|c|c|c|c|c|c|}
\hline & & \multicolumn{2}{|c|}{200} & \multicolumn{2}{|c|}{300} & \multicolumn{2}{|c|}{700} & \multicolumn{2}{|c|}{1000} & \multicolumn{2}{|c|}{2000} & \multicolumn{2}{|c|}{ Melhor semente } \\
\hline & & $\mathrm{K}_{\text {bulk }}$ & $\mathrm{K}_{\text {wall }}$ & $\mathrm{K}_{\text {bulk }}$ & $\mathrm{K}_{\text {wall }}$ & $\mathrm{K}_{\text {bulk }}$ & $\mathrm{K}_{\text {wall }}$ & $\mathrm{K}_{\text {bulk }}$ & $\mathrm{K}_{\text {wall }}$ & $\mathrm{K}_{\text {bulk }}$ & $\mathrm{K}_{\text {wall }}$ & $\mathrm{K}_{\text {bulk }}$ & $\mathrm{K}_{\text {wall }}$ \\
\hline \multirow{2}{*}{ T.1.A } & Resultados & $-0,0040$ & $-0,0101$ & $-0,0467$ & $-0,0079$ & $-0,0519$ & $-0,0079$ & $-0,0499$ & $-0,0076$ & $-0,0585$ & $-0,0077$ & $-0,0519$ & $-0,0079$ \\
\hline & Função Objetivo & \multicolumn{2}{|c|}{0,0693390} & \multicolumn{2}{|c|}{0,0689023} & \multicolumn{2}{|c|}{0,0688965} & \multicolumn{2}{|c|}{0,0694802} & \multicolumn{2}{|c|}{0,0690813} & \multicolumn{2}{|c|}{0,0688965} \\
\hline \multirow{2}{*}{ T.2.A } & Resultados & $-0,0436$ & $-0,0100$ & $-0,0547$ & $-0,0101$ & $-0,0109$ & $-0,0951$ & $-0,0237$ & $-0,0098$ & $-0,0107$ & $-0,0089$ & $-0,0109$ & $-0,0951$ \\
\hline & Função Objetivo & \multicolumn{2}{|c|}{0,0788164} & \multicolumn{2}{|c|}{0,0778891} & \multicolumn{2}{|c|}{0,0773954} & \multicolumn{2}{|c|}{0,0779354} & \multicolumn{2}{|c|}{0,0786340} & \multicolumn{2}{|c|}{0,0773954} \\
\hline \multirow{2}{*}{ T.1.GJ } & Resultados & $-0,0036$ & $-0,0101$ & $-0,0467$ & $-0,0079$ & $-0,0073$ & $-0,0100$ & $-0,0653$ & $-0,0074$ & $-0,0022$ & $-0,0101$ & $-0,0022$ & $-0,0101$ \\
\hline & Função Objetivo & \multicolumn{2}{|c|}{0,0688048} & \multicolumn{2}{|c|}{0,0688320} & \multicolumn{2}{|c|}{0,0688312} & \multicolumn{2}{|c|}{0,0690283} & \multicolumn{2}{|c|}{0,0687938} & \multicolumn{2}{|c|}{0,0687938} \\
\hline \multirow{2}{*}{ T.2.GJ } & Resultados & $-0,0030$ & $-0,0097$ & $-0,0039$ & $-0,0097$ & $-0,0073$ & $-0,0096$ & $-0,0007$ & $-0,0100$ & $-0,0188$ & $-0,0095$ & $-0,0030$ & $-0,0097$ \\
\hline & Função Objetivo & \multicolumn{2}{|c|}{0,0680883} & \multicolumn{2}{|c|}{0,0681593} & \multicolumn{2}{|c|}{0,0680986} & 0,068 & 5341 & 0,068 & 8582 & 0,068 & 0883 \\
\hline T 3 G & Resultados & $-0,0290$ & $-0,0098$ & $-0,0760$ & $-0,0094$ & $-0,0327$ & $-0,0093$ & $-0,0946$ & $-0,0094$ & $-0,0954$ & $-0,0095$ & $-0,0327$ & $-0,0093$ \\
\hline $1.0 .0 \mathrm{~J}$ & Função Objetivo & 0,093 & 9536 & 0,094 & 0552 & 0,093 & 39378 & 0,09 & 0997 & 0,094 & 1096 & 0,093 & 9378 \\
\hline G. & Resultados & $-0,0568$ & $-0,0199$ & $-0,0801$ & $-0,0782$ & $-0,0159$ & $-0,0099$ & $-0,0578$ & $-0,0109$ & $-0,0568$ & $-0,0072$ & $-0,0578$ & $-0,0109$ \\
\hline & Função Objetivo & 0,077 & 1879 & 0,077 & 2150 & 0,077 & 1450 & 0,076 & 3609 & 0,076 & 5415 & 0,076 & 3609 \\
\hline & Resultados & $-0,0039$ & $-0,0089$ & $-0,0134$ & $-0,0065$ & $-0,0120$ & $-0,0070$ & $-0,0098$ & $-0,0078$ & $-0,0066$ & $-0,0088$ & $-0,0098$ & $-0,0078$ \\
\hline 1.1 .1 & Função Objetivo & 1,250 & 9710 & 1,250 & 8912 & 1,250 & 7900 & 1,250 & 7513 & 1,250 & 7981 & 1,250 & 7513 \\
\hline T 2 T & Resultados & $-0,0114$ & $-0,0079$ & $-0,0068$ & $-0,0089$ & $-0,0180$ & $-0,0078$ & $-0,0099$ & $-0,0079$ & $-0,0073$ & $-0,0084$ & $-0,0099$ & $-0,0079$ \\
\hline 1.2 .1 & Função Objetivo & 1,231 & 6700 & 1,231 & 13700 & 1,232 & 9800 & 1,230 & 9700 & 1,231 & 2700 & 1,230 & 9700 \\
\hline & Resultados & 0,0090 & $-0,0125$ & $-0,0237$ & $-0,0125$ & $-0,0297$ & $-0,0106$ & $-0,0213$ & $-0,0105$ & $-0,0064$ & $-0,0103$ & $-0,0064$ & $-0,0103$ \\
\hline 1.0 .1 & Função Objetivo & $1,04 \mathrm{C}$ & 7800 & 1,049 & 7200 & 1,049 & 6800 & $1,04 \Omega$ & 7900 & $1,04 \mathrm{c}$ & 5100 & 1,049 & 5100 \\
\hline T 4 T & Resultados & $-0,0137$ & $-0,0111$ & $-0,0097$ & $-0,0099$ & $-0,0255$ & $-0,0095$ & $-0,0872$ & $-0,0099$ & $-0,0312$ & $-0,0097$ & $-0,0097$ & $-0,0099$ \\
\hline 1.4 .1 & Função Objetivo & 1,046 & 8900 & 1,046 & 5600 & 1,046 & 6900 & 1,046 & 7100 & 1,046 & 7300 & 1,046 & 5600 \\
\hline
\end{tabular}


$\mathrm{Na}$ terceira calibração de qualidade, verificou-se que os resultados das funções objetivos (Tabela 4.74) não melhoraram em comparação aos da segunda calibração de qualidade (Tabela 4.71). O teste T.2.GJ continua sendo o de melhor resultado seguido dos testes T.1.GJ e T.1.A, com essa ordem repetida em todas as calibrações de qualidade realizadas. Os piores resultados da $3^{\mathrm{a}}$ calibração são atribuídos ao modelo de TUCCIARELLI et al. (1999), e o mesmo acontece em todas as calibrações de qualidade.

O resultado final da calibração de qualidade foi $-0,0110 \mathrm{dia}^{-1}$ e $-0,0094 \mathrm{~m} / \mathrm{dia}$, para $\mathrm{K}_{\text {bulk }}$ e $\mathrm{K}_{\text {wall, }}$, respectivamente (resultado encontrado na $2^{\mathrm{a}}$ calibração de qualidade no teste T.2.GJ). O EPANET 2.0 também possibilitou diferenciar as parcelas que são responsáveis pelo consumo de cloro ( $\mathrm{K}_{\text {bulk }}$ e $\left.\mathrm{K}_{\text {wall }}\right)$. A Figura 4.32 indica as frações de decaimento do cloro, representadas por $\mathrm{K}_{\text {bulk }}$ e $\mathrm{K}_{\text {wall. }}$ Para tanto, foram usados os resultados da calibração hidráulica do teste T.2.GJ em conjunto com as informações de entrada da calibração de qualidade do respectivo teste.

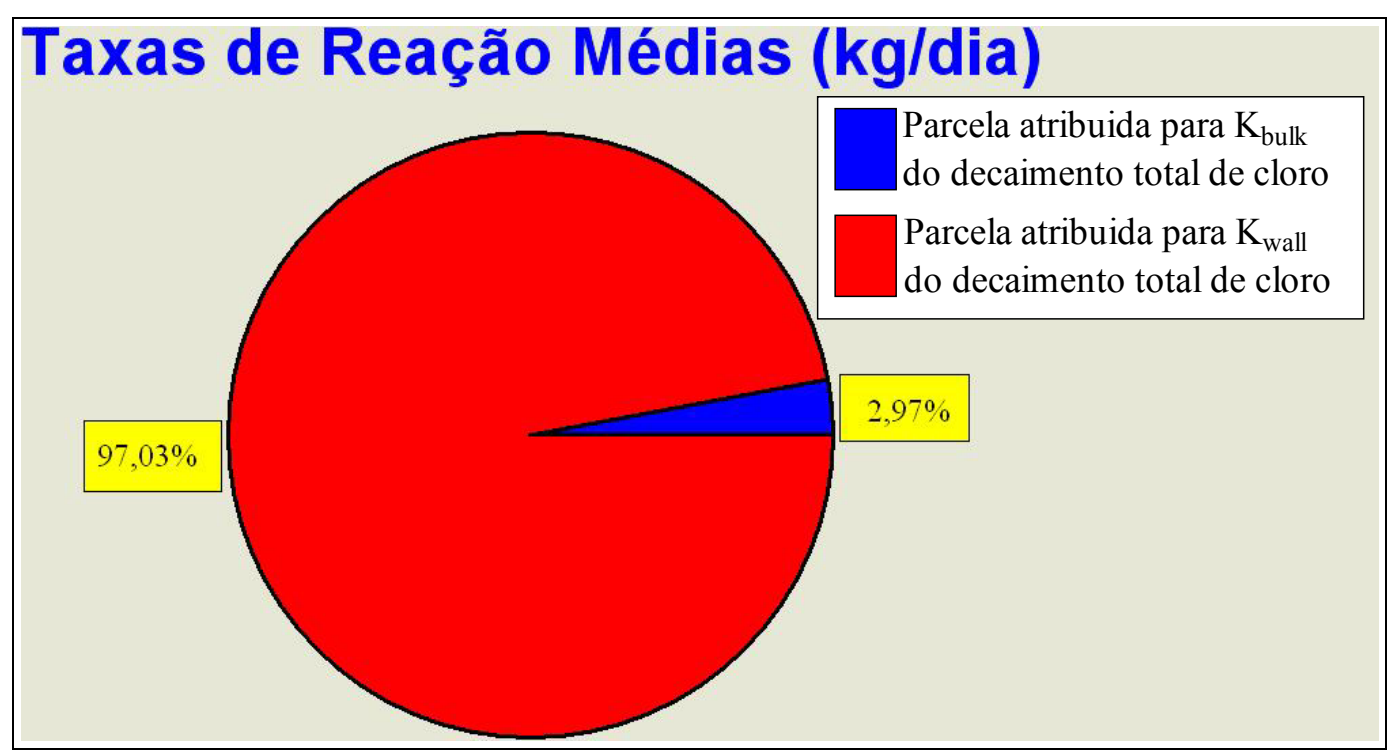

FIGURA 4.32 - Discriminação das parcelas de consumo de cloro

O tratamento estatístico que o EPANET 2.0 disponibiliza, permitiu fazer automaticamente algumas análises sobre os resultados obtidos da calibração de qualidade apresentado na Tabela 4.75 . 
TABELA 4.75 - Tratamento estatístico dos dados de calibração para o decaimento de cloro

\begin{tabular}{|c|c|c|c|c|c|}
\hline $\begin{array}{c}\text { Localização } \\
\text { (nó) }\end{array}$ & $\begin{array}{c}\text { Número de } \\
\text { Observações }\end{array}$ & $\begin{array}{c}\text { Leitura Média } \\
\text { Observada } \\
\text { (mg/L) }\end{array}$ & $\begin{array}{c}\text { Leitura Média } \\
\text { Simulada } \\
\text { (mg/L) }\end{array}$ & $\begin{array}{c}\text { Erro } \\
\text { Médio }\end{array}$ & $\begin{array}{c}\text { Desvio } \\
\text { Padrão }\end{array}$ \\
\hline 82 & 24 & 1,20 & 1,20 & 0,002 & 0,003 \\
\hline 43 & 24 & 1,03 & 1,02 & 0,034 & 0,044 \\
\hline----------------------------------------------11 & 1,11 & 0,018 & 0,036 \\
\hline
\end{tabular}

Na Figura 4.33 é possível observar um comparativo das médias das leituras dos nós monitorados. No nó 43, existe uma pequena diferença entre os valores observados e simulados.

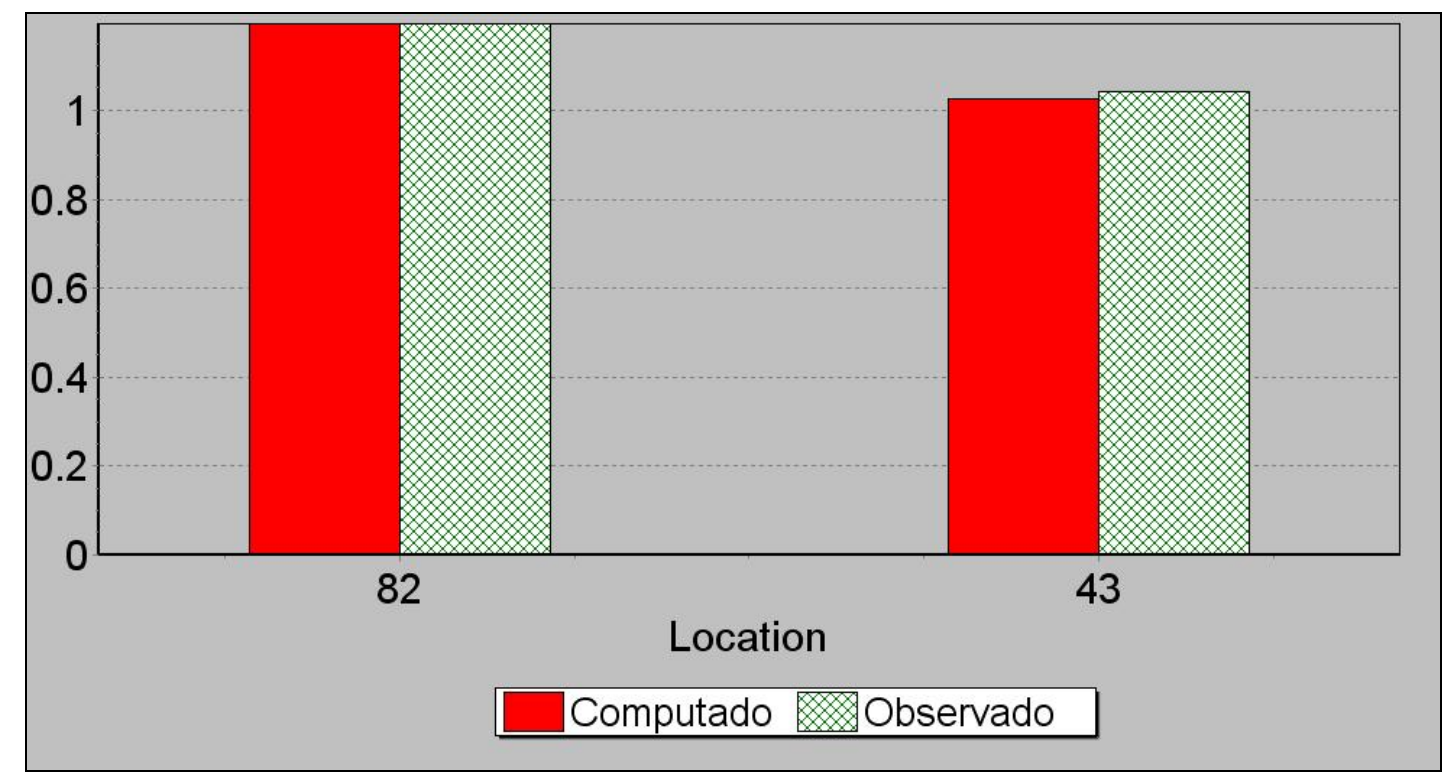

FIGURA 4.33 - Comparativo das Concentrações de cloro observadas nos nós

Na Figura 4.34, é possível verificar o comportamento da concentração de cloro no nó 43 e observar que os dados simulados para a concentração de cloro ficaram bem próximos da concentração de cloro observada para este período de 24 horas. Assim, pode-se dizer que os resultados da calibração hidráulica e de qualidade são satisfatórios, visto que a simulação de qualidade no EPANET 2.0 foi capaz de reproduzir o comportamento do fenômeno. 


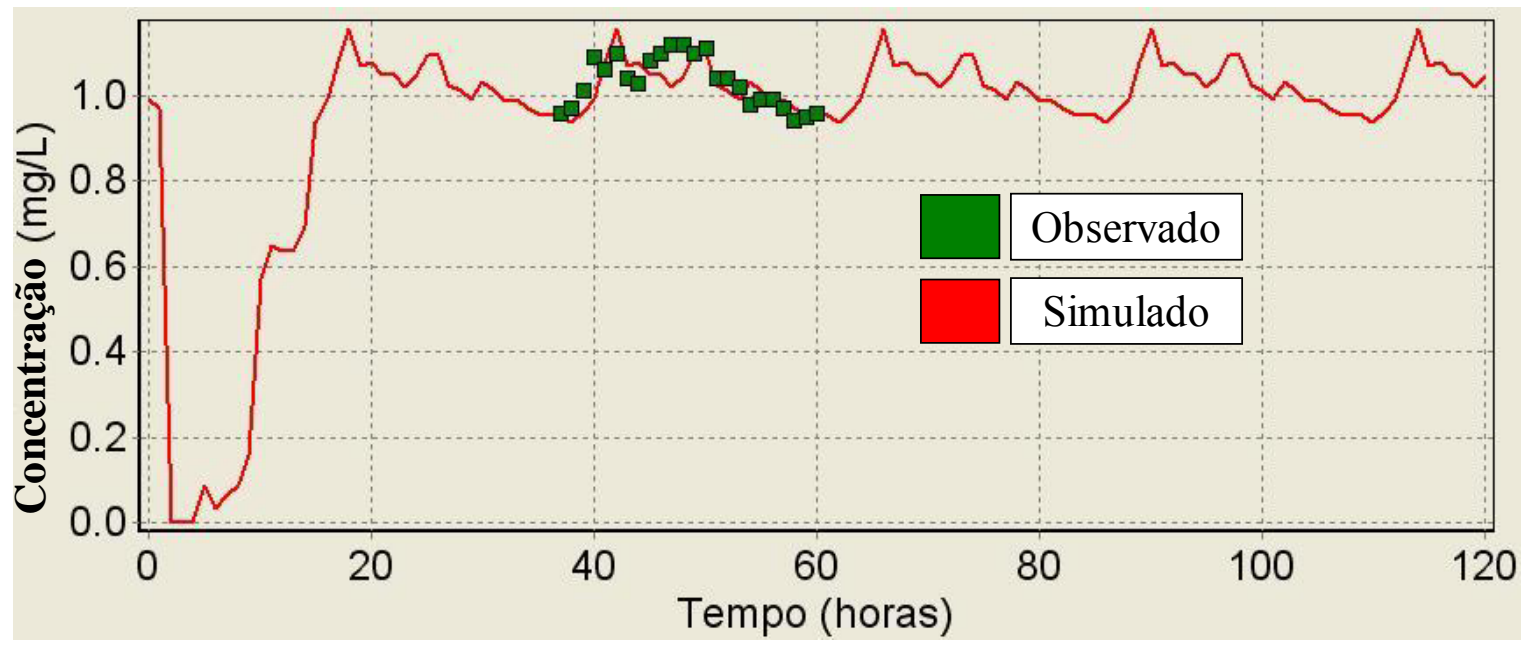

FIGURA 4.34 - Comportamento da concentração de cloro do nó 43 com os dados observados em campo

VIEIRA (2002), em sua dissertação de mestrado, calibrou os parâmetros de qualidade ( $\left.\mathrm{K}_{\text {bulk }}, \mathrm{K}_{\mathrm{wall}}\right)$ do sistema de distribuição de água de Caparica no Concelho de Almada - Lisboa - Portugal, sendo o resultado final representado pela Figura 4.35.
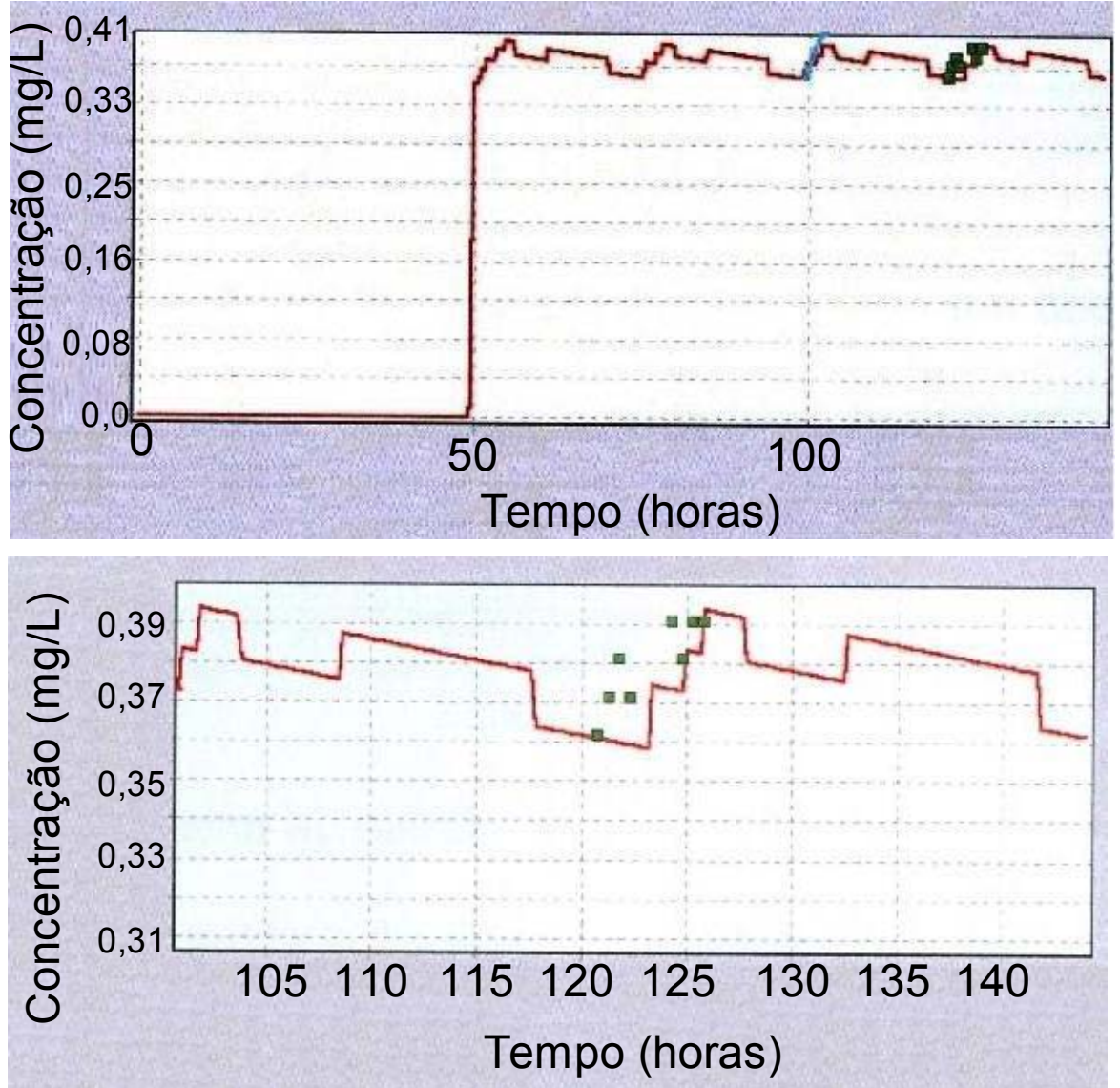

FIGURA 4.35 - Comportamento da concentração de cloro com os dados observados em campo (Fonte: Vieira, 2002) 
Comparando os resultados finais de VIEIRA (2002) (Figura 4.35) com o resultado final do presente trabalho (Figura 4.34), verificou-se que:

- Na atual pesquisa, o número de pontos observados é superior ao de VIEIRA (2002);

- O resultado da calibração de qualidade do presente estudo pode ser considerado melhor do que o obtido por VIEIRA (2002), pois retrata de maneira mais fidedigna o comportamento da concentração de cloro no determinado nó.

A Figura 4.36 apresenta conjuntamente o comportamento das concentrações de cloro do sistema calibrado, os pontos observados em campo e o erro do sensor de cloro usado na campanha de campo que é de $0,05 \mathrm{mg} / \mathrm{L}$ (setas da Figura).

Assim, ao se observar a Figura 4.36, pode-se concluir que o comportamento da concentração de cloro está dentro da faixa dos possíveis valores de leitura do sensor de cloro, ficando fora apenas nos horários da madrugada.

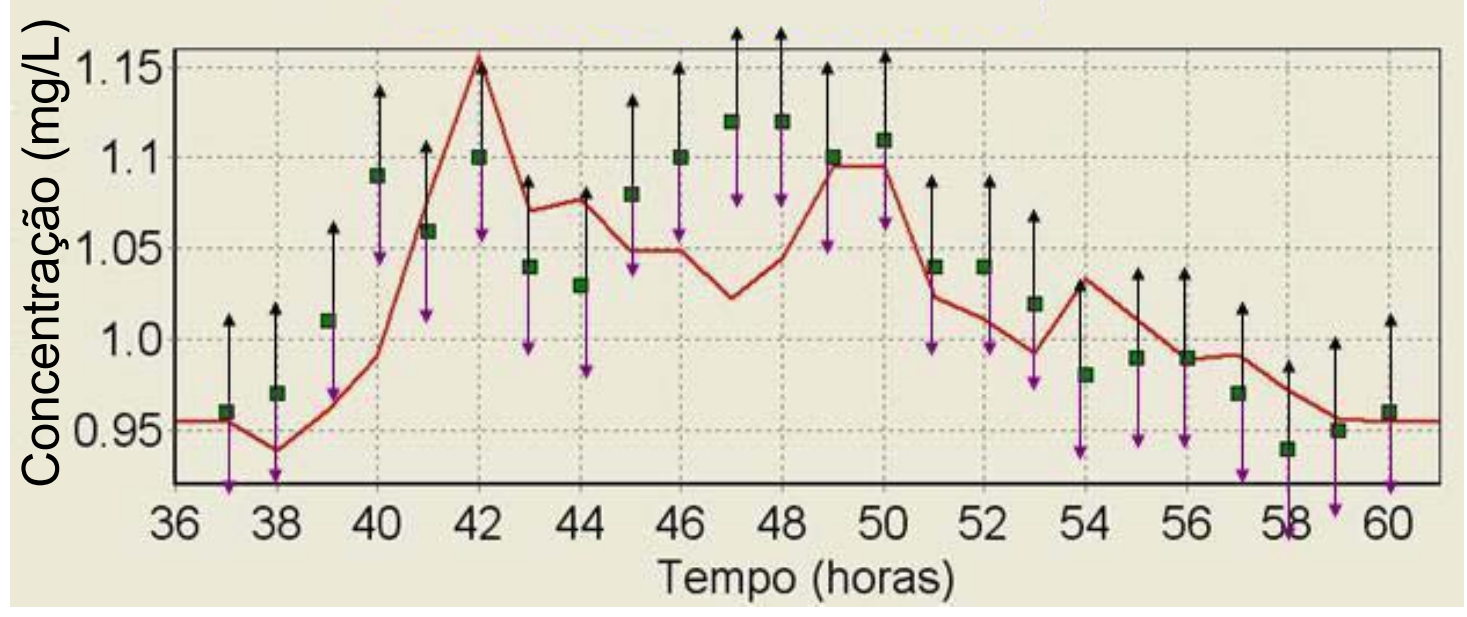

FIGURA 4.36 - Comportamento da concentração de cloro do nó 43 com dados observados em campo e demostrando o erro relativo do sensor da sonda de medição de cloro de \pm 0,05 $\mathrm{mg} / \mathrm{L}$ 


\subsection{CALIBRAÇÃO DA REDE SEM CONSIDERAR O VAZAMENTO E COMPARAÇÃO DOS RESULTADOS}

A rede do parque Fehr também foi calibrada sendo considerada como uma rede estanque, já que trabalhos anteriores como os de VIEIRA (2002) e CASAGRANDE (1997) não consideram o vazamento. No entanto, SALGADO (2008) já evidência a necessidade de considerar os vazamentos em redes devido a sua interferência nos resultados da calibração de qualidade. Seguindo a metodologia de SALGADO (2008), a rede do parque Fehr só foi calibrada como sendo estanque para se verificar a importância da consideração dos vazamentos na calibração em redes reais e permitir a comparação entre os resultados com e sem vazamentos.

Nesta calibração hidráulica, são usados os mesmos parâmetros dos AGs calibrados anteriormente (Tabela 4.12), os resultados encontrados para as variáveis de estado estão apresentados na Tabela 4.76 e na Tabela 4.77, onde são demonstrados os valores da função objetivo e rugosidade. $\mathrm{O}$ expoente e coeficiente $(\theta$ ou $C)$ são dados como zero pois não existe vazamento.

TABELA 4.76 - Resultados obtidos com a calibração hidráulica sem vazamentos

\begin{tabular}{|c|c|c|c|c|c|c|c|c|c|c|c|c|c|}
\hline \multirow{2}{*}{\multicolumn{2}{|c|}{ Padrões }} & \multicolumn{5}{|c|}{ Valores simulados } & \multirow{4}{*}{ 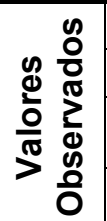 } & \multirow{3}{*}{\multicolumn{5}{|c|}{$\begin{array}{c}\text { Valores simulados } \\
\mathbf{2} \\
\text { Semente }\end{array}$}} & \multirow{4}{*}{ 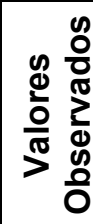 } \\
\hline & & \multirow{2}{*}{\multicolumn{5}{|c|}{$\begin{array}{l}1 \\
\text { nente }\end{array}$}} & & & & & & & \\
\hline \multirow{2}{*}{\multicolumn{2}{|c|}{$\begin{array}{l}\text { Variáveis } \\
\text { de estado }\end{array}$}} & & & & & & & & & & & & \\
\hline & & 200 & 300 & 700 & 1000 & 2000 & & 200 & 300 & 700 & 1000 & 2000 & \\
\hline \multicolumn{2}{|c|}{ Vazão (L/s) } & 2,93 & 2,93 & 2,93 & 2,93 & 2,93 & 2,98 & 6,11 & 6,11 & 6,11 & 6,11 & 6,11 & 6,18 \\
\hline \multirow{4}{*}{ 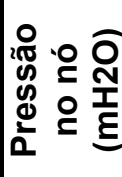 } & 22 & 32,11 & 32,11 & 32,11 & 32,11 & 32,11 & 31,23 & 29,49 & 49 & 29,49 & 29,49 & 49 & 28,59 \\
\hline & 44 & 9 & 25,79 & 9 & 3 & 9 & 35,00 & 09 & 3 & & 09 & & 31,90 \\
\hline & 66 & 23,70 & 23,70 &, 10 & 23,70 & 0 & 23,66 & 21,05 & 2 & 21 & 21,05 & & 20,78 \\
\hline & 80 & 32,14 & 32,14 & 32,14 & 32,14 & 32,14 & 31,86 & 29,58 & 29,58 & 29,58 & 29,58 & 29,58 & 29,15 \\
\hline \multicolumn{2}{|c|}{$\begin{array}{c}\text { Perdas } \\
\text { (L/s) }\end{array}$} & 0,00 & 0 & 0,00 & 0 & 0 & & 0,00 & $\mathbf{0}$ & 0,00 & 0,00 & 0,00 & \\
\hline
\end{tabular}


TABELA 4.77 - Resultados obtidos com a calibração hidráulica sem vazamentos

\begin{tabular}{|c|c|c|c|c|c|}
\hline \multirow{2}{*}{ Função Objetivo $\left(.10^{-3}\right)$} & \multicolumn{5}{|c|}{ Semente } \\
\cline { 2 - 6 } & 200 & 300 & 700 & 1000 & 2000 \\
\cline { 2 - 6 } & 5,2014 & 5,2014 & 5,2011 & 5,2016 & 5,2012 \\
\hline Rugosidade $(\varepsilon) \mathrm{mm}\left(.10^{-3}\right)$ & 9,83 & 9,83 & 9,96 & 9,72 & 9,93 \\
\hline Coeficiente teta $(\theta)\left(.10^{-8}\right)$ & 0 & 0 & 0 & 0 & 0 \\
\hline Expoente $(\beta)$ & 0 & 0 & 0 & 0 & 0 \\
\hline
\end{tabular}

Considerando-se as informações desta calibração hidráulica, foi possível calcular os multiplicadores do consumo de referência para cada hora do dia (Tabela 4.78).

TABELA 4.78 - Multiplicadores do consumo de referência desconsiderando os vazamentos

\begin{tabular}{|c|c|c|c|}
\hline $\begin{array}{c}\text { Horas do } \\
\text { dia de } \\
\text { observação }\end{array}$ & $\begin{array}{c}\text { Multiplicadores } \\
\text { do consumo } \\
\text { de referência }\end{array}$ & $\begin{array}{c}\text { Horas do } \\
\text { dia de } \\
\text { observação }\end{array}$ & $\begin{array}{c}\text { Multiplicadores } \\
\text { do consumo } \\
\text { de referência }\end{array}$ \\
\hline $1^{\mathrm{a}}$ & 2,04 & $13^{\mathrm{a}}$ & 0,06 \\
\hline $2^{\mathrm{a}}$ & 1,65 & $14^{\mathrm{a}}$ & 0,15 \\
\hline $3^{\mathrm{a}}$ & 1,21 & $15^{\mathrm{a}}$ & 0,84 \\
\hline $4 \mathrm{a}$ & 0,34 & $16^{\mathrm{a}}$ & 2,04 \\
\hline $5^{\mathrm{a}}$ & 0,29 & $17^{\mathrm{a}}$ & 3,14 \\
\hline $6^{\mathrm{a}}$ & 0,63 & $18^{\mathrm{a}}$ & 3,41 \\
\hline $7^{\mathrm{a}}$ & 0,48 & $19^{\mathrm{a}}$ & 2,68 \\
\hline $8^{\mathrm{a}}$ & 0,17 & $20^{\mathrm{a}}$ & 2,19 \\
\hline $9^{\mathrm{a}}$ & 0,02 & $21^{\mathrm{a}}$ & 2,35 \\
\hline $10^{\mathrm{a}}$ & 0,10 & $22^{\mathrm{a}}$ & 2,54 \\
\hline $11^{\mathrm{a}}$ & 0,07 & $23^{\mathrm{a}}$ & 2,97 \\
\hline $12^{\mathrm{a}}$ & 0,30 & $24^{\mathrm{a}}$ & 2,72 \\
\hline
\end{tabular}

Assim, da mesma forma que nos demais testes realizados na calibração hidráulica, após a determinação da rugosidade e dos multiplicadores do consumo de referência, foi possível realizar a análise do tempo de residência da água (Figura 4.37). 


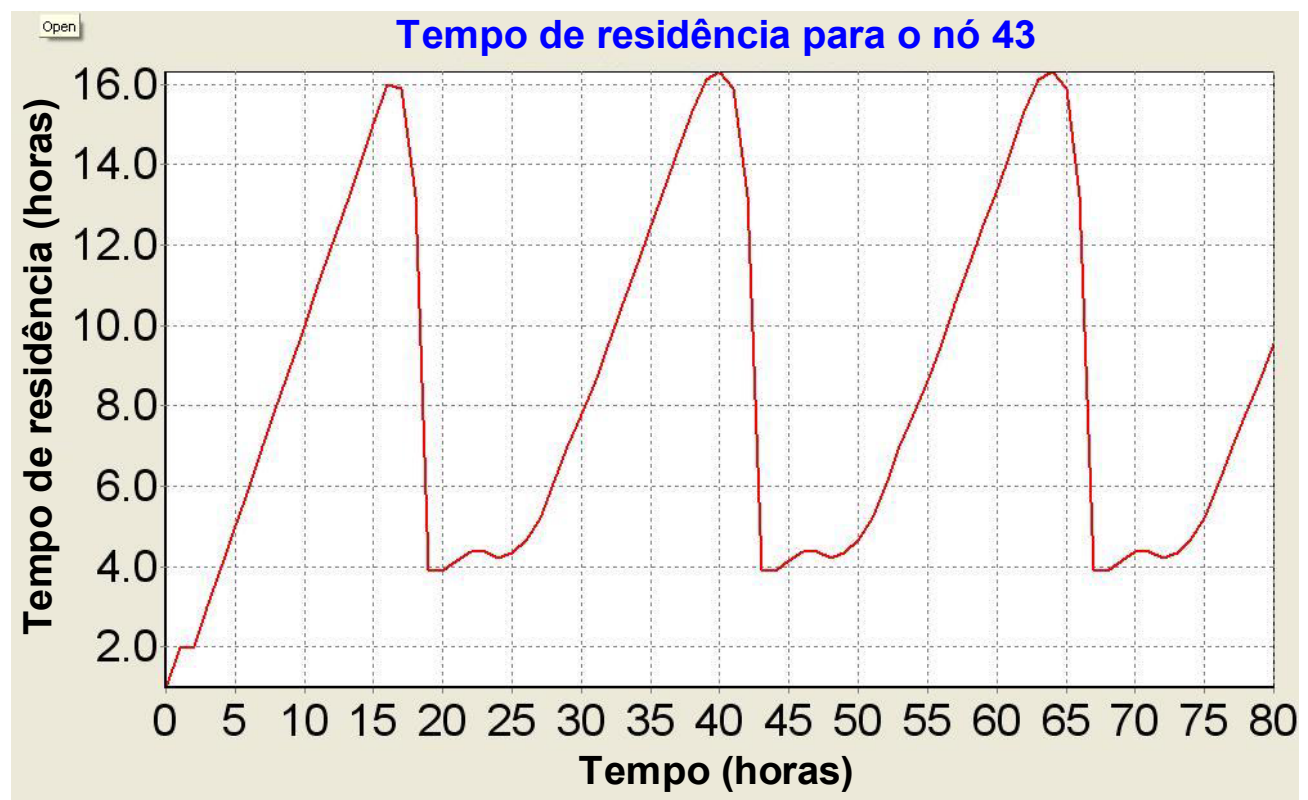

FIGURA 4.37 - Tempo de residência do nó 43 sem considerar o vazamento

Com essas informações foi possível realizar a calibração de qualidade. Nesta calibração de qualidade foram adotados os valores da Tabela 4.69 (intervalos de procura de $\mathrm{K}_{\text {bulk }}, \mathrm{K}_{\text {wall }}$ e valores iniciais) e da Tabela 4.70 (parâmetros dos AGs na calibração de qualidade). Os valores destas tabelas foram usados por serem os intervalos e parâmetros de calibração de qualidade que apresentaram os melhores resultados. Assim os resultados da calibração de qualidade sem vazamentos são apresentados na Tabela 4.79.

TABELA 4.79 - Resultados da calibração para $K_{\text {bulk }}$ e $K_{\text {wall }}$ sem vazamentos

\begin{tabular}{|c|c|c|c|}
\hline \multirow{2}{*}{ Semente } & \multicolumn{2}{|c|}{ Valores } & \multirow{2}{*}{$\begin{array}{c}\text { Função } \\
\text { Objetivo }\end{array}$} \\
\cline { 2 - 3 } & $\mathrm{K}_{\text {bulk }}$ & $\mathrm{K}_{\text {wall }}$ & 0,0872347 \\
\hline 200 & $-0,0282$ & $-0,0083$ & 0,0872881 \\
\hline 300 & $-0,0168$ & $-0,0065$ & 0,087 \\
\hline 700 & $-0,0188$ & $-0,0061$ & 0,0876698 \\
\hline 1000 & $-0,0249$ & $-0,0074$ & 0,0872520 \\
\hline 2000 & $-0,0310$ & $-0,0068$ & 0,0873389 \\
\hline $\begin{array}{c}\text { Melhor } \\
\text { semente }\end{array}$ & $-0,0392$ & $-0,0073$ & 0,0872347 \\
\hline
\end{tabular}

As mesmas análises são repetidas da calibração de qualidade com a rede estanque. $\mathrm{Na}$ Figura 4.38 estão demonstradas as parcelas que foram responsáveis pelo decaimento de cloro. 
Foi possível perceber que houve um acréscimo na reação em função do escoamento, o que pode ser explicado pelo maior tempo de residência da água na rede sem vazamentos.

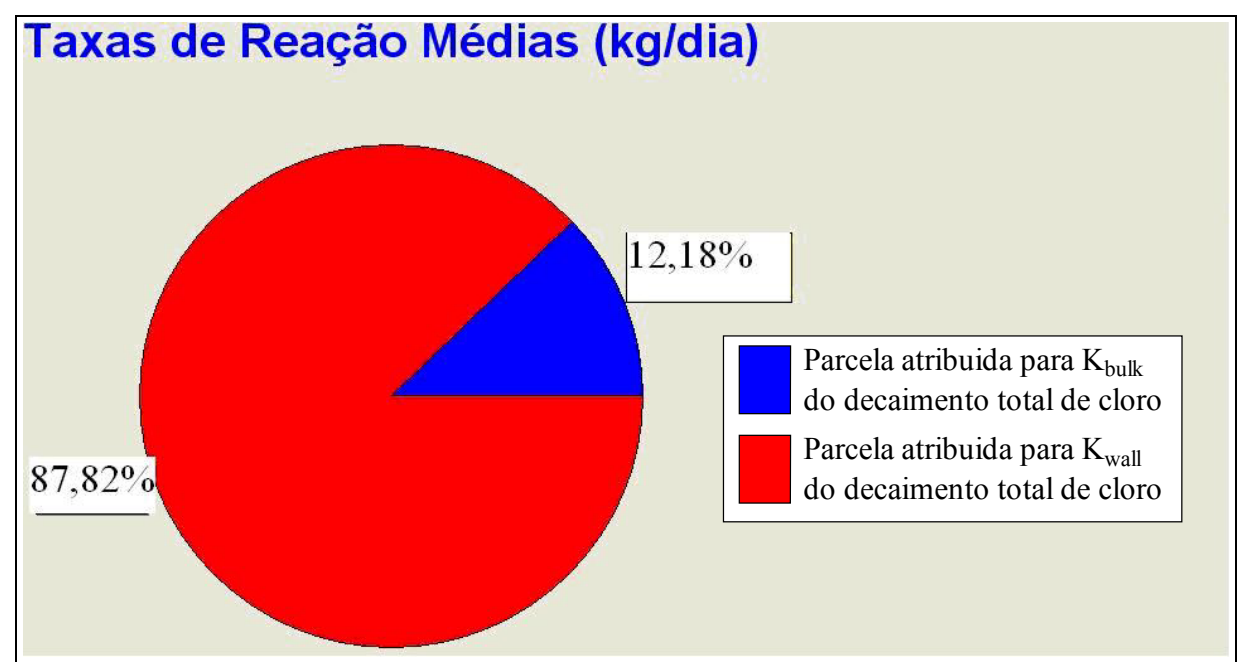

FIGURA 4.38 - Discriminação das parcelas de consumo de cloro desconsiderando-se os vazamentos

Na Tabela 4.80 são apresentados os resultados obtidos da calibração do decaimento de cloro. Quando se compara esses valores com os da Tabela 4.75, observa-se que os resultados obtidos sem vazamentos são inferiores aos encontrados anteriormente.

TABELA 4.80 - Tratamento estatístico dos dados de calibração para o decaimento de cloro

\begin{tabular}{|c|c|c|c|c|c|}
\hline $\begin{array}{l}\text { Localização } \\
\text { (nó) }\end{array}$ & $\begin{array}{c}\text { Número de } \\
\text { Observações }\end{array}$ & $\begin{array}{l}\text { Leitura Média } \\
\text { Observada } \\
\text { (mg/L) }\end{array}$ & $\begin{array}{c}\text { Leitura Média } \\
\text { Simulada } \\
\text { (mg/L) }\end{array}$ & $\begin{array}{l}\text { Erro } \\
\text { Médio }\end{array}$ & $\begin{array}{l}\text { Desvio } \\
\text { Padrão }\end{array}$ \\
\hline 82 & 24 & 1,20 & 1,19 & 0,007 & 0,014 \\
\hline 43 & 24 & 1,03 & 0,99 & 0,054 & 0,063 \\
\hline \multicolumn{6}{|c|}{ } \\
\hline Rede & 48 & 1,11 & 1,09 & 0,030 & 0,045 \\
\hline
\end{tabular}

Na Figura 4.39 é mostrado o comportamento da concentração de cloro no simulador de cloro e os dados observados em campo. Observa-se que diversos pontos estão distantes do valor simulado. 


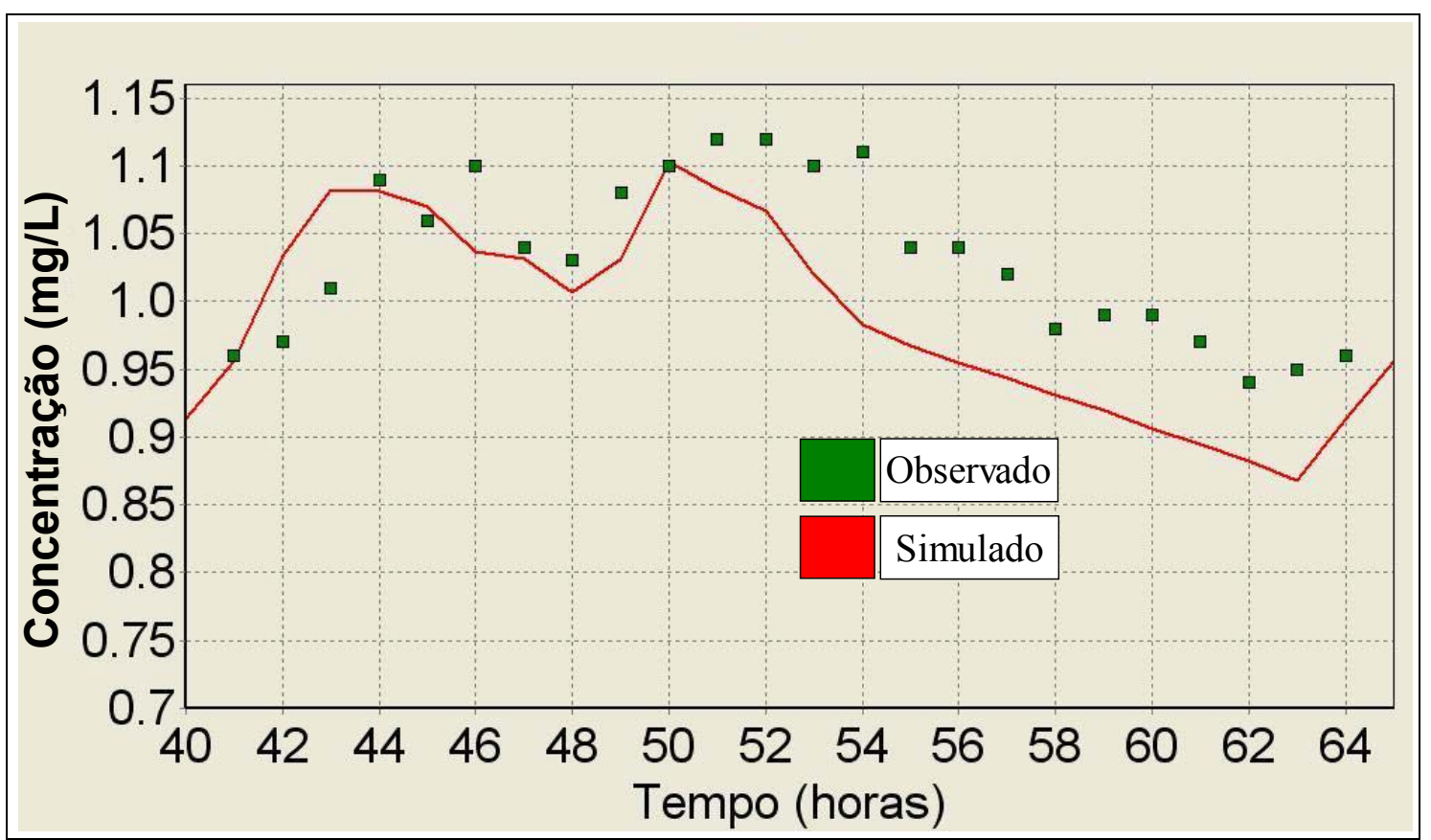

FIGURA 4.39 - Comportamento da concentração de cloro com os dados observados em campo desconsiderando-se os vazamentos

Na Figura 4.40 são apresentados os resultados considerando-se a faixa de erro de leitura do sensor de cloro. Pode-se observar que diversos pontos ficaram distante do simulado, mesmo quando se considerou o erro de leitura do sensor de cloro livre usado.

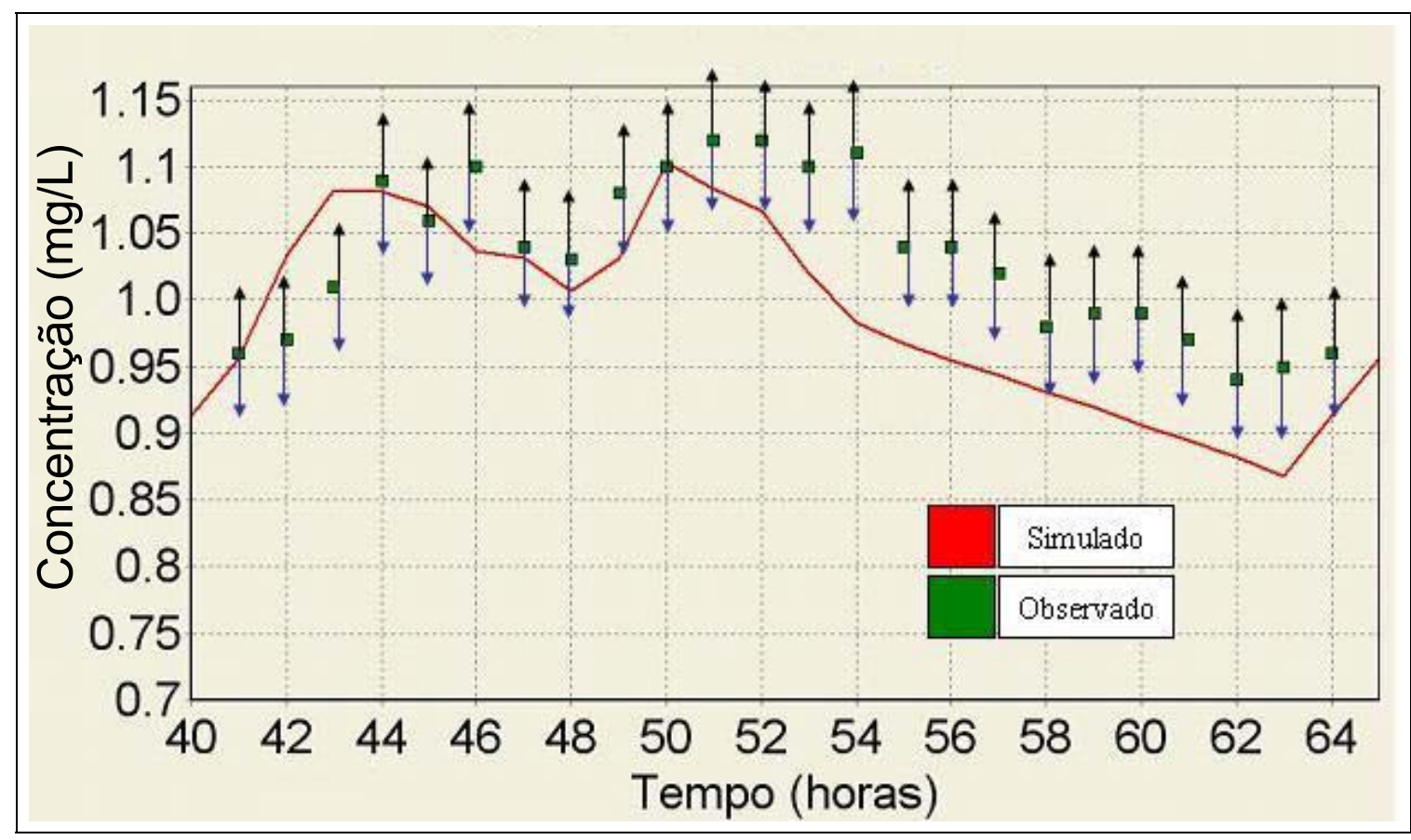

FIGURA 4.40 - Comportamento da concentração de cloro do nó 43 com dados observados em campo e demostrando o erro relativo do sensor da sonda de medição de cloro de $\pm \mathbf{0 , 0 5} \mathrm{mg} / \mathrm{L}$ desconsiderando-se os vazamentos 
Por fim, é apresentado o gráfico que compara todos os valores dos multiplicadores do consumo de referência e seus comportamentos ao longo do período considerado (Figura 4.41). Percebe-se que todos apresentam comportamento semelhante, diferenciando-se apenas na escala dos valores.

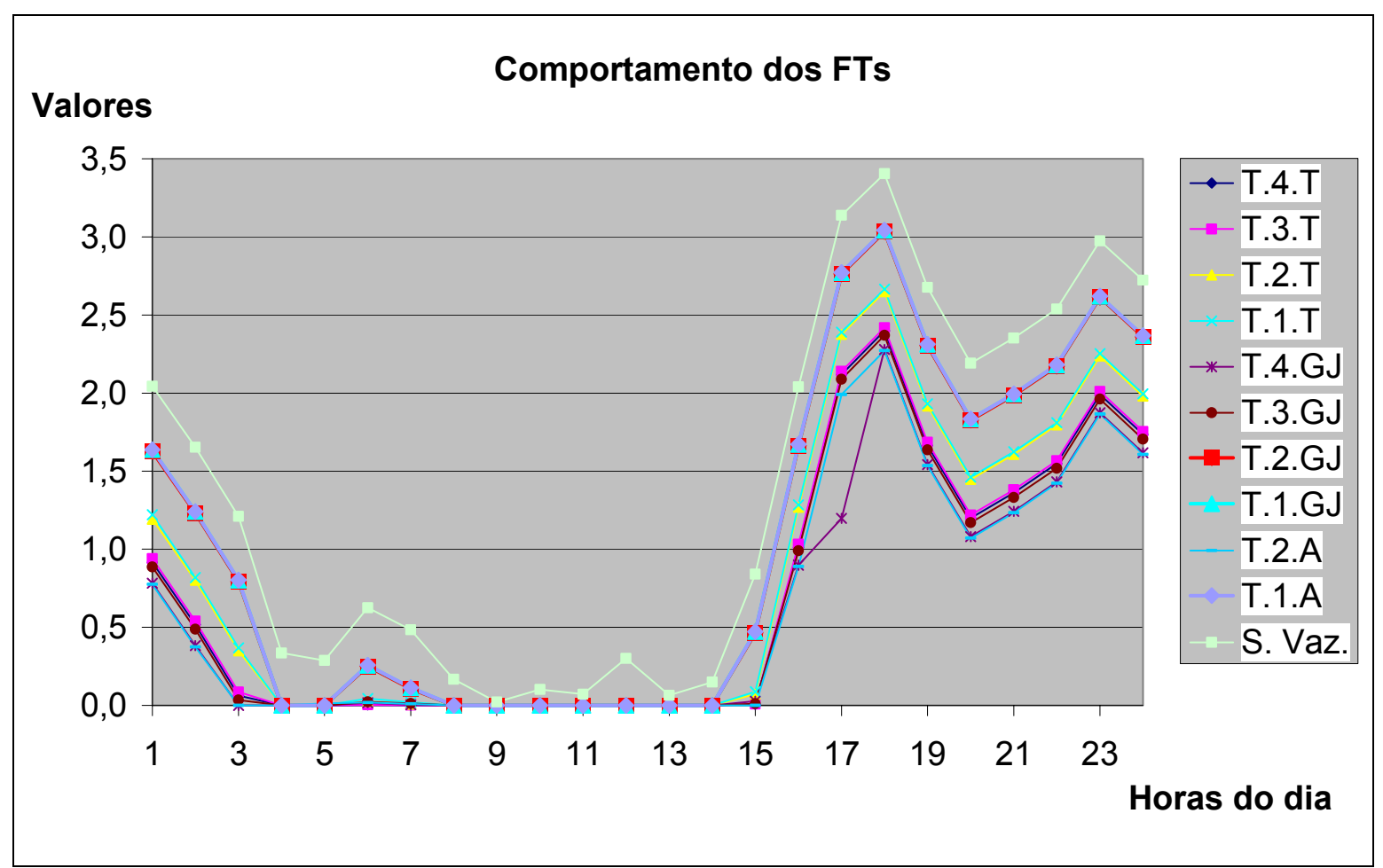

FIGURA 4.41 - Comportamento dos multiplicadores do consumo de referência de todos os teste ao longo do dia

$\mathrm{Na}$ Figura 4.41 observa-se que o limite superior do comportamento dos multiplicadores do consumo de referência é dado pelos valores encontrados ao se considerar a rede estanque. Outra observação feita foi com relação aos multiplicadores do consumo de referência, que produziram os melhores resultados de calibração de qualidade (T.2.GJ , T.1.GJ, T.1.A), são próximos ou coincidentes entre si. Também é apresentado na Figura 4.42, o gráfico que compara todos os $K f$ s dos testes realizados 


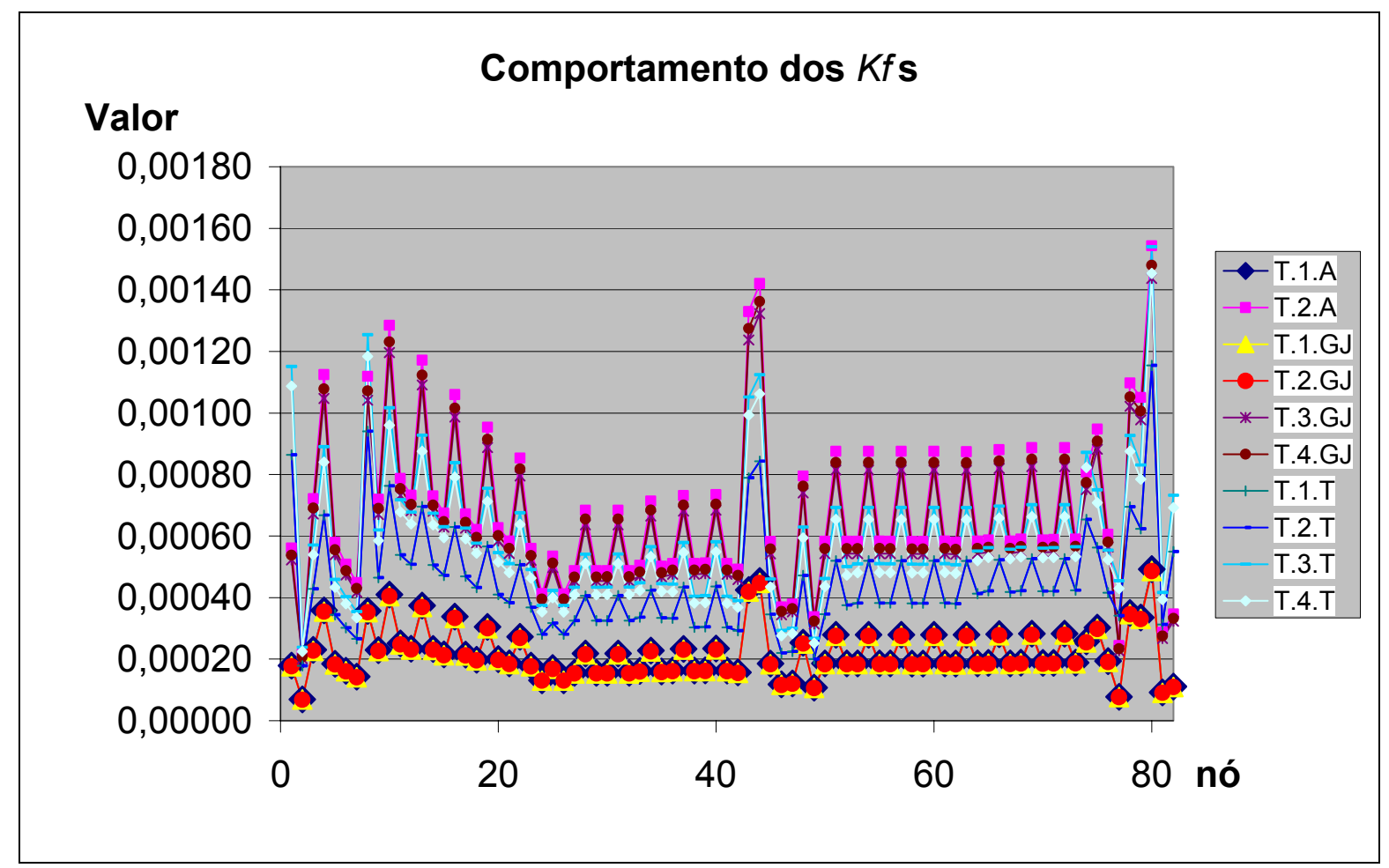

FIGURA 4.42 - Comportamento dos $K f$ s de todos os teste ao longo do dia

Observa-se que as calibrações de qualidade, que obtiveram melhores resultados (T.2.GJ , T.1.GJ, T.1.A), apresentaram valores e comportamentos de $K f$ s semelhantes (Figura 4.42). Coincidentemente também são os $K f \mathrm{~s}$ de menores valores encontrados para todos os testes realizados.

Em relação aos parâmetros hidráulicos, observou-se que a rede foi pouco sensível, gerando resultados muito próximos, sendo isso decorrente da subutilização da rede, ou seja, por ser um loteamento ainda novo e não estar totalmente ocupado, foi difícil determinar os parâmetros hidráulicos. 


\section{CONCLUSÕES}

Foi realizado um estudo de calibração de diversos modelos de redes de distribuição de água calibrando-se os parâmetros hidráulicos e de qualidade. O algoritmo produzido utiliza a tecnologia dos AGs como ferramenta de otimização. Os resultados produzidos bem como as conclusões realizadas são apresentadas aqui de forma sintética.

O modelo de vazamento de TUCCIARELLI et al. (1999), que é baseado na perda de água por área de superfície do tubo, é o modelo que pior apresentou resultados para a calibração de qualidade, e logo, não é o modelo que melhor retrata o comportamento hidráulico da rede.

O modelo de vazamento de GERMANOPOULOS \& JOWITT (1989), que é baseado na perda de água por comprimento da tubulação, foi o modelo que melhor apresentou resultados na calibração de qualidade e devido a isso, acredita-se que seja também o modelo de vazamento que melhor representa o vazamento.

Para alguns testes realizados com os modelos de vazamento de GERMANOPOULOS \& JOWITT (1989) e TUCCIARELLI et al. (1999), mais especificamente nos testes T.2.GJ, T.3.GJ, T.4GJ, T.1.T e T.4.T, ocorreram eventuais variações bruscas na ordem de grandeza das perdas totais obtidas para sementes aleatórias distintas. Tal comportamento pode ser explicado devido ao alto grau de indeterminação do problema de calibração hidráulica. Contudo, em nenhuma das calibrações hidráulicas, ocorreu dessas sementes, que produziram perda total discrepantes na ordem de grandeza, produzirem o melhor (menor) valor para a função objetivo.

O modelo de ARAUJO et al (2006) é o único modelo no qual não se verificaram oscilações bruscas nos valores das perdas totais do vazamento para o mesmo teste, 
evidenciando que a diminuição da indeterminação da calibração hidráulica pode evitar esse problema.

Uma das dificuldades encontradas no presente trabalho, também observada por SOARES (2003), é a respeito da faixa de procura dos valores das variáveis de decisão (coeficientes e expoente de vazamento, rugosidade absoluta), pois a combinação dos valores dos parâmetros resultou, em alguns casos, em não convergência do calibrador hidráulico. Assim como SOARES (2003), percebeu-se que o coeficiente é a variável de decisão mais sensível quanto à convergência.

O procedimento de calibração dos parâmetros dos AGs, através do PSO, mostrou-se como uma ferramenta eficiente no critério de escolha dos parâmetros dos AGs. Apesar do PSO fixar algumas variáveis dos AGs, ele possibilitou que os parâmetros escolhidos para calibração fossem usados posteriormente na calibração da rede de distribuição de água de maneira criteriosa, otimizando os resultados das calibrações. A única desvantagem no emprego deste método de calibração dos parâmetros dos AGs é o tempo computacional necessário, visto que, foram necessárias aproximadamente 1500 calibrações hidráulicas para que se tivesse a resposta da calibração dos AGs.

De maneira geral, os testes realizados, com diversos intervalos de busca para as variáveis de decisão hidráulica, cobriram todas os possíveis valores de entrada para o calibrador hidráulico. Além disso, o algoritmo de calibração hidráulico usado apresentou bons resultados, determinando parâmetros de diversas natureza simultaneamente.

Em relação ao calibrador de qualidade, pode-se dizer que o objetivo de determinar os parâmetros do decaimento do cloro em sistemas de distribuição de água foi atingido. $\mathrm{O}$ modelo foi capaz de determinar a melhor combinação dos parâmetros $\left(K_{\text {bulk }}\right.$ e $\left.K_{w a l l}\right)$ para os diversos testes hidráulicos. A determinação neste trabalho de $\mathrm{K}_{\text {bulk }}$ e $\mathrm{K}_{\text {wall }}$ foi realizada para 
valores globais, visto que, é um setor de única fonte de alimentação de água (único $K_{\text {bulk }}$ ) e todos os tubos são do mesmo material (único $\mathrm{K}_{\text {wall }}$ ).

O "teste da garrafa" foi uma informação importante para a determinação do $K_{\text {bulk, uma }}$ vez que através dele, foi possível determinar o intervalo de procura para a respectiva variável de decisão. Algumas dificuldades são associadas ao desenvolvimento desde teste, pois não é um teste padronizado, logo está sujeito a diversas falhas de procedimento. Contudo, a calibração de qualidade evidenciou que, no presente trabalho, o procedimento usado para a determinação do $K_{\text {bulk }}$ foi de boa qualidade, pois o calibrador hidráulico determinou valores próximos ao "teste da garrafa".

Para a rede do parque Fehr, ficou evidente que o parâmetro $\mathrm{K}_{\text {wall }}$ é dominante no decaimento do cloro, pois pequenas variações nos seus valores determinaram comportamentos da concentração de cloro bem distintos. Também ficou clara a influência dos modelos de vazamento sobre os resultados da calibração de qualidade, já que os diferentes modelos de vazamento, com diferentes intervalos de procura, foram capazes de produzir distintos comportamentos de cloro.

Evidenciou-se também que apenas a calibração hidráulica em redes de distribuição de água pode não representar o comportamento hidráulico real da rede. Neste trabalho, o melhor resultado obtido na calibração hidráulica pertenceu ao teste T.2.T. Contudo, para a calibração de qualidade, evidenciou-se que o teste T.2.GJ foi o teste capaz de produzir os melhores parâmetros hidráulicos.

A calibração de qualidade se mostrou satisfatória por fornecer os parâmetros de qualidade $\left(\mathrm{K}_{\text {bulk }}\right.$ e $\left.\mathrm{K}_{\text {wall }}\right)$ ao simulador EPANET 2.0, de maneira que fosse capaz de reproduzir o comportamento da concentração de cloro na rede estuda.

Em comparação aos resultados obtidos em trabalhos desenvolvidos anteriormente, na área de calibração dos parâmetros de qualidade em redes reais, a presente pesquisa 
demonstrou que o procedimento adotado é capaz de produzir melhores resultados de calibração de qualidade.

Por fim, conclui-se que os valores de $K_{\text {bulk }}$ e $K_{\text {wall, encontrados na calibração de }}$ qualidade, podem ser válidos apenas para a rede de distribuição de água do Parque Fehr, uma vez que foi percebido que esses parâmetros são extremamente peculiares às diversas características da rede. 


\section{RECOMENDAÇÕES PARA TRABALHOS FUTUROS}

Devido ao fato desses resultados serem extremamente ligados às características da rede, recomenda-se que este procedimento seja repetido nas posteriores calibrações de qualidade para as diversas redes de distribuição de água, para que se tenha maior confiança nos resultados produzidos.

Não desprezar a parcela de água perdida por vazamentos na rede, pois evidenciou-se sua importância nas calibrações.

Desenvolver e testar um modelo de simulação de qualidade que seja capaz de comparar automaticamente as concentrações de cloro em nós que tenham tempo de residência elevado, pois no presente trabalho evidenciou-se que o modelo de qualidade adotado pelo EPANET 2.0 é deficiente em nós que tenham tempo de residência elevado, fato também discutido por OZEDEMIR \& UCAK (2002).

O próximo passo de desenvolvimento do procedimento de calibração (adotado no presente trabalho) é testar o mesmo procedimento em uma rede com diversas fontes de alimentação de água e consequentemente diversos áreas de influência de $\mathrm{K}_{\text {bulk }}$ e com tubos de diferentes materiais (diversos $\mathrm{K}_{\mathrm{wall}}$ ). 


\section{REFERÊNCIAS}

ALONSO, J.M.; ALVARRUIZ, F.; GERRETO, D.; HERNÁNDEZ, V.; RUIZ, P.A.; VIDAL, A.M.; MARTÍNEZ, F.; VERCHER, J.; ULANICKI, B. (2000). Parallel computing in water network analysis and leakage minimization. Journal of water Resources Planning and Management, v. 126, n. 4, p. 251-260, July/Aug.

AL-JASSER, A.O. (2006). Chlorine decay in drinking-water transmission and distribution systems: Pipe service age effect. Water Research, v. 41, n. 2, p. 387-396, Apr.

ARAUJO, L.S.; RAMOS, H.; COELHO, S.T. (2006). Pressure control for leakage minimization in water distribution systems management. Water Resources Management, v. 20, n. 3, p. 133-149, Mar.

AZEVEDO, S. M. F. O. (1996). Toxic cyanobacteria and the Caruaru tragedy. IV Simpósio da Sociedade Brasileira de Toxinologia. Recife, Pernanbuco, Brasil, p. 108-119.

BASCIÀ, A.; TUCCIARELLI, T. (2003). Simultaneous zonation and calibration of pipe network parameters. Journal of Hydraulic Engineering, v. 129, n. 5, p. 394-403, May.

BHAVE, P.R. (1988). Calibrating water distribution network models. Journal of Environmental Engineering, v. 144, n. 1, p.120-136, Feb.

BISWAS, P.; LU G.; CLARK, R.M. (1993). A model for chlorine concentration decay in pipes. Water Research, v. 19, n. 6, p. 543-560.

BOCCELLI, D.L.; TRYBY, M.E., UBER, J.G.; SUMMERS, R.S. (2003). A reactive species model for chlorine decay and THM formation under rechlorination conditions. Water Research, v. 37, n. 11, p. 2654-2666, Jun.

BOULOS, P.A.; WOOD, D.J. (1991). Explicit network calibration of multiple loading conditions. Civil Engineering Systems, v. 8, p. 153-160.

BULL, R.J.; BIRNBAUM, L.S.; CANTOR, K.P.; ROSE, J.B.; BUTTERWORTH, B.E.; PEGRAM, R.; TUOMISTO, J. (1995). Fundamental and applied toxicology, v. 28, n. 7, p. 155-166, Jun.

BRASIL. Ministério da Saúde. Portaria 518 de 25 de Março de 2004. Estabelece os procedimentos e responsabilidades relativas ao controle e vigilância da qualidade da água para consumo humano e seu padrão de potabilidade e dá outras providências. Diário Oficial da Republica Federativa do Brasil, Brasília, DF, 26 mar. 2005. Disponível em: http://elegis. anvisa.gov.br. Acesso em: 10 de maio de 2006.

BRASIL. Agencia Nacional da Vigilância Sanitária. Decreto No 5.440, DE 4 DE MAIO DE 2005. Estabelece definições e procedimentos sobre o controle de qualidade da água de sistemas de abastecimento e institui mecanismos e instrumentos para divulgação de 
informação ao consumidor sobre a qualidade da água para consumo humano. Diário Oficial [da] Republica Federativa do Brasil, Brasília, DF, 05 mai. 2005.

CASAGRANDE, J. Modelagem matemática da qualidade de água em sistemas de distribuição. Vitória, (1997). 145p. Dissertação (Mestrado) - Universidade Federal do Espírito Santo, Vitória.

CHAU, K.W. (2006). Particle swarm optimization training algorithm for ANNs in stage prediction of Sing Mun River. Journal of Hydrology, v. 329, n. 2, p. 363-367.

CHEUNG, P.B. (2005). Computation tools for water quality modeling in hydraulic networks - Calibrations Model. Technical Report at Cemagref Bodeaux.

CLARK, R.; ROSSMAN, L.A.; WYMER, L.J. (1995). Modeling distribution system water quality: Regulatory implications. Journal of water resources planning and management. $\mathrm{v}$. 121 , v. 4 , p. $803-820$.

CLARK, R.M; GRAYMAN, W.; MALES, R.; HESS, A. (1993). Modeling contaminant propagation in drinking water distribution systems. Journal of Environmental Engineering, v. 119, n. 2, p. 349-364, Mar/Apr.

CLARK, R.M. (1998). Chlorine demand and TTHM formation Kinetics: a second-order model. Journal of Environmental Engineering, v. 124, n. 1, p. 16-24, Jan.

CLARK, R.M.;HAUGHT, R.C. (2005). Charactering pipe wall demand: implications for water quality modeling. Journal of Water Resources planning and management, v. 131, n. ., p.208-217, May/Jun.

CLARK, R.M.; SIVAGANESAN, M. (1998). Predicting Chlorine Residuals and Formation of TTHMs in Drinking Water. Journal of Water Resources planning and management, v.128, n. 2, p.152-161, Mar/Apr.

COELHO, S.C.M.T (2005). Water Simulation for Packages (WSP). Forum \& EPANET archive. Disponível em: <http://water-simulation.com/wsp/bb/viewtopic.php?id=51>. Acessado em 17 out. 2007.

COPASA - Companhia de Saneamento de Minas Gerais. O abastecimento. 2005. Disponível em: $<$ http://www.copasa.com.br/cgi/cgilua.exe/sys/start.htm?sid=2>. Acessado em 24 de março de 2006.

DANIELI, R. D.; GASTALDINI, M. C.; BARROSO, L. B. ( 2006). Modelagem do cloro residual em redes de distribuição - Aplicação ao sistema de abastecimento de Santa. RBRH (Revista Brasileira de Recursos Hídricos), v. 11, n. 4, p. 201-208.

DATTA, R.S.N.; SRIDHARAN, K. (1994). Parameter estimation in water-distribution systems by least squares. Journal of Water Resources Planning and Management, v. 120, n. 4, p. 405-422, July/Aug.

DEJONG, K. (1975) The analysis and behavior of a class of genetic adaptive system. University of Michigan. (PhD thesis). 
DI BERNARDO, L.; DI BERNARDO, A. (2005). Métodos e técnicas de tratamento de água. 2ed. São Carlos: RIMA, p. 1152-1312.

FAIR, G.M.; GEYER, J.C. (1954). Water supply and waste-water disposal. John Wiley and Sons, London.

GANG, D.C.; CLEVENGER, T.E.; BANERJI, S.K. (2003). Relationship of chlorine decay and THMs formation to NOM size. Journal of Hazardous Materials, v. 96, n. 1, p. 1-12, Jan.

GERMANOPOULOS, G.; JOWITT, P.W. (1989). Leakage reduction by excess pressure minimization in a water supply network. Proc. Instn. Civ. Engrs., Part 2 (June), p. 195-214.

GOLDBERG D.E. (1989). Genetic algorithms in search, optimization and machine learning. Addison-Wesley, Reading, Massachusetts.

GRECO, M.; DEL GIUDICE, G. (1999) New approach to water distribution network calibration. Jounal of Hydraulic Engineering, v. 125, n. 8, p. 849-854, Aug.

HALLAM N.B.; WEST J.R.; FORTER C.F.; POWELL J.C.; SPENCER I. (2002).The decay of chlorine associated with the pipe wall in water distribution systems. Water Research, v. 36, n. 14, p. 3479-3488, Aug.

HUA F.; WEST J.R.; BARKER R.A.; FORSTER C.F. (1998). Modelling of chlorine decay in municipal water supplies. Water Research, v. 33, n. 12, p. 2735-2746, Aug.

Internacional Water Association (2005). A carta de Bona para o abastecimentoseguro de água para consumo humano. Edição do Institudo Regulador de Águas e Resíduos. Centro Empresarial Torres de Lisboa, Lisboa, Porgutal.

JOWITT, P.W.; XU, C. (1990). Optimal valve control in water distribution networks. Journal of Water Resources Planning and Management, v. 116, n. 4, p.455-472, July/Aug.

JUNG, .B.S.; KARNEY, B.W. (2006). Hydraulic optimization of transient protection devices using GA and PSO approaches. Journal of Water Resources Planning and Management, v. 132, n. 1, p. 44-52.

LACERDA E.G.M.; CARVALHO A.C.P.L.F. (1999). Introdução aos Algoritmos Genéticos. In: Galvão C. O. (org.); VALENÇA M.J.S. (org.): Sistemas Inteligentes: aplicações a recursos hídricos e sistemas ambientais. Ed. Universidade/UFRGS/ABRH, Porto Alegre, p.99150.(Coleção ABRH de Recursos Hídricos; 7).

LANSEY, K. E.; BASNET, C. (1991). Parameter estimation for water distribution networks. Journal of Water Resources Planning and Management, v. 117, n. 1, p 126-144, Jan/Feb.

LEE B.H.; DEININGER R.A. (1992). Optimal locations of monitoring stations in water distribution system. Journal of Environmental Engineering, v. 118, n. 1, p. 4-16, Jan. 
LEE, J.; LEE, D.; SOHN, J. (2007). An experimental study for chlorine residual and trihalomethane formation with rechlorination. Water Science \& Techinology, v. 55, n. 2, p. 3007-313.

LIN, Y.C.; YEH, H.D. (2005). Trihalomethne species Forecast using optimization methods: Genetic Algorithms and Simulated Annealing. Journal of Computing in Civil Engineering, v. 19 , n. 3, p. 248-258, Jun.

LINGIREDDY, S.; ORMSBEE, L.E. (2002) Hydraulic network calibration using genetic optimization. Civil Engineering and Environmental Systems, v.19, n. 1, p. 13-39.

KAPELAN, Z.S.; SAVIC, D.A.; WALTERS, G.A. (2007). Calibration of water distribuition hydraulic models using a bayesian-type procedure. Journal of Hydraulic Engineering, DOI: 10.1061/(ASCE)0733-9429, 133:8(927), Aug.

KENNEDY, J.; EBERHART, R.C. (1995). Particle swarm optimization. Proceedings of the IEEE International Conference on Neural Networks, Piscataway, NJ, USA, 1942-1948.

KENNEDDY, M.S.; MOEGLING, S.; SARIKELLE, S.; SURAVALLOP, K. (1993). Assessing the effects of storage tank design. J. AWWA, v. 85, n. 7, p. 78-88.

KIM, S.H. (2008). Address-Oriented Impedance Matrix Method for generic calibration of heterogeneous pipe network systems. Journal of Hydraulic Engineering, v. 134, n. 1, p. 6675, Jan.

MALLICK, K.N.; AHMED, I.; TICKLE, K.S.; LANSEY, K.E. (2002) Determining pipe grouping for water distribution networks. Journal of Water Resources Planning and Management, v. 128, n. 2, p. 130-139, Mar/Apr.

MARTINS, G.; LATORRE, M.R.D.O.; BORANGA J.A.; PEREIRA H.A.S.L. (2001).Curar é mais barato do que prevenir. Certo ou errado?. In: XII Encontro Técnico da Associação dos Engenheiros da Sabesp, São Paulo. Revista SANEAS.

MUNAVALLI G.R.; KUMAR M.S.M. (2003). Water quality parameter estimation in steadystate distribution system. Journal of water resources planning and management, v. 129, n. 2 , p. 4287-4298, Nov.

MUNAVALLI G.R.; KUMAR M.S.M. (2004). Dynamic simulation of ulticomponent reaction transport in water distribution systems. Water Research, v. 38, n. 8, p. 1971-1988, Apr.

MUNAVALLI G.R.; KUMAR M.S.M. (2005). Water quality parameter estimation in a distribution system under dynamic state. Water Research, v. 39, n. 18, p. 4278-4298, Nov.

MUNAVALLI G.R.; KUMAR M.S.M. (2006). Autocalibration of a water distribution model for water quality parameters using GA. Journal $A W W A$, v. 98, n. 9, p. 109-123, Sep.

NELDER, J.A.; MEAD, R. (1965). A simplex method for function minimization. The Computer Journal, v. 7, n. 4, p. 308-313. 
OZDEMIR O.N.; UCAK A. (2002). Simulation of chlorine decay in drinking-water distribution systems. Journal of Environmental Engineering, v. 128, n. 1, p. 31-39, Jan.

ORMSBEE, L.E.; WOOD, D.J. (1986). Explicit pipe network calibration. Journal of Water Resources Planning and Management, v. 112, n. 2, p. 166-182, Apr.

POWELL, J.C.; HALLAM N.B.; WEST, J. R.; FOSTER C. F.; SIMMS JOHN (2000). Factors which control bulk chlorine decay rates. Water Resources, v 34, n. 1, p.117-126.

REIS, L.F.R.; SOARES, A.K.; ODAN, F.K. (2007). A modelagem de vazamentos em sistemas de distribuição de água para abastecimento. VI Encontro Nacional de Águas Urbanas. São Carlos, São Paulo, Brasil, p 120- 138.

ROSSMAN, L.; BOULOS, P. (1996). Numerical methods for modeling water quality in distribution systems: A comparison. Journal of water resources planning an management, $\mathrm{v}$. 122, n. 2, p. 137-146, Mar/Apr.

ROSSMAN, L.; BOULOS P.; ALTMAN, T. (1993). Discrete Volume-Element Method for Network Water-Quality Models. Journal Water Res. Planning and Mannagement, v. 119,n. 5, p. 505-517, Sep/Oct.

ROSSMAN L.A. (2000). EPANET 2 users manual. U.S. Environmental Protection Agency, Cincinnati, Ohio.

ROSSMAN L.A. (2006). The effect of advanced treatment on chlorine decay in metallic pipes. Water Research, v. 40, n. 2, p. 2493-2502, Jun.

SALGADO, S.R.T. (2008). Estudo dos parâmetros do decaimento do cloro residual em sistema de distribuição de água tratada considerando vazamento. São Carlos. 145p. Dissertação (Mestrado). Escola de Engenharia de São Carlos, Universidade de São Paulo, Brasil.

SAVIC, D. A.; WALTERS, G.A. (1997) Genetic Algorithms for least-cost design of water distribution networks. Journal of Water Resources Planning and Management, v.123, n. 2, p. 67-77, Mar/Apr.

SOARES A.K. (2003). Calibração de modelos de redes de distribuição de água pa abastecimento considerando vazamentos e demanda dirigia pela pressão. São Carlos. 153p. Dissertação (Mestrado). Escola de Engenharia de São Carlos, Universidade de São Paulo, Brasil.

SORLINI, S.; COLLIVIGNARELLI, C. (2004). Trihalomethane formation during chemical oxidation with chlorine, chlorine dioxide and ozone of tem Italian natural waters. Presented at the Seminar in Environmental Science and Technology: Evaluation of Alternative Water Treatment Systems for Obtaining Safe Water. Organized by the University of Salerno with support of NATO Science Programme, Fisciano (SA), Italy, Sept.

TSUTIYA M.T. (2005). Abastecimento de água. Ed. 2. Departamento de Engenharia Hidráulica e Sanitária da Escola Politécnica da Universidade de São Paulo. São Paulo. 
TUCCIARELLI,T.; CRIMINISI, A.; TERMINI, D. (1999). Leak analysis in pipeline systems by means of optimal valve regulation. Journal of Hydraulic Engineering, v.125, n.3, p. 277285, Mar.

TUCCIARELLI, T.; TERMINI, D. (1998). Optimal valves regulation for calibration of pipe network models. Proceeding, Hydroinformatics 98 Conf., Balkema, Rotterdam, The Netherlands, p. 1029-1036.

VAIRAVAMOORTHY, K.; LUMBERS, J. (1998). Leakage reduction in water distribution systems: Optimal valve control. Journal of Hydraulic Engineering, v. 124, n. 11, p. 11461153, Nov.

VASCONCELOS J.J., ROSSMAN A., GRAYMAN W.M., BOULOS P.F., CLARK R.M. (1997). Kinetics of chlorine decay. Journal American Water Works Association, v. 89, n. 7, p. 54-55, Jul.

VIEIRA, P. (2002). Decaimento do cloro em sistemas de distribuição de água para consumo humano. (Teses de Mestrado do LNEC), Universidade Nova de Lisboa

VIEIRA, P., COELHO S.T., (2003). Practical conditions for the use of a first order chlorine decay model in water supply. Proc. Computing and Control for the Water Industry.

VIEIRA P., COELHO S.T., LOUREIRO D. (2004). Accounting for the influence of initial chlorine concentration, TOC, iron and temperature when modeling chlorine decay in water supply. Journal of Water Supply Research and Technology, v. 53, n. 7, p. 453-467, Nov.

VÍTKOVSKÝ, J.P.; SIMPSON, A.R.; LAMBERT, M.F. (2000). Leak detection and calibration using transients and genetic algorithms. Journal of Water Resources Planning and Management, v. 126, n. 4, p. 262-265, July/Aug.

ZEFERINO, J.A.; ANTUNES, A.P.; CUNHA, M.C. (2006). An efficient simulated annealing algorithm for regional wastewater systems planning. Joint International Conference on Computing and Decision Making in Civil and Building Engineering, Montréal, Canada, p. 2636-2647.

ZIEROLF, M.L.; POLYCARPOU, M.M.; UBER, J.G. (1998). Development and autocalibration of an imput-output model of chlorine transport in drinking water distribution systems. IEEE Transactions on Control Systems Technology, v. 6, n. 4, p. 543-553, Jul.

WALL, M. (1996). GAlib: A C++ Library of Genetic Algorithm Components. Mechanical Engineering Department, Massachusetts Institute of Technology.

WARTON, B.; HEITZ, A.; JOLL, C.; KAGI, R. (2006). A new method for calculation of the chlorine demand of natural and treated waters. Water Research, v. 40, n.15, p. 2877-2884, Aug.

WALSKI, T.M. (1983). Technique for calibrating network models. Journal of Water Resources Planning and Management, v.109, n.4, p360-372, Oct. 
YSI (2005). YSI incorporated, 6- Series drinking water systems (600DW-B Sonde) Manual Users. 
APÊNDICE A 


\section{[TITLE]}

Fehr1

\section{[JUNCTIONS]}

; ID Elev

1863.0

Demand

863.0

0.0408

862.2

0.0000

859.8

0.0455

861.4

0.0757

861.5

0.0208

861.1

0.0136

862.8

0.0334

862.7

0.0000

859.4

0.0493

862.7

0.0570

861.9

0.0412

857.7

0.0328

861.9

0.0907

860.6

0.0462

856.0

0.0190

860.6

0.0491

858.3

0.0175

853.0

0.0267

858.3

0.0253

0.0177

854.8

0.0147

849.1

0.0258

854.8

0.0131

852.8

0.0241

848.4

0.0044

852.8

0.0044

850.2

0.0297

843.7

0.0334

$850.2 \quad 0.0044$

$848.0 \quad 0.0171$

$841.3 \quad 0.0180$

$848.0 \quad 0.0153$

$845.7 \quad 0.0337$

$838.2 \quad 0.0270$

$845.7 \quad 0.0163$

$843.6 \quad 0.0195$

$834.7 \quad 0.0261$

$849.2 \quad 0.0308$

$841.4 \quad 0.0336$

$831.6 \quad 0.0168$

$841.4 \quad 0.0065$

$838.9 \quad 0.0236$

$828.9 \quad 0.0311$

$845.4 \quad 0.0516$

$842.8 \quad 0.0365$

$842.8 \quad 0.0000$

$839.3 \quad 0.0000$

$842.3 \quad 0.0000$

$845.0 \quad 0.0000$

$844.6 \quad 0.0157$

$847.7 \quad 0.0531$

$844.6 \quad 0.0320$

$846.5 \quad 0.0220$

$849.5 \quad 0.0280$

$\begin{array}{lll}55 & 846.5 & 0.0352 \\ 56 & 848.4 & 0.0284\end{array}$ 


$\begin{array}{lll}57 & 851.5 & 0.0291 \\ 58 & 848.4 & 0.0410 \\ 59 & 850.3 & 0.0233 \\ 6 \odot & 853.6 & 0.0262 \\ 61 & 850.3 & 0.0230 \\ 62 & 852.8 & 0.0287 \\ 63 & 855.6 & 0.0265 \\ 64 & 852.8 & 0.0125 \\ 65 & 854.9 & 0.0385 \\ 66 & 857.5 & 0.0409 \\ 67 & 854.9 & 0.0496 \\ 68 & 857.8 & 0.0019 \\ 69 & 859.8 & 0.0801 \\ 70 & 857.8 & 0.0491 \\ 71 & 860.0 & 0.0454 \\ 72 & 861.5 & 0.0739 \\ 73 & 860.0 & 0.0613 \\ 74 & 862.0 & 0.0800 \\ 75 & 862.5 & 0.0478 \\ 76 & 863.8 & 0.0298 \\ 77 & 863.8 & 0.0127 \\ 78 & 863.8 & 0.00 \odot \odot \\ 79 & 851.5 & 0.00 \odot \odot \\ 80 & 849.1 & 0.00 \odot \odot \\ 81 & 863.5 & 0.00 \odot \odot \\ 82 & 861.4 & 0.0195\end{array}$

[RESERVOIRS]

$\begin{array}{llc}\text {;ID } & \text { Head } & \text { Pattern } \\ 83 & 879.5 & ;\end{array}$

[PIPES]

\begin{tabular}{|c|c|c|c|c|c|c|c|}
\hline ; ID & Node1 & Node2 & Length & Diameter & Roughness & MinorLoss & Status \\
\hline 1 & 1 & 2 & 21.13 & 100 & 0.0093 & 0 & Open \\
\hline 2 & 2 & 3 & 49.39 & 50 & $\odot .0093$ & 0 & Open \\
\hline 3 & 3 & 4 & 258.56 & 50 & $\odot .0093$ & 0 & Open \\
\hline 4 & 4 & 5 & 221.69 & 50 & $\odot .0093$ & 0 & Open \\
\hline 5 & 5 & 6 & 25.78 & 50 & $\odot .0093$ & 0 & Open \\
\hline 6 & 6 & 7 & 191.41 & 50 & $\odot .0093$ & $\odot$ & Open \\
\hline 7 & 2 & 9 & 22.019 & 100 & 0.0093 & $\odot$ & Open \\
\hline 8 & 9 & 11 & 10.81 & 100 & 0.0093 & $\odot$ & Open \\
\hline 9 & 9 & 10 & 274.33 & 50 & $\odot .0093$ & $\odot$ & Open \\
\hline 10 & 11 & 10 & 274.2 & 50 & ๑. 0093 & $\odot$ & Open \\
\hline 11 & 11 & 12 & 50.87 & 100 & $\odot .0093$ & $\odot$ & Open \\
\hline 12 & 12 & 14 & 11.95 & 100 & ๑. 0093 & $\odot$ & Open \\
\hline 13 & 12 & 13 & 250.19 & 50 & $\odot .0 \odot 93$ & $\odot$ & Open \\
\hline 14 & 13 & 14 & 250.06 & 50 & $\odot .0 \odot 93$ & $\odot$ & Open \\
\hline 15 & 14 & 15 & 49.95 & 100 & $\odot .0 \odot 93$ & $\odot$ & Open \\
\hline 16 & 15 & 17 & 11.95 & 100 & $\odot .0 \odot 93$ & $\odot$ & Open \\
\hline 17 & 15 & 16 & 226.24 & 50 & $\odot .0093$ & $\odot$ & Open \\
\hline 18 & 16 & 17 & 226.1 & 50 & $\odot .0093$ & $\odot$ & Open \\
\hline 19 & 17 & 18 & 48.86 & 100 & $\odot .0093$ & $\odot$ & Open \\
\hline 20 & 18 & 20 & 12.51 & 75 & $\odot .0093$ & $\odot$ & Open \\
\hline 21 & 18 & 19 & 203.71 & 50 & 0.0093 & $\odot$ & Open \\
\hline 22 & 19 & 20 & 203.41 & 50 & 0.0093 & $\odot$ & Open \\
\hline 23 & 20 & 21 & 51.91 & 75 & 0.0093 & $\Theta$ & Open \\
\hline 24 & 21 & 23 & 10.05 & 75 & $\odot .0093$ & 0 & Open \\
\hline 25 & 21 & 22 & 187.44 & 50 & ๑. 0093 & $\odot$ & Open \\
\hline
\end{tabular}




\begin{tabular}{|c|c|c|c|c|c|c|c|}
\hline 26 & 22 & 23 & 177.03 & 50 & 0.0093 & $\odot$ & Open \\
\hline 27 & 23 & 24 & 51.95 & 75 & 0.0093 & $\odot$ & Open \\
\hline 28 & 24 & 26 & 10.05 & 75 & 0.0093 & $\odot$ & Open \\
\hline 29 & 24 & 25 & 114.15 & 50 & 0.0093 & $\odot$ & Open \\
\hline 30 & 25 & 26 & 114.09 & 50 & 0.0093 & $\odot$ & Open \\
\hline 31 & 26 & 27 & 51.87 & 75 & 0.0093 & $\odot$ & Open \\
\hline 32 & 27 & 29 & 10.05 & 75 & $\odot .0 \odot 93$ & $\odot$ & Open \\
\hline 33 & 27 & 28 & 146.03 & 50 & 0.0093 & $\odot$ & Open \\
\hline 34 & 28 & 29 & 145.85 & 50 & 0.0093 & $\odot$ & Open \\
\hline 35 & 29 & 30 & 52.09 & 75 & 0.0093 & $\odot$ & Open \\
\hline 36 & 30 & 32 & 10.05 & 75 & 0.0093 & $\odot$ & Open \\
\hline 37 & 30 & 31 & 146.05 & 50 & ๑. .0०93 & $\odot$ & Open \\
\hline 38 & 31 & 32 & 145.96 & 50 & 0.0093 & $\odot$ & Open \\
\hline 39 & 32 & 33 & 52.18 & 75 & 0.0093 & $\odot$ & Open \\
\hline 40 & 33 & 35 & 10.87 & 75 & 0.0093 & $\odot$ & Open \\
\hline 41 & 33 & 34 & 152.52 & 50 & 0.0093 & 0 & Open \\
\hline 42 & 34 & 35 & 152.43 & 50 & 0.0093 & $\odot$ & Open \\
\hline 43 & 35 & 36 & 50.94 & 75 & 0.0093 & $\odot$ & Open \\
\hline 44 & 36 & 38 & 11.02 & 50 & 0.0093 & $\odot$ & Open \\
\hline 45 & 36 & 37 & 156.18 & 50 & 0.0093 & $\odot$ & Open \\
\hline 46 & 37 & 38 & 156.01 & 50 & 0.0093 & $\odot$ & Open \\
\hline 47 & 38 & 39 & 51.17 & 50 & 0.0093 & $\odot$ & Open \\
\hline 48 & 39 & 41 & 11.02 & 50 & 0.0093 & 0 & Open \\
\hline 49 & 39 & 40 & 156.89 & 50 & 0.0093 & $\odot$ & Open \\
\hline 50 & 40 & 41 & 156.67 & 50 & ๑. .0०93 & $\odot$ & Open \\
\hline 51 & 41 & 42 & 50.44 & 50 & 0.0093 & 0 & Open \\
\hline 52 & 42 & 43 & 147.74 & 50 & 0.0093 & 0 & Open \\
\hline 53 & 43 & 44 & 419.7 & 50 & 0.0093 & $\odot$ & Open \\
\hline 54 & 44 & 45 & 186.83 & 50 & $\odot .0093$ & $\odot$ & Open \\
\hline 55 & 45 & 46 & 10.86 & 50 & 0.0093 & 0 & Open \\
\hline 56 & 46 & 47 & 62.46 & 50 & 0.0093 & 0 & Open \\
\hline 57 & 47 & 48 & 87.48 & 50 & 0.0093 & $\odot$ & Open \\
\hline 58 & 48 & 49 & 59.45 & 50 & 0.0093 & 0 & Open \\
\hline 59 & 49 & 46 & 84.69 & 50 & 0.0093 & 0 & Open \\
\hline 60 & 42 & 47 & 12.12 & 50 & 0.0093 & $\odot$ & Open \\
\hline 61 & 45 & 50 & 50.88 & 50 & 0.0093 & 0 & Open \\
\hline 62 & 50 & 52 & 11.44 & 50 & 0.0093 & 0 & Open \\
\hline 63 & 50 & 51 & 186.79 & 50 & 0.0093 & $\odot$ & Open \\
\hline 64 & 51 & 52 & 186.97 & 50 & 0.0093 & 0 & Open \\
\hline 65 & 52 & 53 & 50.62 & 75 & 0.0093 & 0 & Open \\
\hline 66 & 53 & 55 & 11.44 & 75 & 0.0093 & 0 & Open \\
\hline 67 & 53 & 54 & 186.79 & 50 & $\odot .0093$ & 0 & Open \\
\hline 68 & 54 & 55 & 186.97 & 50 & $\odot .0 \odot 93$ & $\odot$ & Open \\
\hline 69 & 55 & 56 & 50.74 & 75 & 0.0093 & 0 & Open \\
\hline 70 & 56 & 58 & 11.44 & 75 & 0.0093 & 0 & Open \\
\hline 71 & 56 & 57 & 186.79 & 50 & 0.0093 & 0 & Open \\
\hline 72 & 57 & 58 & 186.97 & 50 & 0.0093 & 0 & Open \\
\hline 73 & 58 & 59 & 50.26 & 75 & $\odot .0093$ & 0 & Open \\
\hline 74 & 59 & 61 & 11.44 & 75 & $\odot .0093$ & $\odot$ & Open \\
\hline 75 & 59 & 60 & 186.79 & 50 & 0.0093 & 0 & Open \\
\hline 76 & 60 & 61 & 186.97 & 50 & $\odot .0093$ & 0 & Open \\
\hline 77 & 61 & 62 & 50.75 & 75 & 0.0093 & $\odot$ & Open \\
\hline 78 & 62 & 64 & 10.47 & 75 & $\odot .0093$ & $\odot$ & Open \\
\hline 79 & 62 & 63 & 186.62 & 50 & 0.0093 & 0 & Open \\
\hline
\end{tabular}




\begin{tabular}{|c|c|c|c|c|c|c|c|}
\hline 80 & 63 & 64 & 186.61 & 50 & 0.0093 & $\odot$ & Open \\
\hline 81 & 64 & 65 & 52.21 & 100 & ๑.0093 & $\odot$ & Open \\
\hline 82 & 65 & 67 & 10.46 & 100 & $\odot .0 \odot 93$ & $\odot$ & Open \\
\hline 83 & 65 & 66 & 188.27 & 50 & 0.0093 & $\odot$ & Open \\
\hline 84 & 66 & 67 & 187.74 & 50 & 0.0093 & $\odot$ & Open \\
\hline 85 & 67 & 68 & 51 & 100 & $\odot .0093$ & $\odot$ & Open \\
\hline 86 & 68 & 70 & 11.44 & 100 & ๑.0०93 & 0 & Open \\
\hline 87 & 68 & 69 & 189.52 & 50 & 0.0093 & $\odot$ & Open \\
\hline 88 & 69 & 70 & 189.07 & 50 & ๑. 0093 & $\odot$ & Open \\
\hline 89 & 70 & 71 & 50.46 & 100 & 0.0093 & $\odot$ & Open \\
\hline 90 & 71 & 73 & 11.44 & 100 & ๑.0093 & $\odot$ & Open \\
\hline 91 & 71 & 72 & 189.52 & 50 & 0.0093 & $\odot$ & Open \\
\hline 92 & 72 & 73 & 189.07 & 50 & ๑. 0093 & $\odot$ & Open \\
\hline 93 & 73 & 74 & 51.65 & 100 & ๑.0093 & $\odot$ & Open \\
\hline 94 & 74 & 75 & 193.93 & 50 & ๑. 0093 & $\odot$ & Open \\
\hline 95 & 75 & 76 & 210.67 & 50 & $\odot .0093$ & 0 & Open \\
\hline 96 & 81 & 74 & 99.09 & 100 & ๑. 0093 & 0 & Open \\
\hline 97 & 76 & 77 & 24.49 & 100 & ๑.0०93 & $\odot$ & Open \\
\hline 98 & 77 & 78 & 9.43 & 75 & $\odot .0093$ & 0 & Open \\
\hline 99 & 78 & 8 & 65.87 & 75 & ๑.0०93 & $\odot$ & Open \\
\hline 100 & 78 & 79 & 393.34 & 50 & 0.0093 & $\odot$ & Open \\
\hline 101 & 79 & 80 & 54.91 & 50 & $\odot .0093$ & 0 & Open \\
\hline 102 & 80 & 8 & 411.61 & 75 & ๑. .0०93 & $\odot$ & Open \\
\hline 103 & 81 & 76 & 23.59 & 100 & $\odot .0 \odot 93$ & $\odot$ & Open \\
\hline 104 & 48 & 80 & 192.51 & 50 & 0.0093 & $\odot$ & Open \\
\hline 105 & 77 & 1 & 70.15 & 140 & ๑. .0०93 & $\odot$ & Open \\
\hline 106 & 82 & 1 & 148.22 & 140 & ๑. .0093 & $\odot$ & Open \\
\hline 107 & 83 & 82 & 1 & 1000 & ๑. .०९93 & $\odot$ & Open \\
\hline
\end{tabular}

$\begin{array}{ll}\text { [REPORT] } & \\ \text { File } & \text { saida } \\ \text { Status } & \text { Full } \\ \text { Summary } & \text { Yes } \\ \text { Nodes } & \text { All } \\ \text { Pressure } & \text { Yes } \\ \text { Links } & \text { All } \\ \text { Flow } & \text { Yes }\end{array}$

[OPTIONS]

$\begin{array}{ll}\text { Units } & \text { LPS } \\ \text { Headloss } & \text { D-W } \\ \text { Specific Gravity } & 1 \\ \text { Viscosity } & 1 \\ \text { Trials } & 4 \odot \\ \text { Accuracy } & \odot .001 \\ \text { Unbalanced } & \text { Stop } \\ \text { Demand Multiplier } & 1 . \odot \\ \text { Tolerance } & \odot .01\end{array}$

[END] 
2 //Dempat (demand patterns)

2 //Número de padrões de observação de vazões

1 //Número máximo de trechos de vazões observados

2 //Número de padrões de observação de reservatórios

1 //Número máximo de reservatórios observados

2 //Número de padrões de observação de pressões

5 //Número máximo de nós de pressões observados

๑.० //Demanda de Consumidor Especial

1 //trecho; NobsFlow (pat1);

$$
82 \quad 1 \quad 2.98
$$

2.98 //TotalSupply (pat1)

1 //NobsHead (pat1)

$$
83 \quad 881.28
$$

5 //Node; NobsPressure (pat1);

$4 \quad 19.53$

$22 \quad 31.23$

$44 \quad 35.00$

$66 \quad 23.66$

$80 \quad 31.86$

1 //trecho; NobsFlow (pat2);

$$
82 \quad 1 \quad 6.18
$$

6.18 //TotalSupply (pat2)

$1 / /$ NobsHead(pat2)

83878.83

5 //Node; NobsPressure(pat2);

$4 \quad 16.83$

$22 \quad 28.59$

$44 \quad 31.90$

$66 \quad 20.78$

$80 \quad 29.15$ 


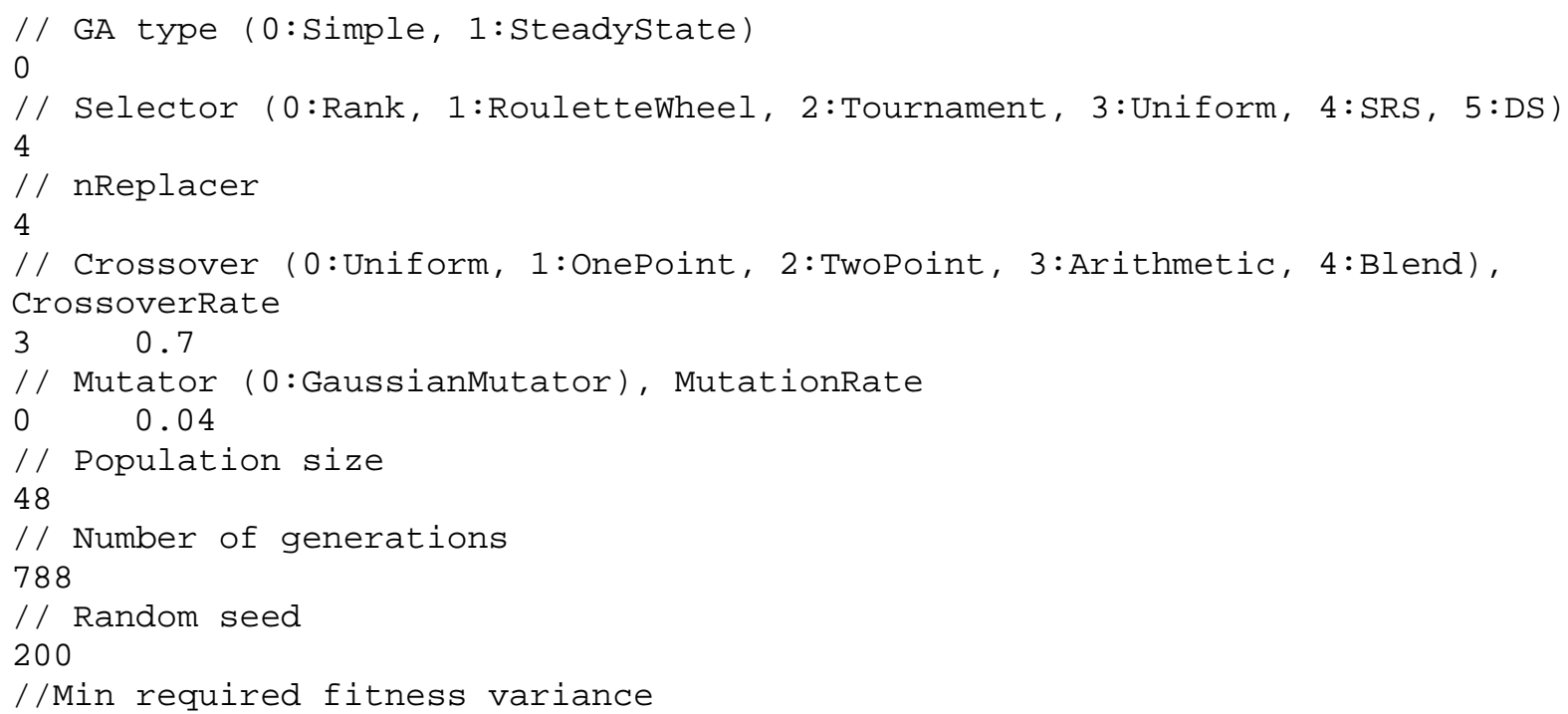




$\begin{array}{ll}79 & 80 \\ 80 & 8 \\ 81 & 76 \\ 48 & 80 \\ 77 & 1 \\ 82 & 1\end{array}$

$1 / /$ NleakAreas

106 //MaxLeakPipes

106 //Leakpipes(1)

12

23

34

45

56

67

29

$9 \quad 11$

$9 \quad 10$

$11 \quad 10$

$11 \quad 12$

$12 \quad 14$

$12 \quad 13$

$13 \quad 14$

$14 \quad 15$

$15 \quad 17$

$15 \quad 16$

$\begin{array}{ll}16 & 17\end{array}$

$17 \quad 18$

$18 \quad 20$

$18 \quad 19$

$19 \quad 20$

$20 \quad 21$

$21 \quad 23$

$21 \quad 22$

$22 \quad 23$

$23 \quad 24$

$24 \quad 26$

$24 \quad 25$

$25 \quad 26$

$26 \quad 27$

$27 \quad 29$

$27 \quad 28$

$28 \quad 29$

$29 \quad 30$

$30 \quad 32$

$30 \quad 31$

$31 \quad 32$

$32 \quad 33$

$33 \quad 35$

$33 \quad 34$

$34 \quad 35$

$35 \quad 36$

$36 \quad 38$

$\begin{array}{ll}36 & 37\end{array}$

$37 \quad 38$

$38 \quad 39$

$39 \quad 41$

$39 \quad 40$

$40 \quad 41$

$41 \quad 42$

$42 \quad 43$ 
5

6

7

8

9

10

11

12

13

14

15

16

17

18

19

20

21

22

23

24

25

26

27

28

29

30

31

32

33

34

35

36

37

38

39

40

41

42

43

44

45

46

47

48

49

50

51

52

53

54

55

56

57

58

59

60

61

62

63

64

65 
66

67

68

69

70

71

72

73

74

75

76

77

78

79

80

81

82

- //NdiameterAreas

- //MaxDiameterPipes

$\odot$ // Nodes for which ground level has to be determined

$\odot$ // Nodes for which demand has to be determined

//theXMin, theXMax (roughness, leakage parameters[teta $(\times 10 e-7)$ and exponents], diameters, elevations and demands)
0.00150
0.010
//roughness (1)
0.005
0.15
$/ / \operatorname{teta}(1)$

$\odot .6$

1.1

//expoente (1)

//DemandModel (0:Tucciarelli, 1:Tabesh $(n j=2.0)$-na mesma linha, 2:Fujiwara) $0 \quad 2.0$

//LeakageModel (०:Tucciarelli, 1: Jowitt-Xu)

$\odot$ 
APÊNDICE B 


\section{[TITLE]}

Fehr1

\section{[JUNCTIONS]}

$$
\text { ; ID }
$$

1

2

3

4

5

6

7

8

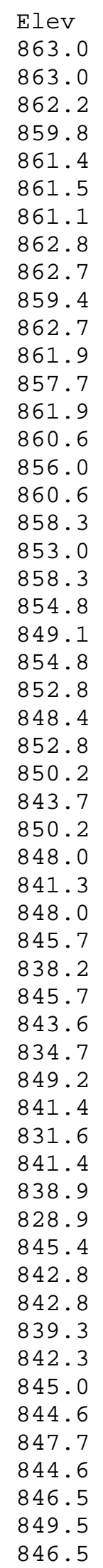

Demand

0.0408

๑. 0000

0.0455

0.0757

๑. 0208

0.0136

0.0334

0.0000

0.0493

0.0570

$\odot .0412$

$\odot .0328$

๑. 0907

0.0462

$\odot .0190$

0.0491

0.0175

0.0267

๑. 0253

0.0177

0.0147

๑. 0258

0.0131

0.0241

0.0044

○. 0032

$\odot .0297$

$\odot .0334$

0.0044

0.0171

๑. 0180

$\odot .0153$

$\odot .0337$

๑. 0270

$\odot .0163$

0.0195

๑. 0261

0.0308

๑. 0336

$\odot .0168$

๑. 0065

๑. 0236

0.0311

๑. 0516

$\odot .0365$

$\odot .000 \%$

○. 0000

○. 0000

๑. 0000

0.0157

๑. 0531

๑. 0320

$\odot .0220$

0.0280

$\odot .0352$
Pattern

PAT1

PAT1

PAT1

PAT1

PAT1

PAT1

PAT1

PAT1

PAT1

PAT1

PAT1

PAT1

PAT1

PAT1

PAT1

PAT1

PAT1

PAT1

PAT1

PAT1

PAT1

PAT1

PAT1

PAT1

PAT1

PAT1

PAT1

PAT1

PAT1

PAT1

PAT1

PAT1

PAT1

PAT1

PAT1

PAT1

PAT1

PAT1

PAT1

PAT1

PAT1

PAT1

PAT1

PAT1

PAT1

PAT1

PAT1

PAT1

PAT1 


\begin{tabular}{|c|c|c|c|c|c|c|c|c|c|}
\hline \multicolumn{2}{|l|}{56} & \multicolumn{2}{|l|}{848.4} & \multicolumn{3}{|c|}{0.0284} & PAT1 & & \\
\hline 57 & & \multicolumn{2}{|l|}{851.5} & \multicolumn{2}{|c|}{0.0291} & & PAT1 & & \\
\hline 58 & & \multicolumn{2}{|l|}{848.4} & \multicolumn{2}{|c|}{0.0410} & \multicolumn{2}{|r|}{ PAT1 } & & \\
\hline 59 & & \multicolumn{2}{|l|}{850.3} & \multicolumn{2}{|c|}{0.0233} & \multicolumn{2}{|r|}{ PAT1 } & & \\
\hline 60 & & \multicolumn{2}{|l|}{853.6} & \multicolumn{2}{|c|}{0.0262} & & PAT1 & & \\
\hline 61 & & 850.3 & & 0.02 & & & PAT1 & & \\
\hline 62 & & 852.8 & & 0.02 & & & PAT1 & & \\
\hline 63 & & 855.6 & & $\odot .02$ & & & PAT1 & & \\
\hline 64 & & 852.8 & & 0.01 & & & PAT1 & & \\
\hline 65 & & 854.9 & & 0.03 & & & PAT1 & & \\
\hline 66 & & 857.5 & & $\odot .04$ & & & PAT1 & & \\
\hline 67 & & 854.9 & & 0.04 & & & PAT1 & & \\
\hline 68 & & 857.8 & & 0.00 & & & PAT1 & & \\
\hline 69 & & 859.8 & & $\odot .08$ & & & PAT1 & & \\
\hline 70 & & 857.8 & & 0.04 & & & PAT1 & & \\
\hline 71 & & 860.0 & & 0.04 & & & PAT1 & & \\
\hline 72 & & 861.5 & & 0.07 & & & PAT1 & & \\
\hline 73 & & 860.0 & & 0.06 & & & PAT1 & & \\
\hline 74 & & 862.0 & & 0.08 & & & PAT1 & & \\
\hline 75 & & 862.5 & & 0.04 & & & PAT1 & & \\
\hline 76 & & 863.8 & & 0.02 & & & PAT1 & & \\
\hline 77 & & 863.8 & & 0.01 & & & PAT1 & & \\
\hline 78 & & 863.8 & & $\odot . \odot \odot$ & & & & & \\
\hline 79 & & 851.5 & & $\odot .0 \odot$ & & & & & \\
\hline 80 & & 849.1 & & 0.00 & & & & & \\
\hline 81 & & 863.5 & & $\odot .0 \odot$ & & & & & \\
\hline 82 & & 861.4 & & 0.01 & & & PAT1 & & \\
\hline$[\mathrm{RE}$ & IRS ] & & & & & & & & \\
\hline ; ID & & Head & & Patt & $e r n$ & & & & \\
\hline 83 & & 879.5 & & Rese & rvatorio & & ; & & \\
\hline$[\mathrm{PI}$ & & & & & & & & & \\
\hline ;ID & Node1 & Node2 & Length & Diameter & Roughness & & MinorLoss & Status & \\
\hline 1 & 1 & 2 & 21.13 & 100 & 0.009788 & 0 & & Open & ; \\
\hline 2 & 2 & 3 & 49.39 & 50 & 0.009788 & 0 & & Open & ; \\
\hline 3 & 3 & 4 & 258.56 & 50 & 0.009788 & 0 & & Open & ; \\
\hline 4 & 4 & 5 & 221.69 & 50 & 0.009788 & 0 & & Open & ; \\
\hline 5 & 5 & 6 & 25.78 & 50 & 0.009788 & 0 & & Open & , \\
\hline 6 & 6 & 7 & 191.41 & 50 & 0.009788 & 0 & & Open & ; \\
\hline 7 & 2 & 9 & 22.019 & 100 & 0.009788 & 0 & & Open & ; \\
\hline 8 & 9 & 11 & 10.81 & 100 & 0.009788 & 0 & & Open & ; \\
\hline 9 & 9 & 10 & 274.33 & 50 & 0.009788 & 0 & & Open & , \\
\hline 10 & 11 & 10 & 274.2 & 50 & 0.009788 & 0 & & Open & ; \\
\hline 11 & 11 & 12 & 50.87 & 100 & 0.009788 & 0 & & Open & ; \\
\hline 12 & 12 & 14 & 11.95 & 100 & 0.009788 & 0 & & Open & \\
\hline 13 & 12 & 13 & 250.19 & 50 & 0.009788 & 0 & & Open & ; \\
\hline 14 & 13 & 14 & 250.06 & 50 & 0.009788 & 0 & & Open & ; \\
\hline 15 & 14 & 15 & 49.95 & 100 & 0.009788 & 0 & & Open & ; \\
\hline 16 & 15 & 17 & 11.95 & 100 & 0.009788 & 0 & & Open & ; \\
\hline 17 & 15 & 16 & 226.24 & 50 & 0.009788 & 0 & & Open & ; \\
\hline 18 & 16 & 17 & 226.1 & 50 & 0.009788 & 0 & & Open & ; \\
\hline 19 & 17 & 18 & 48.86 & 100 & 0.009788 & 0 & & Open & ; \\
\hline 20 & 18 & 20 & 12.51 & 75 & 0.009788 & 0 & & Open & ; \\
\hline 21 & 18 & 19 & 203.71 & 50 & 0.009788 & 0 & & Open & ; \\
\hline 22 & 19 & 20 & 203.41 & 50 & 0.009788 & 0 & & Open & \\
\hline 23 & 20 & 21 & 51.91 & 75 & 0.009788 & 0 & & Open & \\
\hline 24 & 21 & 23 & 10.05 & 75 & 0.009788 & 0 & & Open & \\
\hline
\end{tabular}




\begin{tabular}{|c|c|c|c|c|c|c|c|}
\hline 25 & 21 & 22 & 187.44 & 50 & 0.009788 & 0 & Open \\
\hline 26 & 22 & 23 & 177.03 & 50 & 0.009788 & 0 & Open \\
\hline 27 & 23 & 24 & 51.95 & 75 & 0.009788 & 0 & Open \\
\hline 28 & 24 & 26 & 10.05 & 75 & 0.009788 & 0 & Open \\
\hline 29 & 24 & 25 & 114.15 & 50 & 0.009788 & 0 & Open \\
\hline 30 & 25 & 26 & 114.09 & 50 & 0.009788 & 0 & Open \\
\hline 31 & 26 & 27 & 51.87 & 75 & 0.009788 & 0 & Open \\
\hline 32 & 27 & 29 & 10.05 & 75 & 0.009788 & 0 & Open \\
\hline 33 & 27 & 28 & 146.03 & 50 & 0.009788 & 0 & Open \\
\hline 34 & 28 & 29 & 145.85 & 50 & 0.009788 & 0 & Open \\
\hline 35 & 29 & 30 & 52.09 & 75 & 0.009788 & 0 & Open \\
\hline 36 & 30 & 32 & 10.05 & 75 & 0.009788 & 0 & Open \\
\hline 37 & 30 & 31 & 146.05 & 50 & 0.009788 & 0 & Open \\
\hline 38 & 31 & 32 & 145.96 & 50 & 0.009788 & 0 & Open \\
\hline 39 & 32 & 33 & 52.18 & 75 & 0.009788 & 0 & Open \\
\hline 40 & 33 & 35 & 10.87 & 75 & 0.009788 & 0 & Open \\
\hline 41 & 33 & 34 & 152.52 & 50 & 0.009788 & 0 & Open \\
\hline 42 & 34 & 35 & 152.43 & 50 & 0.009788 & 0 & Open \\
\hline 43 & 35 & 36 & 50.94 & 75 & 0.009788 & 0 & Open \\
\hline 44 & 36 & 38 & 11.02 & 50 & 0.009788 & 0 & Open \\
\hline 45 & 36 & 37 & 156.18 & 50 & 0.009788 & 0 & Open \\
\hline 46 & 37 & 38 & 156.01 & 50 & 0.009788 & 0 & Open \\
\hline 47 & 38 & 39 & 51.17 & 50 & 0.009788 & 0 & Open \\
\hline 48 & 39 & 41 & 11.02 & 50 & 0.009788 & 0 & Open \\
\hline 49 & 39 & 40 & 156.89 & 50 & 0.009788 & 0 & Open \\
\hline 50 & 40 & 41 & 156.67 & 50 & 0.009788 & 0 & Open \\
\hline 51 & 41 & 42 & 50.44 & 50 & 0.009788 & 0 & Open \\
\hline 52 & 42 & 43 & 147.74 & 50 & 0.009788 & 0 & Open \\
\hline 53 & 43 & 44 & 419.7 & 50 & 0.009788 & 0 & Open \\
\hline 54 & 44 & 45 & 186.83 & 50 & 0.009788 & 0 & Open \\
\hline 55 & 45 & 46 & 10.86 & 50 & 0.009788 & 0 & Open \\
\hline 56 & 46 & 47 & 62.46 & 50 & 0.009788 & 0 & Open \\
\hline 57 & 47 & 48 & 87.48 & 50 & 0.009788 & 0 & Open \\
\hline 58 & 48 & 49 & 59.45 & 50 & 0.009788 & 0 & Open \\
\hline 59 & 49 & 46 & 84.69 & 50 & 0.009788 & 0 & Open \\
\hline 60 & 42 & 47 & 12.12 & 50 & 0.009788 & 0 & Open \\
\hline 61 & 45 & 50 & 50.88 & 50 & 0.009788 & 0 & Open \\
\hline 62 & 50 & 52 & 11.44 & 50 & 0.009788 & 0 & Open \\
\hline 63 & 50 & 51 & 186.79 & 50 & 0.009788 & 0 & Open \\
\hline 64 & 51 & 52 & 186.97 & 50 & 0.009788 & 0 & Open \\
\hline 65 & 52 & 53 & 50.62 & 75 & 0.009788 & 0 & Open \\
\hline 66 & 53 & 55 & 11.44 & 75 & 0.009788 & 0 & Open \\
\hline 67 & 53 & 54 & 186.79 & 50 & 0.009788 & 0 & Open \\
\hline 68 & 54 & 55 & 186.97 & 50 & 0.009788 & 0 & Open \\
\hline 69 & 55 & 56 & 50.74 & 75 & 0.009788 & 0 & Open \\
\hline 70 & 56 & 58 & 11.44 & 75 & 0.009788 & 0 & Open \\
\hline 71 & 56 & 57 & 186.79 & 50 & 0.009788 & 0 & Open \\
\hline 72 & 57 & 58 & 186.97 & 50 & 0.009788 & 0 & Open \\
\hline 73 & 58 & 59 & 50.26 & 75 & 0.009788 & 0 & Open \\
\hline 74 & 59 & 61 & 11.44 & 75 & 0.009788 & 0 & Open \\
\hline 75 & 59 & 60 & 186.79 & 50 & 0.009788 & 0 & Open \\
\hline 76 & 60 & 61 & 186.97 & 50 & 0.009788 & 0 & Open \\
\hline 77 & 61 & 62 & 50.75 & 75 & 0.009788 & 0 & Open \\
\hline 78 & 62 & 64 & 10.47 & 75 & 0.009788 & 0 & Open \\
\hline
\end{tabular}




\begin{tabular}{|c|c|c|c|c|c|c|c|}
\hline 79 & 62 & 63 & 186.62 & 50 & 0.009788 & \multicolumn{2}{|c|}{ Open } \\
\hline 80 & 63 & 64 & 186.61 & 50 & 0.009788 & \multicolumn{2}{|c|}{ Open } \\
\hline 81 & 64 & 65 & 52.21 & 100 & 0.009788 & \multicolumn{2}{|c|}{ Open } \\
\hline 82 & 65 & 67 & 10.46 & 100 & 0.009788 & \multicolumn{2}{|c|}{ Open } \\
\hline 83 & 65 & 66 & 188.27 & 50 & 0.009788 & \multicolumn{2}{|c|}{ Open } \\
\hline 84 & 66 & 67 & 187.74 & 50 & 0.009788 & \multicolumn{2}{|c|}{ Open } \\
\hline 85 & 67 & 68 & 51 & 100 & 0.009788 & \multicolumn{2}{|c|}{ Open } \\
\hline 86 & 68 & 70 & 11.44 & 100 & 0.009788 & \multicolumn{2}{|c|}{ Open } \\
\hline 87 & 68 & 69 & 189.52 & 50 & 0.009788 & \multicolumn{2}{|c|}{ Open } \\
\hline 88 & 69 & 70 & 189.07 & 50 & 0.009788 & \multicolumn{2}{|c|}{ Open } \\
\hline 89 & 70 & 71 & 50.46 & 100 & 0.009788 & \multicolumn{2}{|c|}{ Open } \\
\hline 90 & 71 & 73 & 11.44 & 100 & 0.009788 & \multicolumn{2}{|c|}{ Open } \\
\hline 91 & 71 & 72 & 189.52 & 50 & 0.009788 & Oper & ; \\
\hline 92 & 72 & 73 & 189.07 & 50 & 0.009788 & Oper & ; \\
\hline 93 & 73 & 74 & 51.65 & 100 & 0.009788 & Oper & ; \\
\hline 94 & 74 & 75 & 193.93 & 50 & 0.009788 & Oper & ; \\
\hline 95 & 75 & 76 & 210.67 & 50 & 0.009788 & Oper & ; \\
\hline 96 & 81 & 74 & 99.09 & 100 & 0.009788 & Oper & ; \\
\hline 97 & 76 & 77 & 24.49 & 100 & 0.009788 & Oper & ; \\
\hline 98 & 77 & 78 & 9.43 & 75 & 0.009788 & Oper & ; \\
\hline 99 & 78 & 8 & 65.87 & 75 & 0.009788 & Oper & ; \\
\hline 100 & 78 & 79 & 393.34 & 50 & 0.009788 & Oper & ; \\
\hline 101 & 79 & 80 & 54.91 & 50 & 0.009788 & Oper & ; \\
\hline 102 & 80 & 8 & 411.61 & 75 & 0.009788 & Oper & ; \\
\hline 103 & 81 & 76 & 23.59 & 100 & 0.009788 & Oper & ; \\
\hline 104 & 48 & 80 & 192.51 & 50 & 0.009788 & Oper & ; \\
\hline 105 & 77 & 1 & 70.15 & 140 & 0.009788 & Oper & ; \\
\hline 106 & 82 & 1 & 148.22 & 140 & 0.009788 & Oper & ; \\
\hline 107 & 83 & 82 & 1 & 1000 & 0.009788 & Oper & ; \\
\hline$[\mathrm{PA}]$ & & & & & & & \\
\hline ;ID & & Mult & oliers & & & & \\
\hline & & & & & & & \\
\hline PAT1 & & 1.638151 & 1.241840 & 0.803419 & $\Theta$ & 0 & 0.258212 \\
\hline PAT1 & & 0.114067 & $\odot$ & 0 & 0 & 0 & $\odot$ \\
\hline PAT1 & & $\odot$ & $\odot$ & $\odot .47350 \odot$ & $\quad 1.671619$ & 2.771821 & 3.042902 \\
\hline PAT1 & & 2.312694 & 1.834655 & 1.994643 & 32.180386 & 2.620433 & 2.368075 \\
\hline & & & & & & & \\
\hline Rese & orio & 1.001986 & 1.002045 & 1.002303 & 31.002495 & 1.000863 & ๑. 999014 \\
\hline Rese & orio & 0.999146 & $\odot .999989$ & 1. $00 \odot 762$ & $2 \quad 1.001536$ & 1.002294 & $1.0 \odot 2039$ \\
\hline Rese & orio & 1.000165 & $\odot .998770$ & $\odot .999168$ & $\odot .999374$ & 0.999348 & $\odot .999153$ \\
\hline Rese & orio & $\odot .999091$ & $\odot .998536$ & $\odot .998507$ & $\odot .998502$ & 0.998441 & $\odot .998549$ \\
\hline
\end{tabular}

$\begin{array}{ll}\text { [EMITTERS] } & \\ \text { junction } & \text { Coefficient } \\ 1 & 0.000179069 \odot \\ 2 & 0.0000691893 \\ 3 & 0.0002302470 \\ 4 & 0.0003590720 \\ 5 & 0.0001850280 \\ 6 & 0.0001623880 \\ 7 & 0.0001431130 \\ 8 & 0.0003570010 \\ 9 & 0.000229656 \odot \\ 10 & 0.0004101230 \\ 11 & 0.000251130 \odot \\ 12 & 0.000234030 \odot\end{array}$




\begin{tabular}{|c|c|}
\hline 13 & $\odot . \odot \odot \odot 374 \odot 25 \odot$ \\
\hline 14 & 0.0002332450 \\
\hline 15 & $\odot .000215436 \odot$ \\
\hline 16 & $\odot .000338204 \odot$ \\
\hline 17 & $\odot .00 \odot 2145160$ \\
\hline 18 & $\odot .0001981940$ \\
\hline 19 & $\odot .0 \odot \odot 3 \odot 43940$ \\
\hline 20 & $\odot .00 \odot 20 \odot 250 \odot$ \\
\hline 21 & 0.0001864710 \\
\hline 22 & $\odot .00 \odot 272506 \odot$ \\
\hline 23 & $\odot .000178717 \odot$ \\
\hline 24 & $\odot .0001317030$ \\
\hline 25 & $\odot .000170650 \odot$ \\
\hline 26 & $\odot .0001315990$ \\
\hline 27 & $\odot .000155479 \odot$ \\
\hline 28 & 0.0002182320 \\
\hline 29 & $\odot .0001555090$ \\
\hline 30 & $\odot .0001556590$ \\
\hline 31 & $\odot .00 \odot 218329 \odot$ \\
\hline 32 & $\odot .0 \odot \odot 155659 \odot$ \\
\hline 33 & $\odot .0001611770$ \\
\hline 34 & $\odot .00 \odot 2280 \odot 4 \odot$ \\
\hline 35 & $\odot .0001601820$ \\
\hline 36 & ๑. 0001630980 \\
\hline 37 & $\odot .000233417 \odot$ \\
\hline 38 & $\odot . \odot \odot \odot 1631430$ \\
\hline 39 & ๑. 0001638010 \\
\hline 40 & 0.0002344420 \\
\hline 41 & $\odot .0001630910$ \\
\hline 42 & $\odot .0001572360$ \\
\hline 43 & 0.0004242620 \\
\hline 44 & $\odot .0004534880$ \\
\hline 45 & $\odot .000185850 \odot$ \\
\hline 46 & $\odot .0001181400$ \\
\hline 47 & 0.0001211690 \\
\hline 48 & $\odot .0002537910$ \\
\hline 49 & $\odot .000107770 \odot$ \\
\hline 50 & $\odot .0001862540$ \\
\hline 51 & $\odot .0002794520$ \\
\hline 52 & $\odot .0001861940$ \\
\hline 53 & $\odot .000186059 \odot$ \\
\hline 54 & $\odot .0002794520$ \\
\hline 55 & $\odot .0001862840$ \\
\hline 56 & $\odot .0001861490$ \\
\hline 57 & $\odot .00 \odot 2794520$ \\
\hline 58 & $\odot .0001859250$ \\
\hline 59 & $\odot .000185790 \odot$ \\
\hline 60 & $\odot .0002794520$ \\
\hline 61 & ๑. 0001862910 \\
\hline 62 & $\odot .0001853040$ \\
\hline 63 & $\odot .0 \odot \odot 279055 \odot$ \\
\hline 64 & $\odot .0001863880$ \\
\hline 65 & ๑. 0001876220 \\
\hline 66 & 0.0002811340 \\
\hline 67 & $\odot .0001863210$ \\
\hline 68 & $\odot .0001883850$ \\
\hline 69 & $\odot .0002830630$ \\
\hline 70 & $\odot .0001876440$ \\
\hline 71 & $\odot .0001879810$ \\
\hline 72 & $\odot .0002830630$ \\
\hline 73 & $\odot . \odot \odot \odot 188534 \odot$ \\
\hline
\end{tabular}




$\begin{array}{ll}74 & 0.00 \odot 2577020 \\ 75 & 0.00 \odot 302510 \odot \\ 76 & 0.0 \odot \odot 1934610 \\ 77 & 0.00 \odot \odot 778107 \\ 78 & 0.00 \odot 3503910 \\ 79 & 0.0003351460 \\ 80 & 0.00 \odot 4927410 \\ 81 & 0.0 \odot \odot \odot 917250 \\ 82 & 0.00 \odot 1108210\end{array}$

\begin{tabular}{|c|c|}
\hline \multicolumn{2}{|l|}{ [TIMES] } \\
\hline Duration & $86: \odot \odot$ \\
\hline Hydraulic Timestep & $1: 00$ \\
\hline Quality Timestep & $\odot: 01$ \\
\hline Pattern Timestep & $1: 00$ \\
\hline Pattern Start & $\odot: \odot \odot$ \\
\hline Report Timestep & $1: \odot \odot$ \\
\hline Report Start & $\odot: \odot \odot$ \\
\hline Start ClockTime & $0: 00$ \\
\hline Statistic & NONE \\
\hline \multicolumn{2}{|l|}{ [REPORT ] } \\
\hline Status & No \\
\hline Summary & No \\
\hline Page & $\odot$ \\
\hline \multicolumn{2}{|l|}{ [OPTIONS] } \\
\hline Units & LPS \\
\hline Headloss & $D-W$ \\
\hline Specific Gravity & 1 \\
\hline Viscosity & 1 \\
\hline Trials & 40 \\
\hline Accuracy & 0.001 \\
\hline Unbalanced & Stop \\
\hline Pattern & PAT1 \\
\hline Demand Multiplier & 1 \\
\hline Emitter Exponent & 1.18 \\
\hline Quality & Age $\mathrm{mg} / \mathrm{L}$ \\
\hline Diffusivity & 1 \\
\hline Tolerance & 0.01 \\
\hline
\end{tabular}

[COORDINATES]

$\begin{array}{lll}; \text { Node } & \text { X-Coord } & \text { Y-Coord } \\ 1 & 1426.23 & 1325.00 \\ 2 & 1419.89 & 1304.84 \\ 3 & 1467.22 & 1290.74 \\ 4 & 1622.41 & 1090.35 \\ 5 & 1503.72 & 1259.16 \\ 6 & 1567.69 & 1259.36 \\ 7 & 1681.75 & 1105.65 \\ 8 & 1402.97 & 1306.03 \\ 9 & 1402.26 & 1291.66 \\ 10 & 1558.23 & 1072.66 \\ 11 & 1393.60 & 1285.18 \\ 12 & 1352.87 & 1254.71 \\ 13 & 1494.32 & 1055.63 \\ 14 & 1343.29 & 1247.55 \\ 15 & 1303.30 & 1217.64 \\ 16 & 1430.29 & 1036.98\end{array}$




\begin{tabular}{|c|c|c|}
\hline 17 & 1293.73 & 1210.48 \\
\hline 18 & 1254.60 & 1181.21 \\
\hline 19 & 1368.07 & 1019.29 \\
\hline 20 & 1244.70 & 1173.55 \\
\hline 21 & 1203.48 & 1142.01 \\
\hline 22 & 1299.15 & 1005.97 \\
\hline 23 & 1195.49 & 1135.90 \\
\hline 24 & 1154.23 & 1104.34 \\
\hline 25 & 1215.15 & 1014.31 \\
\hline 26 & 1146.25 & 1098.23 \\
\hline 27 & 1105.06 & 1066.71 \\
\hline 28 & 1184.90 & 951.33 \\
\hline 29 & 1097.07 & 1060.60 \\
\hline 30 & 1055.70 & 1028.95 \\
\hline 31 & 1136.57 & 912.62 \\
\hline 32 & 1047.72 & 1022.84 \\
\hline 33 & 1006.27 & 991.13 \\
\hline 34 & 1090.21 & 869.40 \\
\hline 35 & 997.64 & 984.53 \\
\hline 36 & 957.18 & 953.58 \\
\hline 37 & 1043.01 & 829.08 \\
\hline 38 & 948.46 & 946.84 \\
\hline 39 & 906.99 & 916.86 \\
\hline 40 & 993.23 & 791.81 \\
\hline 41 & 898.26 & 910.12 \\
\hline 42 & 857.56 & 880.33 \\
\hline 43 & 937.93 & 763.02 \\
\hline 44 & 693.79 & 1091.11 \\
\hline 45 & 806.44 & 948.80 \\
\hline 46 & 812.92 & 940.08 \\
\hline 47 & 850.09 & 889.88 \\
\hline 48 & 920.10 & 942.98 \\
\hline 49 & 882.31 & 986.51 \\
\hline 50 & 846.99 & 979.54 \\
\hline 51 & 743.46 & 1128.55 \\
\hline 52 & 856.08 & 986.48 \\
\hline 53 & 896.97 & 1016.33 \\
\hline 54 & 793.59 & 1165.14 \\
\hline 55 & 906.21 & 1023.07 \\
\hline 56 & 947.19 & 1052.98 \\
\hline 57 & 843.81 & 1201.80 \\
\hline 58 & 956.44 & 1059.73 \\
\hline 59 & 997.03 & 1089.36 \\
\hline 60 & 893.65 & 1238.18 \\
\hline 61 & 1006.28 & 1096.11 \\
\hline 62 & 1047.27 & 1126.03 \\
\hline 63 & 943.48 & 1274.78 \\
\hline 64 & 1055.62 & 1132.34 \\
\hline 65 & 1097.98 & 1162.87 \\
\hline 66 & 992.25 & 1313.08 \\
\hline 67 & 1106.32 & 1169.19 \\
\hline 68 & 1147.58 & 1199.17 \\
\hline 69 & 1042.87 & 1350.35 \\
\hline 70 & 1156.83 & 1205.91 \\
\hline 71 & 1197.66 & 1235.56 \\
\hline 72 & 1092.95 & 1386.74 \\
\hline 73 & 1206.91 & 1242.30 \\
\hline 74 & 1248.71 & 1272.65 \\
\hline 75 & 1144.00 & 1423.82 \\
\hline 76 & 1335.95 & 1353.40 \\
\hline 77 & 1359.31 & 1346.05 \\
\hline
\end{tabular}




$\begin{array}{lll}78 & 1356.48 & 1337.05 \\ 79 & 1040.32 & 1103.05 \\ 80 & 1073.50 & 1059.30 \\ 81 & 1328.87 & 1330.90 \\ 82 & 1567.62 & 1280.52 \\ 83 & 1571.96 & 1284.30\end{array}$

\section{[VERTICES]}

\section{; Link}

4

5

9

13

17

21

25

29

33

37

37

41

45

49

53

53

58

59

63

67

71

75

79

83

87

91

94

95

99

[LABELS]

;X-Coord

[BACKDROP]

DIMENSIONS

UNITS

FILE

OFFSET
X-Coord

1630.14

1503.58

1566.86

1503.58

1440.29

1378.23

1307.64

1222.45

1194.46

1144.57

1140.57

1098.32

1052.08

1002.18

930.38

685.77

889.61

875.01

733.21

785.02

835.59

886.17

934.27

983.62

1034.19

1083.53

1131.64

1160.02

1405.49

Y-Coord

644.39

None

0.00
Y-Coord

1097.07

1267.45

1081.25

1063.00

1044.74

1026.49

1011.88

1020.40

957.12

918.18

915.40

875.58

834.20

797.69

755.10

1086.12

985.11

986.93

1122.41

1159.42

1195.19

1230.96

1269.20

1306.21

1343.21

1380.22

1414.76

1407.36

1321.01

Label \& Anchor Node

729.98

1731.15

1456.86

[END] 
APÊNDICE C 


\section{[TITLE]}

Fehr1

\section{[JUNCTIONS]}

; ID

1

2

3

4

5

6

7

8

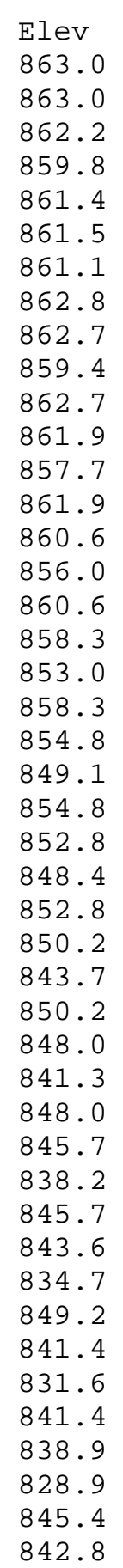

Demand

0.0408

0.0000

0.0455

0.0757

0.0208

๑. 0136

$\odot .0334$

$\odot .0000$

0.0493

$\odot .0570$

0.0412

$\odot$. 0328

0.0907

๑. 0462

0.0190

0.0491

$\odot .0175$

0.0267

$\odot .0253$

0.0177

๑ . 0147

๑. 0258

$\odot .0131$

0.0241

$\odot .0044$

0.0032

๑. 0297

$\odot .0334$

0.0044

$\odot .0171$

๑ . 0180

0.0153

0.0337

$\odot .0270$

$\odot .0163$

๑. 0195

๑. 0261

0.0308

๑. 0336

๑. 0168

๑. 0065

๑. 0236

0.0311

0.0516

$\odot .0365$
Pattern

PAT1

PAT1

PAT1

PAT1

PAT1

PAT1

PAT1

PAT1

PAT1

PAT1

PAT1

PAT1

PAT1

PAT1

PAT1

PAT1

PAT1

PAT1

PAT1

PAT1

PAT1

PAT1

PAT1

PAT1

PAT1

PAT1

PAT1

PAT1

PAT1

PAT1

PAT1

PAT1

PAT1

PAT1

PAT1

PAT1

PAT1

PAT1

PAT1

PAT1

PAT1

PAT1

PAT1 


\begin{tabular}{|c|c|c|c|c|c|c|c|}
\hline \multicolumn{2}{|l|}{46} & \multicolumn{2}{|l|}{842.8} & \multicolumn{2}{|c|}{$\odot . ๑ \odot \odot \odot$} & & \\
\hline 47 & & \multicolumn{2}{|l|}{839.3} & \multicolumn{2}{|c|}{0.0000} & & \\
\hline 48 & & \multicolumn{2}{|l|}{842.3} & \multicolumn{2}{|c|}{$\odot .0000$} & & \\
\hline 49 & & \multicolumn{2}{|l|}{845.0} & \multicolumn{2}{|c|}{$\odot .0 \odot \odot \odot$} & & \\
\hline 50 & & \multicolumn{2}{|l|}{844.6} & \multicolumn{2}{|c|}{0.0157} & \multicolumn{2}{|l|}{ PAT1 } \\
\hline 51 & & \multicolumn{2}{|l|}{847.7} & \multicolumn{2}{|c|}{ ๑. 0531} & \multicolumn{2}{|l|}{ PAT1 } \\
\hline 52 & & \multicolumn{2}{|l|}{844.6} & \multicolumn{2}{|c|}{0.0320} & PAT1 & \\
\hline 53 & & 846.5 & & 0.022 & & PAT1 & \\
\hline 54 & & 849.5 & & 0.028 & & PAT1 & \\
\hline 55 & & 846.5 & & 0.035 & & PAT1 & \\
\hline 56 & & 848.4 & & 0.028 & & PAT1 & \\
\hline 57 & & 851.5 & & 0.029 & & PAT1 & \\
\hline 58 & & 848.4 & & 0.041 & & PAT1 & \\
\hline 59 & & 850.3 & & 0.023 & & PAT1 & \\
\hline 60 & & 853.6 & & 0.026 & & PAT1 & \\
\hline 61 & & 850.3 & & 0.023 & & PAT1 & \\
\hline 62 & & 852.8 & & 0.028 & & PAT1 & \\
\hline 63 & & 855.6 & & 0.026 & & PAT1 & \\
\hline 64 & & 852.8 & & 0.012 & & PAT1 & \\
\hline 65 & & 854.9 & & 0.038 & & PAT1 & \\
\hline 66 & & 857.5 & & 0.040 & & PAT1 & \\
\hline 67 & & 854.9 & & $\odot .049$ & & PAT1 & \\
\hline 68 & & 857.8 & & 0.001 & & PAT1 & \\
\hline 69 & & 859.8 & & $\odot .080$ & & PAT1 & \\
\hline 70 & & 857.8 & & $\odot .049$ & & PAT1 & \\
\hline 71 & & 860.0 & & 0.045 & & PAT1 & \\
\hline 72 & & 861.5 & & 0.073 & & PAT1 & \\
\hline 73 & & 860.0 & & 0.061 & & PAT1 & \\
\hline 74 & & 862.0 & & $\odot .080$ & & PAT1 & \\
\hline 75 & & 862.5 & & 0.047 & & PAT1 & \\
\hline 76 & & 863.8 & & 0.029 & & PAT1 & \\
\hline 77 & & 863.8 & & 0.012 & & PAT1 & \\
\hline 78 & & 863.8 & & 0.000 & & & \\
\hline 79 & & 851.5 & & 0.000 & & & \\
\hline 80 & & 849.1 & & 0.000 & & & \\
\hline 81 & & 863.5 & & 0.000 & & & \\
\hline 82 & & 861.4 & & 0.019 & & PAT1 & \\
\hline [RES & OIRS ] & & & & & & \\
\hline ; ID & & Head & & Patte & $\mathrm{rn}$ & & \\
\hline 83 & & 879.5 & & Reser & vatorio & ; & \\
\hline [PIF & & & & & & & \\
\hline ; ID & Node1 & Node2 & Length & Diameter & Roughness & MinorLoss & Status \\
\hline 1 & 1 & 2 & 21.13 & 100 & ๑. .0०9788 & $\odot$ & Open \\
\hline 2 & 2 & 3 & 49.39 & 50 & ๑. . 009788 & $\odot$ & Open \\
\hline 3 & 3 & 4 & 258.56 & 50 & ๑. . 009788 & $\odot$ & Open \\
\hline 4 & 4 & 5 & 221.69 & 50 & ๑. . 009788 & $\odot$ & Open \\
\hline 5 & 5 & 6 & 25.78 & 50 & ๑. . 009788 & $\odot$ & Open \\
\hline 6 & 6 & 7 & 191.41 & 50 & ๑. . 09788 & $\odot$ & Open \\
\hline 7 & 2 & 9 & 22.019 & 100 & ๑. .0०9788 & $\odot$ & Open \\
\hline 8 & 9 & 11 & 10.81 & 100 & ๑. .0०9788 & $\odot$ & Open \\
\hline 9 & 9 & 10 & 274.33 & 50 & ๑. . 009788 & $\odot$ & Open \\
\hline 10 & 11 & 10 & 274.2 & 50 & ๑. . 09788 & $\odot$ & Open \\
\hline 11 & 11 & 12 & 50.87 & 100 & ๑. . 009788 & $\odot$ & Open \\
\hline 12 & 12 & 14 & 11.95 & 100 & ๑. . 009788 & $\odot$ & Open \\
\hline 13 & 12 & 13 & 250.19 & 50 & ๑. . 009788 & $\odot$ & Open \\
\hline 14 & 13 & 14 & 250.06 & 50 & ๑. . 009788 & $\odot$ & Open \\
\hline 15 & 14 & 15 & 49.95 & 100 & 0.009788 & $\odot$ & Open \\
\hline
\end{tabular}




\begin{tabular}{|c|c|c|c|c|c|c|c|}
\hline 16 & 15 & 17 & 11.95 & 100 & ๑. . 009788 & $\odot$ & Open \\
\hline 17 & 15 & 16 & 226.24 & 50 & 0.009788 & $\odot$ & Open \\
\hline 18 & 16 & 17 & 226.1 & 50 & ๑. . 009788 & $\odot$ & Open \\
\hline 19 & 17 & 18 & 48.86 & 100 & ๑ . 009788 & $\odot$ & Open \\
\hline 20 & 18 & 20 & 12.51 & 75 & ๑ . 009788 & $\odot$ & Open \\
\hline 21 & 18 & 19 & 203.71 & 50 & ๑. . 009788 & $\odot$ & Open \\
\hline 22 & 19 & 20 & 203.41 & 50 & ०. . 009788 & $\odot$ & Open \\
\hline 23 & 20 & 21 & 51.91 & 75 & ๑ . 009788 & $\odot$ & Open \\
\hline 24 & 21 & 23 & 10.05 & 75 & ๑. .009788 & $\odot$ & Open \\
\hline 25 & 21 & 22 & 187.44 & 50 & ०. . 009788 & $\odot$ & Open \\
\hline 26 & 22 & 23 & 177.03 & 50 & ๑. . 009788 & $\odot$ & Open \\
\hline 27 & 23 & 24 & 51.95 & 75 & ๑. . 009788 & $\odot$ & Open \\
\hline 28 & 24 & 26 & 10.05 & 75 & ०. . 009788 & $\odot$ & Open \\
\hline 29 & 24 & 25 & 114.15 & 50 & 0.009788 & 0 & Open \\
\hline 30 & 25 & 26 & 114.09 & 50 & ०. . 009788 & 0 & Open \\
\hline 31 & 26 & 27 & 51.87 & 75 & 0.009788 & $\odot$ & Open \\
\hline 32 & 27 & 29 & 10.05 & 75 & 0.009788 & $\odot$ & Open \\
\hline 33 & 27 & 28 & 146.03 & 50 & ०. . 009788 & $\odot$ & Open \\
\hline 34 & 28 & 29 & 145.85 & 50 & ๑. . 009788 & $\odot$ & Open \\
\hline 35 & 29 & 30 & 52.09 & 75 & ०. . 009788 & $\odot$ & Open \\
\hline 36 & 30 & 32 & 10.05 & 75 & ०. . 009788 & $\odot$ & Open \\
\hline 37 & 30 & 31 & 146.05 & 50 & ๑. . 009788 & $\odot$ & Open \\
\hline 38 & 31 & 32 & 145.96 & 50 & 0.009788 & $\odot$ & Open \\
\hline 39 & 32 & 33 & 52.18 & 75 & ๑. . 009788 & $\odot$ & Open \\
\hline 40 & 33 & 35 & 10.87 & 75 & ๑. . 009788 & 0 & Open \\
\hline 41 & 33 & 34 & 152.52 & 50 & 0.009788 & $\odot$ & Open \\
\hline 42 & 34 & 35 & 152.43 & 50 & 0.009788 & $\odot$ & Open \\
\hline 43 & 35 & 36 & 50.94 & 75 & ०. . 009788 & 0 & Open \\
\hline 44 & 36 & 38 & 11.02 & 50 & ๑. .009788 & 0 & Open \\
\hline 45 & 36 & 37 & 156.18 & 50 & 0.009788 & 0 & Open \\
\hline 46 & 37 & 38 & 156.01 & 50 & 0.009788 & $\odot$ & Open \\
\hline 47 & 38 & 39 & 51.17 & 50 & ๑. . 009788 & $\odot$ & Open \\
\hline 48 & 39 & 41 & 11.02 & 50 & ๑. . 009788 & $\odot$ & Open \\
\hline 49 & 39 & 40 & 156.89 & 50 & ๑. . 009788 & $\odot$ & Open \\
\hline 50 & 40 & 41 & 156.67 & 50 & ๑. . 009788 & $\odot$ & Open \\
\hline 51 & 41 & 42 & 50.44 & 50 & ๑. . 009788 & $\odot$ & Open \\
\hline 52 & 42 & 43 & 147.74 & 50 & 0.009788 & $\odot$ & Open \\
\hline 53 & 43 & 44 & 419.7 & 50 & ๑. . 009788 & $\odot$ & Open \\
\hline 54 & 44 & 45 & 186.83 & 50 & 0.009788 & $\odot$ & Open \\
\hline 55 & 45 & 46 & 10.86 & 50 & ๑. . 009788 & $\odot$ & Open \\
\hline 56 & 46 & 47 & 62.46 & 50 & ๑. . 009788 & $\odot$ & Open \\
\hline 57 & 47 & 48 & 87.48 & 50 & ๑. . 009788 & 0 & Open \\
\hline 58 & 48 & 49 & 59.45 & 50 & 0.009788 & $\odot$ & Open \\
\hline 59 & 49 & 46 & 84.69 & 50 & 0.009788 & $\odot$ & Open \\
\hline 60 & 42 & 47 & 12.12 & 50 & ०. . 009788 & 0 & Open \\
\hline 61 & 45 & 50 & 50.88 & 50 & 0.009788 & $\odot$ & Open \\
\hline 62 & 50 & 52 & 11.44 & 50 & 0.009788 & $\odot$ & Open \\
\hline 63 & 50 & 51 & 186.79 & 50 & ๑. . 009788 & $\odot$ & Open \\
\hline 64 & 51 & 52 & 186.97 & 50 & 0.009788 & $\odot$ & Open \\
\hline 65 & 52 & 53 & 50.62 & 75 & 0.009788 & $\odot$ & Open \\
\hline 66 & 53 & 55 & 11.44 & 75 & 0.009788 & $\odot$ & Open \\
\hline 67 & 53 & 54 & 186.79 & 50 & ๑. . 009788 & $\odot$ & Open \\
\hline 68 & 54 & 55 & 186.97 & 50 & 0.009788 & $\odot$ & Open \\
\hline 69 & 55 & 56 & 50.74 & 75 & ๑ . 009788 & $\odot$ & Open \\
\hline
\end{tabular}




\begin{tabular}{|c|c|c|c|c|c|c|c|}
\hline 70 & 56 & 58 & 11.44 & 75 & ๑. . 009788 & $\odot$ & Open \\
\hline 71 & 56 & 57 & 186.79 & 50 & 0.009788 & $\odot$ & Open \\
\hline 72 & 57 & 58 & 186.97 & 50 & ๑. . 009788 & $\odot$ & Open \\
\hline 73 & 58 & 59 & 50.26 & 75 & ๑. . 009788 & $\odot$ & Open \\
\hline 74 & 59 & 61 & 11.44 & 75 & ๑. . 009788 & $\odot$ & Open \\
\hline 75 & 59 & 60 & 186.79 & 50 & ๑. . 009788 & $\odot$ & Open \\
\hline 76 & 60 & 61 & 186.97 & 50 & $\odot .009788$ & $\odot$ & Open \\
\hline 77 & 61 & 62 & 50.75 & 75 & ๑. . 009788 & $\odot$ & Open \\
\hline 78 & 62 & 64 & 10.47 & 75 & ๑. . 009788 & $\odot$ & Open \\
\hline 79 & 62 & 63 & 186.62 & 50 & ๑. . 009788 & $\odot$ & Open \\
\hline 80 & 63 & 64 & 186.61 & 50 & $\odot .009788$ & $\odot$ & Open \\
\hline 81 & 64 & 65 & 52.21 & 100 & ๑. . 009788 & $\odot$ & Open \\
\hline 82 & 65 & 67 & 10.46 & 100 & ๑. . 009788 & $\odot$ & Open \\
\hline 83 & 65 & 66 & 188.27 & 50 & ๑. . 009788 & $\odot$ & Open \\
\hline 84 & 66 & 67 & 187.74 & 50 & $\odot .0 \odot 9788$ & $\odot$ & Open \\
\hline 85 & 67 & 68 & 51 & 100 & 0.009788 & $\odot$ & Open \\
\hline 86 & 68 & 70 & 11.44 & 100 & ๑. . 009788 & $\odot$ & Open \\
\hline 87 & 68 & 69 & 189.52 & 50 & $\odot .0 \odot 9788$ & $\odot$ & Open \\
\hline 88 & 69 & 70 & 189.07 & 50 & $\odot .0 \odot 9788$ & $\odot$ & Open \\
\hline 89 & 70 & 71 & 50.46 & 100 & ๑. . 009788 & $\odot$ & Open \\
\hline 90 & 71 & 73 & 11.44 & 100 & $\odot .009788$ & $\odot$ & Open \\
\hline 91 & 71 & 72 & 189.52 & 50 & $\odot .0 \odot 9788$ & $\odot$ & Open \\
\hline 92 & 72 & 73 & 189.07 & 50 & ๑. . 009788 & $\odot$ & Open \\
\hline 93 & 73 & 74 & 51.65 & 100 & $\odot . \odot \odot 9788$ & $\odot$ & Open \\
\hline 94 & 74 & 75 & 193.93 & 50 & ๑. . 009788 & $\odot$ & Open \\
\hline 95 & 75 & 76 & 210.67 & 50 & ๑. . 009788 & $\odot$ & Open \\
\hline 96 & 81 & 74 & $99 . \odot 9$ & 100 & ๑. . 009788 & $\odot$ & Open \\
\hline 97 & 76 & 77 & 24.49 & 100 & $\odot .0 \odot 9788$ & $\odot$ & Open \\
\hline 98 & 77 & 78 & 9.43 & 75 & $\odot .009788$ & $\odot$ & Open \\
\hline 99 & 78 & 8 & 65.87 & 75 & ๑. . 009788 & $\odot$ & Open \\
\hline $10 \odot$ & 78 & 79 & 393.34 & 50 & ๑. . 009788 & $\odot$ & Open \\
\hline 101 & 79 & 80 & 54.91 & 50 & $\odot .0 \odot 9788$ & $\odot$ & Open \\
\hline 102 & 80 & 8 & 411.61 & 75 & $\odot .009788$ & $\odot$ & Open \\
\hline 103 & 81 & 76 & 23.59 & 100 & ๑. . 009788 & $\odot$ & Open \\
\hline 104 & 48 & 80 & 192.51 & 50 & $\odot .0 \odot 9788$ & $\odot$ & Open \\
\hline 105 & 77 & 1 & 70.15 & 140 & ๑. . 009788 & $\odot$ & Open \\
\hline 106 & 82 & 1 & 148.22 & 140 & ๑. . 009788 & $\odot$ & Open \\
\hline 107 & 83 & 82 & 1 & $10 \odot \odot$ & ๑. . 009788 & $\odot$ & Open \\
\hline
\end{tabular}

[PATTERNS]

\begin{tabular}{|c|c|c|c|c|c|c|}
\hline PAT1 & 1.638151 & 1.241840 & 0.803419 & 0 & 0 & 0.258212 \\
\hline PAT1 & $\odot .114067$ & $\Theta$ & 0 & 0 & $\odot$ & 0 \\
\hline PAT1 & $\odot$ & $\Theta$ & 0.473500 & 1.671619 & 2.771821 & 3.042902 \\
\hline PAT1 & 2.312694 & 1.834655 & 1.994643 & 2.180386 & 2.620433 & 2.368075 \\
\hline Recervatorio & & & & & & \\
\hline eservatorio & 1.001986 & 1.002045 & 2303 & 495 & 0863 & $\odot .999014$ \\
\hline Reservatorio & $\odot .999146$ & $\odot .999989$ & 1.000762 & 1.001536 & 1.002294 & $1.0 \odot 2039$ \\
\hline Reservatorio & 1.000165 & $\odot .998770$ & ๑. 999168 & 0.999374 & $\odot .999348$ & 0.999153 \\
\hline Reservatorio & 0.999091 & 0.998536 & 0.99 & $\odot .998502$ & 0.998441 & 0.998549 \\
\hline$a n+r$ & 388 & & 722 & ๑. 995138 & ๑. 994444 & 1.05 \\
\hline ao & 0.9965277 & $\odot .989583$ & 1.034722 & 1.075 & 1.049305 & 1.055 \\
\hline oncentracao & 1.0708333 & 1.057575 & 1.025 & $\odot .962037$ & $\odot .974305$ & $\odot .941666$ \\
\hline ncentracao & 0.9458333 & $\odot .914583$ & $\odot .938194$ & 1.001572 & $\odot .935416$ & $\odot .982051$ \\
\hline
\end{tabular}




\section{[EMITTERS]}

; Junction

Coefficient

1

2

0.0001790690

๑. . 0000691893

$\odot .0 \odot \odot 2302470$

$\odot .0003590720$

$\odot$. 0001850280

$\odot .0001623880$

$\odot$. $0 \odot \odot 1431130$

$\odot .0003570010$

$\odot .0002296560$

๑. 0004101230

$\odot .0002511300$

$\odot .0002340300$

0.0003740250

$\odot .0002332450$

$\odot .0002154360$

$\odot$. 0003382040

$\odot$. 0002145160

๑ . 0001981940

๑ . 0003043940

$\odot .0002002500$

$\odot .0001864710$

$\odot .0002725060$

$\odot .0001787170$

$\odot .0001317030$

$\odot$. $0 \odot \odot 170650 \odot$

$\odot .0001315990$

0.0001554790

○. 0002182320

$\odot .0001555090$

$\odot .0001556590$

○. 0002183290

$\odot .0001556590$

$\odot .0001611770$

$\odot$. $00 \odot 2280 \odot 40$

๑ . 0001601820

$\odot$. 0001630980

๑ . 0002334170

0.0001631430

๑ . 0001638010

๑ . 0002344420

๑ . 0001630910

๑ . 0001572360

$\odot$. $0 \odot \odot 4242620$

$\odot$. $00 \odot 4534880$

๑ . 0001858500

$\odot .0001181400$

$\odot .0001211690$

$\odot .0002537910$

$\odot .0001077700$

$\odot .0001862540$

○. 0002794520

$\odot$. 0001861940

๑ . 0001860590

$\odot .0 \odot \odot 2794520$

$\odot .0001862840$

$\odot .0001861490$

$\odot .0002794520$

$\odot .0001859250$ 


\begin{tabular}{|c|c|}
\hline 59 & $\odot .000185790 \odot$ \\
\hline 60 & $\odot .0 \odot \odot 279452 \odot$ \\
\hline 61 & ๑. 0001862910 \\
\hline 62 & ๑. 0001853040 \\
\hline 63 & $\odot .0002790550$ \\
\hline 64 & ๑. 0001863880 \\
\hline 65 & ๑. 0001876220 \\
\hline 66 & $\odot .0002811340$ \\
\hline 67 & $\odot .0001863210$ \\
\hline 68 & ๑. $000188385 \odot$ \\
\hline 69 & 0.0002830630 \\
\hline 70 & $\odot .000187644 \odot$ \\
\hline 71 & ๑. 0001879810 \\
\hline 72 & $\odot .0002830630$ \\
\hline 73 & ๑. 0001885340 \\
\hline 74 & $\odot .0 \odot \odot 257702 \odot$ \\
\hline 75 & $\odot .0 \odot \odot 3 \odot 2510 \odot$ \\
\hline 76 & ๑. 0001934610 \\
\hline 77 & ๑.๑०००778107 \\
\hline 78 & $\odot .0003503910$ \\
\hline 79 & $\odot .000335146 \odot$ \\
\hline 80 & ๑. $00 \odot 4927410$ \\
\hline 81 & $\odot .00 \odot \odot 91725 \odot$ \\
\hline 82 & $\odot .0 \odot \odot 110821 \mathrm{c}$ \\
\hline
\end{tabular}

[SOURCES]

;Node

83

\section{Type}

CONCEN
Quality

1.20
Pattern

Concentracao

[REACTIONS]

order Bulk

Order Tank

Order wall

1

Global Bulk

1

1

$-0.0231$

Global Wall

$-0.005$

Limiting Potential

$\odot$

Roughness Correlation $\odot$

\section{[TIMES]}

Duration

$84: 00$

Hydraulic Timestep $1: 00$

Quality Timestep $0: 01$

Pattern Timestep 1:00

Pattern Start $0: 00$

Report Timestep 1:00

Report Start $0: 0 \odot$

Start ClockTime $\quad 0: 00$

Statistic NONE

\section{[OPTIONS]}

Units

Headloss

Specific Gravity 1

Viscosity 1

Trials 40

Accuracy

0.001

Unbalanced

Stop

Pattern

PAT1

Demand Multiplier 1

Emitter Exponent $\quad 1.18$ 


$\begin{array}{ll}\text { Quality } & \text { Chemical mg/L } \\ \text { Diffusivity } & 1 \\ \text { Tolerance } & 0.01\end{array}$

[END]

2 // NUMERO DE NÓS OBSERVADOS

24 //Numero maximo de padrões de tempos observados

82 //ID do nó; TEMPO=horas $+48 \mathrm{~h}$ valor;

$\begin{array}{ll}49 & 1.18 \\ 50 & 1.16 \\ 51 & 1.18 \\ 52 & 1.19 \\ 53 & 1.19 \\ 54 & 1.26 \\ 55 & 1.20 \\ 56 & 1.19 \\ 57 & 1.24 \\ 58 & 1.29 \\ 59 & 1.26 \\ 60 & 1.27 \\ 61 & 1.29 \\ 62 & 1.27 \\ 63 & 1.23 \\ 64 & 1.15 \\ 65 & 1.17 \\ 66 & 1.13 \\ 67 & 1.14 \\ 68 & 1.10 \\ 69 & 1.13 \\ 70 & 1.20 \\ 71 & 1.12 \\ 72 & 1.18\end{array}$

43 //ID do nó; TEMPO=horas $+48 \mathrm{~h}$ valor;

$\begin{array}{ll}61 & 0.96 \\ 62 & 0.97 \\ 63 & 1.01 \\ 64 & 1.09 \\ 65 & 1.06 \\ 66 & 1.10 \\ 67 & 1.04 \\ 68 & 1.03 \\ 69 & 1.08 \\ 70 & 1.10 \\ 71 & 1.12 \\ 72 & 1.12 \\ 73 & 1.10 \\ 74 & 1.11 \\ 75 & 1.04 \\ 76 & 1.04 \\ 77 & 1.02 \\ 78 & 0.98 \\ 79 & 0.99 \\ 80 & 0.99 \\ 81 & 0.97\end{array}$




$\begin{array}{ll}82 & 0.94 \\ 83 & 0.95 \\ 84 & 0.96\end{array}$

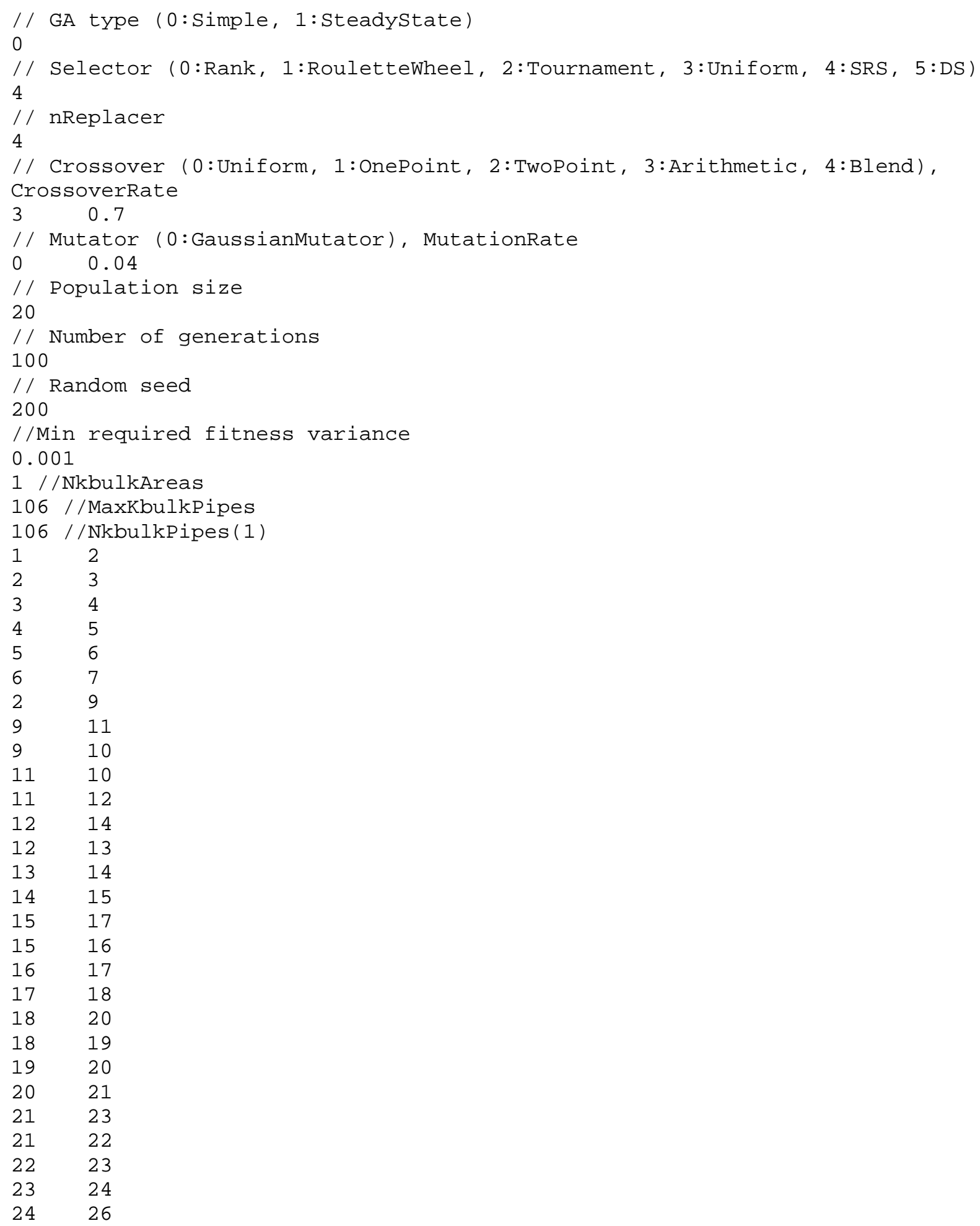


$24 \quad 25$

$25 \quad 26$

$26 \quad 27$

$27 \quad 29$

$27 \quad 28$

$28 \quad 29$

$29 \quad 30$

$30 \quad 32$

$30 \quad 31$

$31 \quad 32$

$32 \quad 33$

$33 \quad 35$

$33 \quad 34$

$34 \quad 35$

$35 \quad 36$

$36 \quad 38$

$36 \quad 37$

$37 \quad 38$

$38 \quad 39$

$39 \quad 41$

$39 \quad 40$

$40 \quad 41$

$41 \quad 42$

$42 \quad 43$

$43 \quad 44$

$44 \quad 45$

$45 \quad 46$

$46 \quad 47$

$47 \quad 48$

$48 \quad 49$

$49 \quad 46$

$42 \quad 47$

$45 \quad 50$

$50 \quad 52$

$50 \quad 51$

$51 \quad 52$

$52 \quad 53$

$53 \quad 55$

$53 \quad 54$

$54 \quad 55$

$55 \quad 56$

$56 \quad 58$

$56 \quad 57$

$57 \quad 58$

$58 \quad 59$

$59 \quad 61$

$59 \quad 60$

$60 \quad 61$

$61 \quad 62$

$62 \quad 64$

6263

$63 \quad 64$

$64 \quad 65$

$65 \quad 67$

$65 \quad 66$

$66 \quad 67$

$67 \quad 68$

$68 \quad 70$

$68 \quad 69$

$69 \quad 70$

$70 \quad 71$ 


$\begin{array}{ll}71 & 73 \\ 71 & 72 \\ 72 & 73 \\ 73 & 74 \\ 74 & 75 \\ 75 & 76 \\ 81 & 74 \\ 76 & 77 \\ 77 & 78 \\ 78 & 8 \\ 78 & 79 \\ 79 & 80 \\ 80 & 8 \\ 81 & 76 \\ 48 & 80 \\ 77 & 1 \\ 82 & 1\end{array}$

$1 / /$ Nkwallareas

106 //MaxKwallPipes

106 //KwallPipes(1)

12

23

34

$4 \quad 5$

$5 \quad 6$

$6 \quad 7$

29

$9 \quad 11$

$9 \quad 10$

$11 \quad 10$

$11 \quad 12$

$12 \quad 14$

$12 \quad 13$

$13 \quad 14$

$14 \quad 15$

$15 \quad 17$

$15 \quad 16$

$16 \quad 17$

$17 \quad 18$

$18 \quad 20$

$18 \quad 19$

$19 \quad 20$

$20 \quad 21$

$21 \quad 23$

$21 \quad 22$

$22 \quad 23$

$23 \quad 24$

$24 \quad 26$

$24 \quad 25$

$25 \quad 26$

$26 \quad 27$

$27 \quad 29$

$27 \quad 28$

$28 \quad 29$

2930

$30 \quad 32$

$30 \quad 31$

$31 \quad 32$

$32 \quad 33$

$33 \quad 35$

$33 \quad 34$ 
$34 \quad 35$

$35 \quad 36$

$36 \quad 38$

$36 \quad 37$

$37 \quad 38$

$38 \quad 39$

$39 \quad 41$

$39 \quad 40$

$40 \quad 41$

$41 \quad 42$

$42 \quad 43$

$43 \quad 44$

$44 \quad 45$

$45 \quad 46$

$46 \quad 47$

$47 \quad 48$

$48 \quad 49$

$49 \quad 46$

$42 \quad 47$

$45 \quad 50$

$50 \quad 52$

$50 \quad 51$

$51 \quad 52$

$52 \quad 53$

$53 \quad 55$

$53 \quad 54$

$54 \quad 55$

$55 \quad 56$

$56 \quad 58$

$56 \quad 57$

$57 \quad 58$

$58 \quad 59$

$59 \quad 61$

$59 \quad 60$

$60 \quad 61$

$61 \quad 62$

$62 \quad 64$

6263

$63 \quad 64$

$64 \quad 65$

$65 \quad 67$

$65 \quad 66$

$66 \quad 67$

$67 \quad 68$

$68 \quad 70$

$68 \quad 69$

$69 \quad 70$

$70 \quad 71$

$71 \quad 73$

$71 \quad 72$

$72 \quad 73$

$73 \quad 74$

$74 \quad 75$

$75 \quad 76$

$81 \quad 74$

$76 \quad 77$

$77 \quad 78$

$78 \quad 8$

$78 \quad 79$

$79 \quad 80$

$80 \quad 8$ 
$81 \quad 76$

$48 \quad 80$

$\begin{array}{ll}77 & 1\end{array}$

821

//theXMin, theXMax (kbulk, kwall]

$-0.04 \quad 0.0$

$-0.01 \quad 0.0$ 